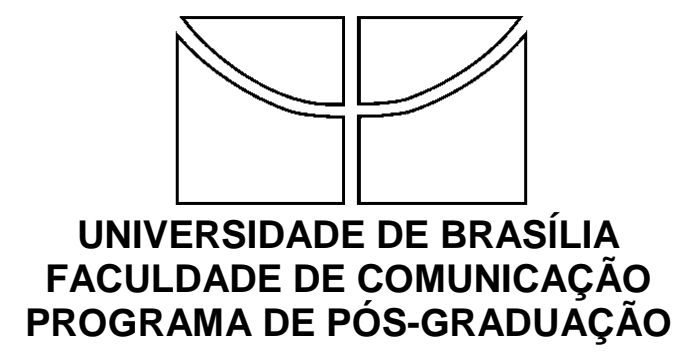

\title{
Harold Lasswell e o Campo da Comunicação
}

\author{
Rafiza Luziani Varão Ribeiro Carvalho
}

Brasília, outubro de 2012 


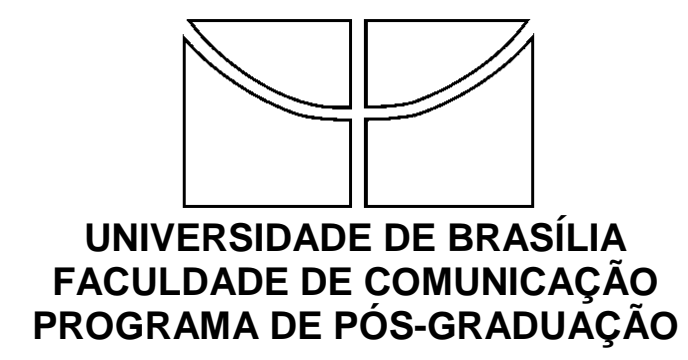

\title{
Harold Lasswell e o Campo da Comunicação
}

\author{
Rafiza Luziani Varão Ribeiro Carvalho \\ Tese apresentada ao PPG/FAC para \\ obtenção do grau de Doutor em \\ Comunicação. Linha de pesquisa: \\ Teorias e Tecnologias da \\ Comunicação \\ Orientador: Prof. Dr. Luiz C. Martino
}

Brasília, outubro de 2012 


\section{Harold Lasswell e o Campo da Comunicação}

Tese apresentada ao PPG/FAC para obtenção do grau de Doutor em Comunicação. Linha de pesquisa: Teorias e Tecnologias da Comunicação.

Aprovada em

BANCA EXAMINADORA

Orientador: Prof. Dr. Luiz Claudio Martino (FAC/UnB)

$1^{\circ}$ Examinador: Prof. Dra. Ana Carolina Rocha Pessoa Temer (FACOMB/UFG)

$2^{\circ}$ Examinador: Prof. Dr. Antonio Carlos Hohlfeldt (PUC-RS)

$3^{\circ}$ Examinador: Prof. Dr. Tiago Quiroga Fausto Neto (FAC/UnB)

$4^{\circ}$ Examinador: Prof. Dr. Virgílio Caixeta Arraes (HIS/UnB)

Suplente: Prof. Dra. Janara Kalline Leal Lopes de Sousa (FAC/UnB) 
Para Theo, que desenhou nos esboços.

Para Fausto, que segurou a minha mão. 


\section{Agradecimentos}

O ponto final de um doutorado nos leva de volta aos seus muitos inícios e nos relembra o valor das pessoas e instituições que nos possibilitaram chegar até ele. Felizmente, são muitos os que tenho a agradecer.

Em primeiro lugar, agradeço ao Fausto e ao Theo, que acompanharam tão de perto e tão intensamente cada dia de textos lidos, rabiscados, impressos, papeis e papeis espalhados pela casa; cada dia de ausência e de correria.

Agradeço a família de onde eu vim. Aos meus pais, Raimundo e Maridalva. Um jornalista de formação, a outra professora universitária por escolha. Sem querer, me tornei um pouco de cada um. Às duas pessoas que me ensinaram o amor aos estudos e me deram a educação mais humanista que alguém poderia ter. Aqueles que tatuaram em mim a palavra respeito.

Agradeço aos meus irmãos, Markos Magnoni, Wandréa Marcinoni, Taíse Alini e Ivonete, que testemunharam minha infância e adolescência e viram a menina que se escondia para não ir a escola se transformar numa estudiosa compulsiva. Aos meus sobrinhos, Gabrielli, Raí, Pedro e Gabriel, por todos os risos e o chamado de "dindinha".

Agradeço a família para onde eu fui. A Magali e ao Carlos (in memoriam), que foram escrevendo sua história na minha vida. A Ayeska, ao Fabrício, a Edina e ao Onei, que torceram juntos. Aos meus sobrinhos Anna Beatriz, Carlos Eduardo e Arthur.

A família que não compartilha sobrenome, meus amigos mais que leais: Rosana e Liana, que chegaram há muito tempo, Raquel e Rodrigo, que parecem ter chegado junto. Aos companheiros do doutorado, Duda, Katrine e Silnei. A Leila Marcena, que veio do Maranhão com o segundo grau e hoje é pós-graduada em Letras, e cuidou do meu filho quando eu não podia. A Adelice, simplesmente pela bondade. A Inajá, que também chegou há muito tempo.

Aos amigos da Universidade Católica de Brasília, que me abraçam ou apertam minha mão todas as manhãs e algumas noites: Elen, Joadir, Janete, Suellen, Angélica, Bárbara, Juliana, Alex, Karina, Bernadete, André, Daniela, Sheila, Luísa, João, Valesca, Liliana, Florence, Lunde. Aos alunos que me ensinaram a ser professora, nesses 11 anos de profissão. 
Ao orientador que se transformou em amigo e mentor, Luiz Claudio Martino. Antes, uma inspiração. Hoje, ainda uma inspiração. Respeito e admiração que não param de crescer.

Ao professor Pedro Russi, pelo coração de ouro, a perspicácia superior e, é claro, pela amizade.

Agradeço a UnB e ao Programa de Pós-Graduação em Comunicação da Faculdade de Comunicação, que me acolheram aos 21 anos para o mestrado e que me receberam novamente aos 28 para o doutorado. A Regina e ao Luciano.

A Universidade de Yale e a Sterling Memorial Library pelo acesso livre aos papeis de Harold Lasswell, disponíveis na seção de Manuscritos e Arquivos.

Ao professor Rodney Muth, da Universidade do Colorado, autor de Harold Dwight Lasswell: a Biographical Profile, pela ajuda constante e desinteressada.

Agradeço em especial aos professores que aceitaram compor minha banca tão prontamente: Ana Carolina Rocha Pessoa Temer, Antonio Carlos Hohlfeldt, Janara Kalline Leal Lopes de Sousa, Tiago Quiroga Fausto Neto e Virgílio Caixeta Arraes. Muito obrigada pela honra de participarem da minha avaliação.

Por fim, agradeço aos médicos, enfermeiras e auxiliares de enfermagem da UTI do Hospital Santa Luzia. A eles, devo mais um dos muitos inícios do doutorado. A eles, devo a certeza da frase de Gonçalves Dias que meu pai pronuncia até hoje: a vida é combate. 


\section{Resumo}

Harold Lasswell é um autor comumente citado pelo campo da Comunicação como um de seus pioneiros, no que tange ao estudo da propaganda no início do século XX e também em relação ao desenvolvimento do campo comunicacional, com a criação do famoso modelo que leva seu nome. A tradicional narrativa da história do campo da Comunicação afirma que foi este modelo o responsável pela organização da pesquisa em comunicação e a classificou em áreas: o estudo do emissor, o estudo da mensagem, o estudo do canal, o estudo do receptor, o estudo dos efeitos. Contudo, dificilmente encontra-se uma análise mais qualificada de sua obra ou uma explicação mais detalhada de suas teorias, inclusive de seu modelo. A presente tese busca perscrutar as relações que se estabelceram entre o campo comunicacional e Harold Lasswell, tentando compreender de que maneira a área da Comunicação constrói a figura deste pesquisador como um de seus pais fundadores. Buscamos analisar a obra comunicacional de Lasswell, a partir de um olhar histórico e epistemológico, realizando uma observação crítica de suas contribuições para o domínio de estudos da comunicação.

Palavras-chave: Teoria da Comunicação. História do Campo da Comunicação. Propaganda. Harold Lasswell. Clássicos. 


\begin{abstract}
Harold Lasswell is commonly cited by authors of the field of communication as one of its pioneers, regarding the study of propaganda in the early twentieth century and also in relation to the development of the communication field, with the creation of the famous model that bears his name. The traditional narrative of the history of the field of communication states that it was this model is responsible for the organization of research in communication and ranked areas: the study of the sender, the study of the message, the study of the channel, the study of the receiver, the study of effects. However, there is hardly a more qualified of his work or a more detailed explanation of his theories, including his model. This thesis seeks to scrutinize the relationships between communication field and Harold Lasswell, trying to understand how the field of communication builds the figure of this researcher as one of its founding fathers. We seek to analyze the Lasswell's communication works, from a historical and epistemological view, making critical remarks of his contributions to the field of communication studies.
\end{abstract}

Keywords: Communication Theory. History of the Field of Communication. Propaganda. Harold Lasswell. Classics. 


\section{Resumé}

Harold Lasswell est souvent invoquée par les auteurs du domaine de la communication comme un de ses pionniers, en ce qui concerne l'étude de la propagande dans le début $\mathrm{du}$ siècle vint et aussi en ce qui concerne le développement du domaine de la communication, avec la création du fameux modèle qui porte son nom. Le récit traditionnel de l'histoire du domaine de la communication affirme que c'était ce modèle le responsable de l'organisation de la recherche en communication et des zones classées: l'étude de l'expéditeur, l'étude de le message, l'étude de la chaîne, l'étude de le récepteur, l'étude des effets. Cependant, il ya à peine un plus qualifié de son travail ou une explication plus détaillée de ses théories, y compris son modèle. Cette thèse vise à examiner les relations entre la communication et Harold Lasswell, en essayant de comprendre comment le domaine de la communication construit la figure de ce chercheur comme l'un de ses pères fondateurs. Nous cherchons à analyser les travaux de communication de Lasswell, à partir d'un point de vue historique et épistémologique, de faire des remarques critiques de ses contributions aux sciences de la communication.

Mots-chefs: Théorie de la communication. Domaine de la communication. Propagande. Harold Lasswell. Classiques. 


\section{ÍNDICE DE FIGURAS}

Figura 1. Sterling Memorial Library, na Universidade de Yale, onde estão os arquivos de Harold Lasswell.................................................................... 26 Figura 2. Imagem representativa da Teoria das Transformações, de D'Arcy Thompson. ......................................................................................... 70

Figura 3. Rua de Donnellson na primeira metade do século XX ................. 123

Figura 4. Residência dos Lasswell em Enfield. ........................................... 123

Figura 5. Igreja Presbiteriana de Donnellson, onde Linden Lasswell era pastor. 124

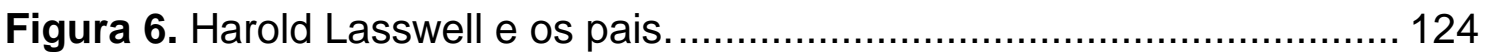

Figura 7. Decatur High School. Foto de 1915.......................................... 125

Figura 8. Fotografia de formatura na Decatur High School .......................... 126

Figura 9. Fotografia de formatura em Economia na Universidade de Chicago, em 1922...................................................................................... 130

Figura 10. Charles Edward Merriam, orientador de doutorado de Lasswell. . 140

Figura 11. Harold Lasswell e colegas da Universidade de Chicago ............... 141

Figura 12. Manuscrito de Lasswell sobre Técnica de propaganda na Guerra Mundial............................................................................................. 142

Figura 13. Curva de obras sobre propaganda entre 1900 e $1950 \ldots \ldots \ldots \ldots \ldots . . . .146$

Figura 14. Carta de Harold Gosnell ao governo estadunidense, atestando desconhecer ligações de Lasswell com o comunismo................................. 159

Figura 15. Carta de Charles Merriam ao governo estadunidense, atestando desconhecer ligações de Lasswell com o comunismo, página 1 ................. 160

Figura 16. Carta de Charles Merriam ao governo estadunidense, atestando desconhecer ligações de Lasswell com o comunismo, página 2 .................. 161

Figura 17. Gráfico que mostra a freqüência do símbolo "Guerra" no jornal Neue Züricher Zeitung, de 1939 a 1941.......................................................... 162

Figura 18. Mapa elaborado pela Divisão Experimental para o Estudo das Comunicações em Tempo de Guerra mostrando emissoras de rádio em língua estrangeira nos EUA em 1942 ................................................................. 162

Figura 19. Gráfico produzido pela Divisão Experimental para a Comunicação em Tempos de Guerra. ............................................................................. 163

Figura 20. Manual para utilização do esquema de Lasswell na Divisão Experimental para o Estudo das Comunicações em Tempo de Guerra......... 164

Figura 21. Primeira página do arquivo "Termos-chave para uma Teoria da

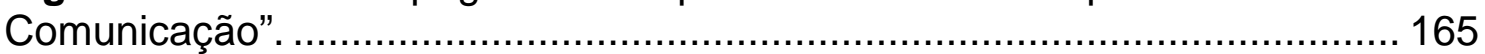

Figura 22. Produção de Harold Lasswell em quantidade de palavras........... 167

Figura 23. Carl Hovland........................................................................ 174

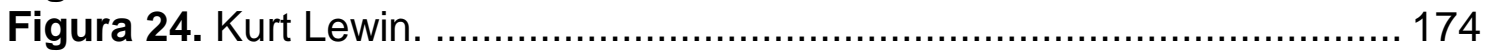

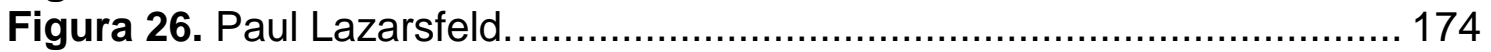

Figura 25. Harold Lasswell. ................................................................ 174

Figura 27. Lasswell em seu escritório em Yale. .......................................... 175

Figura 28. Lasswell ministrou cursos de Teoria da Comunicação até próximo

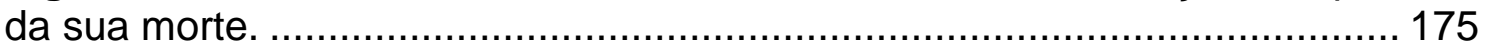

Figura 29. Uma das raras fotos de Lasswell coloridas, já no final da vida. ... 176

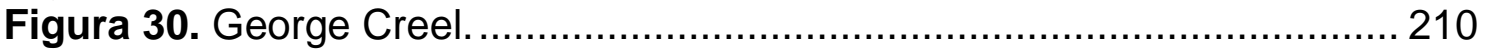

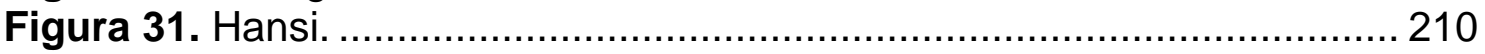

Figura 32. Stuart Campbell................................................................. 210

Figura 33. Walter Nicolai. ................................................................... 210 


\section{ÍNDICE DE TABELAS}

Tabela 1. Variáveis utilizadas na busca cruzada sobre Harold Lasswell. ........ 33

Tabela 2. Quantidade de obras teorográficas que contemplam o trabalho de Harold Lasswell (Inicial). 34

Tabela 3. Quantidade de obras teorográficas que contemplam o trabalho de Harold Lasswell (Final).

Tabela 4. Temas relacionados a Harold Lasswell em obras teorográficas. ..... 37 Tabela 5. Obras teorográficas em espanhol com referências a Harold Lasswell. 38

Tabela 6. Obras de Harold Lasswell presentes nas referências da bibliografia teorográfica em língua espanhola. ................................................................ 44 Tabela 7. Obras teorográficas em francês com referências a Harold Lasswell.

Tabela 8. Obras de Harold Lasswell presentes nas referências da bibliografia teorográfica em língua francesa.

Tabela 9. Obras teorográficas em inglês com referências a Harold Lasswell.. 51 Tabela 10. Obras de Harold Lasswell presentes nas referências da bibliografia teorográfica em língua inglesa.

Tabela 11. Obras teorográficas em português com referências a Harold Lasswell (Inicial). 64

Tabela 12. Obras teorográficas em português com referências a Harold Lasswell (Final). 64

Tabela 13. Obras de Harold Lasswell presentes nas referências da bibliografia teorográfica em língua portuguesa. 66

Tabela 14. A obra comunicacional de Harold Lasswell. 183

Tabela 15. Obras do Período Inicial de Harold Lasswell. 186

Tabela 16. Obras de Lasswell do Período Intermediário de Harold Lasswell. 211 Tabela 17. Obras do período tardio de Harold Lasswell. 


\section{ÍNDICE DE GRÁFICOS}

Gráfico 1. Relação número de obras e temas relacionados à Lasswell na bibliografia de língua espanhola

Gráfico 2. Temas relacionados à Lasswell na bibliografia de língua francesa. 44

Gráfico 3. Temas relacionados à Lasswell na bibliografia de língua inglesa... 51

Gráfico 4. Temas relacionados à Lasswell na bibliografia de língua portuguesa

Gráfico 5. Temas relacionados à Lasswell na bibliografia de língua portuguesa. 


\section{Sumário}

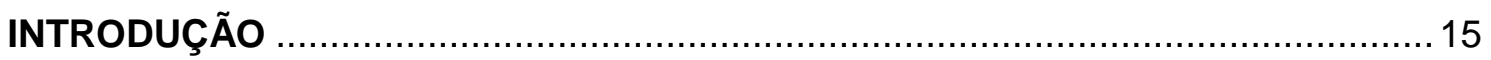

Apresentação do problema de pesquisa e justificativa......................................... 15

Objetivos, procedimentos metodológicos e estrutura da tese ................................ 22

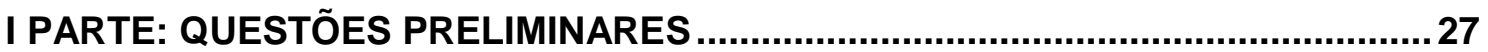

1. Inventário: o que os livros de teorias da comunicação dizem sobre Harold Lasswell

1.1. Levantamento do material: montando o inventário ..................................... 32

1.2. Analisando o inventário: o que dizem os livros de teorias da comunicação sobre

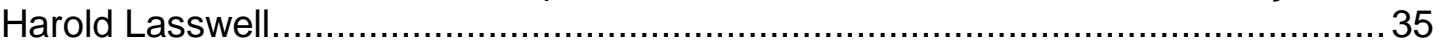

1.3 Sobre o que foi dito: Harold Lasswell, um ilustre desconhecido ........................67 67

2. Sobre Clássicos, Tradição, Harold Lasswell e o Campo da Comunicação...............72

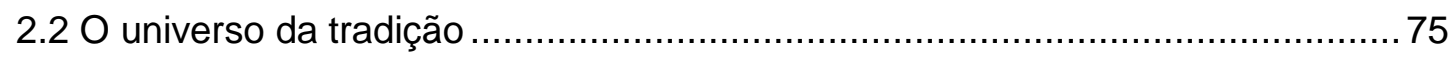

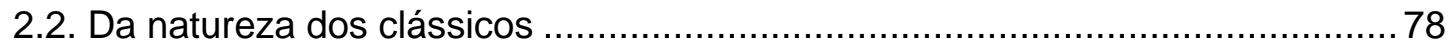

1.3. Harold Lasswell como clássico............................................................ 81

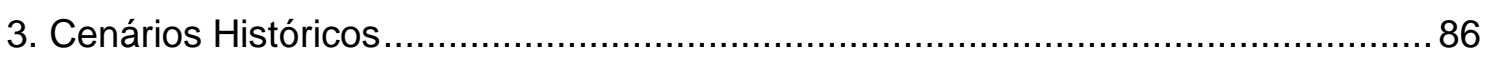

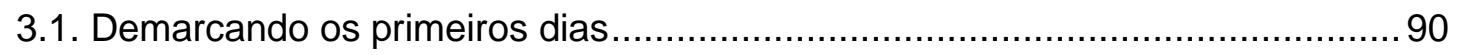

3.2. As rotas européias da pesquisa em Comunicação .......................................... 95

3.3. As tradições estadunidenses de pesquisa e os meios de comunicação.......... 101

3.3. Hipodérmica: a primeira teoria? ............................................................. 110

II PARTE: HAROLD LASSWELL E O CAMPO DA COMUNICAÇÃO .....................114

4. PANORAMA BIOGRÁFICO E INTELECTUAL .............................................. 115

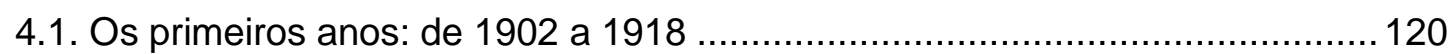

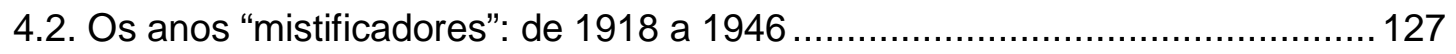

4.2.1. De Política e Propaganda ............................................................... 131

4.2.2. De Propaganda e Comunicação ............................................................... 143

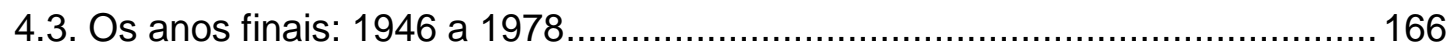

5. A OBRA COMUNICACIONAL DE HAROLD LASSWELL............................... 177

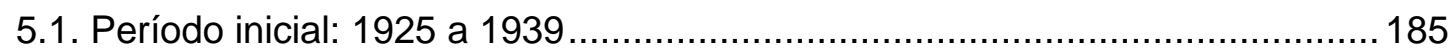

5.1.1. Conceituando a propaganda, suas técnicas e organização (1925 a 1934).. 186

5.1.2 Analisando a propaganda (1935 a 1939) ................................................ 201

5.2. Período intermediário: de 1940 a 1950 ...................................................... 211

5.2.1. A Comunicação (1940 a 1946) ............................................................ 213

5.2.2 As funções da comunicação (1947 a 1950) ............................................. 220

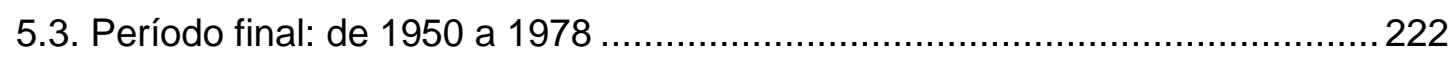

CONCLUSÃO: HAROLD LASSWELL E O CAMPO DA COMUNICAÇÃO................225

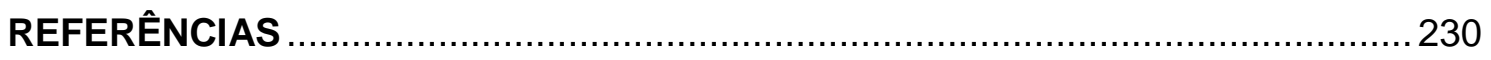


"Quando comecei no campo da opinião pública e da pesquisa em comunicação, não existia Roper, Gallup, Cantril, Stouffer, Hovland. Lazarsfeld não era nem uma pessoa nem uma unidade de medida, nem mesmo uma categoria. Não havia survey, análise de conteúdo ou análise aprofundada de dados quantitativos, não existiam sistemas informatizados de armazenamento, recuperação e utilização de dados; não existiam redes universitárias de cooperação, não havia institutos de treinamento, bureaus de pesquisa, bibliografias profissionais ou associações. $\mathrm{Na}$ verdade, não existia praticamente nenhuma rádio nem radiodifusão televisiva, nenhuma fotografia instantânea, nem mesmo em preto e branco, nem sonares [radares], infravermelho ou laser"

Harold Lasswell

"Ele era uma LENDA no CAMPUS"

Luis Kutner 


\section{INTRODUÇÃO}

\section{Apresentação do problema de pesquisa e justificativa}

Que caminhos percorridos por um domínio do saber fazem com que alguns autores se coloquem no âmbito do canônico e se tornem referência ulterior? Há 87 anos, Harold Dwight Lasswell (1902-1978), então com 22 anos, entrou numa das salas da Universidade de Chicago, em Illinois, nos Estados Unidos, para cumprir um ritual costumeiro na Academia: de posse de uma pesquisa original, iria defendê-la diante de uma banca composta por professores laureados, preparados para o debate científico. Era o ano de 1925, e Lasswell, cientista social fortemente influenciado pelas ideias de sua época, apresentava Técnicas de propaganda na Guerra Mundial, sua tese de doutorado. Trabalho centrado na análise de conteúdos simbólicos e não-simbólicos das propagandas de guerra americanas, inglesas, francesas e alemãs, produzidas durante a Primeira Guerra Mundial, buscava compreender como foram elaborados os seus temas mais comuns e de que maneira esse material foi utilizado para fins ideológicos.

Formado em Economia, em 1922, Lasswell iniciava com Técnicas de propaganda na Guerra Mundial sua trajetória na Ciência Política, campo no qual se tornou especialmente importante, pois passou a ser considerado seu fundador moderno, com obras definidoras de bases para os estudos políticos no século XX, como World Politics and Personal Insecurity (1935), Politics: Who Gets What, When, How (1936) e Power and Personality (1948).

Não existia nesse momento nenhuma intenção ou ambição fora dos domínios da Ciência Política. Quando do seu doutorado, portanto, Lasswell não poderia imaginar a notabilidade que sua obra assumiria, dali por diante, para outro campo de conhecimento,

que se formava de maneira progressiva e pouco sistematizada: o campo da Comunicação.

O que chamamos de campo da Comunicação ou simplesmente Comunicação, nasce sob o signo de um contexto social novo, a Sociedade Tecnológica (RIOUX, 1975), forma de organização social que emerge no mundo pós Revolução Industrial, marcada, entre outras características, por uma economia de produção com predomínio da indústria; comércio transnacional; substituição acentuada do ambiente natural pelo ambiente técnico; distinção entre produtor e consumidor; cultura voltada para a atualidade; surgimento das ideias de cultura de massa e de consumidor cultural; 
aparecimento dos modernos meios de comunicação em grande parte elétricos, instituidores da comunicação de massa; comunicação social baseada na técnica desses meios, responsáveis, por sua vez, pela divulgação da atualidade.

É esse último aspecto que nos interessa mais: a dimensão que tange à comunicação na Sociedade Tecnológica. Diante desse quadro, a compreensão da Sociedade Tecnológica requeria um melhor entendimento dos fenômenos da comunicação de massa, entre eles a propaganda, objeto de investigação de Lasswell. Que efeitos teriam os meios de comunicação na sociedade? É sobre esse questionamento que aparecem os primeiros estudos em Comunicação, que surgem na esteira das reflexões sobre a sociedade de massa, na qual os meios de comunicação começavam a ter um papel relevante para a integração social. Não por acaso, portanto, se encontram nessas primeiras discussões nomes como Alexis de Tocqueville, John Stuart Mill, Karl Marx, Ferdinand Tönnies, Gabriel Tarde, Max Weber (SouSA, 2008), e outros, todos eles autores que procuravam interpretar as características da organização social resultante da economia de produção e da crescente industrialização. A trajetória inicial dos estudos em Comunicação, dessa forma, ingressa na própria formação das Ciências Sociais e segue o quadro descrito por Luiz C. Martino quando este afirma que:

\begin{abstract}
A constituição do campo comunicacional está associado ao surgimento dos modernos meios de comunicação, aproximadamente em meados do século XVIII. Na verdade, trata-se de uma trajetória que vai da invenção dos tipos móveis em metal (ou mesmo da industrialização da imprensa, já que esse procedimento, com exceção do uso do metal, já era bem conhecido no Oriente desde o início da era cristã) até seu emprego regular e sistemático com os periódicos cotidianos do final do século XIX. [...] Mas o verdadeiro debate se instaura junto mesmo com a consolidação da imprensa ainda na primeira metade do século XIX, quando é cunhada a expressão "quarto poder". [...] Nesse período, o campo comunicacional se confunde com a discussão da própria atualidade, não havendo ainda um recuo teórico, necessário à elaboração de um conhecimento específico. Essa etapa é marcada pela liberação do objeto de estudo, ou seja, a formação histórica de um processo comunicacional singular, isto é, a própria atualidade como produto da atividade dos meios de comunicação (2006, p.41).
\end{abstract}

Essa fase se estende até a década de 1920. Contudo, quando Lasswell edita Técnica de propaganda na Guerra Mundial, dois anos após a sua defesa na Universidade de Chicago, em 1927, os nascentes estudos de Comunicação começavam a adquirir contornos científicos e logo o trabalho sobre propaganda, realizado pelo cientista político, seria associado ao campo da Comunicação, assumindo um papel decisivo na formação deste domínio do saber. 
Para Wilbur Schramm ${ }^{1}$ (1963), Lasswell foi um dos quatro forefathers (precursores ou pais fundadores) do campo da Comunicação - cuja fundação é atribuída hoje ao próprio Schramm ${ }^{2}$. Além de Lasswell, fazem parte da quadríade elencada por Schramm, o sociólogo Paul Felix Lazarsfeld (1901-1976), e os psicólogos Carl Iver Hovland (1912-1961) e Kurt Zadek Lewin (1890-1947), homens que "Mais precisamente, [...] entraram no campo antes de existir um campo [...] e acabaram criando-o" (SCHRAMM, 1997, p.4) ${ }^{3}$. A afirmação de Schramm obscurece um fato incontestável, no entanto: afirmar categoricamente que Lasswell, Lazarsfeld, Hovland e Lewin criaram o campo da Comunicação carece de uma investigação mais profunda, posto que nenhum desses autores aparentemente tinha a intenção de criar um novo campo, estando mais voltados a problemas de suas próprias áreas. Contudo, essa percepção não descarta a importância do papel que Lasswell, Lazarsfeld, Hovland e Lewin desempenharam nos primeiros anos nos quais a pesquisa em comunicação iniciou seu diálogo com a ciência. Ao se questionarem sobre os efeitos dos então novos meios de comunicação na sociedade - mesmo que a partir de uma perspectiva não propriamente comunicacional - estes autores lançaram sementes muito importantes na constituição do novo campo teórico emergente, que na época de seu aparecimento não tinha a preocupação de formar um arcabouço teórico sólido (MARTINO, 2001, p. 51), mas de atender a uma forte demanda social.

Pesquisadores como Lasswell, Lazarsfeld, Lewin e Hovland "eram produtos de uma nova era, um novo tempo na história humana, que nós chamamos Era dos Meios de Comunicação de Massa" (SCHrAMM, 1997, p.6) ${ }^{4}$. Para Bernard Berelson (1959), os quatro pesquisadores foram os responsáveis pela divisão da pesquisa em comunicação em quatro grandes frentes, separadas, sobretudo, de acordo com opções metodológicas: 1) a pesquisa voltada para a política, fundamentada em análises de conteúdo (Lasswell); 2) a pesquisa com utilização de surveys (Lazarsfeld); 3) a observação experimental com pequenos grupos (Lewin); 4) a pesquisa experimental de cunho psicológico, voltada

\footnotetext{
${ }^{1}$ Teórico da Comunicação e fundador dos primeiros cursos de Comunicação nos Estados Unidos, o que o credencia, para muitos autores, como o verdadeiro fundador do campo da Comunicação.

${ }^{2}$ A ideia dos quatro precursores aparece primeiro em Berelson para depois ser popularizada por Schramm sob a designação acima apresentada. Todavia, essa visão, conhecida como "mito dos quatro fundadores", é bastante discutida, pois deixaria de fora outros pesquisadores que podem ser considerados como pioneiros, como Robert Ezra Park (ROGERS, 1994). Quanto à fundação do campo da Comunicação pelo próprio Schramm, também há posições discordantes. Karin Wahl-Worgensen (2007), por exemplo, escreveu um sugestivo artigo intitulado "Wilbur Schramm was not the father of our discipline" ("Wilbur Schramm não foi o pai da nossa disciplina").

${ }^{3}$ No original: "More acuratelly, (...) entered into the field before there was a field called communication research or communication study and they created one".

${ }^{4}$ No original: "They were products of a new age, a new time in human history, wich we call the Age of the Mass Media".
} 
para a otimização das mensagens persuasivas dos meios de comunicação de massa (Hovland).

Não obstante, é a obra de Harold Lasswell que vai adquirir, num primeiro momento, o status de instauradora da pesquisa em comunicação, apesar da relevância inegável que cada um dos membros da quadríade fundadora tenha adquirido. Técnicas de propaganda na Guerra Mundial foi considerado por muitos como "[...] o primeiro trabalho representativo daquilo que depois ficou conhecido como pesquisa em comunicação de massa" (MATTELART, 1994, p. 66) ${ }^{5}$.

Alguns autores - Mauro Wolf (1985), Robert Lawrence Heath e Jennings Bryant (2000), Melvin DeFleur e Sandra-Ball Rockeach (1993) - chegaram a que considerar esta obra como um marco da teoria hipodérmica ${ }^{6}$, cuja matéria central se baseava na crença em meios de comunicação todo-poderosos e na manipulação das massas. A ideia de manipulação se encontraria representada na seguinte passagem de Lasswell, numa edição mais recente de Técnicas de propaganda na Guerra Mundial:

\begin{abstract}
A escolha da propaganda como um tópico de estudo cresceu a partir de um desejo de examinar o lugar ocupado pelo simbólico e os eventos nãosimbólicos da guerra ou da paz. (...) O comportamento envolvido numa sequiência de uma comunicação é (...) sinal da manipulação, e os sinais são eventos físicos (a saber, movimentos do músculo, sons, e similares) ${ }^{7}$ (LASSWELL, 1971, p. X).
\end{abstract}

Essa visão é abalizada intrinsecamente pelo behaviorismo ${ }^{8}$, e dá a entender que o processo de comunicação efetuado pelos meios de massa atua seguindo um esquema estímulo-resposta, no qual as respostas apareceriam sob a forma de um comportamento previsível pelos emissores e detentores dos media 9 .

Ainda de acordo com os autores supracitados, o próprio Lasswell seria, mais tarde, o responsável pela "superação" do modelo hipodérmico ao instituir a célebre questão-programa “Quem? Diz o quê? Por qual canal? Com que efeito? Para quem?", em 1935, que segmentou e sedimentou os territórios da pesquisa científica em

\footnotetext{
${ }^{5}$ No original: "[...] the first representative work what would later be known as mass communications research". 6 Teoria Hipodérmica é um nome dado a posteriori a um conjunto de reflexões que seguiam a linha determinada acima. O termo também é, em geral, atribuído a Lasswell. Contudo, Chaffee e Hochheimer (1985), não conseguiram encontrar, após uma pesquisa minuciosa da obra lasswelliana, nenhuma evidência dessa criação, nem mesmo do uso do termo para descrever os efeitos dos meios de comunicação de massa.

${ }^{7}$ No original: "The choice of propaganda as a topic of study grew out of a wish to examine the place occupied by the symbolic among the nonsymbolic events of war or peace. (...) The behavior involved in a sequence of communication is (...) sign of manipulation, and signs are physical events (namely, muscle movements, sounds, and the like)".

${ }^{8} \mathrm{O}$ pensamento lasswelliano é marcado pelas influências que circundavam a Universidade de Chicago de então: os temas da política, da comunicação e da psicologia. Aliás, a Universidade de Chicago acabou se transformando, nesse primeiro momento, num importante pólo das pesquisas em Ciências Sociais.

${ }_{9}^{9}$ Além do Behaviorismo, há fortes influências do Pragmatismo e da Escola de Chicago na primeira fase da pesquisa em Comunicação.
} 
Comunicação e tornou-se um verdadeiro paradigma. A questão-programa, conhecida como Esquema de Lasswell, aparece, então, como o cerne da obra do cientista político e a mais impactante de suas proposições sobre a comunicação.

É esse esquema que vai ser identificado como norteador nos anos seguintes das pesquisas em comunicação (ver, por exemplo, WoLF, 2000), organizando e fornecendo unidade aos seus diversos aspectos, embora sempre tenha sido alvo de críticas negativas.

Apesar desse papel determinante, o Esquema de Lasswell costuma ser carimbado com data de validade vencida, mais ou menos por volta da última década de 60 , quando temos aquilo que Miège identificou como ampliação das perspectivas em comunicação, sendo mesmo considerado "superado", embora em análises mais detidas se perceba que a sua força ainda se faz presente ${ }^{10}$. Contudo, dentro de uma perspectiva de uma história mainstream (LANG, 1996), as contribuições de Lasswell acabam datadas, ultrapassadas, de uma maneira geral (tanto no que diz respeito a sua visão inicial da ação dos meios de comunicação sobre a audiência, identificando-o com a teoria Hipodérmica, quanto no que diz respeito ao paradigma acima apresentado), além de ficarem bastante resumidas a esses dois tópicos.

Mas, afinal, seria somente essa a contribuição de Lasswell aos estudos em Comunicação? Esse questionamento foi se formando em especial pelos meus anos como professora de Teoria da Comunicação, matéria que comecei a lecionar em 2001. A princípio, o raciocínio das obras da área acerca de Lasswell me parecia bastante plausível. Com o passar do tempo, e a necessidade de ampliar o repertório sobre a área na qual começava a me especializar na docência, as incongruências sobre o que era dito sobre o cientista político e o campo da Comunicação começaram a aparecer cada vez mais. Ora, Lasswell teve uma intensa produção sobre comunicação, que perdurou até o fim de sua vida, como demonstram as obras Propaganda, Communication and Public Opinion (1946), Political Communication: the Public Language (1969), Propaganda and Communication in World History (1979), publicado após sua morte, e até mesmo um estudo sobre o uso de meios audiovisuais na educação: The Contextual Use of Audiovisual Means in Teaching, Research and Consultation (1966).

Desconsiderar grande parte da obra de Lasswell, portanto, e reduzi-la a dois tópicos começou a se mostrar como aquilo que James Carey (1988) identificou como

\footnotetext{
${ }^{10}$ Cf. MARTINO, Luiz C. "Contribuições para o estudo dos meios de comunicação". In: Revista Famecos. Porto Alegre: PUC-RS, 2000, nº 13, pp. 103-114.
} 
uma "caricaturização" da história do campo comunicação, na qual o passado - o mesmo passado do qual Lasswell faz parte - acaba sendo visto a partir de clichês, repetido a exaustão sem o aparato de uma reflexão mais profunda.

Mas Lasswell se colocava como um autor especial nessa história: muitos o apontavam como precursor do campo. Se era assim, o tratamento dispensado ao autor precisava de uma análise mais detalhada.

Entendendo que a compreensão do pensamento lasswelliano para além dos clichês da área era importante, uma vez que sua relevância era continuamente demarcada, nos colocamos a seguinte questão: de que maneira Harold Lasswell foi associado ao campo da Comunicação e quais foram suas contribuições ao saber comunicacional?

O questionamento inicialmente nos mostrou que, apesar da grande quantidade de material bibliográfico produzido a respeito das pesquisas em comunicação e das teorias que emergem no século passado, poucos são os que se ocupam em problematizar a história dessas pesquisas e seus conteúdos. O que temos, em geral, se refere a compilações de teorias, que elencam, sob a efígie "teoria da comunicação", as mais diversas propostas, analisando-as de maneira superficial e apressada, e listando, também dessa forma, a figura daqueles pesquisadores que foram essenciais no desenvolvimento desse corpus de conhecimento. Ora, conhecer a história da fundação e do desenvolvimento do saber comunicacional de maneira mais profunda é vital para se entender a própria constituição do campo enquanto área do saber, sendo mesmo uma tarefa essencial. Nesse sentido, conhecer mais a fundo o trabalho de Lasswell, que muitos autores situam nos primeiros movimentos da pesquisa em Comunicação, se revela um ganho aos estudos epistemológicos da área. Além disso, Lasswell assumiu um lugar capital nas pesquisas em Comunicação, especialmente pelo desenvolvimento do esquema que leva seu nome. Como referendarmos um autor como um dos fundadores do campo, se tomamos a parte pelo todo? A obra de Lasswell acabou virando "um dado", foi "naturalizada", sendo largamente desacreditada. Paradoxalmente, sabíamos tudo sobre ele e sabíamos muito pouco. O movimento de resgate do pensamento de Lasswell começa a tomar corpo na Ciência Política ${ }^{11}$, campo em que o autor também não encerrou sua carreira da forma mais prestigiada (SCHRAMM, 1997, p. 31), buscando redimensionar suas contribuições. É assim que acreditamos que essa pesquisa possa colaborar com o redimensionamento da obra de Lasswell. Voltar-se

\footnotetext{
${ }^{11}$ Cf. DAINS, Ronald N. Lasswell's Garrison State Reconsidered: Exploring A Paradigm Shift in U.S. Civil-Military Relations Research. Alabama: Alabama University Tuscaloosa, 2004. (Tese de Doutorado)
} 
para os pensadores "do passado" é uma tarefa pouco empreendida, mas que julgamos válida, pois, como afirma Hanno Hardt, "a história nos diz que fomos e o que somos" (HARDT, 2002, p.132).

De uma maneira geral, esta tese foi construída em cima de uma vasta bibliografia, mas devido a uma série de dificuldades (raridade de alguns textos de Lasswell, dificuldades de importação de material, ausência de obras semelhantes na comunicação que pudessem servir de base, ausência de especialistas em Lasswell e o campo comunicacional), precisamos recorrer à visitação do arquivo do cientista político (Harold Lasswell's Papers) na Universidade de Yale, na Sterling Memorial Library, na seção de Manuscritos e Arquivos, o que demandou uma viagem aos Estados Unidos. Essa parte da pesquisa foi especialmente rica, por possibilitar o acesso a materiais originais produzidos por Lasswell, além de inéditos. Outra ação necessária foi o contato estabelecido com alguns professores de comunicação também nos Estados Unidos. Embora não tenham gerado frutos no sentido de contemplar interpretações variadas sobre o autor a respeito do qual se debruça este estudo, certificaram a necessidade do trabalho, pois reforçaram a carência de reflexão sobre Lasswell no campo comunicacional. A fala de Jefferson Polley, um dos historiadores das teorias da Comunicação cujas pesquisas vem ganhando destaque nos últimos anos, é representativa sobre isso. Pooley afirmou em e-mail, ao ser perguntado sobre especialistas em Lasswell, que "é impressionante, agora que penso nisso e pesquiso materiais, como há poucos trabalhos sobre Lasswell, especialmente fora da Ciência Política"12. Em outros episódios, tivemos que entrar em contato com sebos internacionais, devido à dificuldade de encontrar as obras em mercados de fácil acesso, como aqueles disponíveis na internet. A obra mais difícil de ser conseguida foi o livro organizado por Pierce Butler, Books and Libraries in Wartime (1945), no qual se encontra o texto New Rivals of the Press: Film and Radio, de Lasswell. O livro teve que ser importado da Alemanha e a sua compra foi recusada duas vezes. O esforço valeu a pena, pois se conseguiu um quadro completo das obras de Lasswell que acreditávamos serem fundamentais para entender seu trabalho sobre comunicação.

Mas, por que Lasswell? Porque, como ele mesmo descreve,

\footnotetext{
12 "It is striking, now that I think about it and search my materials, how little work there has been on Lasswell, especially outside of political science". (Jefferson Pooley, e-mail de 24 de junho de 2010). Pooley é professor do Muhlemberg College, no Departamento de Meios e Comunicação, na Filadélfia, Estados Unidos. O professor foi indicado por Elihu Katz, também em correspondência eletrônica, na qual afirmou: "Deixe-me sugerir que você contacte o Dr. Jefferson Pooley em pooley@muhlenberg.edu que sabe muito mais do que sobre os primeiros dias" (Elihu Katz, e-mail de 10 de junho de 2010).
} 
quando comecei no campo da opinião pública e da pesquisa em comunicação, não existia Roper, Gallup, Cantril, Stouffer, Hovland. Lazarsfeld não era nem uma pessoa nem uma unidade de medida, nem mesmo uma categoria. Não havia survey, análise de conteúdo ou análise aprofundada de dados quantitativos, não existiam sistemas informatizados de armazenamento, recuperação e utilização de dados; não existiam redes universitárias de cooperação, não havia institutos de treinamento, bureaus de pesquisa, bibliografias profissionais ou associações. Na verdade, não existia praticamente nenhuma rádio nem radiodifusão televisiva, nenhuma fotografia instantânea, nem mesmo em preto e branco, nem sonares [radares], infravermelho ou laser ${ }^{13}$ (LASSWELL, 1972, p. 301).

Porque Lasswell ajudou a formar, de algum modo, aquilo que hoje chamamos de campo da Comunicação. Conhecê-lo é conhecer uma parte importante da fundamentação desse saber.

\section{Objetivos, procedimentos metodológicos e estrutura da tese}

Este trabalho tem uma natureza teórica e não empírica, e busca analisar a obra de Harold Lasswell a partir, conforme assinalado anteriormente, da seguinte pergunta: de que maneira Harold Lasswell foi associado ao campo da Comunicação e quais foram suas contribuições ao saber comunicacional?

O objetivo desta pesquisa consiste, portanto, em elaborar uma revisão crítica e histórica da obra de Harold Lasswell, buscando compreender e problematizar as suas contribuições ao campo da Comunicação, bem como entender de que maneira essas contribuições perpassam a produção acadêmica do campo, hoje. Trata-se, dessa forma, de um trabalho que se coloca, ao mesmo tempo, como uma pesquisa histórica e epistemológica, nos inserindo num contexto no qual o pensamento científico não pode e não deve ser apreendido apenas como uma sucessão de dados. Tal perspectiva nos coloca no esforço de pensar a história do campo comunicacional desde um direcionamento epistemológico, percebendo

[...] a diferença entre o ofício de epistemólogo e o de historiador da ciência.

$\mathrm{O}$ historiador da ciência deve tomar as ideias como se fossem fatos. $\mathrm{O}$

\footnotetext{
${ }^{13}$ No original: "When I first became acquainted with the field of public opinion and communication research, there was no Roper, no Gallup, no Cantril, No Stouffer, no Hovland. Lazarsfeld was neither a person nor a measuring unit, or even a category. There was no survey research, content analysis or quantified depth analysis; no computerized systems of storage, retrieval, and utilization; no inter-university networks of cooperation, no training institutes, research bureaus, professional bibliographies and associations. So far as that goes, there was practically no radio and television broadcasting, no instant photography, either in black or white, and no sonar [radar], infrared or laser".
} 
epistemólogo deve tomar os fatos como se fossem ideias, inserindo-as num sistema de pensamento (BACHELARD, 1996, p. 22)

Não se trata de estabelecer, exatamente, o pioneirismo de Lasswell, nem de caracterizá-lo como o primeiro teórico da Comunicação. Também não é nossa intenção verificar a validade do Esquema de Lasswell, hoje, embora essa seja uma questão intrigante. Trata-se, sim, de realinhar Lasswell na continuidade do pensamento científico sobre comunicação, pela análise de sua obra e do que restou de seus escritos na produção acadêmica contemporânea, buscando compreender e problematizar as suas contribuições ao campo da Comunicação. Apresentamos abaixo a estrutura da tese, com um breve resumo do conteúdo abordado nos capítulos, bem como uma rápida descrição dos procedimentos metodológicos de cada um deles ${ }^{14}$.

Para cumprir tais objetivos, o trabalho estará dividido em duas partes. A primeira, intitulada Questões Preliminares, é composta por três capítulos.

No primeiro capítulo, Inventário: o que os livros de teoria da comunicação dizem sobre Harold Lasswell, fazemos o levantamento quantitativo e qualitativo de obras de teoria da Comunicação que se referem a Harold Lasswell. Para elaborar o levantamento, partimos do conceito de capital teórico, desenvolvido por Luiz C. Martino para a formação do corpus de pesquisa deste primeiro capítulo. Uma vez formado o corpus, utilizamos o método da análise de conteúdo como forma de perscrutar de que maneira o campo comunicacional, representado nos livros de teoria da comunicação, constrói a imagem de Harold Lasswell, tanto para o neófito quanto para o pesquisador experiente. Trabalhamos neste capítulo com quatro blocos lingüísticos: espanhol, francês, inglês e português, com a intenção de obtermos o máximo de referências possíveis sobre Harold Lasswell e também com o intuito de verificarmos a variedade de posicionamentos sobre sua contribuição ao campo comunicacional.

No segundo capítulo, Sobre Clássicos, Tradição, Harold Lasswell e o Campo da Comunicação, são apresentadas as relações entre tradição, clássicos e ciência, estabelecendo bases epistemológicas para empreendermos o retorno a Lasswell, de acordo com a seguinte ordem: 1) reflexão acerca das tradições científicas; 2) o surgimento do termo clássico e a aplicação do termo à ciência (levando em consideração diferenças entre as ciências naturais e as ciências sociais); 3) a questão dos clássicos na Comunicação. A partir disso, verificamos se Lasswell pode ser tomado como autor clássico para o campo da Comunicação.

\footnotetext{
${ }^{14}$ A explicação metodológica mais detalhada se encontra na introdução de cada capítulo.
} 
Já no terceiro capítulo, Cenários Históricos, são apresentadas as bases intelectuais sobre as quais a obra de Harold Lasswell emerge. Em primeiro lugar, fez-se um preâmbulo que apresenta o aparecimento da Comunicação enquanto campo do saber de uma maneira mais geral, para em seguida vincularmos esse aparecimento aos Estados Unidos. Nessa introdução são levadas em consideração questões referentes ao contexto histórico e social que fomentaram as primeiras pesquisas em comunicação, em especial na Alemanha. Em segundo lugar, já partindo para a reflexão sobre a pesquisa em Comunicação nos Estados Unidos, julgou-se necessário uma breve explanação acerca das correntes dominantes na pesquisa social americana para que se possa associálas à Mass Communication Research, pois esta é, até certa medida, fruto do desenvolvimento dessas correntes. Partindo desse ponto de vista, fez-se necessário apresentar em linhas gerais, o Pragmatismo, o Behaviorismo e a Escola de Chicago. Delineia-se também, neste capítulo, o cenário intelectual da primeira metade do século XX, já a partir da própria Mass Communication Research. O último ponto a ser descortinado, em relação aos cenários nos quais a obra de Lasswell, emerge dá continuidade a essa linha fundacional, discutindo, aprofundando e eliminado equívocos referentes à teoria hipodérmica e à filiação de Lasswell a essa corrente de pensamento, posto que comumente o nome do cientista político se encontra associado a este período.

Neste capítulo, optamos por problematizar a história do campo e das constelações de ideias que o formam, somente até o aparecimento da primeira obra de Lasswell sobre comunicação, a já largamente citada Técnicas de propaganda na Guerra Mundial. Isso significa que a história do campo aqui contada se estende somente até a década de 1920. Essa decisão se deu, especialmente, para evitar a sensação de que as correntes de pesquisa em comunicação nos Estados Unidos são substituídas cronologicamente umas pelas outras, quando, na verdade, os diversos posicionamentos epistemológicos coabitam. Além disso, tal opção permite o diálogo de Lasswell com outros autores que o "acompanhavam", para usar a expressão de Alexander Koyré (1982), sem afastá-los pela divisão em correntes de estudo, mas associando-os em contraposições diretas.

A segunda parte da tese, intitulada A Obra Comunicacional de Harold Lasswell, está dividida em dois capítulos, complementares.

Inaugurando essa segunda parte, o quarto capítulo da tese, Harold Dwight Lasswell: um Panorama Biográfico e Intelectual, apresenta a biografia de Lasswell com ênfase na vida e produção intelectual. Apresenta-se, ainda, a ligação com a 
Comunicação como elemento importante em sua trajetória. Nesse momento aparecem as relações de Lasswell com o campo da Comunicação com objetivo também de podermos relacionar sua produção com o que era feito por outros autores da época.

O quinto capítulo, nomeado A Obra Comunicacional de Harold Lasswell, busca compreender as principais formulações de Lasswell sobre a comunicação, bem como seu papel na constituição do campo pela sua obra. Neste tópico, são levados em consideração os paradigmas interseccionados na obra lasswelliana, influências presentes na obra de Lasswell, teorias sobre a comunicação que aparecem na obra do autor, contribuições ao campo, etc. É aqui que a obra propriamente dita de Harold Lasswell é analisada, neste trabalho, e confrontada com o que dizem os livros de teorias da Comunicação. 


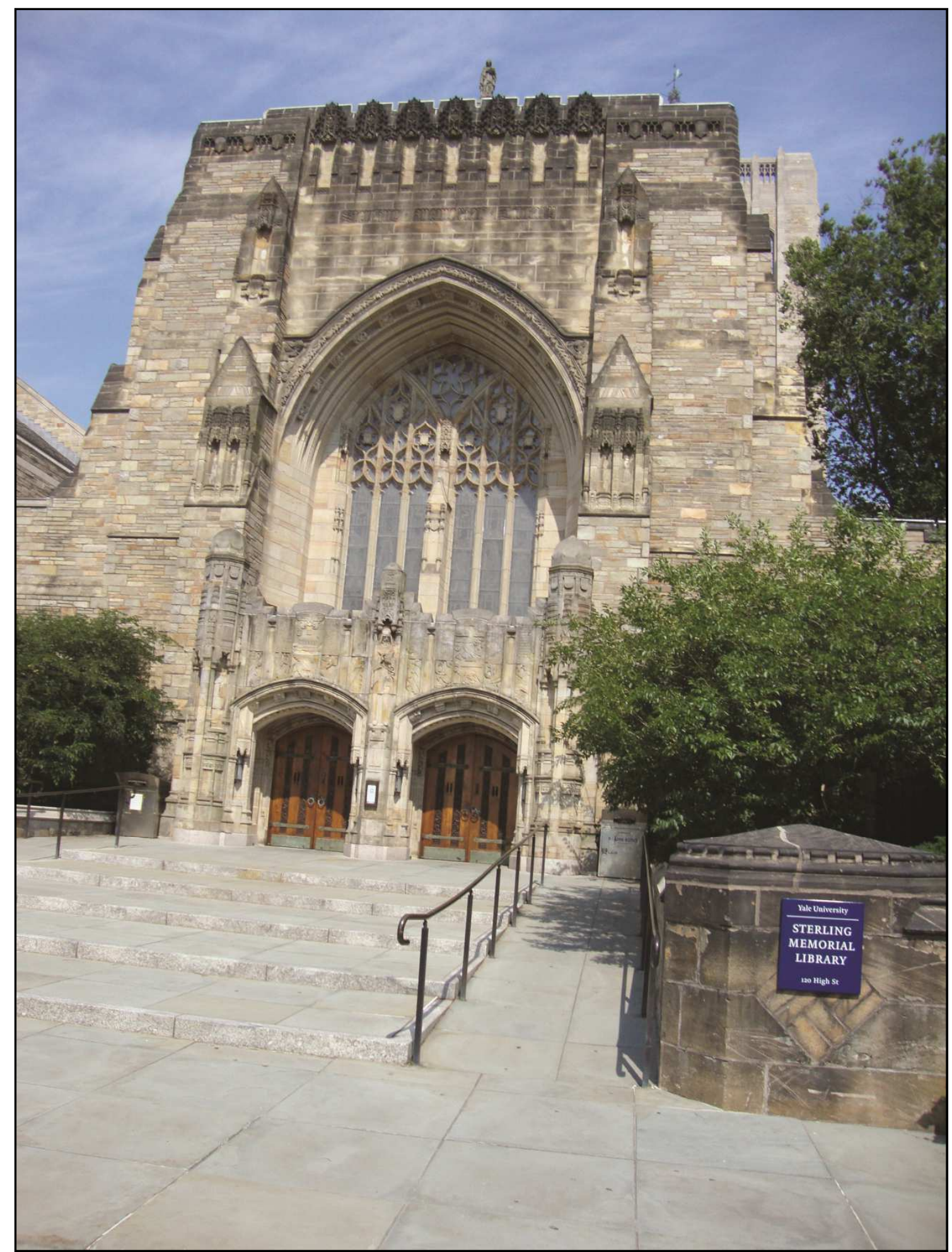

Figura 1. Sterling Memorial Library, na Universidade de Yale, onde estão os arquivos de Harold Lasswell. Fonte: arquivo pessoal. 


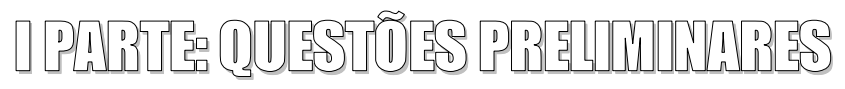




\title{
1. INVENTÁRIO: O QUE OS LIVROS DE TEORIAS DA COMUNICAÇÃO DIZEM SOBRE HAROLD LASSWELL
}

Entender como a Comunicação percebe o trabalho de Harold Lasswell é o primeiro passo para dimensionar a relevância deste pesquisador para a área. Para principiarmos a discussão, tomaremos emprestada uma frase de Michel Foucault sobre autoria e a "morte da autoria":

\begin{abstract}
A [...] noção de autor constitui o momento crucial da individualização na história das idéias, dos conhecimentos, das literaturas, e também na história da filosofia e das ciências. Mesmo hoje, quando se faz a história de um conceito, de um gênero literário ou de um tipo de filosofia, acredito que não se deixa de considerar tais unidades como escansões relativamente fracas, secundárias e sobrepostas em relação à primeira unidade, sólida e fundamental, que é a do autor e da obra (1992, p.53).
\end{abstract}

Ainda que em um contexto diferente do nosso, essa afirmativa traz uma indicação interessante, no que tange à individualização de um autor ou a inserção de uma obra na história dos conhecimentos. A associação desses dois elementos gera uma singularidade em relação a outras obras e outros autores, produz marcas que fazem com que sejam reconhecidos e diferenciados ao mesmo tempo.

Sob esse ponto de vista, a relação autor/obra corresponde a uma das perspectivas as quais se pode recorrer para se tentar reconstituir a trajetória de um determinado saber, pois, tomando de empréstimo as reflexões de Foucault sobre autoria, o autor/obra

[...] exerce um certo papel em relação ao discurso: assegura uma função classificatória; tal nome permite reagrupar um certo número de textos, delimitá-los, deles excluir alguns, opô-los a outros. Por outro lado, ele relaciona os textos entre si; Hermes Trimegisto não existia, Hipócrates, tampouco - no sentido em que se poderia dizer que Balzac existe -, mas o fato de que vários textos tenham sido colocados sob um mesmo nome indica que se estabelecia entre eles uma relação de homogeneidade ou de filiação, ou de autenticação de uns pelos outros, ou de explicação recíproca, ou de utilização concomitante (FOUCAULT, 1992, p.59).

Essa função classificatória atribui valor a um determinado autor ou obra, ela não se dá sem que exista um certo "acordo" sobre a definição do campo de conhecimento. Ela não emana desses elementos de forma inadvertida. Sua significação lhes é concedida, descrita e apontada, tornada conhecida. O trabalho de agrupar uma quantidade de textos sob o nome de um autor (dando-lhe o nome de "obra") realiza um processo de autenticação do próprio autor, uma legitimação e uma explicação do valor deste último, que deve ser reconhecido pelos seus pares e também pelo saber no qual 
está inserido. No domínio da ciência - além do que já foi destacado pelo historiador francês - devemos acrescentar que as disciplinas científicas funcionam como construtoras da "individualização" de cada pesquisador. Autor e obra constituem o patrimônio de um saber. Não existem por si, mas relativamente a um campo, a um domínio do saber. Então, quem atribui valor a Harold Lasswell para o campo da Comunicação senão o próprio campo?

Assim, entendemos que cada saber nos oferece sinalizações que demarcam a relevância de seus produtores e os individualiza frente a seus pares, fazendo com que sejam dignos de atenção ou ignorados. Onde encontrar essas sinalizações é, então, a primeira argüição a ser feita para entendermos como a Comunicação apreende seus autores de destaque e, portanto, Lasswell.

Para elucidarmos este ponto, delimitamos os registros que seriam válidos para serem investigados, fornecendo dados mais consistentes acerca de como o campo individualiza e sinaliza o lugar de Lasswell na Comunicação. A seleção foi feita buscando o "material mais prontamente acessível, efetivamente responsável pela formação" e que pudesse servir "de recurso para as atividades de ensino e pesquisa na área de comunicação" (MARTiNO, 2006, p.6).

Foram adotados dois procedimentos iniciais para se chegar ao material submetido à análise. $\mathrm{O}$ primeiro procedimento teve como objetivo averiguar a existência de materiais específicos de estudo da obra lasswelliana, materiais que trouxessem o trabalho de Lasswell como foco e que fossem produzidos pela Comunicação. O segundo se deu com foco nas obras de teorias da Comunicação. Expliquemos o primeiro, antes.

A meta era divisar pesquisas cuja centralidade estivesse na observação crítica das obras de Lasswell que interessariam ao campo comunicacional. Para tentar alcançála, realizamos uma busca ampla, em ambiente digital, com a intenção de organizar um extenso painel.

O mecanismo de busca utilizado foi o do muito conhecido Googlebooks ${ }^{15}$. A escolha da ferramenta se deu em função do Googlebooks disponibilizar mais de 20 milhões de títulos escaneados, tendo como parceiros grandes bibliotecas do mundo, como as das universidades de Harvard, Stanford e Oxford. Além disso, a utilização de

\footnotetext{
${ }^{15}$ Anteriormente conhecido como Google Print ou Google Book Search (2004). O Googlebooks é um search engine (em português "mecanismo de busca" ou "motor de busca"), interno ao Google, site de busca criado em 1998 pelos americanos Larry Page e Sergey Brin. O Googlebooks realiza buscas apenas relacionadas a livros e periódicos. Insere-se um termo-chave na janela de busca e um "robô" (software) vasculha a internet gerando links com páginas de referências.
} 
ferramentas distintas da disponibilizada pelo Googlebooks acabaria por nos direcionar ao próprio site, uma vez que elas somente buscam, mas não armazenam os livros. Somado a isso, a grande quantidade de títulos disponíveis no Googlebooks, em várias línguas, se apresentou como a forma mais rápida de construir um corpus amplo, em múltiplos idiomas, que possibilitasse uma visão menos parcial da bibliografia sobre Harold Lasswell.

Foi realizada uma busca simples, utilizando somente o nome "Harold Lasswell" como um único termo, com o objetivo de abarcar a maior quantidade de textos possíveis que pudessem ter sido produzidos acerca de Lasswell e sua contribuição ao campo da Comunicação. Essa fase foi particularmente trabalhosa, pois o termo-chave, intencionalmente, era bastante inclusivo. Quantitativamente, e conforme o esperado, os resultados foram extensos quanto à bibliografia a respeito de Lasswell (o Googlebooks retornou cerca de 227.000 resultados). O escrutínio das obras, contudo, eliminou o susto numérico. Vejamos o porquê.

Ainda na busca ampla, inúmeros resultados foram livros escritos pelo próprio Lasswell, correspondente à maior fração das obras listadas pelo Googlebooks. Fez-se necessário eliminar essas obras, para que se evidenciasse somente escritos sobre Lasswell. Feito isso, passamos a eliminar livros que não fossem produzidos por autores da Comunicação ou que não tivessem como finalidade refletir sobre a relação entre o cientista político e os problemas do campo comunicacional ${ }^{16}$.

Qualitativamente, essa sondagem que a princípio parecia um esforço hercúleo, se mostrou insuficiente para a constituição de um painel sobre o que nosso campo de estudos pensa sobre Harold Lasswell, pois encontramos um único livro que trata da obra de Lasswell sobre comunicação: o alemão Die Lasswell-Formel: Ursprung und Bedeutung (A Fórmula de Lasswell: Origem e Significado ${ }^{17}$ ), de Stefan Meingast, produzido em 2000.

Visto que essa diligência se mostrou aquém da proposta deste capítulo, compreendemos que o procedimento mais adequado seria a procura por elementos nas obras que se propõem a oferecer um panorama das teorias da Comunicação. Ao traçar um quadro em que se distinguem teorias e autores essenciais ao campo da Comunicação

\footnotetext{
${ }^{16}$ Grande parte dos estudos de outras áreas foram selecionados como forma de compreender Lasswell, mas não como forma de entender como a Comunicação percebe o autor. Esses estudos nos auxiliaram em capítulos posteriores.

${ }^{17} \mathrm{O}$ livro é resultado de um seminário realizado na Universidade de Munique e traz uma apresentação mainstream do esquema de Lasswell.
} 
(a despeito de sua diversidade), são esses os materiais que nos dão uma ideia geral daquilo que deve ser valorizado e destacado do pano de fundo.

Optamos, portanto, por aquilo que Martino chamou de obras teorográficas,

[...] ou seja, livros que não criam ou se servem de teorias para analisar um determinado fenômeno, mas que têm como objeto as próprias teorias. Ao fornecerem uma visão panorâmica das tendências e escolas estas obras introduzem uma sistematização do campo teórico, dando-lhe forma na medida mesmo que o trazem à luz e que reconhecem aquelas teorias selecionadas como as principais teorias da área (2006, p.8-9).

Contudo, o universo de publicações sobre teorias da Comunicação não é pequeno. Além disso a variedade de livros que tratam sobre o tema, as discrepâncias sobre o que propriamente deve ser definido como teorias da Comunicação ${ }^{18}$, são fatores que tornariam bastante complexo esse levantamento inicial sobre Lasswell. Particularmente porque - dependendo da posição adotada pelo teorógrafo ${ }^{19}$ a respeito de quais teorias fazem parte do campo da Comunicação - pode-se desenhar um panorama em que Lasswell esteja presente como um autor importante ou, por outro lado, um quadro no qual o cientista político seja completamente ignorado. Por isso fez-se necessário limitar o alcance de nossa pesquisa para que pudéssemos fazer $\mathrm{o}$ levantamento do material.

Empregamos, então, a noção de capital teórico para selecionar deste universo de cerca de 227 mil obras aquelas que formam o corpus de análise deste trabalho, não procurando examinar a totalidade dos livros sobre o assunto (o que nos levaria a estudar textos que ignoram por completo Harold Lasswell), mas unicamente aqueles que trazem sinalizações sobre o papel do pesquisador para o campo da Comunicação. A noção de capital teórico se opõe à de patrimônio teórico (totalidade dos livros panorâmicos sobre teorias da Comunicação) e nos possibilita um conjunto de obras mais preciso sobre a questão a que nos propomos, dado que o

[...] capital teórico caracteriza [...] o conjunto de teorias mais imediatamente disponíveis (critério de acessibilidade, ou de disponibilidade dessas obras), bastante reconhecidas (critério de reconhecimento) e que indubitavelmente têm peso na formação teórica de nossa área (MARTINO, 2006, p.10).

\footnotetext{
${ }^{18}$ Cf. Martino, 2006.

${ }^{19}$ Nome dado por MARTINO, 2006, para identificar os autores de livros de teorias.
} 
Neste caso, nos importa especialmente o que a área de comunicação, em sua produção bibliográfica, diz sobre Lasswell. Mesmo tendo um tamanho reduzido em relação ao patrimônio teórico, o capital teórico visa expressar a forma como um determinado autor é aproveitado por um domínio de conhecimento. Foi a partir dessa percepção que iniciamos o levantamento do material a ser examinado.

\subsection{Levantamento do material: montando o inventário}

Dado que nossa intenção é bastante pontual - verificar de que forma os livros de teoria da comunicação nos apresentam Harold Lasswell - optamos por uma busca cruzada em ambiente digital. A busca cruzada associa diversas palavras-chave, com duas ou mais variáveis, para que se obtenha como resultado elementos mais próximos do escopo final pretendido pelo pesquisador. A utilização da busca cruzada proporciona um resultado mais sistemático e enxuto, ela nos oferece um corpus de estudo mais exato, pois nos apresenta apenas as obras nas quais Lasswell é citado. Aqui também utilizamos o Googlebooks (pelos mesmos motivos listados anteriormente).

A busca foi dividida em quatro blocos linguísticos, correspondentes a quatro idiomas (espanhol, inglês, francês e português), o que permitiu um esquadrinhamento mais detalhado da bibliografia. Para efetivá-la, utilizamos palavras-chave relacionadas à teoria da comunicação somadas ao termo "Harold Lasswell". As palavras-chave foram inicialmente pensadas em português e depois traduzidas para os outros três idiomas. São elas: estudos em comunicação, estudos dos meios, pesquisa em comunicação, teoria da comunicação, teoria dos efeitos. O objetivo dessa seleção foi encontrar de maneira mais direta as obras teorográficas, procurando as expressões nos títulos dos livros listados pelo Googlebooks. Esse método nos possibilitou uma triagem ainda mais substancial, uma vez que o aparecimento desses vocábulos apenas no corpo do texto não necessariamente indica uma obra teorográfica. Por outro lado, os termos selecionados, ao aparecerem nos títulos dos trabalhos, dificilmente indicariam outro tipo de abordagem $^{20}$.

Dessa forma, utilizamos as seguintes variáveis nos quatro idiomas que compõem o nosso universo de pesquisa:

\footnotetext{
${ }^{20}$ De fato, a pesquisa pelos termos no título se mostrou apropriada em $100 \%$ dos livros selecionados.
} 


\begin{tabular}{|c|c|c|c|}
\hline Espanhol & Francês & Inglês & Português \\
\hline $\begin{array}{l}\text { Estudios de Comunicación } \\
\qquad+ \text { Harold Lasswell }\end{array}$ & $\begin{array}{l}\text { Études en Communication } \\
\qquad+ \text { Harold Lasswell }\end{array}$ & $\begin{array}{l}\text { Communication Studies } \\
\text { + Harold Lasswell }\end{array}$ & $\begin{array}{l}\text { Estudos em Comunicação } \\
\qquad+ \text { Harold Lasswell }\end{array}$ \\
\hline $\begin{array}{l}\text { Estudios de los Medios } \\
\text { +Harold Lasswell }\end{array}$ & $\begin{array}{l}\text { Études des Médias } \\
\text { +Harold Lasswell }\end{array}$ & $\begin{aligned} & \text { Media Studies } \\
+ & \text { Harold Lasswell }\end{aligned}$ & $\begin{array}{l}\text { Estudos dos meios } \\
+ \text { Harold Lasswell }\end{array}$ \\
\hline $\begin{array}{l}\text { Investigación de la } \\
\text { Comunicación }^{21} \\
\text { +Harold Lasswell }\end{array}$ & $\begin{array}{l}\text { Recherches en } \\
\text { Communication } \\
+ \text { Harold Lasswell }\end{array}$ & $\begin{array}{c}\text { Communication Research } \\
+ \text { Harold Lasswell }\end{array}$ & $\begin{array}{c}\text { Pesquisa em Comunicação } \\
\text { + Harold Lasswell }\end{array}$ \\
\hline $\begin{array}{c}\text { Teoría de la Comunicación } \\
\text { +Harold Lasswell }\end{array}$ & $\begin{array}{l}\text { Théorie de la } \\
\text { Communication } \\
\text { +Harold Lasswell }\end{array}$ & $\begin{array}{l}\text { Communication Theory } \\
\text { + Harold Lasswell }\end{array}$ & $\begin{array}{l}\text { Teoria da Comunicação } \\
\text { + Harold Lasswell }\end{array}$ \\
\hline $\begin{array}{c}\text { Teoría de los Efectos de } \\
\text { los Medios } \\
+ \text { Harold Lasswell }\end{array}$ & $\begin{array}{l}\text { Théorie des Effets des } \\
\text { Médias } \\
\text { +Harold Lasswell }\end{array}$ & $\begin{array}{l}\text { Media Effects Theory } \\
\text { +Harold Lasswell }\end{array}$ & $\begin{array}{l}\text { Teoria dos Efeitos dos } \\
\text { Meios } \\
+ \text { Harold Lasswell }\end{array}$ \\
\hline $\begin{array}{c}\text { Teoría de los Medios } \\
\text { +Harold Lasswell }\end{array}$ & $\begin{array}{c}\text { Théorie des Médias } \\
\text { +Harold Lasswell }\end{array}$ & $\begin{aligned} & \text { Media Theory }^{22} \\
+ & \text { Harold Lasswell }\end{aligned}$ & $\begin{array}{c}\text { Teoria dos Meios de } \\
\text { Comunicação + Harold } \\
\text { Lasswell }\end{array}$ \\
\hline
\end{tabular}

Tabela 1. Variáveis utilizadas na busca cruzada sobre Harold Lasswell.

A busca cruzada se mostrou uma estratégia acertada, com resultados menos equivocados. Poucas obras das que apareceram na busca não correspondiam a obras teorográficas. Contudo, não eliminou um extenso trabalho de observação e seleção, uma vez que o Googlebooks oferta três opções de visualização (qualquer visualização - que inclui livros que não dispõem de nenhuma visualização -, visualização parcial e visualização completa). Elegemos os dois últimos tipos de visualização, cujos nomes são autoexplicativos, uma vez que não era importante saber quantas vezes Lasswell aparece nas obras de teorias da comunicação, mas como aparece, o que só pode ser feito com a leitura completa dos trechos.

O mecanismo de busca do Googlebooks também oferece várias edições de um mesmo livro, o que requer o constante descarte de material repetido. Outro descarte a ser realizado foi o de obras que se fazem presentes em mais de um idioma, como Teorias da Comunicação de Massa, de Melvin Defleur e Sandra Ball-Rockeach, e História das Teorias da Comunicação, de Armand Mattelart e Michèle Mattelart. O mecanismo facilitou a consulta aos trechos referentes a Lasswell, já que a utilização das

\footnotetext{
${ }^{21}$ Consideramos aqui também obras em catalão, como o termo “recerca en comunicación”, e não apenas em castelhano.

${ }_{22}$ Apesar de Media Theory ser o nome de uma corrente de pesquisa, a designação também aparece nas obras em inglês como sinônimo de teoria da comunicação. A busca cruzada, então, se mostrou mais uma vez um procedimento adequado, pois nos direcionou a livros que usam o termo nessa segunda acepção, uma vez que Lasswell está excluído daquilo que chamamos de Media Theory no sentido de uma corrente de pesquisa.
} 
variáveis de busca faz com que estes sejam destacados do restante. As possíveis omissões (devido, por exemplo, ao uso de pronomes ou a artifícios retóricos) são compensadas pela possibilidade de estender à consulta a um número de obras bastante elevado.

Nessa triagem, obedecemos a critérios clássicos de seleção da análise de conteúdo: representatividade (os trabalhos devem ser representativos de acordo com o objetivo de pesquisa), homogeneidade (devem ser os mais homogêneos possíveis) e pertinência (devem ser adequados em relação ao objetivo de pesquisa).

Os resultados quantitativos da busca foram:

\begin{tabular}{|l|c|c|c|c|}
\hline \multicolumn{2}{|c}{ Espanhol } & \multicolumn{2}{c|}{ Inglês } & Português \\
\hline 7 obras & 4 obras & 65 obras & 6 obras & 83 obras \\
\hline
\end{tabular}

Tabela 2. Quantidade de obras teorográficas que contemplam o trabalho de Harold Lasswell (Inicial).

A esses números - que revelam uma discrepância quantitativa considerável entre a produção em língua inglesa sobre teoria da comunicação e as demais línguas ${ }^{23}$-, deve ser acrescentada a observação de que também não abarcam toda a produção da área sobre teorias da comunicação que traz alguma referência a Lasswell. Ao optar pelo Googlebooks e pelas visualizações parciais e/ou completas, algumas importantes referências acabaram por escapar a esse conjunto exatamente por não possuírem nenhuma dessas opções de visualização. Assim, por exemplo, o livro Teorias da Comunicação, de Mauro Wolf (já citado neste trabalho), não faz parte das obras apresentadas na tabela acima em nenhum dos idiomas. Contudo, a ausência dessas referências não chega a prejudicar a apreensão global da forma como Lasswell é apresentado pelos livros de teoria da comunicação. Além disso, como afirma Sempel (in BAUER, 2004, p.197), o importante neste caso não é a inclusão ou a exclusão de um determinado documento do corpo da análise, mas oferecer uma estimativa confiável. Mesmo assim, as obras que nos eram conhecidas, não foram ignoradas, e foram somadas ao quadro que buscamos gerar neste capítulo, cujos resultados quantitativos foram alterados conforme mostra a tabela abaixo:

\footnotetext{
${ }^{23}$ Mais de $78 \%$ das obras selecionadas para análise estão em língua inglesa.
} 


\begin{tabular}{|c|c|c|c|c|}
\hline Espanhol & Francês & Inglês & \multicolumn{2}{c|}{ Português } \\
\hline 7 obras & 4 obras & 65 obras & 9 obras & 85 obras \\
\hline
\end{tabular}

Tabela 3. Quantidade de obras teorográficas que contemplam o trabalho de Harold Lasswell (Final).

Assim, essas 85 obras teorográficas ${ }^{24}$, que se apresentam em concordância com a noção de capital teórico, foram submetidas a uma análise de conteúdo, tendo em vista que o objetivo deste método é "[...] a manipulação de mensagens (conteúdo e expressão desse conteúdo), para evidenciar os indicadores que permitam inferir sobre uma outra realidade que não a da mensagem" (BARDIN, 1979, p.46). Desse modo, o conjunto das mensagens diz aquilo que as próprias mensagens não dizem: a posição de Lasswell nos trabalhos que apresentam as teorias da comunicação.

Longe de ser um método puramente quantitativo, a análise de conteúdo é tipicamente híbrida, atenta à qualificação que se sobressai da quantidade. Nessa atenção voltada à qualidade que se representa no quantitativo, não levamos em consideração nesse estudo palavras, mas sentenças inteiras, que interpretam "[...] o texto apenas à luz do referencial de codificação, que constitui uma seleção teórica que incorpora o objetivo da pesquisa” (BAUER, 2004, p.199). Pela análise exaustiva dos elementos que surgem no levantamento é que a análise de conteúdo pode ir além do que é dito, inferindo uma realidade que os textos isoladamente não dizem.

\subsection{Analisando o inventário: o que dizem os livros de teorias da comunicação sobre Harold Lasswell}

Antes de expormos os dados sobre Harold Lasswell nos livros de teorias da comunicação, deve-se esclarecer algumas questões acerca do método escolhido para análise do corpus já definido. A preferência pela análise de conteúdo se deu especialmente em função dos objetivos aqui já descritos e pelo fato de tal método oferecer a perspectiva de constituir um "mapa de conhecimento" (BAUER, 2004, p. 194), representando o "conhecimento não apenas por elementos, mas também em suas relações" (Idem, ibidem, p.194). Ao aplicar a análise de conteúdo aos textos inventariados no item anterior, procuramos não observar apenas os elementos que este corpus apresenta sobre Lasswell, mas como esses elementos expressam uma relação

\footnotetext{
${ }^{24}$ De fato, a escolha de obras teorográficas e somente elas já atende a um dos critérios da análise de conteúdo: a homogeneidade do corpus a ser examinado.
} 
para além dos textos, que definem o lugar de Lasswell no campo da Comunicação. É essa última relação que se define como resultado esperado do exame das obras teorográficas, em concordância com Bauer, quando este explica que "[...] Um corpus de texto é a representação e a expressão de uma comunidade que escreve. Sob esta luz, o resultado de uma AC [Análise de Conteúdo] é a variável dependente, a coisa a ser explicada" (2004, p.190, colchetes nossos).

A análise de conteúdo também se alinha aos nossos propósitos por permitir a "ultrapassagem da incerteza" e o "enriquecimento da leitura" (BARDIN, p.29). A transposição da incerteza se dá no momento em que a observação dos materiais revela se o que julgamos estar contido na mensagem está realmente lá, podendo ser partilhado por muitos. O enriquecimento da leitura, por sua vez, tem como pressuposto a "descoberta de estruturas que confirmam (ou infirmam) o que se procura demonstrar a propósito das mensagens" (Idem, ibidem, p.29).

Para cumprir seus desígnios, a análise de conteúdo, como conjunto de técnicas de estudo das comunicações, leva em consideração duas dimensões da linguagem: a semântica (o que é dito num texto) e a sintática (como é dito). A compreensão dessas duas dimensões, que geram, por sua vez, as unidades de análise (por vezes chamadas de categorias): os elementos textuais capazes de fazer com que o pesquisador consiga inferir mais do que a realidade do próprio texto. Dessa forma, ao analisarmos as obras teorográficas selecionadas, o intuito é conseguir inferir certa "imagem" construída sobre o papel de Harold Lasswell na Comunicação, não só em um texto, mas diante de todos os elementos que possam constituir um campo, seja na sua abordagem epistemológica, sociológica, institucional, etc.

A seleção das unidades de análise ou categorias pode ocorrer de duas formas: apriorística, com as categorias definidas previamente pelo investigador, antes de tomar contato com o corpus de análise, e de modo mais espontâneo, definindo-se as categorias após o exame do corpus selecionado. Aqui, devido à imensidade do conjunto de obras a serem perscrutadas, definiu-se as categorias (que chamamos de temas) do segundo modo, levando em conta também o nosso objetivo, pois “[...] embora o corpus de texto esteja aberto a uma multidão de possíveis questões, a AC interpreta o texto apenas à luz do referencial de codificação, que constitui uma seleção teórica que incorpora o objetivo da pesquisa" (BAUER, 2004, p.199). Sem a postura apriorística, a leitura ficou menos restritiva, abrindo possibilidades inclusive para o desconhecido ou o raro. 
Tratamos, então de buscar nas 78 obras teorográficas categorias que representassem os dados mais comuns acerca de Harold Lasswell, o que resultou em 17 temas, listados a seguir:

\begin{tabular}{|l|}
\hline Temas \\
\hline Análise de conteúdo \\
\hline Capítulo biográfico \\
\hline Definição de comunicação \\
\hline Esquema de Lasswell \\
\hline Funções da comunicação \\
\hline Importância do receptor \\
\hline Influência sobre Lazarsfeld \\
\hline Influência no Brasil \\
\hline Grande importancia para o campo \\
\hline Pais fundadores \\
\hline Pesquisa quantitativa \\
\hline Pesquisa sobre os efeitos \\
\hline Pragmatismo \\
\hline Propaganda \\
\hline Relação com Robert Ezra Park \\
\hline Teoria Hipodérmica \\
\hline Trabalho na Divisão de Guerra \\
\hline
\end{tabular}

Tabela 4. Temas relacionados a Harold Lasswell em obras teorográficas.

Uma primeira observação desses temas poderia nos levar a crer que Lasswell é apresentado de uma forma bastante completa pelo campo nas obras de teorias da comunicação, dado que a tabela acima parece fazer uma "varredura" de diversos assuntos relacionados ao cientista político. Contudo, o exame detalhado de cada uma das obras teorográficas dos quatro blocos linguísticos nos mostra situação inversa. Vejamos cada um separadamente.

\section{a) Harold Lasswell no universo de língua espanhola}

A busca cruzada realizada em língua espanhola retornou poucos títulos de obras teorográficas, somente sete. São eles: 


\begin{tabular}{|l|l|l|}
\hline Livro & \multicolumn{2}{|l|}{ Autor } \\
\hline $\begin{array}{l}\text { Teorías de la comunicación: Investigaciones sobre medios en } \\
\text { América y Europa }\end{array}$ & Miguel de Moragas Spà \\
\hline Teorías de la comunicación & Edison Otero Bello & 1981 \\
\hline Teorías de la comunicación: Ámbitos, métodos y perspectivas & Rodrigo Miquel Alsina & 1997 \\
\hline $\begin{array}{l}\text { La recerca en comunicación. Què hem de saber? Quins passos hem } \\
\text { de seguir? }\end{array}$ & $\begin{array}{l}\text { Alfons Medina Cambrón e Josep } \\
\text { Sort Jané }\end{array}$ & 2006 \\
\hline Teoría e investigación de la comunicación de masas & José Carlos Lozano Rendón & 2007 \\
\hline Teorías de los mediosde comunicación & Federico Boni & 2008 \\
\hline Estudios de comunicación y médios & Enric Saperas Lapiedra & 2012 \\
\hline
\end{tabular}

Tabela 5. Obras teorográficas em espanhol com referências a Harold Lasswell.

Apenas Teorías de la comunicación, de Edison Otero Bello, foi editado na América Latina (Chile). Todos os outros foram produzidos na Europa (Espanha). Há concordância entre os temas tratados, sobretudo no que diz respeito ao modelo de Lasswell. Há também pouca variação e aprofundamento nessas obras acerca do cientista político e sua atuação no campo comunicacional. Em geral, é dedicada uma ou duas páginas para falar-se desse autor (exceção feita a Teorías de la comunicación, de Edison Otero Bello), demarcando de forma bastante sucinta seu papel no campo da Comunicação. Os temas trabalhados são poucos e se distribuem de acordo com o gráfico:

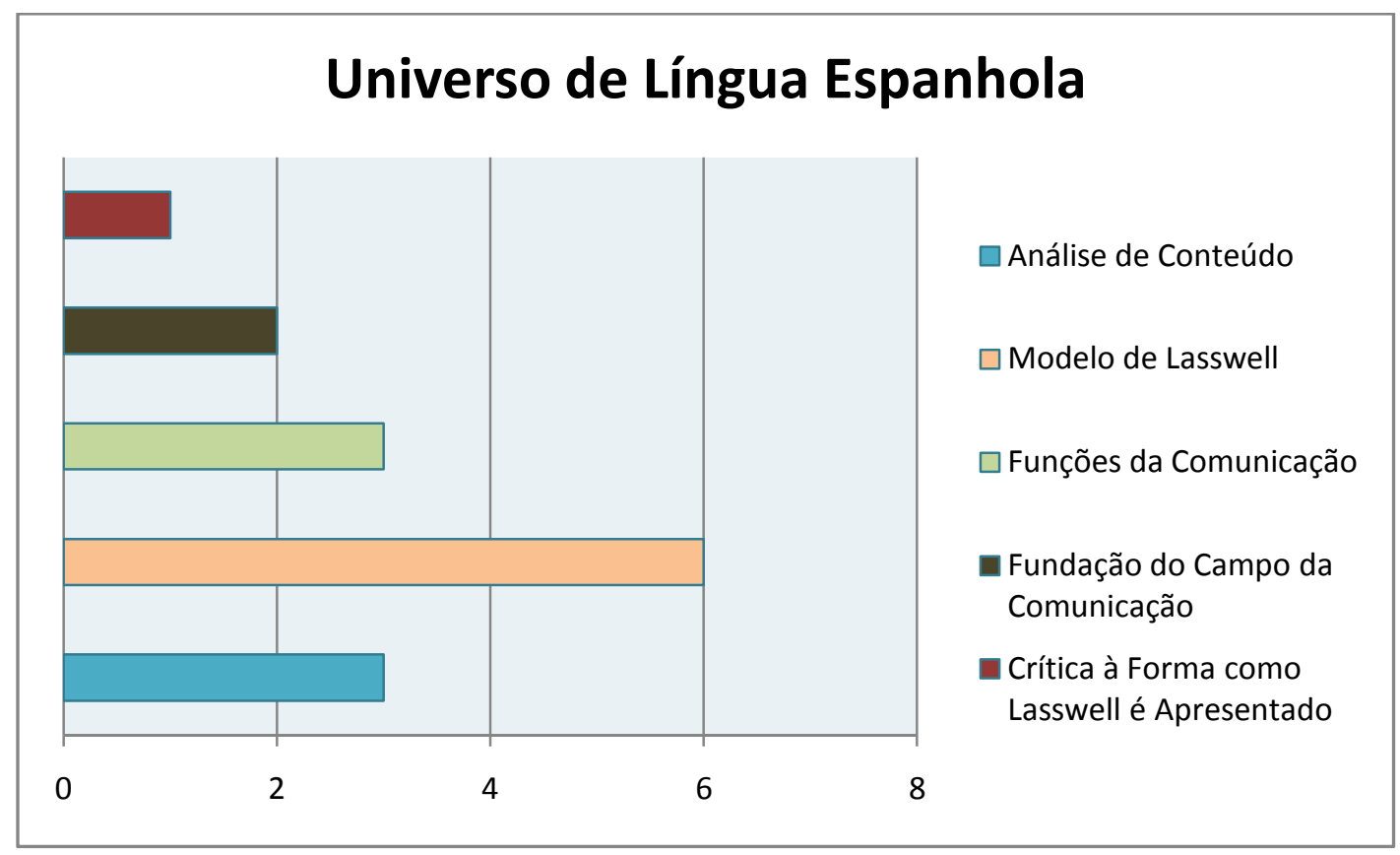

Gráfico 1. Relação número de obras e temas relacionados à Lasswell na bibliografia de língua espanhola. 
O tema mais frequente é o "modelo de Lasswell", presente em cinco das obras analisadas (aproximadamente $72 \%$ dos livros estudados). O único livro analisado a não tratar do assunto é Estudios de comunicación y médios, de Enric Saperas Lapiedra. O que se fala no restante é basicamente sobre as cinco perguntas do esquema e sobre como se dividiu a pesquisa em comunicação a partir dele ou como ele era limitado por não englobar elementos importantes no processo comunicacional, como o contexto social, por exemplo.

A forma como Cambrón \& Jané (2006) e Rendón (2007) expõem o modelo é emblemática desse grupo de livros. Segundo Cambrón e Jané,

A pesquisa em comunicação foi dominada desde as origens por uma concepção de comunicação entendida como um processo de influência. Este modelo linear, baseado no paradigma de Lasswell, fundamentou a pesquisa dominante desde os anos trinta até os setenta e fazia parte do paradigma condutor baseado em um estudo de como o comunicador (que elabora estímulos determinantes) impacta um receptor (considerado como um sujeito estimulado) com a finalidade de conseguir efeitos a curto ou médio prazo.

Este processo tem cinco aspectos ou âmbitos fragmentados, descritos perfeitamente pelo paradigma de Lasswell.

Tabela 2.1

Quem? $\rightarrow$ Estudo do comunicador

Diz o que? $\rightarrow$ Estudo do conteúdo

Por quais canais? $\rightarrow$ Estudo dos meios técnicos

Para quem? $\rightarrow$ Estudo das audiências

Com quais efeitos? $\rightarrow$ Estudo das influências

Esta teoria pressupõe que a iniciativa é sempre do comunicador e vê os membros da audiência como receptores passivos das mensagens ${ }^{25}$ (2006, p.41).

Neste exemplo, que está presente em capítulo sobre história da pesquisa em comunicação (La historia da recerca en comunicació, p.41), Cambrón e Jané asseguram a divisão inicial da pesquisa realizada por Lasswell, delegando ao modelo também a

\footnotetext{
25 "La recerca comunicativa ha estat dominada des dels origens por uma concepció de la comunicacío entesa com un procés d'influència. Aquest model lineal, basat em el paradigma de Lasswell, há fonamentat la recerca dominant des del anys trenta fins als anys setanta i parteix del paradigma conducista basat em l'estudi de com um comunicador (que elabora determinais estímulos) impacta em um receptor ( considerat com a subjecte estimulati) amb la finalitat d'aconseguir determinats efects a curt o mitjá termini.

Aquest procés té cinc aspects o àmbits fragmentats que el paradigma de Lasswell descriu perfectament.
}

Taula 2.1

Qui? $\rightarrow$ Estudi del comunicador

Diu quê? $\rightarrow$ Estudi del contigut

Per quins canals? $\rightarrow$ Estudi dels mitjans tècnics

A qui? $\rightarrow$ Estudi de les audiències

Amb quins efectes? $\rightarrow$ Estudi de lesinfluènces

Aquesta teoria pressuposa que la iniciativa sempre és del comunicador i entés els membres de l'audiència com a objectes passius dels missatges". 
pouca importância que o receptor adquiriu nesses estudos - alinhando-o à teoria hipodérmica, ainda que esta não seja citada. Todavia, os autores ignoram grande parte do contexto da pesquisa em comunicação que possibilitou a construção do modelo e oferecem a ele apenas três parágrafos, entre apresentação e discussão. A bibliografia de Lasswell presente no livro de Cambrón e Jané mostra também a pouca importância que um conhecimento maior sobre o cientista político possui na delimitação do modelo para o próprio Lasswell. A única obra consultada pelos autores é A Estrutura e a Função da Comunicação na Sociedade, o artigo de 1948 que apresenta o modelo, mas de forma alguma o explica por completo.

Quanto à limitação do modelo de Lasswell, no tópico Modelos del proceso de la comunicacion, Rendón afirma:

\begin{abstract}
Este influente modelo, utilizado ainda hoje, define os elementos clássicos de muitos modelos posteriores: emissor, mensagem, canal, receptor, efeito. $\mathrm{O}$ seguinte modelo retoma o anterior:

Fonte-Codificador-Mensagem-Canal-Decodificador-Receptor-

Retroalimentação

Ainda que ambos os modelos sejam bastante completos na identificação dos elementos chave do processo de comunicação, tem um grave problema. As duas elaborações, por sua visão psicologista, ignoram os elementos externos ao processo de comunicação de massas que exercem uma influência decisiva na produção, distribuição e consumo das mensagens ${ }^{26}$ (RENDÓN, 2007, p.14).
\end{abstract}

Rendón toma como fato incontestável a exclusão de qualquer contexto social na análise possibilitada pelo uso do modelo, entendendo-o como resultado de uma visão psicologista (entendida, por sua vez, como fora do campo social). Ao mesmo tempo em que valoriza o modelo, chamando de clássico, que serviu de base para muitos outros modelos e que, nas palavras do próprio Rendón, é "muito completo na identificação dos elementos chave do processo de comunicação", o autor mexicano o desvaloriza por ter o "grave problema" de ignorar os elementos sociais. Tomando esta afirmativa como certeza, Rendón assume uma posição ambígua em relação ao modelo: é muito completo, mas possui uma falha grave. É interessante notar que o autor não aprofunda os estudos sobre Lasswell, assim como Cambrón e Jané, a bibliografia de Teoría e investigación de

\footnotetext{
26،"Este influyente modelo, aún utilizado actualmente, define los elementos clássicos de muchos modelos posteriores: emissor, mensaje, canal, receptor, efecto. El seguinte modelo retorna lo anterior: Fuente-Encodificador-Mensaje-Canal-Decodificador-Receptor-Retroalimentación

Aunque ambos modelos se vem muy completos em la identificación de los elementos clave del processo de la comunicación, tienen um grave problema. Las dos elaboraciones, por su visión psicologista, ignoran los elementos externos al processo de la comunicación de masas que, desde afuera, ejercen uma influencia decisiva em la produción, distribución y consumo de los mensajes".
} 
la comunicación de masas traz apenas uma obra do americano: novamente, A estrutura e a função da comunicação na sociedade.

A "análise de conteúdo" e o tema "funções da comunicação" estão presentes em três livros (aproximadamente $43 \%$ do material disponível). O primeiro aparece como o método mais comumente utilizado por Lasswell; o segundo como a implantação da teoria funcionalista na comunicação e também na forma de lista, elencando quais seriam as funções da comunicação.

De outra parte, é interessante perceber as contradições presentes na análise de Lasswell que aparecem quando os temas começam a se somar ("modelo de Lasswell" + “análise de conteúdo" + "funções da comunicação"). Enquanto Rendón (2007) chamava a abordagem lasswelliana de "psicológica”, Miguel de Moragas Spà chama a atenção, sem no entanto detalhar, para o aporte sociológico do americano: "No início dos anos trinta e por razões já expostas quando falamos, por exemplo, da abordagem sociológica de Lasswell, a análise de conteúdo experimenta um grande impulso"27 (1981, p.55). Mesmo Rendón, ao falar de funções da comunicação descritas por Lasswell e sobre o funcionalismo, os descreve a como uma visão sociológica (até mesmo pelo fato de que o funcionalismo é uma corrente sociológica).

O papel de Lasswell como fundador do campo comunicacional é citado explicitamente duas vezes, de forma muito breve. Saperas, ao citar o famoso artigo de Bernard Berelson sobre os pais fundadores do campo da comunicação, reconhece Lasswell como um dos "grandes arquitetos" do campo (p.31) e Bello diz que "[...] anos antes dos outros pais fundadores, Lasswell, então cientista político, se interessou pela propaganda" (1997, p.30). Mesmo assim, é perceptível que as outras obras perscrutadas dão a Lasswell um destaque similar, pois a sua figura aparece antes de quaisquer outras e seu modelo é sempre apontado como aquele que definiu o campo da comunicação.

A bibliografia em língua espanhola, contudo, traz um dado interessante: é a única que apresenta uma crítica à forma como usualmente conhecemos Lasswell, especialmente no que diz respeito a sua associação direta com a teoria hipodérmica. A crítica está presente no texto de Edison Otero Bello que dispõe de um capítulo inteiro sobre o cientista político. Assim, Bello diz:

[...] No entanto, tal é a responsabilidade atribuída a Lasswell por um modelo extremo de manipulação ilimitada das pessoas pelos meios de comunicação, que cabe perguntar-se até onde se estende efetivamente

\footnotetext{
27، A principio de los años treinta, y por la razones que já expuestas al hablar, por ejemplo, de la aportación sociológica de Lasswell, el análisis de contenido experimenta um gran impulso".
} 
essa responsabilidade. Claro, o antecedente mais comum para ratificar essa responsabilidade é seu livro de 1927, Propaganda Technique in the World War. [...] Mas o que a interpretação usual das ideias de Lasswell faz é saltar desse livro de 1927 até o artigo de 1948, trabalhando com a suposição de que em 20 anos de trabalho intelectual, o referido autor manteve seus pontos de vista sem nada alterar, insistindo neles sem um traço de revisão. É razoável submeter essa suposição a um contraste necessário ${ }^{28}(1997$, p.31).

A crítica de Bello vai se revelar um dos poucos posicionamentos contrários à percepção geral que se tem do trabalho de Lasswell inclusive na bibliografia analisada nas outras línguas e oferece pistas importantes sobre como Lasswell pode ter sido subestimado e mal avaliado pela bibliografia do campo comunicacional. $\mathrm{O}$ autor chileno nos fala:

No texto que estamos considerando, Lasswell escreve dois dos quatro capítulos: Descrevendo os conteúdos da comunicação e Descrevendo os efeitos da comunicação. O primeiro, sendo basicamente um inventário metodológico para a análise de conteúdo, vai mais além e desenvolve formulações que é necessário considerar. Num resumo rápido, são as seguintes:

1. Os meios afetam a audiência.

2. Os meios afetam a audiência através dos conteúdos.

3. Os efeitos são as respostas da audiência, o ponto final do ato de comunicação.

4. As respostas da audiência podem ser classificadas em: atenção, compreensão, desfrute, avaliação e ação.

5. O efeito de qualquer conteúdo sobre qualquer audiência pode ser estudado a partir desses cinco pontos de vista.

6. Isso significa que os conteúdos dos meios tem efeitos sobre o que as audiências pensam, sentem e fazem.

7. As respostas da audiência dependem das identificações, demandas e aceitações de seus membros.

8. Estas, por sua vez, são causadas por dois fatores: o contexto e a predisposição.

9. Os conteúdos dos meios pertencem a uma série de fatores do contexto.

10. Como consequiência, os conteúdos dos meios são um dos fatores que afetam as respostas da audiência.

11. Para distinguir os conteúdos dos meios das outras partes do contexto, é necessário uma teoria geral do processo de comunicação.

Uma revisão dessas afirmações de Lasswell revela uma confirmação das relativizações às quais aludimos. Apesar de Lasswell falar de "causas" e "efeitos", assim como de "respostas" da audiência (em

\footnotetext{
28، [...] Sin embargo, es tal la responsabilidade que se atribuye a Lasswell em um modelo extremo de manipulación ilimitada de las personas por los médios de comunicación, que cabe perguntarse hasta donde alcanza efectivamente esa responsabilidad. Por supuesto, el antecedente más utilizado para ratificar essa responsabilidad es su libro de 1927, Propaganda Technique in the World War. [...] Pero lo que hace la interpretación habitual de las ideas de Lasswell es saltar desde este libro de 1927 hasta El artículo de 1948, trabajando com el supuesto de que em 20 años de trabajo intelectual dito autor mantuvo sus concepciones sin cambiarlas ni um ápice, insistiendo em ellas sin asomo de revisión. Lo razonable es someter tal supuesto a la necesaria contrastación”.
} 
clara adesão a terminologia condutora), vê os meios como um fator entre outros e atribui importância às predisposições da audiência. Apesar de falar do "ato" de comunicação, também fala de "processo" ou "sequência"29 (BELLO, 1997, pp.33-34).

\section{A longa citação de Bello mostra o descompasso entre o que comumente se} escreve sobre Harold Lasswell e aquilo que escreve Harold Lasswell. O desacordo para Bello é patente e coloca em xeque o teor da história das teorias da comunicação.

[...] Isso nos coloca outra vez no caminho das relações nem sempre bem analisadas e esclarecidas entre as pesquisas e determinadas crenças acerca dos meios de comunicação.

[...] Só que a essa altura do estudo da comunicação não está desenvolvida a consciência intelectual suficiente, que permita identificar as concepções implícitas que se assumem como coisas obvias $^{30}$ (BELLO, 1997, p.35-36)

Bello ressoa, destarte, como voz solitária no bloco de língua espanhola, uma vez que é o único autor a perceber os males da reprodução de certas ideias de autores importantes do campo da Comunicação sem a devida reflexão ou estudo. Não por acaso, da bibliografia inspecionada, apenas Bello se preocupou em ler outros textos escritos por Lasswell, além de A estrutura e a função da comunicação na sociedade, conforme mostra a tabela abaixo:

\footnotetext{
29 "En el texto que estamos considerando, Lasswell escribe dos de los cuatro capítulos: Describiendo los contenidos de la comunicación y Describiendo los efectos de la comunicación. El primero, siendo basicamente un inventario metodológico para el análisis de contenido, llega mas allá y desarolla formulaciones que es preciso consignar. Em un resumen apretado, son las seguintes:

1. Los médios afectan a la audiencia.

2. Los médios afectan a la audiência a través de los contenidos.

3. Los efectos son las respuestas de la audiencia, el ponto terminal de lacto de comunicación.

4. Las respuestas de la audiencia puede ser clasificadas en: atención, comprensión, disfrute, evaluación e acción.

5. El efecto de cualquier contenido sobre cualquier audiencia puede ser estudiado desde estos cinco puntos de vista.

6. Esto significa que los contenidos de los médios tienen efectos sobre lo que las audiencias piensan, sienten y hacen.

7. Las respuestas de la audiencia dependen de las identificaciones, demandas y aceptaciones de sus membros.

8. Éstas, a su vez, son causadas por dos series de factores: los del entorno y los de las predisposiciones.

9. Los contenidos de los médios pertenecen a la serie de factores del entorno.

10. Em consecuencia, los contenidos de los médios son uno de los factores que afectan las respuestas de la audiência.

11. Para distinguir los contenidos de los médios respecto de las otras partes del entorno, se requiere uma teoria geral do proceso de comunicación.

Una revisión somera de estas afirmaciones de Lasswell revela una confirmación de las relativizaciones a que aludimos. Si bien Lasswell habla de 'causas' e 'efectos', así como de 'respuestas' de la audiencia (em clara adhesión a la terminologia conductista), ve a los medios como um fator entre otros y atribuye importancia a las predisposiciones de la audiencia. Si bien habla de el 'acto' de comunicación, también habla de 'proceso' o de "secuencia"”.

30 “"...] Esto nos pone em caminho, otra vez, elas relaciones no siempre bien analizadas y esclarecidas entre la investigación y determinadas creencias acerca de los medios de comunicación.

[...] Sólo que a estas alturas del estúdio de la comunicación no está desarollada la consciência intelectual suficiente que permita identificar las concepciones implícitas que se asumen como cosa obvia".
} 


\begin{tabular}{|c|c|c|c|}
\hline Livro & Autor & Ano & Referências \\
\hline $\begin{array}{l}\text { Teorías de la comunicación: } \\
\text { Investigaciones sobre medios en } \\
\text { América y Europa }\end{array}$ & $\begin{array}{l}\text { Miguel de Moragas } \\
\text { Spà }\end{array}$ & 1981 & Nenhuma. \\
\hline Teorías de la comunicación & Edison Otero Bello & 1997 & $\begin{array}{l}\text { A estrutura e a função da comunicação } \\
\text { na sociedade; } \\
\text { Técnica de propaganda na Guerra } \\
\text { Mundial; } \\
\text { Propaganda, Comunicação e Opinião } \\
\text { Pública (com Bruce Lannes Smith e } \\
\text { Raph D. Casey) }\end{array}$ \\
\hline $\begin{array}{l}\text { Teorías de la comunicación: } \\
\text { Ámbitos, métodos y perspectivas }\end{array}$ & $\begin{array}{l}\text { Rodrigo Miquel } \\
\text { Alsina }\end{array}$ & 2001 & $\begin{array}{l}\text { A estrutura e a função da comunicação } \\
\text { na sociedade }\end{array}$ \\
\hline $\begin{array}{l}\text { La recerca en comunicación. Què } \\
\text { hem de saber? Quins passos hem de } \\
\text { seguir? }\end{array}$ & $\begin{array}{l}\text { Alfons Medina } \\
\text { Cambrón } \\
\text { e Josep Sort Jané }\end{array}$ & 2006 & $\begin{array}{l}\text { A estrutura e a função da comunicação } \\
\text { na sociedade }\end{array}$ \\
\hline $\begin{array}{l}\text { Teoría e investigación de la } \\
\text { comunicación de masas }\end{array}$ & $\begin{array}{l}\text { José Carlos Lozano } \\
\text { Rendón }\end{array}$ & 2007 & $\begin{array}{l}\text { A estrutura e a função da comunicação } \\
\text { na sociedade }\end{array}$ \\
\hline $\begin{array}{l}\text { Teorías de los médios de } \\
\text { comunicación }\end{array}$ & Federico Boni & 2008 & $\begin{array}{l}\text { A estrutura e a função da comunicação } \\
\text { na sociedade }\end{array}$ \\
\hline Estudios de comunicación y médios & $\begin{array}{ll}\text { Enric } & \text { Saperas } \\
\text { Lapiedra } & \\
\end{array}$ & 2012 & $\begin{array}{l}\text { A estrutura e a função da comunicação } \\
\text { na sociedade }\end{array}$ \\
\hline
\end{tabular}

Tabela 6. Obras de Harold Lasswell presentes nas referências da bibliografia teorográfica em língua espanhola.

Os autores tomam A estrutura e a função da comunicação na sociedade como súmula do pensamento lasswelliano sobre comunicação e ignoram todo o restante da obra do cientista político (apenas mais 81 títulos em comunicação). Mesmo que o desideratum das obras teorográficas não seja analisar Lasswell a fundo, é no mínimo estranho que um autor tão profícuo seja interpretado de maneira direta a partir de um único artigo. Mais interessante ainda é o caso de Teorías de la comunicación: Investigaciones sobre medios en América y Europa, de Miquel de Moragas Spà, que não traz nenhum trabalho de Lasswell em suas referências - o que reforça a crítica de Bello. Esses resultados, como veremos, se repetem no próximo bloco linguístico: o universo de língua francesa.

\section{b) Harold Lasswell no universo de língua francesa}

A quantidade de obras teorográficas em língua francesa que falam sobre Harold Lasswell teve o menor número entre todos os blocos linguísticos trabalhados: somente quatro. Os títulos são (o último é o único editado fora da Europa, no Canadá): 


\begin{tabular}{|l|l|l|}
\hline Livro & Autor & 1965 \\
\hline $\begin{array}{l}\text { Structure et fondement de la communication humaine: essai critique } \\
\text { sur les théories contemporaines de la communication }\end{array}$ & René Schérer & 2002 \\
\hline Une introduction aux fondements théoriques de l'étude des medias & François Heindeyckx & 2004 \\
\hline $\begin{array}{l}\text { Introduction Aux Théories de la Communication: Analyse Semio- } \\
\text { Pragmatique de la Communication Médiatique }\end{array}$ & $\begin{array}{l}\text { Jean-Pierre Meunier } \\
\text { e Daniel Péraya }\end{array}$ & 2010 \\
\hline $\begin{array}{l}\text { La Recherche en Communication: Un Atout Pour les Campagnes } \\
\text { Sociales }\end{array}$ & Micheline Frenette & \\
\hline
\end{tabular}

Tabela 7. Obras teorográficas em francês com referências a Harold Lasswell.

Os temas trabalhados na bibliografia francesa sobre Lasswell são poucos e poucas vezes retomados, tendo concordância em apenas duas obras. Entretanto, fazem parte do painel mais geral que encontramos no universo dos outros idiomas: "análise de conteúdo", "modelo de Lasswell", "pesquisa sobre efeitos diretos", "control analysis" e "propaganda". O gráfico a seguir detalha a distribuição desses temas.

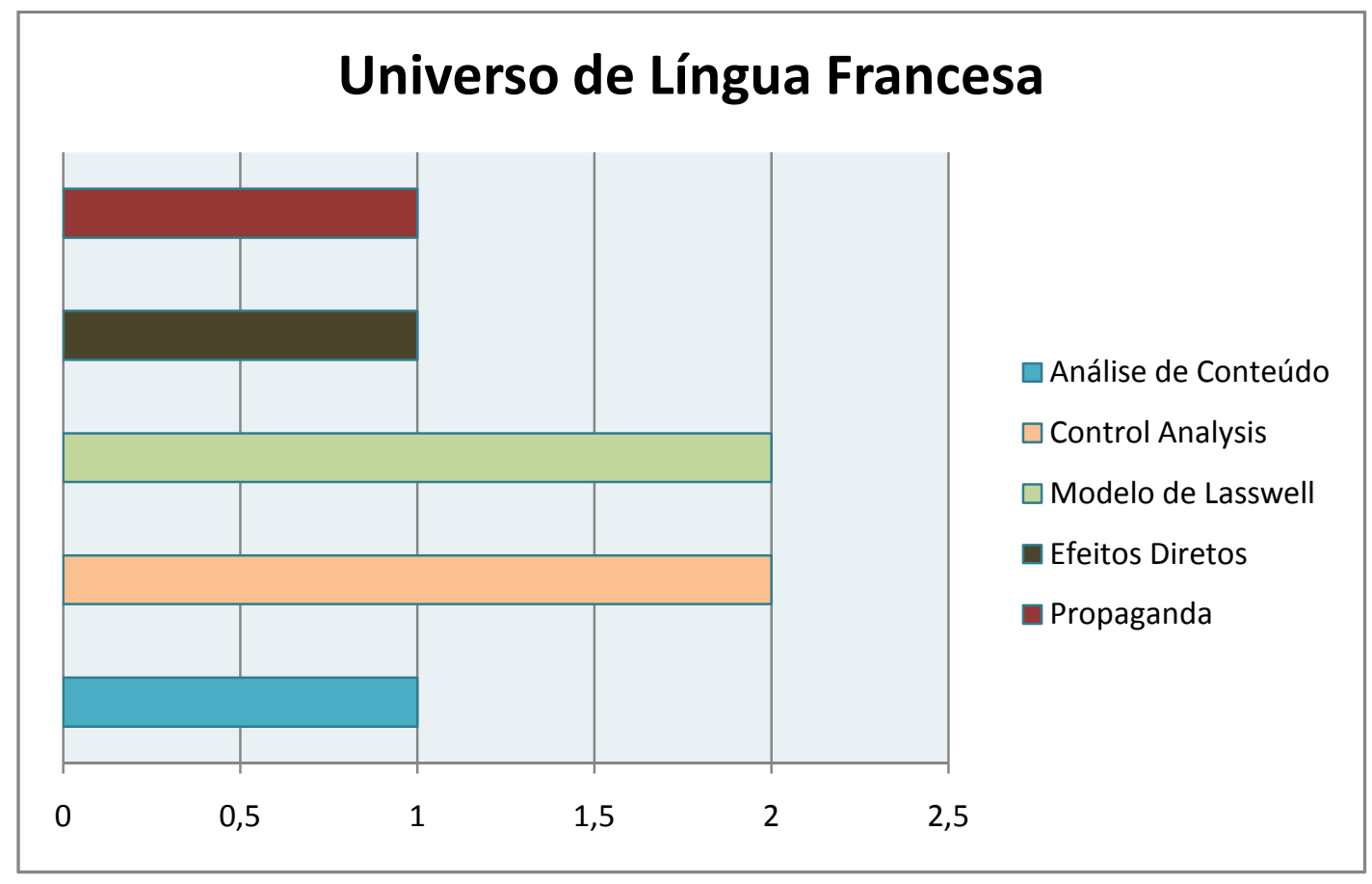

Gráfico 2.Temas relacionados à Lasswell na bibliografia de língua francesa.

Como se vê, à exceção do modelo de Lasswell, os outros temas são tratados em apenas um dos livros que fazem parte da bibliografia estudada. Mais uma vez, o tema mais presente é o modelo de Lasswell, apontado como o organizador da pesquisa em comunicação, assim como na bibliografia em espanhol.

O livro Une introduction aux fondements théoriques de l'étude des médias, de François Heinderyckx, por exemplo, dedica um pequeno capítulo (duas páginas e meia) 
a Lasswell, mais precisamente aquilo que chama de paradigma de Lasswell, o modelo das cinco perguntas. Contudo, não vai muito além do já exposto.

Neste clima bastante consensual, Harold Dwight Lasswell (19021978) traz uma contribuição que marca profundamente a pesquisa em comunicação.

[...] Foi em 1948 que ele desenvolveu o paradigma que convidados pesquisadores para decompor o processo de comunicação em cinco áreas de questionamento com uma fórmula que foi sucesso retumbante: "Quem diz o quê através do qual canal para quem com que efeito?" Falamos do paradigma dos 5Ws, em inglês, e dos 5Qs em francês, ou do paradigma dos efeitos ou da pergunta programa. O estudo científico do fenômeno da comunicação deve se concentrar em uma ou outra dessas perguntas. Cada tema é uma "especialidade" (uma área) ${ }^{31}$ (HEINDERYCKX, 2002, pp.25-26).

Fato semelhante acontece com o segundo livro que trata do modelo de Lasswell.

Introduction Aux Théories de la Communication: Analyse Sémio-Pragmatique de la

Communication Médiatique, de Jean Pierre Meunier e Daniel Péraya, também dedica

um pequeno capítulo a Lasswel, de uma página e meia, no qual o esquema é o tópico

central. Dessa maneira, o tópico Cinq questions pour commencer à en savoir un peu

plus: le modele de Lasswell, afirma:

Contemporâneo do modelo de Shannon, o de Lasswell se inspira diretamente nas ciências e nos meios de comunicação de massa; ele orientou profundamente os trabalhos e as pesquisas em comunicação ulteriores. $\mathrm{O}$ autor descreve $\mathrm{o}$ fenômeno da comunicação respondendo às cinco questões seguintes: quem? Diz o quê? A quem? Por que meios? Com que efeitos? Cada uma dessas questões permite definir um dos pólos da comunicação e o campo específico de investigação que lhe corresponde. Lembremos brevemente das intenções do autor.

Identificar os emissores (Quem?), é analisar os agentes (autores, produtores dos meios de comunicação, grupos de interesse, etc) que são a fonte de comunicação e os mecanismos de produção da informação coletiva (control analysis). Responder à segunda questão, (Diz o quêe), é se vincular à análise da mensagem, isto é, ao conteúdo transmitido pelo meio, ou o que o valha. $\mathrm{O}$ estudo da mensagem está vinculado às metodologias da análise de conteúdo (content analysis), essencialmente quantitativas. Quando se interroga sobre o meio (Por que meios?), se refere à transmissão da mensagem, ao meio e ao canal. No entanto, na perspectiva do autor, o estudo do meio (media

\footnotetext{
31،Dans ce climat plutôt consesuel, Harold Dwight Lasswell (1902-1978) apoorta une contribution qui marqua durablement les travaux de recherché em communication. [...]

C'est en 1948 qu'il développa um paradigme qui invite les chercheurs à décomposer les processus de communication em cinq domaines de questinnement résimés par une formule qui eut um succès retentissant:

Who says What through What channel to Whom and with What effect ou "Qui dit Quoi par Quel canal à Qui et avec Quel effet?"

On parle du paradigm des $5 \mathrm{~W}$ en anglais, des $5 \mathrm{Q}$ en français, ou de paradigme des effets ou encore de questionprogramme. Le scientifique étudiant um phénomène de communication devrait se concentrer sur l'une ou l'autre de ces questions. A chacune correspond um sujet et une "spécialité" (un domaine)".
} 
analysis) não pode ser meramente técnico, pois ele já inclui certos aspectos de codificação e decodificação. A definição dos receptores $(A$ quem?) no campo da comunicação de massa, diz respeito à análise dos destinatários, da audiência (audience analysis). No contexto americano, esses estudos foram principalmente quantitativos e tinham como objetivo determinar as diferentes categorias de público, mensurando sua importância. Por fim, a análise dos efeitos (Com quais efeitos?), determina um vasto campo de análises psicosociológicas (effect analysis) das quais Lazarsfeld é considerado um dos primeiros representantes ${ }^{32}$ (MEUNIER \& PÉRAYA, 2004, p.37).

Tanto Heinderyckx quanto Meunier \& Péraya, desse modo, apresentam o modelo de Lasswell nas linhas tradicionais, sem uma contextualização nem questionamento sobre sua natureza, repetindo o que já havíamos visto na bibliografia em espanhol: temos o trabalho de Lasswell reconhecido como peça fundamental para o campo, mas não se consegue sair da esfera descritiva, quando se trata de apresentá-lo nos livros teorográficos da área. Heinderyckx, além disso, ainda identifica o esquema com o modelo hipodérmico, não os diferenciando. Para o belga,

Este modelo reforça, além disso, uma visão atomista (ele se aplica ao nível individual e deriva de modelos de comunicação interpessoal) e behaviorista (baseado na estrutura estímulo-resposta) da comunicação de massa $^{33}$ (HEINDERYCKX, 2002, p.27).

De certo modo, tal concepção também pode ser inferida em Meunier \& Péraya, pois apesar de Lasswell ter possibilitado pesquisas posteriores a partir da formulação de seu modelo, a análise dos efeitos que se afasta do quantitativo que só se deu a partir de Lazarsfeld.

\footnotetext{
32، Contemporain du modèle de Shannon, celui de Lasswell s'inspire directement des sciences et des moyens de communication de masse; il a profondément oriente les travaux et les recherches em communication ultérieurs. L'auteur tenatit décrire le phénomène de la communication em répondant aux cinq questions suivantes: qui? dit quoi? à qui? par quel moyen? avec quels effets? Chacune de celles-ci permet de definir um des pôles de la communication ainsi que le champ d’investigation particulier que lui correspond. Rappelons succinctement lês relations établies par l'auteur.

Identifier l'émetteur (Qui?), c'est analyser lês agents (auteurs, producteurs des mass medias, grouper d'intérêt, etc.) qui sont à la source de la communication et lês mécanismes de production de l'information collective (control analysis). Répondre à la seconde question (Dit quoi?), c'est s'attacher à l'analyse du message, c'est-a-dire au contenu transmis par le médium, quel qu'il soit. L'etude du message donnera naissance aux nombreuses méthodologies d'analysis du contenu (content analysis) essentiellement quantitatives. Quand on s'interrogue sur le moyen (Par quel moyen?), on se refere à la transmission du message, au médium et à son canal. Cependant, dans la perspective de l'auteur, l'étude du médium (media analysis) n'est pás seulement technique puisqu'elle inclut déjà certains aspects de la codification et de la décodification. La définition des récepteurs (À qui?) dans le domaine des communications de massa, ouvrira le champ de l'analyse des destinataires, de l'audience (audience analysis). Dans le contexte américain, ces études étaient principalement quantitatives et cherchaient à déterminer les différents catégories de public pour em mesurer l'importance respective. Enfin, l'analyse des effets (Avec quels effets?) determine um vaste champ d'analysis psychosociologiques (effect analysis) don't Lazarsfeld est consideré comme l'un des premiers représentants".

33 "Ce modele renforce, par ailleurs, une vision atomiste (il s'applique au niveau individual et derive d'ailleurs de modeles de communication interpersonalle) et béhavioriste (on em reste à la estructure stimulus-réponse) de la communication de masse".
} 
Apesar disso, Introduction Aux Théories de la Communication: Analyse SemioPragmatique de la Communication Médiatique e Une introduction aux fondements théoriques de l'étude des médias fazem parte das poucas obras que relatam a influência de Lasswell no campo da Comunicação em língua francesa. Em La Recherche en Communication: Un Atout Pour les Campagnes Sociales, Micheline Frenette associa Lasswell muito rapidamente à concepção da teoria hipodérmica e, estranhamente utiliza A estrutura e a função da comunicação na sociedade, bastante posterior ao período da teoria mencionada, como referência para a afirmação. Portanto, mais uma vez Lasswell é identificado com o pensamento hipodérmico sem que haja uma leitura crítica de sua obra. É assim que Frenette diz

O mais antigo modelo de comunicação mediática supõe que os indivíduos são extremamente vulneráveis à influência dos meios e que estes determinam suas maneiras de pensar e de fazer (Lasswell, $1948)^{34}$ (FRENETTE, 2010, p.36).

É interessante observar que Frenette dá a Lasswell esse pequeno destaque ao falar dos "efeitos diretos" dos meios de comunicação, mas não se preocupa em fundamentar a ligação do cientista político com a teoria hipodérmica, nem mesmo utiliza como fonte os primeiros escritos do autor, o que seria objetivamente mais lógico, já que Lasswell começou a pesquisar comunicação durante o mesmo período da teoria hipodérmica. Mas Micheline Frenette escreve tão somente dois parágrafos sobre os "efeitos diretos" e logo parte para a teoria dos usos e gratificações.

Situação mais interessante ainda é a de René Schérer. Em Structure et fondement de la communication humaine: essai critique sur les théories contemporaines de la communication, o filósofo francês reconhece em Lasswell não só um autor, mas o coloca como nome de escola de pesquisa - "école de Lasswell et Leite" (1965, p.40). A escola de Lasswell e Leite estaria voltada ao estudo da propaganda política e vinculada a uma teoria dos meios de comunicação "[...] limitada à obtenção de certos resultados, sem princípios mais profundos" $" 35$ (SCHÉRER, 1965, p.40). Isso é tudo o que Schérer laconicamente diz sobre Lasswell, a quem dedica um único parágrafo.

Os outros temas listados no gráfico sobre o universo de língua francesa são tratados ainda mais superficialmente, em geral em uma linha ou duas. A análise de

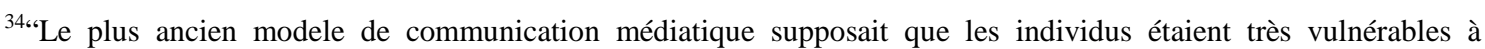
l'influence des médias et que ces derniers pouvaient leur inculquer des manières de penser et de faire" (Lasswell, 1948)".

35 “[...] limitée à l'obtencion de certains résultats, sans approfondissement des principes”.
} 
conteúdo, como na bibliografia em espanhol, é referenciada por ser o método utilizado por Lasswell em suas pesquisas; a propaganda aparece como o tema preferencial do pesquisador; a control analysis é apresentada como uma espécie de escola, à qual Lasswell seria filiado. A discussão sobre essas afirmativas inexiste. Elas são apresentadas como dados.

A pouca leitura das obras de Harold Lasswell pode ser uma explicação para os breves comentários a seu respeito nos livros teorográficos de comunicação franceses, conforme vemos na tabela abaixo:

\begin{tabular}{|c|c|c|c|}
\hline Livro & Autor & Ano & Referências \\
\hline $\begin{array}{l}\text { Structure et fondement de la } \\
\text { communication humaine: essai critique } \\
\text { sur les théories contemporaines de la } \\
\text { communication }\end{array}$ & René Schérer & 1965 & A linguagem da Política \\
\hline $\begin{array}{l}\text { Une introduction aux fondements } \\
\text { théoriques de l'étude des medias }\end{array}$ & François Heindeyckx & 2002 & $\begin{array}{l}\text { A Estrutura e a Função da } \\
\text { Comunicação na Sociedade }\end{array}$ \\
\hline $\begin{array}{l}\text { Introduction Aux Théories de la } \\
\text { Communication: Analyse Semio- } \\
\text { Pragmatique de la Communication } \\
\text { Médiatique }\end{array}$ & $\begin{array}{l}\text { Jean-Pierre Meunier e } \\
\text { Daniel Péraya }\end{array}$ & 2004 & Nenhuma \\
\hline $\begin{array}{l}\text { La Recherche en Communication: Un } \\
\text { Atout Pour les Campagnes Sociales }\end{array}$ & Micheline Frenette & 2010 & $\begin{array}{l}\text { A Estrutura e a Função da } \\
\text { Comunicação na Sociedade }\end{array}$ \\
\hline
\end{tabular}

Tabela 8. Obras de Harold Lasswell presentes nas referências da bibliografia teorográfica em língua francesa.

Como explicar que em livros panorâmicos sobre teorias da comunicação, um autor tenha sua importância citada e um de seus modelos teóricos apresentados e possua apenas um texto citado nas referências bibliográficas? Ou pior, como no caso de Meunier e Péraya, nenhuma obra nas referências? E - considerando La Recherche en Communication: Un Atout Pour les Campagnes Sociales, de Micheline Frenette -, ter uma obra citada indevidamente para identificar outro fenômeno? Fato é que embora Lasswell seja referenciado nas obras teorográficas francesas, estas não se aprofundam em suas idéias.

A bibliografia em língua francesa, portanto, é pouco específica sobre o papel de Lasswell na comunicação, mesmo quando trata de seu modelo, mostrando preconceitos que se repetem, sem produzir um pensamento propriamente reflexivo sobre seu valor. $\mathrm{O}$ que sobressai desses textos é a insistência da ligação (explícita ou implícita) que se faz entre o pesquisador estadunidense e o modelo hipodérmico, aliás presente em todos os blocos linguísticos estudados, sem exceção do universo de língua inglesa, onde aparecem algumas críticas importantes a esta ligação. 


\section{c) Harold Lasswell no universo de língua inglesa}

O universo de língua inglesa corresponde a maior bibliografia referente a obras teorográficas neste estudo. São 65 livros, o que representa quase $78 \%$ do total.

\begin{tabular}{|c|c|c|}
\hline Livro & Autor & Ano \\
\hline Foundations of communication theory & David C. Mortensen & 1970 \\
\hline Content analysis in communication research & Bernard Berelson & 1971 \\
\hline Mass communication research: major issues and future directions & $\begin{array}{l}\text { Walter Phillips Davidson \& Frederick } \\
\text { T.C. Yu }\end{array}$ & 1974 \\
\hline Communication research: a half-century appraisal & $\begin{array}{l}\text { Daniel Lerner; Lyle M. Nelson \& } \\
\text { Wilbur Schramm }\end{array}$ & 1977 \\
\hline Using mass communication theory & Maxwell McCombs \& Lee B. Becker & 1979 \\
\hline $\begin{array}{l}\text { Mass communication and everyday life: a perspective on theory } \\
\text { and effects }\end{array}$ & Denis K. Davis \& Stanley J. Baran & 1981 \\
\hline Human communication theory: comparative essays & Frank. E. Dance & 1982 \\
\hline Mass communication theories and research & Alexis E. Tan & 1985 \\
\hline $\begin{array}{l}\text { Communication Theories: Origins, Methods and Uses in the Mass } \\
\text { Media }\end{array}$ & $\begin{array}{l}\text { Werner J. Severin \& James W. } \\
\text { Tankard }\end{array}$ & 1988 \\
\hline Theories of mass communication & $\begin{array}{l}\text { Melvin Laurence DeFleur \& Sandra } \\
\text { Ball-Rockeach }\end{array}$ & 1989 \\
\hline Human communication: theory and research & $\begin{array}{l}\text { Gordon L. Dahnke \& Glenn W. } \\
\text { Clatterbuck }\end{array}$ & 1990 \\
\hline A First Look at Communication Theory & Em Griffin & 1991 \\
\hline $\begin{array}{l}\text { Critical communication studies: communication, history, and } \\
\text { theory in America }\end{array}$ & Hanno Hardt & 1992 \\
\hline $\begin{array}{l}\text { Using communication theory: an introduction to planned } \\
\text { communication }\end{array}$ & $\begin{array}{l}\text { Sven Windhal; Benno Signitzer \& Jean } \\
\text { T. Olson }\end{array}$ & 1992 \\
\hline $\begin{array}{l}\text { Mass communication research on problems and policies: the art of } \\
\text { asking the right questions }\end{array}$ & Cees J. Hamelink \& Olga Linné & 1994 \\
\hline Milestones in mass communication research: media effects & $\begin{array}{l}\text { Sheron Lowery \& Melvin Lawrence } \\
\text { Defleur }\end{array}$ & 1994 \\
\hline $\begin{array}{l}\text { Science of coercion: communication research and psychological } \\
\text { warfare, 1945-1960 }\end{array}$ & Christopher Simpson & 1994 \\
\hline Building communication theories: a socio/cultural approach & Fred L. Casmir & 1994 \\
\hline Communication theory today & David J. Crowley\& David Mitchell & 1994 \\
\hline Mass communication theory: an introduction & Dennis McQuail & 1994 \\
\hline Essentials of mass communication theory & Arthur Asa Berger & 1995 \\
\hline Theorizing communication: a history & Dan Schiller & 1996 \\
\hline Communication theory: epistemological foundations & James Arthur Anderson & 1996 \\
\hline American communication research: the remembered history & Everett E. Dennis \& Ellen Wartella & 1996 \\
\hline $\begin{array}{l}\text { The beginnings of communication study in America: a personal } \\
\text { memoir }\end{array}$ & $\begin{array}{l}\text { Wilbur Schramm; Steven H. Chafee } \\
\text { \&Everett M. Rogers }\end{array}$ & 1997 \\
\hline A history of communication study: a biographical approach & Everett M. Rogers & 1997 \\
\hline Mass communications research resources: an annotated guide & $\begin{array}{l}\text { Christopher H. Sterling; James H. } \\
\text { Bracken \&Susan M. Hill }\end{array}$ & 1998 \\
\hline Theories of communication: a short introduction & $\begin{array}{l}\text { Armand } \quad \text { Mattelart } \quad \text { \&Michèle } \\
\text { Mattelart }\end{array}$ & 1998 \\
\hline Media communication: an introduction to theory and process & James Watson & 1998 \\
\hline Clarifying communication theories: a hands-on approach & $\begin{array}{l}\text { Gerald Stone; Michael W. Singletary \& } \\
\text { Virginia P. Richmond }\end{array}$ & 1999 \\
\hline $\begin{array}{l}\text { Human communication theory and research: concepts, contexts, } \\
\text { and challenges }\end{array}$ & $\begin{array}{l}\text { David Corson; Robert Lawrence Heath } \\
\text { \& Jennings Bryant }\end{array}$ & 2000 \\
\hline $\begin{array}{l}\text { Origins of mass communications research during the American } \\
\text { Cold War }\end{array}$ & Thimothy Richard Glander & 2000 \\
\hline Media Studies: Institutions, theories, and issues & Pieter J. Fourie & 2001 \\
\hline A Handbook of Media and Communication Research: Qualitative & Klaus Bruhn Jensen & 2002 \\
\hline
\end{tabular}




\begin{tabular}{|c|c|c|}
\hline and Quantitative Methodologies & & \\
\hline $\begin{array}{l}\text { Theory and research in mass communication: contexts and } \\
\text { consequences }\end{array}$ & David K. Perry & 2002 \\
\hline Media Effects: Advances in Theory and Researc & Jennings Bryant \& Dolf Zimman & 2002 \\
\hline Building communication theory & $\begin{array}{l}\text { Dominic A. Infante; Andrew S. Rancer } \\
\text { \& Deanna F. Womack }\end{array}$ & 2003 \\
\hline $\begin{array}{l}\text { Canonic texts in media research: are there any? should there be? } \\
\text { how about these? }\end{array}$ & Elihu Katz & 2003 \\
\hline Understanding media theory & Kevin Williams & 2003 \\
\hline Communication researchers and policy-making & Sandra Braman & 2003 \\
\hline Handbook of political communication research & Linda Lee Kaid & 2004 \\
\hline New frontiers in international communication theory & Mehdi Semati & 2004 \\
\hline Communication Research: Techniques, Methods and Applications & G. M. du Plooy & 2004 \\
\hline Communication as--: perspectives on theory & $\begin{array}{l}\text { Gregori J. Sheperd; Jeffrey St. John \& } \\
\text { Theodore G. Striphas }\end{array}$ & 2006 \\
\hline Communication studies & Sky Marsen & 2006 \\
\hline Theorizing communication: readings across traditions & Robert T. Craig \& Heidi L. Muller & 2007 \\
\hline Theories of human communication & Stephen W. Littlejohn \& Karen A. Foss & 2007 \\
\hline Key Themes in Media Theory. & Dan Laughey & 2007 \\
\hline An Introduction to Communication Studies & Sheila Steinberg & 2007 \\
\hline $\begin{array}{l}\text { The history of media and communication research: contested } \\
\text { memories }\end{array}$ & David W. Park \& Jefferson Pooley & 2008 \\
\hline An integrated approach to communication theory and research & Don W. Stacks \& Michael Brian Saven & 2008 \\
\hline McQuail's reader in mass communication theory & Denis McQuail & 2008 \\
\hline Recharting media studies: essays on neglected media critics & Philip Bounds \& Mala Jagmohan & 2008 \\
\hline Introducing Communication Theory: Analysis and Application & Richard West Lynn H. Turner & 2009 \\
\hline Communication Theory: Media, Technology and Society & David Holmes & 2009 \\
\hline Reading media theory: thinkers, approaches and contexts & David M. Barlow \& Brett Mills & 2009 \\
\hline $\begin{array}{l}\text { Normative theories of the media: journalism in democratic } \\
\text { societies }\end{array}$ & Clifford G. Christians \& Denis McQuail & 2009 \\
\hline Doing Media Research: an Introduction & Susanna Horning Priest & 2009 \\
\hline Routledge handbook of applied communication research & Kenneth N. Cissna & 2009 \\
\hline Encyclopedia of Communication Theory & Stephen W. Littlejohn \& Karen A. Foss & 2009 \\
\hline Mass Media Research: An Introduction & $\begin{array}{l}\text { Roger D. Wimmer \& Joseph R. } \\
\text { Dominick }\end{array}$ & 2010 \\
\hline $\begin{array}{l}\text { Media and Communication Research Methods: An Introduction to } \\
\text { Qualitative and Quantitative Approaches }\end{array}$ & Arthur Asa Berger & 2010 \\
\hline Media Studies: Media History, Media and Society & Pieter J. Fourie & 2010 \\
\hline Mass Communication Theory: Foundations, Ferment, and Future & Stanley J. Barey \&Dennis K. Davis & 2011 \\
\hline Media Industries: History, Theory, and Method & Jennifer Holt \& Alisa Perren & 2011 \\
\hline
\end{tabular}

Tabela 9. Obras teorográficas em inglês com referências a Harold Lasswell.

Com uma coleção tão grande de textos, o que se esperava era uma leitura diferenciada da obra lasswelliana. De fato, a bibliografia em inglês traz algumas distinções em relação aos outros três blocos linguísticos. Mas também ela não consegue ir muito além na sua interpretação da obra comunicacional de Harold Lasswell, embora constitua a mais variada lista de temas acerca do cientista político, representada na tabela seguinte: 


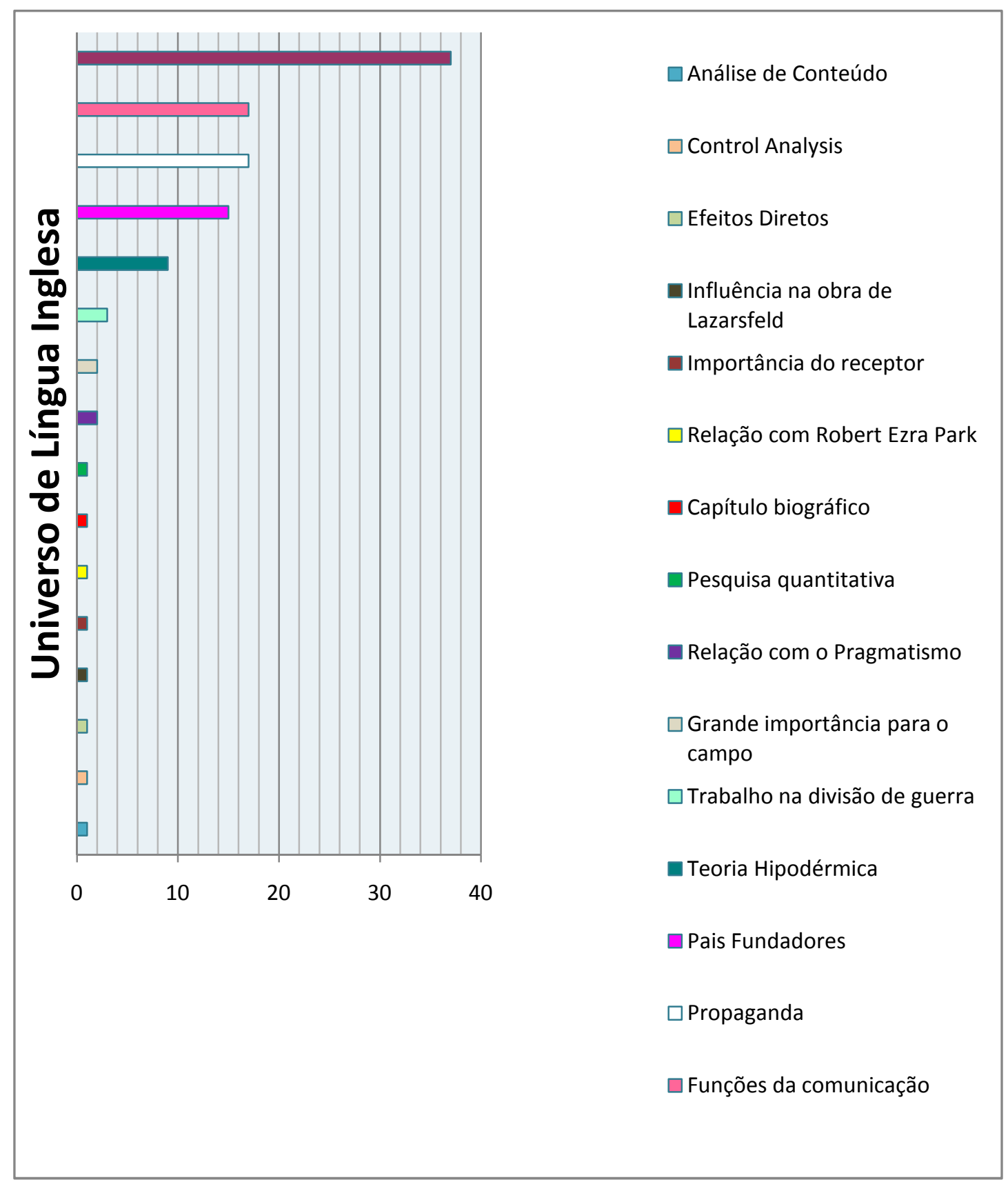

Gráfico 3. Temas relacionados a Lasswell na bibliografia de língua inglesa.

Repetindo o resultado dos dois primeiros blocos linguísticos levantados, o modelo de Lasswell é o tema mais presente em língua inglesa: 40 livros tratam do assunto. O modelo, contudo, é mostrado em linhas gerais, praticamente da mesma forma que o é nas bibliografias anteriores. Portanto, podemos tomar como representativa dessa bibliografia, o trabalho de Hanno Hardt sobre a história das teorias da comunicação nos Estados Unidos. Apesar de Critical communication studies: communication, history, and theory in America nos oferecer mais elementos para pensar 
a obra lasswelliana, sua interpretação do esquema de Lasswell não foge ao que já vimos.

Hardt sintetiza os elementos mais comuns acerca do modelo. Segundo ele,

[...] quando Lasswell ofereceu uma "maneira conveniente de descrever um ato de comunicação" (1948:37), ele propôs o que se tornou uma influente e consideravelmente poderosa fórmula de entender a comunicação humana. Ele identificou não só os elementos do processo de comunicação - emissor, mensagem, meio, receptor, e efeitos - mas ele rotulou os campos correspondentes da pesquisa em comunicação: análise dos meios, análise da audiência e análise dos efeitos (1948:37). A descrição revelou o interesse primário de Lasswell no poder da comunicação persuasiva (política), mas também se referia a equivalências organísmicas dentro de uma abordagem dominada pela intenção do comunicador e o efeito de mensagens (1948:41). Assim, a sua definição de comunicação tem como base o modelo estímulo-resposta, advindo da teoria do aprendizado, que se tornou uma força significante na teoria da comunicação de massa. Focada nos efeitos, essa abordagem implicava num conceito de sociedade como um agregado de anônimos, indivíduos isolados expostos a instituições mediáticas poderosas, comprometidas em reforçar ou modificar o comportamento social ${ }^{36}$ (HARDT, 2010, p.36).

Hardt fornece um desenho de linhas mais minuciosas, mas acaba repetindo clichês e associando o esquema de Lasswell ao modelo comportamentalista, malgrado não faça isso explicitamente. $\mathrm{O}$ autor também discute a influência do modelo, a divisão das áreas de estudo na Comunicação, o poder do emissor, o estudo dos efeitos das mensagens, a identificação do modelo com instituições mediáticas super poderosas (hipodérmico). Mesmo sob o compromisso de analisar criticamente a história das teorias da comunicação, Hardt apenas reproduz a história "oficial”, sem acrescentar muita coisa, e a despeito do largo acervo de Lasswell disponível em sua língua materna, há apenas dois livros do cientista político em suas referências: A Estrutura e a Função da Comunicação na Sociedade e Pesquisa em Comunicação e Políticas Públicas.

A essa síntese abalizada por Hardt, somam-se pequenas críticas em outras obras de nosso repertório, que não se estendem, pois possivelmente não conseguiriam sustentar-se desconhecendo o trabalho de Lasswell mais a fundo. David K. Perry, por exemplo, resume sumariamente que "obviamente, o modelo de Lasswell ignora certos

\footnotetext{
36، [...] when Lasswell offered a "convenient way to describe an act of communication" (1948:37), he proposed what became an influential and considerably powerful formula for understanding human communication. He proceeded to identify not only the element of communication process - communicator, message, medium, receiver, and effects but he also labeled the corresponding fields of communication research: media analysis, audience analysis and effect analysis (1948:37). The description revealed Lasswell's primary interest in the power of persuasive (political) communication, but also referred to organismic equivalencies within an approach dominated by the intent of the communicator and the effect of messages (1948:41). As such, his definition of communication harks back to the stimulus-response model, rooted in learning theory, which became a significant force in mass communication theory. Focused upon effects, this approach implied a concept of society as an aggregate of anonymous, isolated individuals exposed to powerful media institutions engaged in reinforce or changing social behavior".
} 
aspectos da comunicação de massa" (2002, p.8), mas não especifica exatamente em que o modelo falha. Perry, assim como Hardt, possui dois livros de Harold Lasswell em suas referências: Técnica de Propaganda na Guerra Mundial e A Estrutura e a Função da Comunicação na Sociedade. Falta notoriamente um melhor tratamento ao trabalho de Lasswell nas obras teorográficas em língua inglesa. Como indicado no quadro abaixo, as escassas aparições de obra de Lasswell nas referências dos livros dos teorográficos, com poucas exceções, confirma o que dizemos.

\begin{tabular}{|c|c|c|c|}
\hline Livro & Autor & Ano & Referências \\
\hline Foundations of communication theory & David C. Mortensen & 1970 & Language of Politics \\
\hline $\begin{array}{l}\text { Mass communication research: major issues } \\
\text { and future directions }\end{array}$ & $\begin{array}{l}\text { Walter Phillips Davidson \& } \\
\text { Frederick T.C. Yu }\end{array}$ & 1974 & Nenhuma \\
\hline $\begin{array}{l}\text { Communication research: a half-century } \\
\text { appraisal }\end{array}$ & $\begin{array}{l}\text { Daniel Lerner; Lyle } \mathrm{M} \text {. } \\
\text { Nelson \& Wilbur Schramm }\end{array}$ & 1977 & $\begin{array}{l}\text { The Policy Sciences; } \\
\text { The Policy Orientation }\end{array}$ \\
\hline Using mass communication theory & $\begin{array}{l}\text { Maxwell McCombs \& Lee } \\
\text { B. Becker }\end{array}$ & 1979 & $\begin{array}{l}\text { The structure and function of } \\
\text { communication in society }\end{array}$ \\
\hline $\begin{array}{l}\text { Mass communication and everyday life: a } \\
\text { perspective on theory and effects }\end{array}$ & $\begin{array}{l}\text { Denis K. Davis \& Stanley J. } \\
\text { Baran }\end{array}$ & 1981 & The Policy Sciences \\
\hline $\begin{array}{l}\text { Human communication theory: comparative } \\
\text { essays }\end{array}$ & Frank. E. Dance & 1982 & $\begin{array}{l}\text { The structure and function of } \\
\text { communication in society }\end{array}$ \\
\hline Mass communication theories and research & Alexis E. Tan & 1985 & $\begin{array}{l}\text { The structure and function of } \\
\text { communication in society }\end{array}$ \\
\hline $\begin{array}{l}\text { Communication Theories: Origins, Methods } \\
\text { and Uses in the Mass Media }\end{array}$ & $\begin{array}{l}\text { Werner J. Severin \& James } \\
\text { W. Tankard }\end{array}$ & 1988 & Nenhuma \\
\hline Theories of mass communication & $\begin{array}{l}\text { Melvin Laurence DeFleur } \\
\text { \& Sandra Ball-Rockeach }\end{array}$ & 1989 & $\begin{array}{l}\text { Propaganda Technique in the } \\
\text { World War }\end{array}$ \\
\hline Human communication: theory and research & $\begin{array}{l}\text { Gordon L. Dahnke \& } \\
\text { Glenn W. Clatterbuck }\end{array}$ & 1990 & $\begin{array}{l}\text { The structure and function of } \\
\text { communication in society }\end{array}$ \\
\hline A First Look at Communication Theory & Em Griffin & 1991 & Nenhuma \\
\hline $\begin{array}{l}\text { Critical communication studies: } \\
\text { communication, history, and theory in } \\
\text { America }\end{array}$ & Hanno Hardt & 1992 & $\begin{array}{l}\text { Communication Research and } \\
\text { Public Policy; } \\
\text { The Structure and Function of } \\
\text { Communication in Society }\end{array}$ \\
\hline $\begin{array}{l}\text { Using communication theory: an } \\
\text { introduction to planned communication }\end{array}$ & $\begin{array}{l}\text { Sven Windhal; Benno } \\
\text { Signitzer \& Jean T. Olson }\end{array}$ & 1992 & $\begin{array}{l}\text { The structure and function of } \\
\text { communication in society }\end{array}$ \\
\hline $\begin{array}{l}\text { Mass communication research on problems } \\
\text { and policies: the art of asking the right } \\
\text { questions }\end{array}$ & $\begin{array}{l}\text { Cees J. Hamelink \& Olga } \\
\text { Linné }\end{array}$ & 1994 & Nenhuma \\
\hline $\begin{array}{l}\text { Milestones in mass communication } \\
\text { research: media effects }\end{array}$ & $\begin{array}{l}\text { Sheron Lowery \& Melvin } \\
\text { Lawrence Defleur }\end{array}$ & 1994 & Nenhuma \\
\hline $\begin{array}{l}\text { Science of coercion: communication } \\
\text { research and psychological warfare, 1945- } \\
1960\end{array}$ & Christopher Simpson & 1994 & Nenhuma \\
\hline $\begin{array}{l}\text { Building communication theories: a } \\
\text { socio/cultural approach }\end{array}$ & Fred L. Casmir & 1994 & $\begin{array}{l}\text { The structure and function of } \\
\text { communication in society }\end{array}$ \\
\hline Communication theory today & $\begin{array}{l}\text { David J. Crowley \& David } \\
\text { Mitchell }\end{array}$ & 1994 & $\begin{array}{l}\text { The structure and function of } \\
\text { communication in society; } \\
\text { Propaganda, communication } \\
\text { and public opinion }\end{array}$ \\
\hline Mass communication theory: an & Dennis McQuail & 1994 & propaganda \\
\hline
\end{tabular}




\begin{tabular}{|c|c|c|c|}
\hline introduction & & & $\begin{array}{l}\text { Enciclopédia de Ciências } \\
\text { Sociais } \\
\text { The structure and function of } \\
\text { communication in society }\end{array}$ \\
\hline Essentials of mass communication theory & Arthur Asa Berger & 1995 & Nenhuma \\
\hline Theorizing communication: a history & Dan Schiller & 1996 & $\begin{array}{l}\text { Propaganda Technique in the } \\
\text { World War; } \\
\text { The structure and function of } \\
\text { communication in society }\end{array}$ \\
\hline $\begin{array}{l}\text { Communication theory: epistemological } \\
\text { foundations }\end{array}$ & James Arthur Anderson & 1996 & $\begin{array}{l}\text { Propaganda Technique in the } \\
\text { World War }\end{array}$ \\
\hline $\begin{array}{l}\text { American communication research: the } \\
\text { remembered history }\end{array}$ & $\begin{array}{l}\text { Everett E. Dennis \& Ellen } \\
\text { Wartella }\end{array}$ & 1996 & $\begin{array}{l}\text { The structure and function of } \\
\text { communication in society } \\
\text { Propaganda, communication } \\
\text { and public opinion }\end{array}$ \\
\hline $\begin{array}{l}\text { The beginnings of communication study in } \\
\text { America: a personal memoir }\end{array}$ & $\begin{array}{l}\text { Wilbur Schramm; Steven } \\
\text { H. Chafee \& Everett M. } \\
\text { Rogers }\end{array}$ & 1997 & $\begin{array}{l}\text { Propaganda and } \\
\text { Communication in the World } \\
\text { History; } \\
\text { Propaganda, Communication } \\
\text { and Public Opinion; } \\
\text { Propaganda and Promotional } \\
\text { Activities: an Annoted } \\
\text { Bibliography }\end{array}$ \\
\hline $\begin{array}{l}\text { A history of communication study: a } \\
\text { biographical approach }\end{array}$ & Everett M. Rogers & 1997 & $\begin{array}{l}\text { Propaganda and } \\
\text { Communication in the World } \\
\text { History; } \\
\text { Propaganda, Communication } \\
\text { and Public Opinion; } \\
\text { Propaganda and Promotional } \\
\text { Activities: an Annoted } \\
\text { Bibliography }\end{array}$ \\
\hline $\begin{array}{l}\text { Mass communications research resources: } \\
\text { an annotated guide }\end{array}$ & $\begin{array}{l}\text { Christopher H. Sterling; } \\
\text { James H. Bracken \& Susan } \\
\text { M. Hill }\end{array}$ & 1998 & $\begin{array}{l}\text { Propaganda and } \\
\text { Communication in the World } \\
\text { History; } \\
\text { Propaganda, Communication } \\
\text { and Public Opinion; } \\
\text { Propaganda and Promotional } \\
\text { Activities: an Annoted } \\
\text { Bibliography }\end{array}$ \\
\hline $\begin{array}{l}\text { Theories of communication: a short } \\
\text { introduction }\end{array}$ & $\begin{array}{l}\text { Armand Mattelart } \\
\text { \&Michèle Mattelart }\end{array}$ & 1998 & $\begin{array}{l}\text { Propaganda Technique in the } \\
\text { World War; } \\
\text { The structure and function of } \\
\text { communication in society; } \\
\text { The future of political Science; } \\
\text { World Politics and Personal } \\
\text { Insecurity }\end{array}$ \\
\hline $\begin{array}{l}\text { Media communication: an introduction to } \\
\text { theory and process }\end{array}$ & James Watson & 1998 & $\begin{array}{l}\text { The structure and function of } \\
\text { communication in society }\end{array}$ \\
\hline $\begin{array}{l}\text { Human communication theory and research: } \\
\text { concepts, contexts, and challenges }\end{array}$ & $\begin{array}{l}\text { David Corson; Robert } \\
\text { Lawrence Heath \& } \\
\text { Jennings Bryant }\end{array}$ & 2000 & $\begin{array}{l}\text { Propaganda Techinique in the } \\
\text { World War; } \\
\text { The structure and function of } \\
\text { communication in society }\end{array}$ \\
\hline $\begin{array}{l}\text { Media Studies: Institutions, theories, and } \\
\text { issues }\end{array}$ & Pieter J. Fourie & 2001 & $\begin{array}{l}\text { The structure and function of } \\
\text { communication in society }\end{array}$ \\
\hline $\begin{array}{l}\text { A Handbook of Media and Communication } \\
\text { Research: Qualitative and Quantitative } \\
\text { Methodologies }\end{array}$ & Klaus Bruhn Jensen & 2002 & $\begin{array}{l}\text { Propaganda Technique in the } \\
\text { World War; } \\
\text { The structure and function of } \\
\text { communication in society; } \\
\text { The policy sciences }\end{array}$ \\
\hline $\begin{array}{l}\text { Theory and research in mass } \\
\text { communication: contexts and consequences }\end{array}$ & David K. Perry & 2002 & $\begin{array}{l}\text { Propaganda Technique in the } \\
\text { World War; }\end{array}$ \\
\hline
\end{tabular}




\begin{tabular}{|c|c|c|c|}
\hline & & & $\begin{array}{l}\text { The structure and function of } \\
\text { communication in society }\end{array}$ \\
\hline $\begin{array}{l}\text { Canonic texts in media research: are there } \\
\text { any? should there be? how about these? }\end{array}$ & Elihu Katz & 2003 & Nenhuma \\
\hline Building communication theory & $\begin{array}{l}\text { Dominic A. Infante; } \\
\text { Andrew S. Rancer \& } \\
\text { Deanna F. Womack }\end{array}$ & 2003 & $\begin{array}{l}\text { Propaganda Technique in the } \\
\text { World War } \\
\text { The structure and function of } \\
\text { communication in society }\end{array}$ \\
\hline $\begin{array}{l}\text { Handbook of political communication } \\
\text { research }\end{array}$ & Lynda Lee Kaid & 2004 & $\begin{array}{l}\text { The structure and function of } \\
\text { communication in society; } \\
\text { The comparative study of } \\
\text { symbols; } \\
\text { Propaganda Technique in the } \\
\text { world war; } \\
\text { Psychopatology and politics; } \\
\text { The structure and function of } \\
\text { communication in society }\end{array}$ \\
\hline $\begin{array}{l}\text { New frontiers in international } \\
\text { communication theory }\end{array}$ & Mehdi Semati & 2004 & $\begin{array}{l}\text { Propaganda Technique in the } \\
\text { world war }\end{array}$ \\
\hline Communication as--: perspectives on theory & $\begin{array}{l}\text { Gregori J. Sheperd; Jeffrey } \\
\text { St. John \& Theodore G. } \\
\text { Striphas }\end{array}$ & 2006 & $\begin{array}{l}\text { The structure and function of } \\
\text { communication in society }\end{array}$ \\
\hline Communication studies & Sky Marsen & 2006 & $\begin{array}{l}\text { The structure and function of } \\
\text { communication in society }\end{array}$ \\
\hline $\begin{array}{l}\text { Theorizing communication: readings across } \\
\text { traditions }\end{array}$ & $\begin{array}{l}\text { Robert T. Craig \& Heidi L. } \\
\text { Muller }\end{array}$ & 2007 & $\begin{array}{l}\text { The structure and function of } \\
\text { communication in society }\end{array}$ \\
\hline Theories of human communication & $\begin{array}{l}\text { Stephen W. Littlejohn \& } \\
\text { Karen A. Foss }\end{array}$ & 2007 & $\begin{array}{l}\text { The structure and function of } \\
\text { communication in society }\end{array}$ \\
\hline Key Themes in Media Theory. & Dan Laughey & 2007 & $\begin{array}{l}\text { Propaganda Technique in the } \\
\text { world war }\end{array}$ \\
\hline An Introduction to Communication Studies & Sheila Steinberg & 2007 & $\begin{array}{l}\text { The structure and function of } \\
\text { communication in society }\end{array}$ \\
\hline $\begin{array}{l}\text { The history of media and communication } \\
\text { research: contested memories }\end{array}$ & $\begin{array}{l}\text { David W. Park \& Jefferson } \\
\text { Pooley }\end{array}$ & 2008 & $\begin{array}{l}\text { Harold Lasswell Papers; } \\
\text { Propaganda Technique in the } \\
\text { World War }\end{array}$ \\
\hline $\begin{array}{l}\text { An integrated approach to communication } \\
\text { theory and research }\end{array}$ & $\begin{array}{l}\text { Don W. Stacks \& Michael } \\
\text { Brian Saven }\end{array}$ & 2008 & $\begin{array}{l}\text { Propaganda Technique in the } \\
\text { World War; } \\
\text { The structure and function of } \\
\text { communication in society }\end{array}$ \\
\hline $\begin{array}{l}\text { McQuail's reader in mass communication } \\
\text { theory }\end{array}$ & Denis McQuail & 2008 & $\begin{array}{l}\text { Verbete propaganda na } \\
\text { Enciclopédia de Ciências } \\
\text { Sociais } \\
\text { The structure and function of } \\
\text { communication in society }\end{array}$ \\
\hline $\begin{array}{l}\text { Recharting media studies: essays on } \\
\text { neglected media critics }\end{array}$ & $\begin{array}{l}\text { Philip Bounds \& Mala } \\
\text { Jagmohan }\end{array}$ & 2008 & Nenhuma \\
\hline $\begin{array}{l}\text { Introducing Communication Theory: Analysis } \\
\text { and Application }\end{array}$ & $\begin{array}{l}\text { Richard West Lynn H. } \\
\text { Turner }\end{array}$ & 2009 & Nenhuma \\
\hline $\begin{array}{l}\text { Normative theories of the media: journalism } \\
\text { in democratic societies }\end{array}$ & $\begin{array}{l}\text { Clifford G. Christians \& } \\
\text { Denis McQuail }\end{array}$ & 2009 & $\begin{array}{l}\text { The structure and function of } \\
\text { communication in society }\end{array}$ \\
\hline Doing Media Research: an Introduction & Susanna Horning Priest & 2009 & Nenhuma \\
\hline $\begin{array}{l}\text { Routledge handbook of applied } \\
\text { communication research }\end{array}$ & Kenneth N. Cissna & 2009 & $\begin{array}{l}\text { The structure and function of } \\
\text { communication in society }\end{array}$ \\
\hline Encyclopedia of Communication Theory & $\begin{array}{l}\text { Stephen W. Littlejohn \& } \\
\text { Karen A. Foss }\end{array}$ & 2009 & $\begin{array}{l}\text { Propaganda Technique in the } \\
\text { world war }\end{array}$ \\
\hline Mass Media Research: An Introduction & $\begin{array}{l}\text { Roger D. Wimmer \& } \\
\text { Joseph R. Dominick }\end{array}$ & 2010 & $\begin{array}{l}\text { Propaganda Technique in the } \\
\text { world war }\end{array}$ \\
\hline $\begin{array}{l}\text { Media and Communication Research } \\
\text { Methods: An Introduction to Qualitative and } \\
\text { Quantitative Approaches }\end{array}$ & Arthur Asa Berger & 2010 & Nenhuma \\
\hline $\begin{array}{l}\text { Media Studies: Media History, Media and } \\
\text { Society }\end{array}$ & Pieter J. Fourie & 2010 & Nenhuma \\
\hline
\end{tabular}




\begin{tabular}{|c|c|c|c|}
\hline $\begin{array}{l}\text { Mass Communication Theory: Foundations, } \\
\text { Ferment, and Future }\end{array}$ & $\begin{array}{l}\text { Stanley J. Baran\& Dennis } \\
\text { K. Davis }\end{array}$ & 2011 & $\begin{array}{l}\text { The structure and function of } \\
\text { communication in society; } \\
\text { Propaganda Technique in the } \\
\text { World War; } \\
\text { The theory of political } \\
\text { propaganda }\end{array}$ \\
\hline $\begin{array}{l}\text { Media Industries: History, Theory, and } \\
\text { Method }\end{array}$ & $\begin{array}{l}\text { Jennifer Holt \& Alisa } \\
\text { Perren }\end{array}$ & 2011 & $\begin{array}{l}\text { The structure and function of } \\
\text { communication in society }\end{array}$ \\
\hline
\end{tabular}

Tabela 10. Obras de Harold Lasswell presentes nas referências da bibliografia teorográfica em língua inglesa.

Vê-se, pela tabela, que dos 65 livros listados, apenas sete tem três ou mais referências de Harold Lasswell, algo em torno de 10,7\%. Doze livros trazem duas obras de Lasswell em suas referências, aproximadamente $20 \%$ do total. Vinte livros têm somente uma obra de Lasswell em suas referências, perto de 44\% do levantamento. Desse número, 19 são A Estrutura e a Função da Comunicação na Sociedade, seis são Propaganda Technique in the World War e os restantes são Language of Politics e The Policy Sciences. Doze obras não possuem nenhum texto de Harold Lasswell em sua bibliografia, $22 \%$ do levantamento.

O número total de obras produzidas por Lasswell sobre comunicação nos faz questionar o uso dessas referências: 70. Se pegarmos a maior quantidade de referências levantadas aqui, em torno de três, seria como se os livros teorográficos consultassem apenas $4,2 \%$ do material produzido por Lasswell sobre comunicação e tomassem esse número como satisfatório. O texto mais utilizado é A Estrutura e a Função da Comunicação na Sociedade, que sequer constitui um livro-texto, é um pequeno artigo no qual Lasswell resume boa parte de um trabalho que ele já vinha desenvolvendo desde a Segunda Grande Guerra. Qualitativamente, seria considerar que apenas duas ou três obras são suficientes para compreender o pensamento de um teórico e que também só essas são suficientes para se conhecer um autor. Talvez, de fato, isso fosse possível, mas a variação constante da seleção dessas duas ou três obras centrais não aparece ao compararmos as referências. A não ser por A Estrutura e a Função da Comunicação na Sociedade, não se consegue um consenso acerca das obras essenciais de Lasswell para a teoria da Comunicação. Assim, as referências oscilam entre aquelas que o teorógrafo escolhe de modo particular, aquela que traz o modelo de Lasswell mais claramente $(A$ Estrutura e a Função da Comunicação na Sociedade), sua tese de doutorado, ponto inicial de suas relações com a comunicação, e nenhuma obra do cientista político. Dessa forma, uma análise variada ou mesmo mais completa do autor se torna mais difícil.

Até exceções como o livro de David K. Park e Jefferson Pooley, The history of media and communication research: contested memories, que tenta construir uma 
discussão diferenciada e mais crítica sobre a história das teorias da comunicação, traz somente duas referências de Harold Lasswell aos arquivos disponíveis em Yale e Propaganda Technique in the World War, sem citar o restante da obra.

O desconhecimento da produção lasswelliana sobre comunicação leva também às contradições quanto à interpretação da obra de Lasswell ${ }^{37}$. Ainda em relação ao modelo, o próprio Hanno Hardt se vale de uma citação de Bauer na qual este autor afirma que "com a possível exceção de alguns trabalhos de Lasswell, o período inicial não foi marcado por grandes idéias, mas por abordagens metodológicas diversificadas" ${ }^{38}$ (2010, p.120). Ou seja, ao mesmo tempo em que Lasswell pode ser identificado com um modelo superado, o de meios de comunicação super poderosos, alguns de seus trabalhos podem ser considerados exceções em relação ao período inicial da pesquisa em comunicação no que diz respeito a "grandes ideias". O modelo de Lasswell se mostra, então, na bibliografia de língua inglesa, de modo similar aos outros blocos lingüísticos. Seu maior número não chega a gerar uma diferença que possa modificar a visão acerca de seu funcionamento e proposição, com mínima diversidade.

Em uma variação sobre a identificação de Lasswell e de seu modelo com o postulatum hipodérmico (quinto tema mais frequentemente associado ao autor), Park e Pooley tentam esclarecer a confusão que se formou envolvendo pesquisador e teoria sobretudo como decorrente de sua primeira obra Propaganda Technique in the World War.

[...] apesar de Lasswell não ter cunhado o termo hipodérmico, ele faz referência a injeções no contexto da propaganda, e a sua pesquisa em propaganda é geralmente considerada um exemplo dos primeiros trabalhos que assumiam uma direta e poderosa influência dos meios. Jesse G. Delia, por exemplo, afirma que Propaganda pode ser lido como "uma indiferenciada concepção da comunicação de massa de efeito direto," e Viekko Pietilã afirma que a noção de meios poderosos devorando vítimas indefesas está "claramente presente" neste livro.

[...] Werner J. Severin and James W. Tankard, Jr, acusam Jacques Ellul de abrigar uma "forma pouco revista" do modelo hipodérmico em Propaganda: A Formação de atitudes dos homens, mas Francis Balle e Idalina Cappe de Baillon dão crédito ao mesmo trabalho como um desafio "à relevância do modelo de 'agulha hipodérmica' como uma representação dos efeitos da mídia". Harold Lasswell, como discutido anteriormente, é citado como acreditando nos efeitos hipodérmicos, apesar de Chaffee e Hochheimer colocarem em dúvida nessa associação ${ }^{39}$ (PARK \& POOLEY, 2010, p.36).

\footnotetext{
${ }^{37}$ Já observadas na bibliografia em espanhol.

38 "Bauer argued that 'with the possible exception of some of Lasswell's work, the early period was not marked by great ideas but by diverse methodological approaches"”.

39 " [...] although Lasswell did not coin hypodermic, he did reference injections in the context of propaganda, and his propaganda research is generally considered an example of early work that assumed powerful, direct media influence.
} 
Park e Pooley não conseguem dissipar por completo a questão, ainda que se mostrem mais favoráveis à versão que liberta Harold Lasswell de uma ligação insolúvel com a teoria hipodérmica. Contudo, nas outras obras que falam sobre o assunto, Lasswell é exatamente o pesquisador dos efeitos diretos e seu modelo do processo de comunicação serviu para segmentar as áreas de pesquisa sobre esses efeitos.

Os dois temas mais trabalhados pela bibliografia da área em língua inglesa, depois do "modelo de Lasswell", são "funções da comunicação" e "propaganda", com 18 e 19 entradas, respectivamente. Também neste caso, se repete o que foi visto na bibliografia em língua espanhola e francesa. Lista-se as funções da comunicação descritas por Lasswell em A Estrutura e a Função da Comunicação na Sociedade e coloca-se a propaganda como tema de pesquisa escolhido por Lasswell.

Em geral, Harold Lasswell é descrito como o introdutor do Funcionalismo na Comunicação, como o faz Dennis McQuail:

Os elementos teóricos do paradigma dominante não foram inventados por causa dos meios de comunicação, mas foram largamente "emprestados" da sociologia, psicologia e de uma versão aplicada da ciência da informação. Ele tomou seu lugar especialmente na década seguinte à Segunda Guerra Mundial, quando havia uma ampla hegemonia inconteste norte-americana tanto nas ciências sociais, quanto em relação aos meios de comunicação (Tunstall, 1977). A sociologia, enquanto amadurecia suas teorias, ofereceu um quadro funcionalista de análise dos meios e de outras instituições. Lasswell (1948) foi o primeiro a formular um estatuto claro sobre as "funções" da sociedade de comunicação - significando tarefas essenciais para sua manutenção. [...] A ideia geral é que a comunicação trabalha para a integração, continuidade e ordem da sociedade, ainda que a comunicação de massa possa ter potencialmente consequiências disfuncionais (disruptivas ou prejudiciais). Apesar do reduzido apelo intelectual, a linguagem das funções tem sido difícil de eliminar das discussões sobre os meios e a sociedade (MCQUAIL, 1994, p.63).

A citação acima mostra novamente a ausência de uma reflexão mais apurada a respeito de Lasswell. De um lado trabalha-se com uma visão laudatória do pesquisador, ao identificá-lo como fundador do Funcionalismo na Comunicação e, de outro lado, com uma inferiorização de sua proposta, como sendo de "reduzido apelo intelectual". McQuail não explicita o porquê do apelo intelectual reduzido, nem o motivo pelo qual a

Jesse G. Delia, for one, argues that Propaganda can be read as 'an undifferentiated and direct-effects conception of mass communication,' and Viekko Pietilã asserts that the notion of powerful media preying on defenseless victims is 'present quite clearly' in this book.

[...] Werner J. Severin and James W. Tankard, Jr, accuse Jacques Ellul of harboring a 'somewhat revised form' of the hypodermic model in Propaganda: The Formation of Men's attitudes, but Francis Balle and Idalina Cappe de Baillon credit the same work with challenging 'the relevance of the 'hypodermic needle' model as a representation of media effects.' Harold Lasswell, As discussed previously, is cited as believing in hypodermic effects, although Chaffee and Hochheimer cast doubt on this association". 
ideia das funções tem sido difícil de ser substituída nas discussões sobre os meios de comunicação. No parágrafo seguinte do livro de McQuail, o modelo de ShannonWeaver já é seu assunto.

A propaganda como tema eleito por Lasswell no campo da Comunicação é laborada de forma superficial também, no que diz respeito às concepções de Lasswell sobre a matéria. O interessante é notar que, do mesmo modo, Lasswell é muitas vezes lembrado como pioneiro nessas pesquisas. É assim, por exemplo, em Recharting media studies: essays on neglected media critics, de Philip Bounds e Mala Jagmohan. De acordo com os dois autores,

\begin{abstract}
A análise da propaganda se desenvolveu nos anos de 1920 - a a palavra "propaganda" só passou a fazer parte do discurso politico depois de 1918 - com Harold Lasswell observando que as pessoas tinham a tendência de reagir a impulsos emocionais mais do que a declarações racionais (WILLIANS apud BOUNDS \& JAGMOHAN, 2008, p.90).
\end{abstract}

Mesmo em textos contemporâneos de Lasswell, como Social Communication, de Carl Hovland, o cientista político é tido como fundamental para a sistematização da pesquisa em Comunicação, mas seu papel na pesquisa sobre propaganda é descrito muito rapidamente:

O estudo de Lasswell, Kris e Speier na análise da propaganda inimiga em jornais, rádio e filmes constituem bons exemplos dos desenvolvimentos nos últimos anos nessa área. Esses métodos oferecem análises em torno da comunicação, sua temática, tipo de simbolização, os tipos de dispositivos retóricos utilizados, características sintáticas, etc. Sem a descrição completa posssibilitada por esses novos e mais precisos métodos de descrever o conteúdo do estímulo, a tarefa de formular princípios e generalizações seria bem mais difícil (HOVLAND apud CRAIG \& MULLER, 2007, p.320).

Hovland alinha Lasswell, Kris e Speier à teoria hipodérmica e, ao fazê-lo, indica que as pesquisas realizadas sob esta denominação possuem uma importância a ser considerada, pois desenvolveram métodos necessários para uma melhor organização dos estudos sobre comunicação, mas não minudencia exatamente a contribuição de Lasswell. O fato de serem contemporâneos excluiria essa necessidade?

Mais uma vez The history of media and communication research: contested memories, organizado por David K. Park e Jefferson Pooley, se coloca como uma exceção. Discutindo a disciplinarização da Comunicação e apresentando um dado diferenciado em relação às outras obras do universo de língua inglesa, o artigo 
“"Commmunication': from concept to field to discipline”, de Michael J. Sproule, afirma ter sido Lasswell o responsável pela transição do termo "propaganda", o mais presente nos primeiros estudos da área, para a rubrica "comunicação", que passou a designar os estudos a partir dos Seminários promovidos pela Fundação Rockefeller. Segundo Sproule,

[...] A escolha da palavra comunicação como um termo mestre para estudar as influências sociais foi característica em dois programas de pesquisa particularmente importantes, o de Harold D. Lasswell, na Biblioteca do Congresso, e o de Carl I. Hovland para o Exército americano.

O programa de pesquisa teve origem no fato de ele ter sido desde 1939 um participante ativo num grupo informal, patrocinado pela Fundação Rockefeller, cuja meta era refinar novas abordagens na promissora área da comunicação, com o objetivo de fazer com que as comunicações tivessem mais atenção de importantes administradores do governo. Em 1940, Lasswell foi convidado a se candidatar a uma bolsa da fundação, para criar uma organização, com sede administrativa na Biblioteca do Congresso, e que possuiria dois objetivos. Primeiro, a Divisão Experimental para o Estudo da Comunicação em Tempos de Guerra, de Lasswell, refinaria a análise de conteúdo quantitativa. Segundo, o grupo de Lasswell deveria aplicar diretamente esse método, por um lado, na análise imediata das organizações (para o benefício do Departamento de Justiça) e, por outro, no treinamento de pessoal especializado na análise da propaganda e inteligência.

[...]

A escolha de Lasswell pela rubrica comunicação estava diretamente relacionada à confluência das condições da guerra, das quais patrocinadores, administradores, e acadêmicos tentavam distanciar seu trabalho (o estudo da "comunicação"), daquele feito pelos inimigos (rotulado de "propaganda"). Aqui o consultor Lasswell continuou com a função de construer uma "teoria básica da comunicação". A invocação da rubrica politicamente neutra da comunicação permitiu a fundações, agências do governo, e pesquisadores individuais estudar as mensagens simbólicas domésticas sem a lembrança inconveniente inerente ao termo "propaganda" - de que as mensagens oficiais possuem fins persuasivos mais profundos ${ }^{40}$ (SPROULE apud PARK \& POOLEY, 2008, pp.164-165).

\footnotetext{
40، [...] The turn to communication as master term for studying social influence was characteristic of two particularly important research programs, those of Harold D. Lasswell in the Library of Congress and Carl I. Hovland for the U.S. Army.

Lasswell's research program originated in his having been a regular participant since 1939 in an informal working group, sponsored by the Rockefeller Foundation, that aimed to refine new approaches to knowledge in the promising area of communication, with the further objective of bringing this information to the attention of relevant government administrators. In 1940, Lasswell was invited to apply for a large grant from the foundation, to set up an organization, administratively housed in the Library of the Congress, that would pursue two objectives. First, Lasswell's Experimental Division for the Study of Wartime Communications would refine quantitative content analysis. Second, the Lasswell group would directly apply this method, on the one hand, to the immediate analysis of organizations (for the benefit of the Department of Justice) and, on the other, to the training of personnel for assignments in propaganda analysis and intelligence.

[...] Lasswell's turning to the rubric of communication was directly related to the confluence of wartime conditions whereby grantors, administrators, and academicians all sought to distance their work (the study of 'communication') from that of the enemy (whose output was 'propaganda'). Here consultant Lasswell continued to function as an
} 
Na formação do campo da Comunicação, Sproule assinala um feito de Lasswell que passa despercebido pelo restante da bibliografia em língua inglesa: teria sido ele o responsável pela consolidação do termo "comunicação", no lugar de "propaganda".

Seja de que forma for, com as exceções ou as regras, Lasswell é tido como iniciador, precursor, pioneiro, fundador, para um número considerável de teorógrafos, sendo o quarto tema mais comumente citado. São 16 as obras que colocam de maneira direta Lasswell como fundador do campo, mas quase todas as 65 publicações da bibliografia em língua inglesa, de alguma forma o expõem como pioneiro nas pesquisas em comunicação.

Nesse sentido, Wilbur Schramm é o autor decisivo na construção do perfil de Lasswell como desbravador do campo da Comunicação, com um discurso quase "mitológico" sobre o cientista político. Misticamente, é como se Lasswell, como se diz nos dias de hoje, tivesse "sido escolhido" pela comunicação ("Como ele entrou no campo da comunicação? Lasswell sempre esteve nele"41, SCHRAMM, 1997, p.32).

As maiores contribuições de Lasswell ao estudo da comunicação estavam no campo do pensamento e não no lado prático. Como nós refletimos em seus anos conosco, nós podemos ver três grandes contribuições intelectuais suas.

[...] Uma contribuição foi o grande e rico método que se originou na pesquisa em comunicação. Nem os experimentos de Hovland sobre persuasão, nem a cuidadosa observação lewiniana do processo de grupo, nem os surveys típicos de Lazarsfeld sobre os efeitos e usos dos meios de comunicação o agradavam. Mas ele reconheceu a necessidade de estudar os símbolos significantes da vida política, e por isso, desde o início da sua carreira escolar, ele próprio realizou, ou incentivou outros a realizar, análises de conteúdo.

[...] Enquanto ele enriquecia o estudo do conteúdo, ele também enriquecia o conceito de propaganda, o conteúdo que ele passou tanto tempo estudando.

[...] Uma terceira grande contribuição de Lasswell para a comunicação foi conceitualizar o papel político da comunicação, de um modo que incluiu funções que iam além da persuasao e das campanhas eleitorais $^{42}$ (SCHRAMM, 1997, p.32-35).

academician building up 'basic theory in the field of communication.' Invocation of the politically neutral rubric of communication permited foundations, government agencies, and individual scholars to study domestic symbolic output absent the inconvenient reminder - inherent to the term 'propaganda'- that official messages harbored deeper persuasive purposes".

41 "How did he get into communication study? Lasswell had always been in communication"

42 "Lasswell's major contributions to communication study were on the thinking rather than the doing side. As we reflect on his years with us. We tend to see his great intellectual contributions as threefold. [...] One contribution was the greatly enriched method that can be said to have originated in communication research. Neither the Hovland experiments on persuasion, the careful Lewinian observation of group process, nor Lazarsfeld-type surveys on mass media uses and effects were congenial to him. But he recognized the need to study the significant symbols of political life, and therefore, from the very beginning of his scholarly career he found himself doing, or getting others to do, content analysis. [...]

As he enriched the study of content, so also he enriched the concept of propaganda, the content of which he spent so much time studying.

$[\ldots]$ 
No retrato feito por Schramm, é possível perceber categorias que perpassam os discursos dos outros autores estudados. A contribuição do método da análise de conteúdo para os estudos em comunicação; o estudo da propaganda; o papel político da comunicação. Deve-se dizer que Schramm delineia um perfil mais completo, mas pouco avança em discussões teóricas, pois foca numa escrita que privilegia os dados biográficos, sem relacioná-los com um conteúdo epistemológico. Nesse caso, também, é pertinente dizermos que Schramm se coloca como uma exceção muito provavelmente por suas intenções em definir o campo da Comunicação como autônomo.

Certo é que o caráter pioneiro de Lasswell aparece em quase todas as obras analisadas. Esses são os cinco temas que mais se fazem presentes e, de certa, forma, todos os outros gravitam em torno deles. Se observarmos novamente o gráfico 3 , verificaremos que a incidência dos outros temas é bastante pequena e, outro ponto relevante é o fato de que temas semelhantes são tratados como diferentes pela bibliografia.

Assim, Schramm constrói, ao mesmo tempo, um dos primeiros relatos, pois é um dos textos mais iniciais, e sintetiza o que se encontra na bibliografia em língua inglesa: Lasswell é, em suma, o teórico do modelo de Lasswell, da propaganda, das funções da comunicação e, curiosamente, um autor hipodérmico.

Portanto, fora uma ou outra exceção, o perfil que se faz de Lasswell em sua língua materna não difere muito daquele feito por escritores de outras línguas.

\section{d) Harold Lasswell no universo de língua portuguesa}

Ao contrário do universo de língua inglesa, o bloco linguístico de obras teorográficas em português encontrado pela busca digital é pequeno e pouco substancial. Como algumas produções em língua portuguesa são traduções de outros idiomas, certos livros ficaram de fora dessa listagem, como Teorias da Comunicação de Massa, de Melvin Defleur e Sandra Ball-Rockeach, e História das Teorias da Comunicação, de Armand \& Michèle Mattelart, já estudados no tópico anterior. Entre as obras em português, há uma tradução do inglês, que não teve versão disponível no idioma original: Mais do que palavras: uma introdução à teoria da comunicação, de Richard Dimbleby e Graeme Burton.

A third great contribution of Lasswell to communication was to conceptualize the poltical role of communication, in a way that included functions much beyond persuasion and election campaigns". 
Os livros encontrados pela busca cruzada em português são:

\begin{tabular}{|c|c|c|}
\hline Livro & Autor & Ano \\
\hline Comunicação social: teoria e pesquisa & José Marques de Melo & 1977 \\
\hline $\begin{array}{l}\text { Teoria e pesquisa em comunicação: } \\
\text { panorama latino-americano }\end{array}$ & José Marques de Melo & 1983 \\
\hline $\begin{array}{l}\text { Mais do que palavras: uma introdução à } \\
\text { teoria da comunicação }\end{array}$ & Richard Dimbleby \& Graeme Burton & 1990 \\
\hline $\begin{array}{l}\text { Subsídios para uma teoria da comunicação de } \\
\text { massa }\end{array}$ & Luiz Beltrão & 2004 \\
\hline $\begin{array}{l}\text { Teorias da Comunicação: Trajetórias } \\
\text { Investigativas }\end{array}$ & $\begin{array}{l}\text { Antonio Hohfeldt; Giovandro Marcus Ferreira; Luiz Claudio } \\
\text { Martino\& Osvando J. Morais }\end{array}$ & 2010 \\
\hline
\end{tabular}

Tabela 11. Obras teorográficas em português com referências a Harold Lasswell (Inicial).

Incluímos mais seis livros teorográficos, encontrados no decorrer da pesquisa. Assim, a lista final ficou com nove títulos:

\begin{tabular}{|c|c|c|}
\hline Livro & Autor & Ano \\
\hline Comunicação social: teoria e pesquisa & José Marques de Melo & 1977 \\
\hline $\begin{array}{l}\text { Teoria e pesquisa em comunicação: } \\
\text { panorama latino-americano }\end{array}$ & José Marques de Melo & 1983 \\
\hline $\begin{array}{l}\text { Mais do que palavras: uma introdução à } \\
\text { teoria da comunicação }\end{array}$ & Richard Dimbleby \& Graeme Burton & 1990 \\
\hline Teorias da Comunicação & Mauro Wolf & 2002 \\
\hline $\begin{array}{l}\text { Subsídios para uma teoria da comunicação de } \\
\text { massa }\end{array}$ & Luiz Beltrão & 2004 \\
\hline $\begin{array}{l}\text { Teorias da Comunicação: Conceitos, Escolas e } \\
\text { Tendências }\end{array}$ & Antonio Hohfeldt, Luiz C. Martino \& Vera Veiga França & 2007 \\
\hline Teoria da Comunicação & Luís Mauro Sá Martino & 2009 \\
\hline $\begin{array}{l}\text { Teorias da } \text { Comunicação: } \\
\text { Investigativas }\end{array}$ & $\begin{array}{l}\text { Antonio Hohfeldt; Giovandro Marcus Ferreira; Luiz Claudio } \\
\text { Martino\& Osvando J. Morais }\end{array}$ & 2010 \\
\hline As Teorias da Comunicação & Francisco Rüdiger & 2011 \\
\hline
\end{tabular}

Tabela 12. Obras teorográficas em português com referências a Harold Lasswell (Final).

Mais uma vez, o modelo de Lasswell ${ }^{43}$ é o tema mais comum nos textos perscrutados, presente em sete das nove obras listadas (78\%). Os outros temas são: "funções da comunicação", Harold Lasswell como "clássico", "pais fundadores" e "influência no Brasil". Esses temas se fazem presentes, cada um, em apenas um dos livros analisados. Assim, correspondem isoladamente a $20 \%$ do total. Vejamos.

\footnotetext{
${ }^{43}$ Que aparece em Subsídios para uma teoria da comunicação de massa, de Luiz Beltrão, como "diagrama de Lasswell".
} 


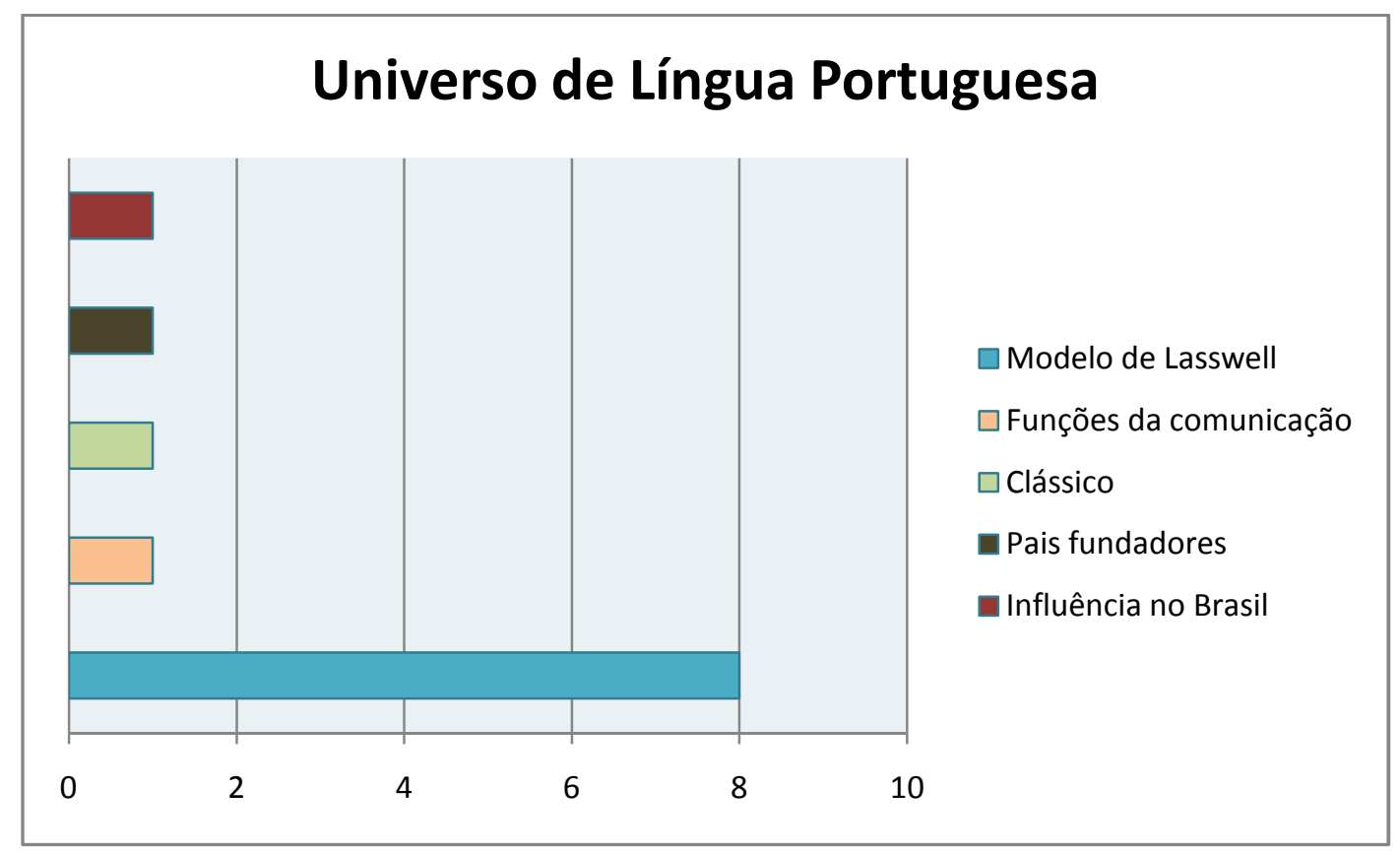

Gráfico 4. Temas relacionados à Lasswell na bibliografia de língua portuguesa.

Mais uma vez, o modelo de Lasswell é referendado como organizador da pesquisa em comunicação ao dividi-la em áreas, sendo considerada uma teoria da comunicação por pelo menos um autor (MARQUES DE Melo, 1983, p.67). Essencialmente, o que se itera é o que aparece mais sinteticamente na citação a seguir:

Um dos mais antigos e ainda mais uteis exemplos para descrever o processo de comunicação é separá-lo em partes, como foi feito por Harold Lasswell, em 1948. Ele disse que o processo de comunicação pode ser decomposto nos seguintes termos:

Quem

Diz o que

Em que canal

Para quem

E com qual efeito

(DIMBLEBY \& BURTON, 1990, p.35).

Novamente, o modelo apenas é apresentado, sem contextualização, sem explicações, sem aprofundamento, como se fosse autoevidente e autoexplicativo. O mesmo ocorre nas seis outras obras que o citam.

A bibliografia em português se parece, em grande medida, com a que foi analisada em língua francesa. Há pouco espaço para Lasswell e o autor é lido em linhas gerais. No máximo, são dedicados três parágrafos a seus trabalhos.

O papel de Lasswell como pai fundador é lembrado em José Marques de Melo (1977, p.44), bem como sua importância como clássico para o campo comunicacional 
(p.47), apesar de Marques de Melo fazê-lo brevemente. Outro que inclui Lasswell no rol dos clássicos da Comunicação é Luís Mauro de Sá Martino que, ao citar o modelo de Lasswell, afirma: “[...] Um dos primeiros modelos para o estudo da Comunicação foi proposto por Harold D. Lasswell em 1948. Seu texto 'A estrutura e a função da comunicação da sociedade' se mantém como um dos clássicos da Comunicação" (2009, p. 23)

Já a influência de Lasswell no Brasil, citada por apenas um dos livros estudados (Teorias da Comunicação: Trajetórias Investigativas, de Giovandro Marcus Ferreira, Antonio Hohfeldt, Luiz Claudio Martino e Osvando J. Morais) também é apresentada bem rapidamente, quando se fala que algumas de suas obras foram editadas no Brasil e ainda se encontram disponíveis no mercado.

A mínima discussão que se estabelece sobre a obra lasswelliana pode ser resultado da ausência da leitura direta do autor. Assim como nos outros blocos linguísticos, é reveladora a ausência de textos de Harold Lasswell nas referências da bibliografia em língua portuguesa.

\begin{tabular}{|c|c|c|c|}
\hline Livro & Autor & Ano & Referências \\
\hline $\begin{array}{l}\text { Subsídios para uma teoria da } \\
\text { comunicação de massa }\end{array}$ & Luiz Beltrão & 2004 & $\begin{array}{l}\text { A Estrutura e a Função da } \\
\text { Comunicação na Sociedade }\end{array}$ \\
\hline $\begin{array}{l}\text { Teorias da Comunicação: } \\
\text { Trajetórias Investigativas }\end{array}$ & $\begin{array}{l}\text { Antonio Hohfeldt; Giovandro Marcus } \\
\text { Ferreira; Luiz Claudio Martino \& } \\
\text { Osvando J. Morais }\end{array}$ & 2010 & $\begin{array}{l}\text { A Linguagem da Política } \\
\text { Poder e Sociedade }\end{array}$ \\
\hline $\begin{array}{l}\text { Mais do que palavras: uma } \\
\text { introdução à teoria } \\
\text { comunicação }\end{array}$ & Richard Dimbleby \& Graeme Burton & 1990 & Nenhuma \\
\hline $\begin{array}{l}\text { Teoria e pesquisa em } \\
\text { comunicação: } \\
\text { americano }\end{array}$ & José Marques de Melo & 1983 & Nenhuma \\
\hline $\begin{array}{l}\text { Comunicação social: teoria } e \\
\text { pesquisa }\end{array}$ & José Marques de Melo & 1977 & Nenhuma \\
\hline Teoria da Comunicação & Luís Mauro Sá Martino & 2009 & $\begin{array}{l}\text { A Estrutura e a Função da } \\
\text { Comunicação na Sociedade }\end{array}$ \\
\hline As Teorias da Comunicação & Francisco Rüdiger & 2011 & $\begin{array}{l}\text { A Estrutura e a Função da } \\
\text { Comunicação na Sociedade }\end{array}$ \\
\hline $\begin{array}{l}\text { Teorias da Comunicação: } \\
\text { Conceitos, Escolas e Tendências }\end{array}$ & $\begin{array}{l}\text { Antonio Hohfeldt, Luiz C. Martino \& } \\
\text { Vera Veiga França }\end{array}$ & 2007 & Nenhuma \\
\hline Teorias da Comunicação & Mauro Wolf & 2002 & $\begin{array}{l}\text { A Estrutura e a Função da } \\
\text { Comunicação na Sociedade } \\
\text { Communication of Ideas }\end{array}$ \\
\hline
\end{tabular}

Tabela 13. Obras de Harold Lasswell presentes nas referências da bibliografia teorográfica em língua portuguesa.

Cabe alertar que em Teorias da Comunicação: Trajetórias Investigativas, de Giovandro Marcus Ferreira, Antonio Hohfeldt, Luiz Claudio Martino e Osvando J. Morais, apesar de fazerem parte das referências, os livros são citados no corpo do livro 
como exemplos de obras de Lasswell editadas no Brasil, mas não tem seu conteúdo utilizado para discussão do pensamento lasswelliano.

A bibliografia em português, destarte, se apresenta como a menos comprometida com uma leitura do trabalho de Lasswell e a mais "rápida" em suas colocações. Parte desse fenômeno pode ser explicado pela língua e pela dificuldade que os autores brasileiros enfrentavam até algum tempo atrás para conseguir obras teorográficas em outros idiomas. Contudo, como visto em Teorias da Comunicação: Trajetórias Investigativas, há obras de Lasswell editadas no país desde a década de 1970, o que justificaria pelo menos a inclusão destas nas referências das obras teorográficas produzidas em terras tupiniquins:

Nos anos 1970, quando o Departamento de Estado norte-americano financiava traduções de obras para os países ditos periféricos, no campo da comunicação social, dentre muitos outros textos, editaramse, no Brasil, a Teoria matemática da comunicação, de Claude Shannon e Warren Weaver, Comunicação de massa e desenvolvimento, de Wilbur Schramm ou Comunicação de massa, de Charles Wright, obras que, infelizmente, logo depois, desapareceriam do mercado e nunca mais foram reeditadas. Melhor sorte teve Harold Lasswell, cujas obras ainda se encontram no mercado brasileiro, publicadas já num momento posterior (HOHLFELDT, 2010, pp.27-28)

Mas o fato de ser mais publicado tornaria Harold Lasswell um afortunado entre o restante dos autores ligados à teoria da comunicação?

\subsection{Sobre o que foi dito: Harold Lasswell, um ilustre desconhecido}

Afinal, que inventário podemos fazer a partir do que foi dito pelas obras de teorias da comunicação sobre Lasswell? Vejamos os cinco pontos essenciais, por ordem de frequência nas 78 obras teorográficas inspecionadas: 


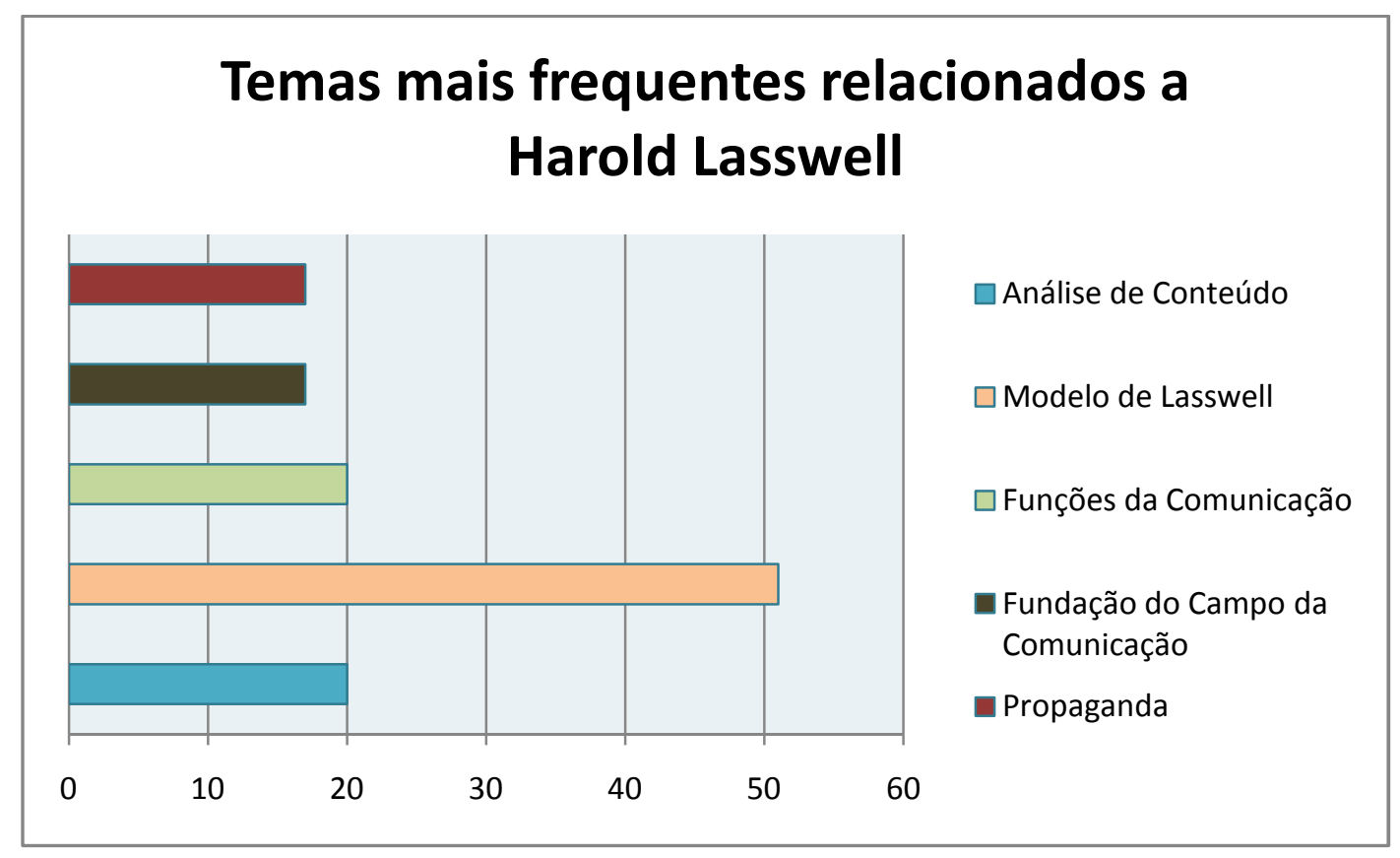

Gráfico 5. Os cinco temas mais freqüentes sobre Lasswell nos quatro blocos lingüísticos.

Uma síntese do que vimos nos blocos lingüísticos nos leva a afirmar que:

1) Harold Lasswell criou o modelo que organizou e seccionou o campo da comunicação em áreas de investigação, o chamado "modelo de Lasswell";

2) Harold Lasswell é um dos principais estudiosos da propaganda, tendo sido pioneiro nesta área;

3) Harold Lasswell, por seus estudos em propaganda, pode ser incluído no rol dos autores hipodérmicos, pois suas concepções sobre a matéria trabalham com a ideia de meios de comunicação super poderosos e de uma audiência passiva;

4) Harold Lasswell é o introdutor do Funcionalismo no campo da Comunicação, ao arrolar as funções da comunicação na sociedade;

5) Harold Lasswell cria um método próprio de análise das comunicações: a análise de conteúdo;

6) Harold Lasswell é um dos fundadores do campo da Comunicação, sendo um de seus primeiros teóricos;

7) O "modelo de Lasswell" está relacionado à pesquisa sobre os efeitos diretos dos meios de comunicação e, como tal, possui falhas; 
8) O "modelo de Lasswell" é a contribuição essencial de Harold Lasswell para o campo da Comunicação.

Em linhas gerais, é assim que as obras de teorias da comunicação apresentam Lasswell, tanto para o neófito, quanto para o pesquisador mais experiente, que busca informações sobre a história do campo da Comunicação. Todos esses pontos delineiam uma conjectura importante para quem os lê: Harold D. Lasswell é um autor seminal para a área da Comunicação. Mais que isso, Lasswell é visto como pesquisador fundador e organizador do campo comunicacional.

Pioneiro, estava junto às primeiras pesquisas hipodérmicas sobre a propaganda; experiente, ajudou a dividir as áreas de pesquisa do novo campo que se formava como "modelo de Lasswell". Ao mesmo tempo, Lasswell introduz uma nova forma de se estudar a comunicação, ao formular o modelo: o funcionalismo.

Como afirma Mauro Wolf,

$\mathrm{O}$ esquema de Lasswell organizou a communication research, que começava a aparecer, em torno de dois dos seus temas centrais e de maior duração - a análise dos efeitos e a análise dos conteúdos - e, ao mesmo tempo, individualizou os outros sectores de desenvolvimento da matéria, sobretudo a control analysis. Se, por um lado, o esquema revela abertamente o período histórico em que nasceu e os interesses cognoscitivos em relação aos quais foi elaborado, surpreende, por outro lado, a sua duração, a sua sobrevivência, por vezes ainda efectiva, como esquema analítico "adequado" a uma pesquisa que se desenvolveu largamente em oposição à teoria hipodérmica de que é devedor (WOLF, 2000, p.27).

Então, o que temos sobre Lasswell nesses recortes é a indicação de um autor de extrema importância (fundador, pioneiro, teórico, iniciador de correntes, organizador do campo). Talvez apenas Paul Lazarsfeld receba tanto louros na história das teorias da comunicação. Por outro lado, a forma como suas contribuições são apresentadas revela, de fato, o descaso com seu trabalho. Isso torna Lasswell, ao mesmo tempo, um ilustre e um desconhecido.

Ao passo em que se reconhece sua importância, conhece-se muito pouco sobre sua obra. Ao que parece, a forma como Lasswell é retratado pelas obras teorográficas reproduz o que o físico francês Nicolas Witkowski conta acerca do biólogo escocês Darcy Wertworth Thompson. De acordo com Witowski, Thompson é

[...] o que convém chamar de um ilustre desconhecido. Ilustre, pois todo cientista, do matemático ao biólogo, conhece seu nome, vendo nele um dos fundadores de uma ciência que não pára de se 
desenvolver à margem e na confluência das outras - a morfogênese, ou ciência das formas, que substituiu a "morfologia" fundada por Goethe. Desconhecido, pois ninguém o leu, os raros curiosos que mergulharam em seu monumental (1.116 págs.) Growth and Form (1917, depois 1942 para a edição definitiva) tendo em sua maioria contentado em olhar as imagens. Mas todos guardam para sempre gravado na memória um pequeno desenho da obra supramencionada e composta de duas vinhetas. Na primeira, figura a silhueta de um Diódon, ou peixe-cofre, superposto numa grade de coordenadas cartesianas. A segunda representa o mesmo peixe, depois que um dos lados da grade foi esticado como um tecido elástico: as verticais foram encurvadas, as horizontais repuxadas para fora e o Diódon inicial tornou-se um peixe-lua (WITKOWSKI, 2004, p.165).

O desenho ao qual Witowski se refere é apenas um entre muitos feitos por Thompson para comprovar sua morfogênese, mas permanece como o traço mais distintivo da obra do escocês.

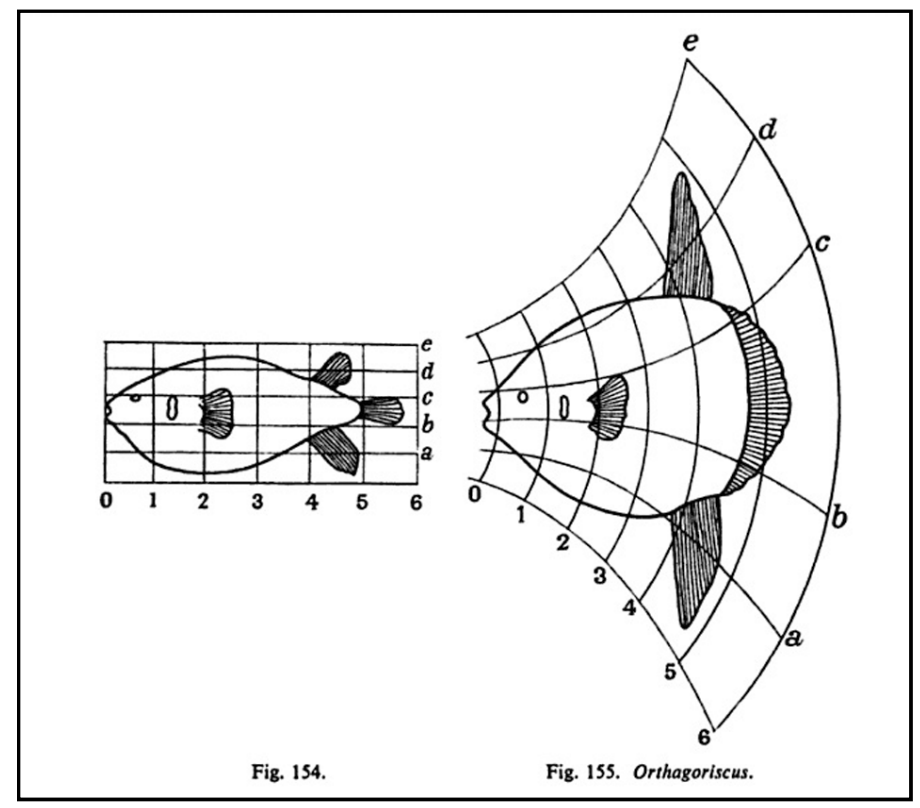

Figura 2. Imagem representativa da Teoria das Transformações, de D’Arcy Thompson. Fonte: Thompson, D’Arcy. On Growth and Form. Cambridge: Cambridge University Press, 2004, p.301.

Em analogia à situação de Thompson, podemos dizer o mesmo de Lasswell. O que temos de forma mais marcada é a representação de seu modelo e uma imagem que se perpetua: a de teórico pioneiro e instaurador da forma majoritária de conduta da pesquisa em comunicação nos Estados Unidos. Contudo, Lasswell é pouquíssimo estudado e o que se fala a seu respeito é predominantemente repetitivo e sem profundidade, como se as obras teorográficas estresissem uma mesma figura e só esta bastasse. Ainda por analogia, o modelo de Lasswell, o tema mais frequentemente 
associado ao autor, ressoa como uma memória pouco clara, como o Diódon e o peixelua de Thompson.

Harold Lasswell, portanto, é reverenciado e ignorado. Ainda que assim seja, o cientista político tem lugar de destaque nas obras de teorias da comunicação, de uma forma que só os clássicos são tratados. Mas, a oscilação entre a reverência e o desprezo não é apenas destinada a ele. Ao fim e ao cabo, esse movimento oscilante nos revela o tratamento destinado a maioria daqueles que são considerados os clássicos da Comunicação. 


\section{SOBRE CLÁSSICOS, TRADIÇÃO, HAROLD LASSWELL E O CAMPO DA COMUNICAÇÃO}

Uma primeira questão se coloca de maneira imperiosa quando efetuamos o regresso a Harold Lasswell: por que retornarmos a ele? A princípio, a resposta a essa interrogação nos convida a refletir sobre a tradição e o lugar dos clássicos nas ciências, para então buscar compreender o papel de Lasswell nos estudos de Comunicação, sua relação com a tradição do campo e a sua possível identificação como um autor clássico nesses estudos.

Falar sobre tradição e clássicos, nos vários sentidos que as diferentes formas de conhecimento nos oferecem, é nos colocarmos, imediatamente, numa frente de batalha entre um passado que se mostra pela fresta de uma porta semicerrada, de dimensões cartapácias, e a contemporaneidade que recolhe, pelas frestas da mesma porta que nos liga ao que já findou, peças antigas para compor o seu próprio quebra-cabeças. Nas ciências, em especial naquelas que chamamos de Sociais, não é diferente. No confronto com o passado, muitas vezes é necessário redefinir não só a importância da tradição e dos clássicos, mas demarcar a extensão e os limites da obra daqueles que devem ser considerados os autores capitais de um determinado campo, bem como reexaminar os paradigmas de uma época, num movimento constante de reconstrução.

Embora presente em certas ocasiões, o retorno à tradição e aos clássicos não é devidamente explorado nas Ciências Sociais. Por vezes, os clássicos adquirem uma centralidade imprescindível; em outros momentos, permanecem em estado periférico, passando ao largo das discussões verdadeiramente importantes. É exemplar do primeiro caso, a Sociologia - não por eventualidade a mais prolífica área das Ciências Sociais quanto à problematização da natureza dos clássicos e da tradição; do segundo, a Comunicação.

Na Sociologia, Durkheim, Marx e Weber são pontos de partida para qualquer exercício que busque compreender a sociedade, e a certeza de que o conhecimento novo não pode existir sem o conhecimento antigo os coloca em posição privilegiada, como fundadores do discurso de uma disciplina. Parafraseando a metáfora religiosa, ninguém vai a Sociologia senão por eles. Na condição de clássico, como observa Shils, sua função "não é ser assimilado, no sentido de ser superado, e datado como nas ciências naturais, mas ser elaborado, adaptado, colocado em um novo idioma, aplicado a uma 
nova situação" (SHILS, 1980, p. 247) ${ }^{44}$. Autores como Durkheim, Marx e Weber, portanto, não estão adormecidos no passado, como pioneiros ingênuos, nem seus discursos se esgotaram em si mesmos e em suas épocas. Antes, na verdade, suas contribuições ao campo da Sociologia são continuamente examinadas, possibilitando não apenas um conhecimento mais profundo de seu objeto, mas da própria Sociologia, independente de qualquer particularidade dos cientistas. Eles formam a tradição, a herança do campo, e como tal são revisitados geração após geração.

Na Comunicação, por outro lado, nos parece que a tendência é diametralmente oposta. Um exemplo é a quadríade, da qual Lasswell faz parte, elencada por Berelson em The State of Communication Research (1959), formada ainda por Paul Lazarsfeld, Carl Hovland e Kurt Lewin, que acabam representando o papel de clássicos na tradição estadunidense de pesquisa ${ }^{45}$. Na verdade, esses mesmos autores encontram-se dispersos, perdidos em discursos que privilegiam não a acumulação, o diálogo com a tradição, ficando relegados a apresentações cronológicas do desenvolvimento do saber comunicacional. Entendida dessa maneira, a tradição não passa de um conhecimento estanque, a ser transferido como uma coleção de alfarrábios ultrapassados, que tiveram valor em sua época. A exceção à regra, talvez, seja Lazarsfeld, cujo prestígio se faz sentir mesmo hoje. Já as referências a Lasswell e Kurt Lewin são costumeiras em obras panorâmicas, mas escassas quando se trata de análises mais profundas. Para se ter uma ideia, num universo de 14 importantes revistas da área ${ }^{46}$, entre os anos de 1958 e 2008 , apenas dois artigos estão voltados para repensar a obra lasswelliana, tendo-a como seu tema central (Harold D. Lasswell's Contribution to Content Analysis, de Morris Janowitz, publicado em 1968; An Extension of "Lasswell's Formula", de Richard Braddock, publicado em 1958). Lewin é ainda menos lembrado: não há, também nesse universo, nenhum artigo que resgate suas contribuições ao campo da Comunicação. Mais que os problemas descritos, sequer sabemos se podemos apontar tais autores como clássicos da Comunicação, o que não ocorre com Durkheim, Marx e Weber, nem

\footnotetext{
${ }^{44}$ No original: "is not to be assimilated, surpassed, and rendered out-of-date as in natural sciences, but to be elaborated, adapted, put into a new idiom, applied to a new situation".

${ }^{45}$ Alguém pode afirmar que os casos de Durkheim, Marx e Weber são completamente distintos da quadríade, afinal, os quatros fundadores de Berelson eram advindos de outras áreas do saber que não a Comunicação. Contudo, será que podemos afirmar que Durkheim, Marx e Weber eram sociólogos conforme aplicamos o termo hoje? A competente avaliação de Peter Baher (2002) nos mostra que, provavelmente, não.

46 Journal of Communication; Public Opinion Quarterly; International Journal of Public Opinion Research; Communication Research; Human Communication Research; Media, Culture and Society; Communication Theory; Canadian Journal of Communication; Communication Education; Communication Monographs; Mass Communication \& Society; Review of Communication; The European Journal of Communication Research; $e$ Critical Studies in Mass Communication.
} 
mesmo com autores posteriormente incluídos no rol da tradição sociológica, como Simmel, que se via, antes de tudo, como um filósofo.

Apontar as diferenças entre Sociologia e Comunicação no tratamento da tradição e dos clássicos, entrementes, não significa, em nenhuma instância, que as duas áreas representem casos isolados. A controvérsia sobre o recurso aos clássicos nas ciências se estende há, pelo menos, alguns séculos. Na obra On Social Structure and Science (1997), Merton observa que Galileu já afirmava que “[...] um homem jamais se tornará um filósofo se preocupando para sempre com os escritos de outro homem" (p. 28) ${ }^{47}$, e o próprio Weber, mais de duzentos anos após a morte de Galileu, sugeria que “[...] cada um de nós sabe que sua produção será considerada antiquada em dez, vinte, cinqüenta anos" (p. 24) ${ }^{48}$. Merton (1997), dessa maneira, questiona, até certa medida, o aforismo newtoniano que prega a importância dos precursores da ciência: "Se eu vi mais longe, foi por estar de pé sobre ombros de gigantes”. Contudo, sensatamente, não o descarta. Merton sintetiza, com Galileu e Weber ${ }^{49}$ de um lado, e Newton do outro, as duas posições antagônicas presentes nas Ciências Sociais: de um lado, aqueles que reconhecem nos clássicos apenas livros velhos, importantes, mas com pouco a dizer sobre a contemporaneidade ou mesmo sobre a formação de uma área do saber. Nesse mesmo lado, as velhas teorias são vistas como resíduos, como superadas, não como construtos que necessitem releituras. No lado oposto, estão os que reiteram a importância e o peso dos clássicos e da tradição no conhecimento científico.

Há razões para que permaneçamos entre os residualistas ${ }^{50}$ ? Ou, por outro lado, há motivos para que desconfiemos da reverência (vazia) aos clássicos que se dá somente por sua antigüidade?

Os motivos para que abandonemos a posição residualista se encontram inscritos na natureza peculiar do conhecimento científico, na qual cada geração deve algo à que a precedeu. A história das ciências, sejam elas quais forem, é uma história de mentes que reconstruíram as ideias de seus predecessores. O estudo de nossos predecessores, nossas tradições, nossos clássicos, não é apenas um exercício de contar a história do campo,

\footnotetext{
${ }^{47}$ No original: "[...] a man will never become a philosopher by worrying forever about the writings of other men".

${ }^{48}$ No original: "[...] each of us knows that what he has accomplished will be antiquated in ten, twenty, fifty years".

${ }^{49}$ Não nos parece, exatamente, que Galileu e Weber estivessem pregando uma rejeição aos clássicos. Apenas, no caso de Galileu, o desenvolvimento de uma autonomia, e no caso de Weber, um ciclo normal no desenvolvimento do conhecimento científico. É curioso notar que Merton apela a dois grandes clássicos para expor sua preocupação ao que ele identifica como uso abusivo da teoria clássica.

50 "Residualista" é usado aqui no sentido de designar a posição daqueles que conferem ao passado do campo o aspecto de mero "resíduo", desconsiderando a continuidade das pesquisas, bem como desprezando os construtos teóricos presentes na formação do campo da comunicação, num processo de valorização apenas do que seria mais "atual".
} 
nem só de atualizá-los a luz da contemporaneidade. Como Charles Camic (1997) afirma,

[...] reclamar nossos clássicos não significa clamar por eles como meras ferramentas que devem servir aos nossos projetos particulares do momento, mas em prover um distanciamento crítico que nos liberta do presente imediato, nos expõe a vozes que fazem mais do que duplicar a nossa própria, e aumenta os horizontes de alternativas teóricas para além dos limites finitos das atuais possibilidades (p. 6) ${ }^{51}$.

Ou, como diz a expressão latina na qual Newton se baseou, creditada a Bernardo de Chartres: nanos, gigantium humeris insidentes, ut possimus plura eis et remotiora videre. Como anões nos ombros de gigantes, nós podemos ver mais do que eles.

Mas, seria Lasswell um clássico para o campo da Comunicação, assim como o é nas Ciências Políticas? Vejamos essa questão.

\subsection{Universo da tradição}

Num mundo no qual tudo o que é sólido se desmancha no ar, o termo tradição se coloca como contrapeso à ebulição das novidades. No entanto, de uma forma geral, tradição não é uma palavra que goze de muito prestígio num orbe que eleva o novo, o super novo, e o mais que super novo às categorias centrais de todas as nossas discussões. Não obstante, na vida social como na ciência, a tradição permanece.

Utilizamos a palavra tradição para muitas coisas. Porém, o seu sentido mais amplo é simplesmente o de traditum (SHILS, 2006). Neste sentido, o termo se refere a qualquer coisa que seja transmitida ou legada como herança do passado ao presente, independente da forma: material ou simbólica, oral ou escrita. Nesse caso, o critério decisivo é que a tradição "foi criada pela ação humana, pelo pensamento e pela imaginação, e foi legada de uma geração para outra" (Idem, ibidem, p. 12) ${ }^{52}$. Dizer que foi criada pela ação humana, inventada, não significa dizer que o foi de maneira proposital, mas sim, que se consolidou como um elemento da cultura. E mesmo que uma ação humana fosse planejada como forma de gerar uma tradição, não haveria garantias de que tal fato se concretizasse.

\footnotetext{
${ }^{51}$ No original: "[...] reclaiming the classics lies not in turning up 'usable bits of lore', that may fit our particular project of the moment, but in providing a larger critical distance wich free us from the immediate present, exposes us to voices that do more than duplicate our own, and enlarge the horizons of theoretical alternatives beyond the finite bounds of current possibilities".

${ }^{52}$ No original: "have been created through human actions, through thought and imagination, it is handed down from one generation to the next".
} 
No sentido de traditum, a tradição é uma necessidade social e se faz sentir de forma evidente, sem muito questionamento. A tradição "é o passado no presente, mas é muito mais parte do presente quanto qualquer inovação recente [...] é algo que foi criado, desenvolvido ou acreditado no passado" (SHILS, 2006, p. 13) $)^{53}$.

A tradição, contudo não é vivida no presente como o era nesse passado. A tradição é continuamente modificada. Embora o seu cerne continue praticamente o mesmo, à tradição são somados diferentes significados e novas práticas podem se constituir em torno delas. Um dos traços mais marcantes no terreno do simbólico, a tradição se reveste de novas possibilidades e é sucessivamente recriada. Não é apenas algo dado, ou puramente irracional, como defendido por alguns teóricos racionalistas, como Edmund Burke (Cf. POPPER, 2002, p.162). A tradição, além de importante repositório do passado, é um ponto de partida para novas crenças e novas ações humanas. Apesar disso, assim como a língua ${ }^{54}$, a tradição só pode ser transformada pelo coletivo, carregando consigo um senso de integração, identidade e filiação dos membros de uma comunidade ou sociedade. A tradição, em sua persistência, gera o sentimento de continuidade e de pertencimento, e armazena, em si, o conhecimento primitivo da vida comunitária.

Mas, por que falar de tradição de forma genérica, se nosso objetivo é falar de tradição na Ciência? Porque, como nos mostra Karl Popper (2002), a Ciência segue uma tradição de segunda ordem, mas cujas características são indiferenciáveis, na maioria das vezes, das tradições sociais comuns, a saber: a ligação com o passado, a própria construção da tradição, a sua contínua recriação, a sua transformação pelo coletivo, a função de integrar e dar identidade a uma comunidade, o sentimento de pertencer e continuar o que já foi feito.

Porém, assim como as Ciências Naturais e as Ciências Sociais aferem de maneira diferente a importância dos seus clássicos, a percepção da Ciência de sua tradição também se constrói a partir de outras instâncias, exatamente o que leva Popper a falar de uma tradição de segunda ordem. Em Tradition (2006), Shils já observa que “[...] o esforço científico destina-se a conseguir algo novo; a crença tradicional está contente com o que se acreditava antes" (p. 104) ${ }^{55}$. Essa diferença repousa, sobretudo,

\footnotetext{
${ }^{53}$ No original: "It is the past in the present but is much part of the present as any very recent inovation [...] It is something which was created, was performed or believed in the past, or which was believed to have existed or to have been performed or believed in the past".

${ }^{54}$ Ela mesma um elemento da tradição.

${ }^{55}$ No original: "[...] Scientific effort is intended to achieve something new; traditional belief is content with what was believed before".
} 
no fato de que a Ciência é igualmente herdeira de uma outra tradição, instituída na Antiguidade Clássica: a do conhecimento crítico.

Há, sinteticamente, duas formas possíveis de se lidar com a tradição: de forma acrítica, muitas vezes sem sequer sabermos que estamos diante de uma tradição, repetindo-a passivamente, sem nos darmos conta do que ela representa. Fazemos isso todos os dias e, em se tratando da vida cotidiana, não há, aí, necessariamente, algum mal. A outra forma possível é a atitude crítica, que pode resultar em rejeição ou aceitação, de uma maneira passiva, da tradição, de uma maneira refletida e criteriosa. É esse o posicionamento que se acredita ser o ideal na Ciência, que deve elaborar o seu discurso, não apenas herdando uma tradição sem questioná-la, mas refletindo e acrescentando a ela novos direcionamentos. É nesse exercício que o novo na Ciência aparece, e não na rejeição ao passado. Como afirma Shils (2006),

O processo de sucessivas substituições não se trata de criar um sistema auto-suficiente que nega o seu antecessor, nem de um corpo de fatos definitivos por um outro corpo de fatos definitivos. É um processo dialético de afirmação e negação, de aceitação e revisão (p. $140)^{56}$.

Embora nos pareça, nesta altura, que, no campo da Comunicação, a primeira forma de se lidar com a tradição predomine, de alguma maneira, as noções de clássico e de tradição permeiam nossos discursos. A primeira delas pouquíssimo aparece na literatura da área de Comunicação, mas se manifesta de uma maneira recorrente quando fazemos a costumeira distinção entre teorias da Comunicação clássicas e teorias contemporâneas, distinção por vezes adotada no discurso cotidiano sobre as Teorias da Comunicação. Não seria errôneo afirmar que internalizamos os primeiros de modo empírico, mas carente de reflexão. Já o termo tradição se encontra mais assentado, inclusive, na literatura da área, e falamos livremente de tradição estadunidense (na qual alocamos Lasswell), Escola de Frankfurt, estudos de recepção, etc. Apesar disso, não se pode discutir a tradição sem passarmos pelos expoentes maiores de um domínio de estudo, justamente aqueles que designamos como sendo os clássicos.

\footnotetext{
${ }^{56}$ No original: "The process of successive replacement is not the replacement of one self-sufficient system which negates its predecessor; nor of one body of definitively reported facts by another body of definitively reported facts. It is a dialectical process of affirmation and denial, of acceptation and revision".
} 


\subsection{Da natureza dos clássicos}

O termo clássico é longevo e, embora seus sentidos hoje sejam aplicados de maneira diversa, todos carregam a marca de sua origem, a velha região da Ática, na Grécia. Foi ali que o gramático latino Aulus Gellius, no século II, o utilizou pela primeira vez, para designar os escritos dos expoentes da primeira das cinco classes romanas, os classici. Gellius recolheu, a partir dessa visão, centenas de histórias, que rechearam 20 livros, sob o nome de Noites Áticas, e decretou: “[...] classicus adsiduusque aliquis scriptor, non proletarius" ou "o clássico é um escritor de distinção, não um proletário" (GELliUS, 19.8.15). A definição restringe os clássicos a representantes de uma classe especial, a mais alta, ideia que permanece hoje num sentido figurado. Além disso, identifica os clássicos com a tradição escrita, o que é válido hoje somente até certo ponto, pois as artes, de uma maneira geral, passaram a ter seus representantes também da "classe mais alta". Essa ideia de um grupo privilegiado de autores chega mais tarde à ciência, conforme veremos adiante. Gellius, contudo, estava falando de literatura.

Segundo Saint-Beauve (2006) ${ }^{57}$, um dos pioneiros na busca da genealogia do termo clássico, a primeira referência oficial à palavra na Academia foi no também primeiro Dicionário da Academia, de 1764, publicado em meio aos avanços da Revolução Científica dos séculos XVII e XVIII, no qual se afirmava ser o detentor do título "um escritor antigo de prestígio, aquele que é uma autoridade no que concerne ao seu tema de trabalho" (p. 4). Embora essa não seja uma definição muito clara, aparecem nela duas características importantes, ausentes em Aullus Gellius: a inscrição dos clássicos no passado e a influição pela autoridade. Mesmo assim, os ecos de Gellius ainda se fazem ouvir. Não há muita distinção entre um autor literário e um autor científico. O lugar do passado na Ciência ainda não estava bem assentado.

Prima facie, a discussão sobre as relações entre o conhecimento científico novo e o conhecimento científico antigo só ganha força, realmente, ao final da época de ouro da Ciência, no século XIX, em que o questionamento da natureza de cada ciência e, por conseguinte, de seus textos estruturantes, começa a fazer parte dos debates epistemológicos, com, é claro, diferenças de campo a campo.

\footnotetext{
${ }^{57}$ Crítico literário, e ele próprio um escritor, Saint-Beauve para por aí no que diz respeito aos usos da palavra clássico na Ciência.
} 
Nas Ciências Naturais, que presenciaram mais de perto a luta do Iluminismo contra as "trevas da ignorância", e nas quais o peso das descobertas se coloca insistentemente, houve um movimento até meados do século XVIII no qual "a ciência parecia ser hostil à tradição; a tradição foi entendida como prejudicial à ciência" (SHILS, 2006 , p. 102$)^{58}$, numa rejeição ao conhecimento forjado no passado ${ }^{59}$, que estaria envolto em ignorância. Evidentemente, não se tratava de rejeitar o passado da própria ciência, pois o emprego do termo tradição ainda não se encontrava associado ao fazer científico. Ao desenvolver o "sentimento" de hostilidade descrito por Shills, a ciência se voltava contra a tradição comum que vicejava na vida social mais cotidiana, marcada pelo obscurantismo e ignorância (como a Idade da Razão acreditava ser a cultura forjada na Idade das Trevas). Não se tratava de negar a tradição científica, pois não se chegava a cogitar sua existência. Não se tardou a perceber que tal postura gerava, ela sim, trevas sobre o próprio conhecimento científico e Newton, talvez, tenha sido um dos primeiros a percebê-lo. A ciência, tendo erigido seu passado, também edificou sua tradição. Todavia, a relação estabelecida hoje entre o passado e o contemporâneo nas Ciências Naturais ocupa um lugar um pouco diferente daquele das Ciências Sociais. Para as Ciências Naturais, a continuidade já está internalizada em sua constituição. As Ciências Naturais possuem aquilo que Kuhn qualifica de trabalhos "exemplares": "exemplos concretos de trabalhos bem-sucedidos" (ALEXANDER, 1993, p. 19) ${ }^{60}$. Inequivocamente, os "exemplares" de Kuhn correspondem aos "clássicos". Porém, o processo de acumulação nas Ciências Naturais faz com que o retorno a eles não seja tão necessário, pois os "exemplares” restam implícitos nas teorias contemporâneas.

Nas Ciências Sociais, cuja história é mais recente e cujas tradições vão ser construídas, de fato, durante o século $\mathrm{XX}$, a direção tomada é diferente: ora tenta se equiparar às Ciências Naturais, ignorando suas características distintas; ora reconhece o retorno aos clássicos como um elemento importante e decisivo na formação de seus discursos.

Avaliemos a primeira direção, aquela que tenta equiparar-se às Ciências Naturais. O que se pode entender por isso? Nessa visão, defendida em grande parte por Merton em On the Shoulders of Giants, as Ciências Sociais devem evitar o retorno constante ao passado e empenhar-se em tornar a acumulação tão intensa que a tradição

\footnotetext{
${ }^{58}$ No original: “(...) Science seemed to be inimical to tradition; tradition was held to be inimical to science".

${ }^{59}$ A célebre frase de Newton, escrita por ele numa carta a Robert Hooke em 1676, utiliza o aforismo para defender o conhecimento passado e se posiciona, justamente, contra a hostilidade.

${ }^{60}$ No original: "[...] concrete example of succesfull work".
} 
permaneça implícita e não mais sirva como objeto de questionamento, como nos "exemplares" de Kuhn. Para Merton, o estudo dos clássicos deve ser relegado aos historiadores do campo. Deste modo, abre-se duas perspectivas para o desenvolvimento da ciência: a longo prazo, as Ciências Sociais não precisariam dar muita atenção aos clássicos e, a curto prazo, deveriam ter cautela em sua utilização. Contudo, tal assertiva não reconhece as diferenças entre as Ciências Naturais e as Ciências Sociais.

Já dissemos que a acumulação nas Ciências Naturais se organizou de forma distinta que nas Ciências Sociais. Segundo Jeffrey Alexander (1993), isso se dá, prioritariamente, pela maior atenção dada pelas Ciências Naturais à dimensão empírica, e não simbólica, de seus dados. As dimensões não-empíricas estão camufladas. Nas Ciências Sociais, pelo contrário, é a dimensão simbólica dos dados empíricos o que realmente conta.

O privilégio dado à dimensão empírica faz com que o background no qual os neófitos das Ciências Naturais são inseridos, apareça muito mais como modelos e técnicas confiáveis para explicar o mundo. Como tais, seus clássicos são assimilados exatamente da forma como Kuhn sugeriu. Mais que isso, a dimensão empírica resulta em um número muito menor de discordâncias entre os pares que nas Ciências Sociais, onde a contenda sobre qualquer assunto é endêmica. Pautadas sobretudo no discurso, as Ciências Sociais "enfocam os processos de raciocínio, mais do que os resultados da experiência imediata" (ALEXANDER, 1993, p. 22) ${ }^{61}$. Dessa maneira, o que resta implícito nas Ciências Naturais se coloca no centro do palco das Ciências Sociais.

Nelas, com a dimensão simbólica tendo primazia, de outro modo, o background ao qual os neófitos devem ser apresentados surge como um grande mural, com algumas partes descascadas, que devem ser completadas pelos novatos. Como completá-lo sem ter, sequer, a noção do que estava no original? Não se pode, simplesmente, pintar um muro novo, pois se corre o risco de já não se estar mais falando da mesma coisa, ou de, inadvertidamente, reinventar a roda.

No cenário das Ciências Sociais, o retorno aos clássicos nos parece mais adequado. São os clássicos, então, que nos dão um sentido de integração e continuidade em meio à avalanche de conhecimento e de discursos produzidos na contemporaneidade. O clássico reduz a complexidade. O que é, então, um clássico para as Ciências Sociais?

\footnotetext{
${ }^{61}$ No original: "focuses the processes of reasoning rather than the results of immediate experience".
} 
Clássicos são trabalhos pioneiros da exploração humana a quem é dado um estatuto privilegiado em relação às explorações contemporâneas num mesmo campo. $\mathrm{O}$ conceito de estatuto privilegiado significa que profissionais contemporâneos da disciplina em questão acreditam que podem aprender tanto sobre como o seu domínio através da compreensão deste trabalho pioneiro como podem a partir dos seus próprios contemporâneos [...] como clássico, tal trabalho estabelece os critérios fundamentais de um campo particular (Idem, p. 11-12) ${ }^{62}$.

Nesse sentido, o termo clássico privilegia o conhecimento que se encontra na origem de um campo. Como conseqüência, há muitas vezes, coincidência entre clássicos e fundadores (como no caso de Durkheim, Marx e Weber). Entretanto, não necessariamente um autor que se encontra na origem de um campo será considerado um clássico. Para tanto, um determinado autor deverá ter instituído um paradigma, no sentido kuhniano: modelo universalmente reconhecido para uma prática científica. $\mathrm{O}$ clássico é assim uma referência, um ponto de passagem do qual não se pode (ou não se deve) desviar. Ainda de acordo com a definição de Alexander, os clássicos ocupam o lugar de mestres, e toda a definição dos critérios particulares e inerentes a um campo passa por eles.

Os clássicos, portanto, os grandes mestres do passado, representam a porta de entrada na tradição (ou tradições) de um campo, peças importantes para compor o quebra-cabeças contemporâneo de um determinado saber.

Tais colocações definiriam, então, Lasswell como um clássico para o campo da Comunicação?

\subsection{Harold Lasswell como clássico}

A falta de ponderação epistemológica sobre o que representam os clássicos e o valor da tradição para o estabelecimento do Saber Comunicacional (e mesmo na Ciência em geral), grosso modo, faz com que partamos de uma atitude pouco científica em relação aos clássicos (ainda que se possa conjeturar os autores dignos de tal título); e, no caso da tradição, apenas a levamos a sério como verbete de enciclopédia. Tudo isso, faz com que fiquemos perdidos, presos às questões mais recentes, ignorando a história de nosso próprio campo.

\footnotetext{
${ }^{62}$ No original: "Classics are earlier works of human exploration which are given a privileged status vis-à-vis contemporary explorations in the same field. The concept of privileged status means that contemporary practitioners of the discipline in question believe that they can learn as much about their field through understanding this earlier work as they can from the work of their own contemporaries [...] as a classic, such work establishes fundamental criteria of a particular field".
} 
O que dizer, portanto, sobre Lasswell? Poderíamos considerá-lo como um autor clássico no campo da Comunicação? Antes de entrar no mérito, retomemos alguns equívocos freqüentes:

1) O clássico é, invariavelmente, um autor fundador de um campo;

2) O clássico só é clássico por sua antiguidade;

3) O clássico é um autor muito citado;

4) O clássico deve ser explicitamente nomeado desta forma pelos seus pares, sendo reconhecido como um autor pertinente ao campo.

O primeiro equívoco delimita o clássico por seu papel na fundação de um campo. Com certeza, essa é uma afirmativa correta na maioria das vezes. Contudo, não consegue dar conta de todos os meandros conceituais que tal título confere a um autor considerado capital a um determinado campo. Não se trata apenas de fundar um campo, mas de instaurar padrões, paradigmas que acabam por representar o alicerce sobre os quais outras pesquisas se fundamentam e se desenvolvem. Trata-se, portanto, do papel determinante na consolidação de uma frente teórica, tanto em seu princípio quanto em seu desenvolvimento.

A ideia de que Lasswell representou esse papel na Comunicação surge primeiro em Berelson (1959), no artigo "The State of Communication Research" (“O Estado da Pesquisa em Comunicação"), publicado na revista Public Opinon Quartely, quando o autor elenca aqueles que, para ele, foram os responsáveis pela divisão da fase inicial da pesquisa em comunicação em quatro grandes frentes, conforme descrito na introdução deste trabalho. Essa ideia vai ser reafirmada pouco tempo depois por Wilbur Schramm, em 1963, na obra Human Communication Research (Pesquisa em Comunicação Humana). De lá para cá, o chamado "mito dos quatro fundadores" tem sido presença constante em grande parte dos livros que traçam a evolução do pensamento comunicacional, mesmo quando se trata de redimensionar sua importância, sob a alegação de exagero por parte de Schramm, como o fazem Everett M. Rogers e Steven H. Chaffee (1995). Ainda assim, a importância de Lasswell, na abertura dessas frentes, é constantemente reverenciada (ARAÚJO, 2001; BUXTON, 1996; DENNIS e WARTELla, 1996; Chafee e Hocheimer, 1985; Hardt, 2002; Melo, 2003; PoOlley, 2007; Wolf, 1985; MATtellart, 1999; SeVErin e TANKARd, 1997; HeAth e BRYANT, 2000; etc). Essa importância muitas vezes é creditada ao pioneirismo na pesquisa em Comunicação, como sintetiza Araújo ao observar que a obra de Lasswell, Propaganda Techniques in 
the World War, publicada em 1927, "costuma ser identificada como o marco inicial da Mass Communication Research" (2001, p. 120) ${ }^{63}$. Mas, para além dessa importância pioneira, nosso autor também é lembrado pela contribuição decisiva na organização da pesquisa em Comunicação ao elaborar a célebre questão-programa "Quem? Diz o quê? Por qual canal? Com que efeito? Para quem?", herdeira de uma tradição aristotélica e também conhecida como Esquema de Lasswell. Ela é apontada como o cerne da obra comunicacional do cientista político e a mais impactante de suas propostas sobre a comunicação.

O esquema aparece pela primeira vez em 1935, publicado em um trabalho coletivo com Bruce Smith e Ralph Casey, intitulado Propaganda and Promotional Activities: an Annotated Bibliography. A tradição de pesquisa em Comunicação norteamericana se institui em torno do Esquema de Lasswell, que segmentou as áreas de interesse dos pesquisadores de acordo com cada uma de suas perguntas: 1) Quem: estudo dos emissores; 2) Diz o quê: estudo das mensagens; 3) Por qual canal: estudo dos meios; 4) Com que efeito: estudo dos efeitos como um todo; 5) Para quem: estudo dos receptores.

Lasswell, desse modo, é identificado com esses dois momentos, o da origem e o da organização da pesquisa em Comunicação, o que, já de saída, o dimensiona como um importante clássico da área.

Continuemos a observação dos demais itens de nossa listagem.

O segundo equívoco é correlato ao primeiro, ou seja, nos leva a identificar um autor como clássico somente por este se encontrar numa época distante da nossa, num passado longínquo. Se assim fosse, nomes como Leonard William Doob e o Sidney Rogerson, cujas obras sobre propaganda circulam nas mesmas sendas que Lasswell e obtiveram uma determinada repercussão em sua época, ainda seriam lembrados como autores fundamentais aos estudos em Comunicação.

Por outro lado, como terceiro equívoco, dizer que o clássico é "um autor muito citado" esvazia o sentido conceitual do termo e o "coisifica": porque há muitas citações, logo é um clássico. Tal concepção nos coloca o problema de utilizar os dados quantitativos já e por si só como reveladores do qualitativo, nos direcionando a uma análise superficial e numérica, nos afastando de pensar as qualidades próprias de um clássico.

\footnotetext{
${ }^{63}$ ARAÚJO, C. A. "A pesquisa norte-americana”. In: Teorias da Comunicação: conceitos, escolas e tendências. HOHLFELDT, MARTINO e FRANÇA (orgs.). Petrópolis, Rio de Janeiro: Editora Vozes, 2001.
} 
O quarto e último equívoco nos coloca no âmbito da reflexão sobre a pertinência de Lasswell, de fato, ao campo da Comunicação, e a relevância que o cientista político assume para os estudos dessa área. Logo de saída, o problema que se coloca é: como cientista político, os estudos de Lasswell privilegiam, obviamente, a centralidade dos fenômenos políticos. Essa, com certeza, é uma inferência justa. Entretanto, não há como se negar que a obra de Lasswell assumiu um caráter de peso nos estudos em Comunicação, não podendo ser ignorada ou diminuída em função da sua ligação original com a Ciência Política. Outro apontamento importante nesse sentido é que, apesar da ausência do termo "clássico", na literatura de Comunicação (uma boa exceção é a obra organizada por Elihu Katz, Canonic texts in media research: are there any? Should there be? How about these?, de 2003), Lasswell é freqüentemente reverenciado na área como tal, embora não se aplique o termo - o que vimos claramente no primeiro item apresentado aqui, tendo sua influência na área sentida desde a origem no século passado até hoje, como nos mostra Martino ao afirmar que o modelo de Lasswell

[...] desenvolveu sobretudo pesquisas no pólo do emissor (quem) e da mensagem ( o que), pois a adoção do modelo positivista de ciência se mostra bem aquém da tarefa do estudo dos meios de comunicação. Precisemos, também, que as críticas que lhe foram dirigidas tiveram um curioso resultado, pois, sem poder superá-lo, elas não tiveram outra conseqüência salvo uma progressiva sobriedade no julgamento de seu alcance e, portanto, não puderam senão aperfeiçoar este paradigma. Ainda que outros modelos de ciência tenham sido adotados, eles não teriam sabido evitar uma desintegração da temática dos mass media em inumeráveis problemáticas isoladas e dispersas em diversas disciplinas científicas (2000, p. 2).

Certa feita, ao ser perguntado por um aluno qual o melhor caminho a ser seguido nos estudos, Durkheim respondeu: "Se quiser amadurecer o pensamento, dedique-se ao estudo escrupuloso de um grande mestre, desmonte um sistema em suas engrenagens mais secretas. Foi o que fiz e meu educador foi Renouvier" (CoHN, 2005, p. 56).

A resposta de Durkheim colocou rapidamente o aluno no âmbito daquilo que ele, provavelmente, considerava essencial no conhecimento cientifico: os clássicos ("um grande mestre") e a tradição (“desmonte um sistema em suas engrenagens mais secretas"). Como nos inserirmos num campo do conhecimento sem distinguir seus clássicos e suas tradições? E como falar em clássicos e tradições desconhecendo sua natureza? Esses são dois problemas a serem superados pela aproximação, mais do que necessária, numa primeira etapa, da essência dos dois termos na Ciência. Os clássicos abrem as portas da tradição e nos convidam a explorar o campo ao qual estamos filiados 
de uma maneira mais profunda e providenciam as bases para a eventual inovação, evitando o bem descrito quadro segundo o qual

[...] Como as novas teorias continuam a se diversificar, se espalhando e amadurecendo, o risco é que as velhas teorias se reduzam a slogans, canalizadas em "escolas", ou entrincheiradas em "paradigmas", inibindo, assim, a aventura da inovação conceitual, que deve ser inspirada pelo retorno aos clássicos, a reflexão sobre os fundadores, e desfamiliarização dos cânones ${ }^{64}$ (BAHER, 2006, p. 11).

Os clássicos não "repousam” no passado. É de sua natureza permanecer no presente. Como nos diz Ítalo Calvino, numa citação que vale tanto para a literatura como para a ciência, "é clássico tudo aquilo que persiste como rumor, mesmo onde predomina a atualidade mais incompatível” (2007, p. 15). Contudo, é naquilo que já transcorreu que suas raízes se assentam - e seria impossível compreender um clássico apenas a partir da atualidade. Assim sendo, vamos ao passado, ao universo da tradição: às origens do campo da comunicação nos Estados Unidos, cenário da obra lasswelliana.

\footnotetext{
${ }^{64}$ No original: "[...] As new theories continue to diversify, spread and mature, the risk is that the older ones will be striped-mined into slogans, channeled into 'schools' or entrenched into 'paradigms', thereby inhibiting the adventure of conceptual innovation that may be inspired by returning to the classics, rethinking the founders, and defamiliarization the "canon"”.
} 


\section{CENÁRIOS HISTÓRICOS}

As tradições se constituem no passado, e o vasto tecido da história, antes de ser ignorado por qualquer observação epistemológica em torno de um campo de conhecimento ou de um autor, deve ser um guia contumaz nas investigações que refletem sobre as balizas que conduziram à fundação e à fundamentação de um novo saber.

Neste capítulo, procuraremos reconhecer não só o tecido histórico que compôs os cenários de fundo ao desenvolvimento da pesquisa em Comunicação nos Estados Unidos e ao aparecimento da obra lasswelliana, mas também entrelaçar esses cenários às bases epistemológicas que permearam as primeiras pesquisas científicas em torno do fenômeno da comunicação, num esforço para interpretar os elementos sobre os quais a tradição da Mass Communication Research foi forjada. Não nos interessa efetuar um panorama exaustivo e extenso sobre a história das pesquisas em Comunicação como um todo, abarcando desde suas origens até seus dias presentes. Não se trata também de expor uma cronologia, nem mesmo um compêndio que esgote as diversas correntes que compuseram os estandartes da pesquisa em comunicação ao longo da história. Para nosso intuito, menos é mais. Aqui nós buscamos compreender um recorte temporal relativamente enxuto, cujo início está situado na discussão sobre a imprensa que desponta ao final do século XIX e se estende até a década de 1920 (quando se dá a defesa de Técnica de Propaganda na Guerra Mundial, de Lasswell). Neste recorte, delineado para compreendermos os antecedentes da Mass Communication Research e seus primeiros movimentos, nos instiga não a sucessão de dados e datas, mas de que maneira o pensamento comunicacional de Harold Lasswell foi fermentado, em concordância com Alexander Koyré, quando este afirma que a história do pensamento científico

[...] visa a dominar a trajetória desse pensamento no próprio movimento de sua atividade criadora. Para esse efeito, é essencial recolocar os trabalhos estudados em seu meio intelectual e espiritual, interpretá-los em função dos hábitos mentais, das preferências e das aversões de seus autores [...] É igualmente essencial integrar, na história de um pensamento científico, a maneira como ele se compreendia a si mesmo e como se situava em relação ao que o precedia e o acompanhava (1982, p. 13).

Antes de nos lançarmos nesse desafio, é necessário nos questionarmos de que maneira a história de uma ciência serve à epistemologia dessa mesma ciência. 
Retomemos uma frase que aparece anteriormente em nosso texto, expressa por Robert K. Merton. Para o sociólogo americano, o estudo do passado de um campo científico e de seus clássicos deve ser relegado àqueles que chamamos historiadores da ciência. A afirmativa de Merton se assenta na percepção de que uma vez que esses profissionais tenham escrito a história de suas áreas respectivas, o foco de cada cientista deveria estar voltado ao futuro, ou pelo menos ao presente de seu campo de atuação. Procuraremos conclamar uma atitude diversa da de Merton, que nos parece ainda muito próxima da ideia de que a história (o passado, objeto de estudo da História) seria uma realidade objetiva, constituindo um objeto inalterável, sendo tarefa do historiador fazer a descrição mais "realista" dos acontecimentos decorridos em tempos anteriores ao dele. O passado restaria intacto nas obras de história da ciência, um arquivo imutável. Esse posicionamento é, no mínimo, intrigante, pois coloca a história como um relato acabado, impassível de mudanças, restando ao historiador apenas coletá-la e depois agrupá-la, sob a forma de um conjunto de informações.

Parece-nos, ainda, que Merton se alinha a uma objetividade epistemológica no trato da história segundo a qual, utilizando as palavras de Helge Kragh, “[...] o sujeito (o historiador) pode distanciar-se dos objetos (os acontecimentos históricos), que podem ser contemplados de maneira imparcial, que podem ser vistos 'desde fora'",65 (2007, p. $62)$.

Ora, essa perspectiva se contrapõe à noção que se tem hoje da história (tanto o objeto de estudo quanto a área de conhecimento), após o questionamento promovido pela própria História (o campo de saber), ao longo do século XX, sobre a sua natureza. O passado é cada vez mais compreendido como um construto, no qual os fatos que nele ocorreram não se confundem imediatamente com fatos históricos, mas no qual estes se apresentam como

[...] produto de uma valorização e de uma interpretação, correspondentes aos interesses do historiador. Não há nenhum critério que possa ser admitido de uma maneira geral para determinar quando um determinado acontecimento tem caráter histórico e pode, portanto, passar a compor o arsenal dos acontecimentos históricos ${ }^{66}$ (KRAGH, 2007, p. 63).

\footnotetext{
${ }^{65}$ No original: “[...] el sujeto (el historiador) puede distanciarse del objeto (los sucesos históricos) que pueden ser contemplados de manera imparcial, que pueden ser vistos "desde fora"”. Tradução sugerida pela autora.

${ }^{66}$ No original: “[...] producto de una valoración y una interpretación, corresponden a los intereses del historiador. No hay ningún criterio que haya sido admitido de forma general para determinar cúando um determinado acontecimiento tiene carácter de histórico y puede, por lo tanto, entrar a formar parte del arsenal de los hechos históricos". Tradução sugerida pela autora.
} 
Assim sendo, os acontecimentos históricos não se encontram no passado enquanto tais e sim surgem como produto de uma valorização sempre elaborada a partir da ótica presente e de um recorte que se ergue com uma intenção inerente ao pesquisador, seja ela qual for, e que por isso mesmo resulta numa reconstrução nunca total, de natureza lacunar intransponível. Ao historiador cabe retirar de modo artificial um certo acontecimento do leito gigantesco do tempo, e dar-lhe um sentido histórico.

A história se nos apresenta, então, como elemento essencial para a compreensão, não de um cenário estático, mas como elemento que se transforma à medida ainda de que nosso olhar se constrói no encaixe entre o presente e o passado, longe de pensar o passado como algo bastante óbvio e simples, longe de pensar o passado como algo dado.

Essas afirmações não significam a fácil conclusão de que tudo em história é subjetivo. Se assim o fosse, sucumbiríamos a uma lógica relativista da história ou mesmo céptica, o que implicaria em aceitar que toda e qualquer coisa é um fato histórico, no primeiro caso, ou que é impossível se ter algum conhecimento histórico, no segundo. Pelo contrário, o historiador não se move pelo desejo de "inventar" uma narrativa, mas pelo impulso de vislumbrar possibilidades de uma realidade da qual ele tem acesso apenas pelo que restou, pelas diversas fontes históricas. $\mathrm{Ou}$, como afirma o historiador francês Paul Veyne, “[...] um livro de história não é [...] o que aparenta ser; assim, ele não trata do Império Romano, mas daquilo que ainda podemos saber sobre esse império" (2008, p.26). Certamente, o processo de inferir uma série de significados não evidentes apresentará variações de historiador a historiador, mas os fatos históricos não são meras construções fortuitas desses profissionais.

O esforço subjetivo, efetuado por todo aquele que se debruça sobre o passado, é a busca de dados que permitam uma avaliação que também apresente unidade e objetividade, não podendo ser estas ultrapassadas por mera vontade individual. A história não se baseia em ilusões ou fantasias. Ainda que estas não estejam ausentes de sua trajetória, não se trata de um ato "criacionista", mas uma tentativa de reconhecer fios invisíveis que unem o que já passou. Nesse sentido, a história é uma trama, cujo ponto final se costura com a intenção humana de, ao conhecer seu passado, decifrar o presente e constituir identidades, embora nunca seja possível "saber de uma vez por todas" (JENKINS, 2007, p. 31) o que aconteceu de verdade no tempo já transcorrido. 
A reconstrução do passado de uma ciência não é diferente, e deve ser entendida como um dos importantes passos para o conhecimento sobre os fundamentos de um campo de saber.

De fato,

[...] a história da ciência se confunde com uma das vias e métodos do pensamento epistemológico, que busca na historicidade do conhecimento científico um parâmetro da variabilidade possível para a abordagem e tratamento de certas questões apresentadas ao pensamento científico (MARTINO, 2003, p.76).

Seguindo essa vocação, a história da ciência serve à epistemologia não como uma forma de legitimar a existência de um campo e de seus temas, como já o foi no passado $^{67}$, mas fundamentalmente de reconhecer a singularidade histórica dos objetos de estudo específicos em torno dos quais gravitam as diferentes ciências, bem como de suas teorias e tradições, inserindo-as no diálogo com o próprio pensamento científico. E, como sabemos, em ciência, objetos, tradições e teorias são construtos, e é dessa forma que devem ser analisados, não como dados empíricos que foram armazenados numa caixa.

Negligenciar a reflexão contínua sobre a história de um campo, tomando-se por base a ideia de que esta já está definitivamente contada, nos leva a assumir uma postura na qual no passado repousam as verdades insubstituíveis, e nos coloca essas verdades como evidências empíricas indiscutíveis - ou seja, acaba por minar, paradoxalmente, um dos acessos ao conhecimento epistemológico, esvaziando até certa medida a discussão sobre a fundação e a fundamentação de um saber.

Por outro lado, é vital perceber que a história, sem a reflexão epistemológica, pouco tem a acrescentar, o que torna história e epistemologia uma dupla, cujas abordagens, ao invés de concorrerem, cooperam e fecundam uma à outra.

Assim, fazer a história do campo da Comunicação nos obriga imediatamente a um "engajamento ontológico" (MARTINO, 2004, p.8), a uma demarcação das origens do pensamento comunicacional, estabelecida a partir de um entendimento sobre este último, que delimite suas fronteiras históricas desde um posicionamento no qual o alicerce epistemológico se faça presente, no qual "fazer uma história da comunicação, marcar a origem do campo, é de certa forma, já saber o que é comunicação" (Idem, ibidem, p.14). Construir esse alicerce nos leva ao século XIX.

\footnotetext{
${ }^{67}$ A história da ciência foi, durante muitos anos, empreendida como um importante elemento de validação para a existência de um determinado saber e sua continuidade pelo simples peso histórico (Cf. KRAGH, 2007).
} 


\subsection{Demarcando os primeiros dias}

Como demarcar nosso recuo em relação aos antecedentes da Mass Communication Research? Até onde retroceder? Até as críticas perpetradas por Sêneca ao conteúdo das Actas Diurnas, na Roma antiga (SousA, 2008)? Até Aristóteles - cujas observações sobre a retórica ${ }^{68}$ foram resgatadas no modelo de Lasswell? Essas perguntas deságuam na ideia expressa por Bineham, ao indagar "o que são 'os primeiros dias’ dos estudos de comunicação" (1988, p. 233).

Sabe-se que a história do pensamento comunicacional está longe de ser uniforme e mesmo a percepção que se tem sobre o campo, suas origens, seu objeto de estudo e suas teorias está longe de ser um consenso. Há uma multiplicidade de versões sobre o nascimento do campo da Comunicação, que ora é situado na antiguidade clássica, ora quando do nascimento das sociedades modernas, ora a partir da década de 1940 ou 1950 etc, com dimensões oscilantes. Muitos autores trabalham com um panorama que se inicia no século III a. C. para demarcar o início da pesquisa em Comunicação ${ }^{69}$, agregando muitas acepções para o termo homônimo, como José Marques de Melo (1998), por exemplo.

Outros autores assumem rapidamente uma posição “interdisciplinar", compreendendo a comunicação pelo viés empírico e tomando-a como uma espécie de saber que atravessaria todas as disciplinas (numa clara confusão entre objeto empírico e objeto de estudo, bem como entre o objeto e o campo), como é o caso de Bernard Miège, para quem o saber comunicacional “[...] supera, quase sempre, as camadas disciplinares existentes ou a flora de especialistas que se sentem confinados em suas disciplinas de origem” (2000, p.21). Ou o caso de Bougnoux, que acredita ser “[...] preciso [...] que nossa comunicação permaneça essa coisa turbulenta e vaga, da qual não há nem ciência nem técnica, mas que está acima e enquadra a maior parte delas" (1998, p. 18). Estas perspectivas, em geral, inserem uma dificuldade enorme a quem se propõe a escrever um retrospecto da história dos estudos de comunicação, pois ao fazerem estes transbordarem toda e qualquer fronteira, também fazem desse saber uma espécie de campo perene, que sempre existiu, que se encontra em todos os lugares e em todas as áreas.

\footnotetext{
${ }^{68}$ Particularmente, a descrição do ato de comunicação: a pessoa que fala $\rightarrow$ o discurso que faz $\rightarrow$ a pessoa que ouve.

${ }^{69}$ Para José Marques de Melo, os estudos de comunicação se iniciam com os sofistas e compreendem, nesse momento inicial, o trabalho de Platão, Aristóteles e seus discípulos.
} 
A multiplicidade de versões, contudo, não representa um problema em si. Vimos que a história não se apresenta como um conjunto de dados acabados, prontos a serem coletados e estocados, correspondendo a uma verdade inabalável. Nenhum relato é capaz de dar conta por completo do passado, que está ausente para sempre, “já aconteceu [...], já passou" (JENKINS, 2001, p. 23).

A variedade de versões sobre o surgimento do campo não seria um problema se não fosse reflexo também de algo mais profundo: a carência de reflexão critica sobre os limites da área, a naturalização de conceitos-chave (o de meios de comunicação, por exemplo), a aceitação de ideias gerais como provas empíricas, etc. Grande parte do material historiográfico do campo se articula a partir de uma série de dados considerados a priori, ajuntados sem a devida meditação, como no caso de Miège (2000) ou Wolton (1997), que

[...] aceitam sem discussão crítica a ideia da diversidade do campo, uma ideia que entretanto deveria estar no centro das análises sobre a identidade do campo; uma ideia que deveria ser discutida e não simplesmente apresentada como evidência empírica ou "dogma teórico". Instaura-se, desde logo, em suas linhas de raciocínio, um circulo vicioso no qual a diversidade do campo orienta o trabalho de produção dessa história, que por sua vez serve de parâmetro para traçar a definição do campo. Desse modo a história parece confirmar a diversidade do campo e esta parece nos dar a identidade da qual se conta a história (MARTINO, 2004, p.3).

Isso faz com que o debate sobre os limites históricos do campo acabe se ausentando das contendas epistemológicas - quando deveria ser um de seus pontos fundamentais -, pois o passado parece estar morto, escrito para sempre nessas linhas gerais. Ocorre que essa ausência leva-nos, muitas vezes, a entender o passado do campo como uma coleção de datas e um elenco de teorias "superadas", sem a promoção do diálogo com esse passado, que vira simplesmente um estoque de teorias, com uma sendo substituída pela outra, ocupando lugares mais altos ou mais baixos nas prateleiras desse estoque ${ }^{70}$.

Mas, afinal, como traçarmos fronteiras históricas para o campo da Comunicação, como demarcarmos suas origens? Neste caso, é imperativa a discussão sobre o saber comunicacional, no sentido de adentrarmos numa compreensão do que poderíamos

\footnotetext{
${ }^{70}$ Mesmo quando foge a esse traçado, a produção historiográfica do campo comunicacional tem sido freqüentemente esparsa, apesar de um relativo crescimento a partir do final da década de 1980, especialmente nos Estados Unidos, cujos frutos mais rigorosos só passam a vigorar a partir do final da década seguinte.
} 
chamar de campo da Comunicação, partindo de um aporte que coteje a singularidade de seu objeto de estudo, assumindo uma perspectiva que

[...] ao invés de admitir a comunicação como [...] um invariante histórico, que atravessa os séculos inalterável, sempre igual a si mesma [...] desnaturaliza a comunicação e se interessa pela variedade de formas que ela assume a partir das múltiplas compreensões as quais se encontram submetidos os sujeitos e as organizações sociais ao longo da história (MARTINO, 2001, p.13).

Uma comparação rápida entre os trabalhos de Lasswell e Aristóteles nos oferece de saída um início para esse entendimento. Embora a influência da filosofia grega na Mass Communication Research seja inegável, é patente que Aristóteles e Lasswell não estavam falando da mesma coisa e que suas épocas históricas os distanciam de um discurso uniforme. Aristóteles, ao se ocupar da retórica, estava voltado para uma construção filosófica. Lasswell se ocupava do processo de comunicação de massa, que se intensificou de maneira poderosa a partir da Revolução Industrial, e seus esforços estavam direcionados à produção de conhecimento cientifico na área de Ciência Política. É nesse ponto da história, portanto, que nos inscrevemos, visto que buscamos nos aproximar do conhecimento cientifico sobre a Comunicação, e não da Filosofia.

Nessa direção, a obra de Lasswell e o que chamamos campo da Comunicação se inscrevem no panorama das ciências, cujo grande fortalecimento se dá no século XIX, o século de ouro do conhecimento científico, e cuja filosofia já se encontrava presente nos primeiros cientistas modernos, como Galileu Galileu e Isaac Newton, já citados neste trabalho - e que Bertolt Brecht, na peça A vida de Galileu, alegorizou da seguinte maneira:

GALILEU - [...] Porque o tempo antigo acabou, e agora é um tempo novo. [...] As cidades são estreitas e as cabeças também. Superstição e peste. Mas agora, veja o que se diz: se as coisas são assim, assim não vão ficar. Tudo se move, meu amigo. [...] Logo a humanidade terá uma ideia clara de sua casa, do corpo celeste que habita. O que está nos livros antigos não lhe basta mais.

Pois onde a fé teve mil anos de assento, sentou-se agora a dúvida. Todo mundo diz: é, está nos livros -, mas agora nós queremos ver com nossos olhos.

As verdades mais consagradas são tratadas sem cerimônia; o que era indubitável agora é posto em dúvida. [...] Mostrou-se que o céu estava vazio, o que causou uma alegre gargalhada [...] Como diz o poeta: "Ó manhã dos inícios..." (BRECHT, 1977, pp.14-15).

O texto de Brecht não deixa de ser um olhar que busca pensar Galileu em seu tempo. Não obstante, inclui uma observação já retrospectiva, posto que Brecht, um 
pensador do século XX, percebe o fim de uma era não só pela Revolução Científica que Galileu ajudou a capitanear, mas o início de um tempo no qual essa revolução foi apenas um dos motores, ou uma "manhã dos inícios" entre várias. O fim do tempo antigo aninhou uma onda de transformações que não poderiam ser justificadas apenas pela nova forma de conhecimento que começava a ter cada vez mais prestígio e que era entendido como a representação mais fidedigna da realidade - embora coubesse à ciência o papel, inclusive, de se fazer as perguntas capazes de explicar as mudanças. Não é por acaso que as Ciências Sociais só podem se desenvolver plenamente a partir desse período.

Desde o início da Era Moderna, uma enxurrada de transformações assolava o que restou de uma ordem antiga: as grandes navegações, a descoberta de "novos mundos", os avanços tecnológicos, a ascensão da burguesia, o Renascimento, o Iluminismo, a Reforma, a criação da imprensa, a derrocada da explicação religiosa aos fenômenos do mundo, a Revolução Francesa... E, ao fim e ao cabo, o evento que iria colocar a última pá de cal sobre o mundo que então existia e agonizava: a Revolução Industrial.

A Revolução Industrial, cuja decolagem (take-off) se deu especialmente ao final do século XVIII, instalou de maneira contundente uma nova ordem social: a sociedade industrial, chamada por vezes de Sociedade Tecnológica. Sua consolidação foi calcada na expansão demográfica, na revolução agrícola, na criação de novas tecnologias em múltiplos setores da atividade humana, na mudança de mentalidade (valorização da instrução e da ciência, em oposição ao pensamento mítico e ao empirismo), na separação entre produtor e consumidor, na economia de produção, e no estabelecimento de um mercado que gira em torno do lucro, distanciado do simples entesouramento. A velha Sociedade Tradicional $^{71}$ deu lugar a uma sociedade cujas relações eram agora muito mais complexas e cujas características encerravam um modo de vida distinto daqueles vividos anteriormente. A Revolução Industrial abriu as portas do século XIX, o qual não foi “[...] a continuação pura e simples do século precedente, mas o ponto de

\footnotetext{
${ }^{71}$ A Sociedade Tradicional é a forma de organização social que irrompe na transição entre a mentalidade mítica e a racionalidade. Nessa fase, o nomadismo vai sendo gradativamente substituído pelo sedentarismo, com o desenvolvimento da agricultura e da criação de animais. O comércio começa a aparecer, numa escala mais regional. A partir daí, a distinção entre produtor e consumidor começa a ser demarcada, especialmente pelas classes sociais, que começam a ser definidas pela divisão do trabalho. Nascem as cidades-Estado e a sociedade de classes, organizada em torno de um soberano. Os objetos técnicos se proliferam, assumindo a função de adaptar o homem a natureza, embora ainda sejam pouco desenvolvidos.

É nessa época que surge o primeiro meio de comunicação de fato, capaz de estocar e transmitir: a escrita, quando podemos realmente falar de uma comunicação mediada. A cultura, ainda voltada para a tradição, passa a ser transmitida de formas distintas: oral ou letrada, de acordo com as classes sociais.
} 
inflexão de uma nova era. [...] a idade da história [...] a era da grande indústria" (DOMINGUES, 1991, p.267).

Neste contexto, os processos comunicacionais igualmente sofreram alterações. Se na Sociedade Tradicional, a quantidade de meios técnicos de comunicação era restrita, limitando-se quase que unicamente à escrita, com o predomínio ainda de uma comunicação natural, baseada na oralidade, a sociedade tecnológica vê irromper uma profusão de meios técnicos (jornais, cinema, rádio, televisão etc). A comunicação passa, assim como tantas outras coisas, a ser baseada na técnica, sendo desnaturalizada e começa a ser um serviço pago ${ }^{72}$. A quantidade de informações que circulam nessa sociedade é gigantesca e os meios de comunicação que despontam após ou se desenvolvem durante a Revolução Industrial passam a selecionar aquilo que seria mais importante socialmente.

No ponto que nos interessa, está claro aí que temos uma ruptura, um momento em que a comunicação passa a ser um problema de outra ordem que não aquela que nos constitui. A comunicação passa a ser algo que se dá em meios técnicos específicos e que desperta a atenção dos meios acadêmicos a partir do instante em que se tornam cada vez mais presentes no cotidiano das sociedades, as modificando e sendo alterados por elas.

Trata-se de uma ocasião histórica em que a

[...] intervenção da técnica na vida social é cada vez maior; os meios elétricos são abundantes e variados; a comunicação passa a ser vendida; e o espaço onde se dá a experiência social, onde algo se torna comum a várias comunidades, o local onde a vida social, a atualidade, é compartilhada, são os meios de comunicação ${ }^{73}$ (MARTINO, 2007).

Esses meios de comunicação possibilitam "a vida para além do espaço comunitário", permitindo a "geração de valores e representações comuns a todas as comunidades" (Idem, 2000, p. 113). São eles que vão possibilitar a sensação de uma experiência social comum entre os indivíduos. São esses meios de comunicação, produtores da realidade social mediada, que se tornam alvo de pesquisas oriundas das mais diversas disciplinas, embora não sejam exatamente per se o foco dos estudos.

Encerrando uma série de problemas e configurações novos, a sociedade tecnológica abriu espaço a novos saberes, preocupados em dimensionar essa forma de organização social, saberes focados no homem e nas relações que este estabelece nessa

\footnotetext{
72 MARTINO, Luiz C. Anotações de aula. Curso de Teorias da Comunicação. Programa de Pós-graduação em Comunicação da Faculdade de Comunicação Social da Universidade de Brasília, 2008.

${ }^{73}$ MARTINO, Luiz C. Anotações de aula. Curso de História da Comunicação. Programa de Pós-graduação em Comunicação da Faculdade de Comunicação Social da Universidade de Brasília, 2007.
} 
sociedade: as chamadas Ciências Humanas ou Sociais. Estas, por sua vez, ao se voltarem para a compreensão do homem na sociedade tecnológica, não poderiam deixar de enfrentar o problema da comunicação. Desse modo, podemos estabelecer um território a ser bem cingido para a Comunicação dentro do tecido das Ciências Sociais: um território onde o estudo dos meios e suas mensagens é o objeto central - o território do pensamento comunicacional, que ganhará força no século XX, nos Estados Unidos da América.

Mas, antes disso, a discussão sobre os meios já começava a ser esboçada em outras ciências, e bem longe dos Estados Unidos, país onde a Mass Communication Research iria florescer: na Europa, mais intensamente na Alemanha, o debate já havia se instaurado.

\subsection{As rotas européias da pesquisa em Comunicação}

Ao traçar um panorama retrospectivo sobre a pesquisa em comunicação no artigo The European Roots, o sociólogo alemão Kurt Lang afirma

[...] que muito do que tem sido definido pelos europeus caracteristicamente como pesquisa americana em comunicação [...] foi introduzido nos Estados Unidos pelo Velho Mundo, em sua maior parte por alemães (o que nesse caso inclui os austríacos) ou por americanos que estudaram na Europa ou foram influenciados por trabalhos desenvolvidos na Europa Central durante o primeiro terço do século $20^{74}$ (LANG, 1996, p.2).

A afirmação de Lang merece uma atenção detida de nossa parte, dado que carrega em si o cerne de uma questão importante ao desenvolvimento da Mass Communication Research. Longe de ser um pensamento totalmente original, a pesquisa inicial sobre os meios de comunicação, nos Estados Unidos, encontra-se vinculada a uma série de estratos que se consolidam na pesquisa social desde o século XIX, e se mostra atrelada a uma tradição que percebe os meios de comunicação de maneira negativa, resultado das doutrinas e conseqüências do Iluminismo no pensamento alemão, em maior escala, e no pensamento francês e inglês, em menor proporção (pelo

\footnotetext{
${ }^{74}$ No original: "much of what is being defined by Europeans as characteristically U.S. communication research [...] had been introduced to the United States from the Old World, mostly by Germans (which in this case included Austrians) or by Americans who had studied in German or had been influenced by work in Central Europe during the first third of the $20^{\text {th }}$ century".
} 
menos, em sua fase inicial, ainda não-empírica). Sob essa perspectiva, a ideia de esclarecimento $^{75}$, "que estimula uma visão crítica do mundo guiada pela razão e não pela crença em dogmas" (BORGES, NUNES, VARÃO, 2008, p.8), se torna característica ausente de todo indivíduo que não busca o conhecimento e a instrução, estando este para sempre aprisionado na ignorância, subjugado por possuí-la. Assim, o filosofo alemão Immanuel Kant (1724-1804) afiança ser

[...] difícil [...] para um homem em particular desvencilhar-se da menoridade que para ele se tornou quase uma natureza. Chegou mesmo a criar amor a ela, sendo por ora realmente incapaz de utilizar seu próprio entendimento, porque nunca o deixaram fazer a tentativa de assim proceder. Preceitos e fórmulas, esses instrumentos mecânicos do uso racional, ou antes do abuso, de seus dons naturais, são os grilhões de uma perpétua menoridade. Quem deles se livrasse só seria capaz de dar um salto inseguro mesmo sobre o mais estreito fosso, porque não está habituado a este movimento livre. Por isso são muito poucos aqueles que conseguiram, pela transformação do próprio espírito, emergir da menoridade e empreender então uma marcha segura (KANT,1974, p.102).

É esse ponto de vista que mais tarde, somado a um corpo de teorias sociais, vai levar também a percepção de que a fragilidade desse indivíduo o torna "presa" fácil dos meios de comunicação, por exemplo.

Compreender como os estudos sobre a comunicação se desenvolveram na Alemanha do século XVII ao XIX - onde receberam o nome de Publizistikwissenchaft ou Kommunikationwissenchaft ${ }^{76}$-, e em outros países europeus, é fornecer pistas importantes sobre as influências que constituíram a Mass Comunication Research. Esse período constitui uma espécie de "pré-história" dos estudos em Comunicação e lançou elementos seminais cujas influências serão sentidas durante um bom tempo na pesquisa que se segue.

Num primeiro momento, pelo menos até o século XVIII, esses estudos ainda carecem de aporte teórico, e não há sequer uma noção de campo comunicacional. Num segundo período, no século XIX, paradigmas sociológicos e psicológicos se alinhavam para cumprir o desafio de explicar, ainda que de forma periférica, sem privilegiá-lo, o papel dos media. Estes paradigmas sofriam inspiração mútua - embora também se repelissem, pois cada uma das Ciências Sociais nascentes perquiria encontrar sua própria especificidade. Tratava-se de esquadrinhar, concentrando-se no humano, as

\footnotetext{
${ }^{75}$ Essas ideias estão presentes de maneira mais intensa na Escola de Frankfurt, por motivos óbvios.

${ }^{76}$ Em português, conhecidos como Publicística.
} 
particularidades e os resultados do "[...] nascimento de nosso mundo" (RIOUX, 1975, p. 10), fruto da Revolução Industrial.

Sobre a nova ordem, a noção de que não se vivia mais em uma Sociedade Tradicional, essencialmente agrícola, baseada ainda nos laços de parentesco e da tradição, com uma divisão do trabalho bastante simplificada, dá lugar a ideia de sociedade de massa, caracterizada pelo fato de que

[...] os indivíduos são considerados numa situação de isolamento psicológico uns dos outros; (2) diz-se predominar a impessoalidade em suas interações com os outros; (3) são considerados isentos das exigências de obrigações sociais informais forçosas (DEFLEUR \& BALL-ROKEACH, 1993, p. 177-178).

Essa visão se formou a partir das primeiras teorias sociológicas acerca da Sociedade Tecnológica, e foi fortemente pautada nas ideias de Auguste Comte, Herbert Spencer, Emile Durkheim, Gabriel Tarde, Gustave Le Bon e outros autores que se viam às voltas com a definição das relações sociais que se estabeleceram então. São fruto dessas ponderações as noções de que a sociedade constituía um organismo vivo, um sistema complexo mantido por diversas partes, em que o sentimento de Gemeinschaft (termo utilizado por Ferdinand Tönnies para designar a sensação de pertencimento a uma comunidade) dava lugar à Gesellschaft, outra designação utilizada por Tönnies para descrever as ligações que se estabeleciam como contratos sociais, nas quais " [...] os indivíduos visam maximizar o que podem obter de trocas e minimizar o que dão, ao mesmo tempo aprendendo a precaver-se dos outros" (Idem, ibidem, p. 173).

Há nessa compreensão uma influência considerável das Ciências Naturais, sobretudo da Biologia. Passar a tratar a sociedade como um organismo vivo libera também a concepção de que o homem deve ser pensado a partir de um viés que o coloca, sob muitos aspectos, em pé de igualdade com os demais animais, sendo regido por leis semelhantes e cuja evolução seguiria aspectos naturais. É por isso que expressões como "divisão fisiológica do trabalho" e "darwinismo social" aparecem com freqüência quando nos referimos às primeiras teorias sociológicas. É por esse motivo também que os indivíduos que compõem a massa passam a ser vistos como uma espécie de involução humana. Essas ideias também vão influenciar a Psicologia, que tentava compreender o impacto das mudanças na mente humana e seu amadurecimento - e seu impacto sobre as pesquisas em comunicação será sentido mais profundamente a partir do século XX, já nos Estados Unidos. 
Contudo, a Sociologia e Psicologia, ao iniciarem a discussão sobre a sociedade industrial, sob o enfoque sociológico e psicológico, adentram ao mesmo tempo na contenda sob o papel dos meios de comunicação, em especial a imprensa (tanto livresca como jornalística). Dessa forma, casam-se uma série de perspectivas, mas que quase sempre tem como pano de fundo a presença de uma teoria da sociedade de massa, além de questionamentos políticos e ideológicos sobre a atuação da imprensa ${ }^{77}$, bem como as implicações psicológicas do uso dos meios. Ainda não há exatamente um contorno científico nessas primeiras observações sobre a imprensa, pois as formulações acerca do fenômeno das comunicações de massa ainda estão mais marcadas pelo senso comum, seguindo um raciocínio no âmbito da opinião, do que sistematizadas a partir de bases teóricas sólidas que dessem conta desse fenômeno. Sendo assim, “[...] Nesse período, o campo comunicacional se confunde com a discussão da própria atualidade, não havendo ainda um recuo teórico, necessário à elaboração de um conhecimento específico" (MARTINO, 2007, p.41).

É possível observar três grandes linhas nos trabalhos de autores que procuram discutir a imprensa nesse período, na Europa: 1) O conteúdo dos jornais; 2) A liberdade de imprensa; 3) O impacto da comunicação de massa. Vejamos cada uma separadamente.

\section{1) O conteúdo dos jornais}

Voltada para a compreensão daquilo que os jornais veiculam, a primeira das três linhas tem sua origem histórica no século XVII, na Alemanha, com os trabalhos pioneiros de Christophorus Besoldus, que forjou o termo "periódico de novidades" em 1629, para se referir aos jornais, embora não se possa dizer que as novidades às quais ele se referia possam ser entendidas como notícias, conforme as definimos hoje; de Ahasver Fristch, que elaborou a primeira crítica aos jornais modernos (na obra Discursus de Novellarum quas Vocant Neue Zeitung Hodierno Usu et Abusu, de 1630), aconselhando os leitores a desconfiar do conteúdo desses veículos; e o de Christian Weise, que publicou, em 1685, a primeira análise de conteúdo sobre jornais alemães. A Alemanha foi o primeiro país a produzir jornais diários, o que talvez explique o seu papel de "fundadora" da discussão sobre o jornalismo, que se consolida com a defesa da primeira tese doutoral voltada para o assunto, defendida por Tobias Peucer em 1690, na

\footnotetext{
${ }^{77}$ É interessante observar que há pouca reflexão voltada para a propaganda e a publicidade.
} 
Universidade de Leipzig, intitulada De Relationibus Nouvellis - algo como "Sobre o relato de novidades". De acordo com Jorge Pedro Sousa, “[...] essa tese inaugura, simbolicamente, a história das Ciências da Comunicação e representa, simultaneamente, a consagração académica do jornalismo como objecto de estudo" (2008, p. 9). Ainda segundo Jorge Pedro Sousa, Peucer lançou em sua tese uma série de concepções embrionárias a respeito de elementos jornalísticos que hoje se fazem presentes nas teorias sobre o jornalismo, “[...] apontando caminhos que só muito mais tarde foram trilhados" (SOUSA, 2004, p.45). Essas primeiras reflexões sobre o conteúdo dos jornais, ainda que pouco ou nada científicas, vão se estender até o século $\mathrm{XX}$, tendo como maior nome o economista Karl Knies, cuja análise dos meios, entretanto, o coloca também nas duas outras frentes abertas pelas primeiras discussões sobre a imprensa.

\section{2) A liberdade de imprensa}

A questão da liberdade de imprensa, apesar de já aparecer em 1644, na Inglaterra, com o escritor John Milton, principal representante do classicismo, só vai ganhar força nas discussões sobre a imprensa a partir do século XIX, quando “[...] o verdadeiro debate se instaura junto mesmo com a consolidação da imprensa, ainda na primeira metade do século XIX, quando é cunhada a expressão 'quarto poder"” (MARTINO, 2006, p.41). São nomes importantes nesse período: o economista inglês John Stuart Mill, um dos mais importantes pensadores do liberalismo; Karl Marx, que entendia a imprensa como um dos meios de dominação ideológica da burguesia sobre o proletariado (SouSA, 2008); Alexis de Tocqueville, que julgava ser a imprensa uma importante peça na consolidação da democracia, devendo garantir a liberdade e integrar a comunidade (ao lhe oferecer referentes comuns); e Karl Knies, para quem a imprensa responderia por "[...] necessidades relacionadas com a tomada de decisões e com o interesse dos indivíduos pelos assuntos públicos" (Idem, ibidem, p.25, grifo do autor). É válido frisar que nenhum desses autores fez uma análise sistemática sobre a imprensa. Contudo, todas essas posturas estão associadas a uma visão da comunicação como elemento político e ecoam notadamente nas pesquisas que hoje tratam de comunicação e política, além de resvalarem no estabelecimento de funções para os meios de comunicação de massa, que será tão caro à pesquisa empírica estadunidense. 


\section{3) O impacto da comunicação de massa}

Esse parece ser o ponto mais contundente e intenso no debate sobre a imprensa, a princípio, e os meios de comunicação de massa que vão ser posteriormente englobados à problematização da comunicação social na Sociedade Tecnológica - e que não deixa, de certa forma, de estar implícito nos dois anteriores. Como bem observa DeFleur (1993), “[...] desde o início da era de comunicação de massa, os estudiosos buscaram entender as influências dos veículos sobre as suas audiências" (p. 164). Neste momento, aparecem os primeiros cientistas sociais - ou filósofos sociais, como os nomeia José Marques de Melo (1993) - preocupados em delinear as peculiaridades da Sociedade Tecnológica e pensar a comunicação nesse contexto. Temos aí uma teoria da sociedade de massa que interfere diretamente na ponderação sobre a imprensa: Comte e a noção de organismo coletivo; a analogia orgânica de Herbert Spencer; a análise da divisão do trabalho de Emile Durkheim; a psicologia das multidões, de Gustave Le Bom, etc. Outros cientistas sociais se voltam, em momentos isolados, para o papel da imprensa, seguindo essa teoria da massa. São eles: o economista Albert Schäffle, que via a imprensa como o sistema nervoso da sociedade, responsável por “[...] organizar a reprodução e o consumo massivo de símbolos" (SOUSA, 2008, p. 32); Gabriel Tarde, com notória influência sobre a teoria da notícia de Robert Park, entendia que a imprensa não agia diretamente sobre a sociedade e que o público não era passivo; Ferdinand Tönnies, que observava o impacto da imprensa na formação da opinião pública; Max Weber, com alguns trabalhos que refletem sobre o jornalismo como cimento das massas (Idem, ibidem, p. 46).

Percebe-se que muito do exposto nessas três grandes linhas vai ao encontro do que comumente associamos às primeiras pesquisas estadunidenses sobre os meios de comunicação de massa: uma preocupação com o conteúdo das mensagens, a ligação forte entre política e comunicação, e a análise dos meios a partir de uma teoria da sociedade de massa. Entretanto, nenhum dos autores aqui citados, exceção feita, talvez, a Tobias Peucer, encarou a tarefa de elaborar uma obra cujo centro fosse os processos de comunicação de massa, nem tampouco fizeram mais que ensaios sobre estes. Esses elementos só vão adquirir um caráter mais sistemático e próximo ao conhecimento cientifico no século XX, quando o pensamento europeu acerca da imprensa entra na rota da produção acadêmica estadunidense das Ciências Sociais. Curiosamente, e como consequiência de um passado fértil na análise do jornalismo, o Velho Mundo vai 
consolidar nessa mesma fase, os estudos acadêmicos sobre jornalismo, enquanto os Estados Unidos se ocuparão mais amiúde da propaganda.

\subsection{As tradições estadunidenses de pesquisa e os meios de comunicação}

A história do questionamento sobre o impacto dos meios de comunicação é consideravelmente mais antiga na Alemanha que nos Estados Unidos. Foi somente no século XX que o jornalismo, que começou a ser identificado com a imprensa, e os outros meios de comunicação passaram a interessar significativamente aos pesquisadores estadunidenses. Até então, os media eram considerados relativamente não problemáticos e vistos de uma forma bastante ingênua, o que direcionou a pesquisa anglo-americana,

[...] quase que exclusivamente ao problema da natureza da liberdade de expressão. Era de consenso geral, entretanto, que, se as condições de liberdade fossem mantidas, as conseqüências da comunicação de massa seriam relativamente automáticas - uma mão invisível a conduzir a vontade dos indivíduos para a maximização do bem social ${ }^{78}$ (CAREY, 2001, p.XII).

Essa mirada se colocava de forma oposta à alemã, uma vez que, guiando-se por uma tradição muito mais céptica, resultante das doutrinas do Iluminismo, os alemães encaravam os meios de comunicação, em especial a imprensa, como instituições problemáticas, com consequiências "pouco claras, assim como sua contribuição ao Estado, e para a ordem social, em geral - o que poderia ser problemático e, às vezes, ameaçador" (idem, ibidem, p.XII) ${ }^{79}$. Entretanto, com o desenvolvimento das universidades estadunidenses e da contínua formação de seus membros em instituições do exterior ${ }^{80}$, notadamente na Alemanha, o pensamento social nos Estados Unidos começou a dar mais atenção aos meios de comunicação enquanto objeto de pesquisa, sob um viés mais próximo da tradição germânica, a partir do início do século XX.

\footnotetext{
${ }^{78}$ No original: "Anglo-american scholarship was devoted almost exclusively to the problem of the nature of freedom of expression. It was generally agreed, however, that if the conditions of freedom were maintained, them the consequences of mass communication were relatively automatic - an invisible hand leading the will of individuals to the maximization of social good". Tradução sugerida pela autora.

${ }^{79}$ No original: "[...] unclear, as well as it contribution to the state, to the capitalist economy, and to the social order generally - that could be troubling, sometimes menacing". Tradução sugerida pela autora.

${ }^{80}$ Lasswell e Robert Ezra Park são bons exemplos, e não podemos esquecer que pelo menos dois nomes da quadríade de Berelson, tinham procedência germânica (Lazarsfeld, nascido em Viena, e Lewin, nascido em Molgino).
} 
Ora, quando o século XIX se encerrou, os Estados Unidos viviam uma fase próspera, após terem passado pela Guerra de Secessão e implantado um vigoroso sistema industrial. Era uma época de reconstruir a ideia de nação, cujos esforços possibilitaram que o século que se seguiu fosse apelidado de século americano (PURDY, 2007): um período de apogeu econômico (a despeito da crise da bolsa de valores de 1929) e político, calcado numa forte urbanização. Os Estados Unidos começaram a ser vistos como o símbolo da Sociedade Tecnológica, o que levaria o frankfurtiano Max Horkheimer, ao comparar esse país com o resto da Europa, a chamar as cidades do Velho Mundo de "aldeias de negros" (Wiggerhaus, 2006). Além disso, já no século XIX, os Estados Unidos haviam excedido a todos os outros países no campo das comunicações, tanto em termos tecnológicos quanto em termos de difusão (a figura de Thomas Alva Edison, que inventou o fonógrafo e o cinetoscópio, entre outros aparelhos, foi emblemática desse período). Crescendo como nação, os EUA também não tardaram a perceber que deveriam ser, assim como a Europa, produtores de conhecimento.

É diante desse cenário que a historiografia do campo comunicacional situa a emergência das primeiras pesquisas em comunicação em terra ianque, que recebe influência direta das Ciências Sociais que se desenvolvem nos Estados Unidos e que tem, nesse momento, como principal base o pensamento desenvolvido pela Universidade de Chicago e pela Universidade de Columbia, além da clara influência européia, como vimos. Nessas duas instituições, as Ciências Sociais encontraram terreno fértil para se desenvolver, fomentando três tradições que seriam capitais para a fase inicial da Mass Communication Research: o Pragmatismo, o Behaviorismo e aquela que ficou conhecida como Escola de Chicago, que vai agregar as mais diversas vertentes sob seu nome.

Faz-se necessário, portanto, apresentar o núcleo dessas três correntes, ainda que em linhas gerais, bem como suas implicações no início da Mass Communication Research.

\section{1) O Pragmatismo}

As ideias pragmatistas aparecem primeiramente no texto do filósofo, químico e matemático estadunidense Charles Sanders Peirce (1839-1914) intitulado "Como tornar nossas ideias claras”, publicado em 1878. Entretanto, não é o Pragmatismo de Peirce expresso em "Como tornar nossas ideias claras", mas o que tem como figuras centrais o psicólogo e filósofo William James (1842-1910) e o pedagogo e também filósofo John 
Dewey (1859-1952), que acabou por se tornar referência como o primeiro movimento relevante e original do pensamento estadunidense. Aliás, o próprio Peirce se negava a se solidarizar com o Pragmatismo de James e Dewey, criando um termo diferente para demarcar seu trabalho, chamando-o de pragmaticismo, "[...] nome feio demais [...] para que alguém tente se apoderar" (DURKHEIM, 2004, p.56), segundo o próprio. Além disso, contribuiu para a pouca influência que Peirce veio a exercer em sua época, e mesmo em períodos posteriores, a personalidade controversa do filósofo, que nunca teve uma carreira acadêmica regular, ao contrário de William James, professor de enorme prestígio em seu tempo.

É assim que já Durkheim, ao ministrar um curso sobre o Pragmatismo na Universidade de Sorbonne, em Paris, entre 1913 e 1914, apontava William James como o "verdadeiro pai do Pragmatismo" (Idem, ibidem, p.56). O que podemos considerar, então, como o Pragmatismo jamesoniano?

Em William James, o termo Pragmatismo está fortemente enraizado no significado que a palavra grega pragma possui: ato, ação, atividade. Qualquer tipo de verdade a ser alcançada, sob esse ponto de vista, é condicionada pela ação humana. Toda construção conceitual, portanto, deve ser submetida à prova da ação, deve ter resultados práticos. Daí, decorre que James afirma

O Pragmatismo representa uma atitude perfeitamente familiar em filosofia, a atitude empirista, mas ele representa, como me parece, tanto seu sentido mais radical quanto a menos censurável forma que jamais assumiu. [...] Ele se afasta da abstração e da insuficiência, das soluções verbais, das más razões, a priori, a partir de princípios fixos, sistemas fechados, pretensamente absolutos e originais. Ele se vira para a concretude e adequação, para os fatos, para a ação, e para o poder. Isso significa que o temperamento empirista passa a reinar, e o temperamento racionalista sinceramente sai de cena ${ }^{81}$ (JAMES, 1995, p.20).

O método pragmático busca, em síntese, interpretar cada concepção a partir de suas consequiências práticas. Apesar de podermos fazer rapidamente uma associação com a forma sob a qual a pesquisa estadunidense em Comunicação foi conduzida (privilegiando as pesquisas empíricas) e o Pragmatismo, esse é o paradigma cujo impacto no campo da Comunicação é menos debatido, apesar de exceções, como a obra

\footnotetext{
${ }^{81}$ No original: "Pragmatism represents a perfectly familiar attitude in philosophy, the empiricist attitude, but it represents, as it seems to me, both in a more radical and in less objectionable form than it has ever yet assumed. [...] He turns away from abstraction and insufficiency, from verbal solutions, from bad a priori reasons, from fixed principles, closed systems, and pretended absolutes and origins. He turns towards concreteness and adequacy, towards facts, towards action, and towards power. That means the empiricist temper regnant, and the rationalist temper sincerely given up".
} 
American Communication Research and Pragmatism, de David K. Perry, na qual são discutidas as influências não só do Pragmatismo inicial na pesquisa em comunicação, mas também as tendências posteriores. É curioso perceber que as relações entre Pragmatismo e comunicação estejam ausentes da discussão sobre o saber comunicacional, mesmo que os maiores pragmatistas, como John Dewey e George Herbert Mead, estivessem ligados a Escola de Chicago, berço de muitas ideias nascentes sobre a comunicação, incluindo a tese de doutorado de Harold Lasswell - além de terem mesmo produzido uma discussão considerável sobre comunicação.

Para além do empirismo, contudo, o Pragmatismo parece ter interferido sobremaneira nas primeiras observações produzidas nos Estados Unidos sobre os meios de comunicação, uma vez que, formando a base do pensamento estadunidense, foram os pragmatistas os primeiros a oferecer alguma reflexão sobre a comunicação.

\section{2) O Behaviorismo}

Um marco decisivo para a formulação do Behaviorismo foram as pesquisas realizadas com cães pelo fisiologista russo Ivan Petrovich Pavlov ${ }^{82}$ (1849-1936) sobre secreções salivares de animais e sobre o condicionamento dos reflexos destes.

Em concordância com a definição dada por Descartes, séculos atrás, Pavlov conceituou reflexo como toda reação do organismo a um estímulo particular do mundo exterior (PAVlov, 1970). Para Pavlov, existem basicamente dois tipos de reflexos: 1) reflexos inatos ou absolutos e 2) reflexos condicionados. O próprio autor nos fornece a distinção mais simples e compreensível entre os dois tipos de reflexo. Segundo ele, “[...] num caso, o reflexo já está pronto, no outro, o reflexo deve ser preparado previamente" (Idem, ibidem, p.56). Os primeiros não são aprendidos, mas instintivos. Os segundos seguem uma diretriz principal, segundo a qual todo reflexo condicionado deve-se à repetição de um determinado comportamento, originado, por sua vez, a partir de um estímulo. Esses experimentos, juntamente com outros de sua época, revelavam que nem todo comportamento é resultante de uma herança genética, mas pode ser moldado e previsto de acordo com aquilo que é oferecido pelo ambiente.

As ideias de Pavlov exerceram uma grande influência no pensamento de sua época sobre os psicólogos, que começaram a utilizar a noção de condicionamento para

\footnotetext{
${ }^{82}$ Pavlov foi ganhador do prêmio Nobel de Medicina em 1904, resultado do seu trabalho sobre processos digestivos. Contudo, foram as pesquisas sobre salivação e condicionamento que lhe deram um status mais impactante no panteão das ciências.
} 
avaliar questões da psicologia humana. Entre os psicólogos mais influenciados por Pavlov, estava o estadunidense John Broadus Watson (1878-1958), cuja dissertação de graduação (Educação Animal: um Estudo Experimental sobre o Desenvolvimento Físico do Rato Branco, Relacionado ao Crescimento de seu Sistema Nervoso, de 1903) estava voltada para a análise do comportamento e aprendizado em animais, aos quais Watson se dedicou mesmo após a graduação. Esses estudos levaram Watson a se questionar sobre a validade de se pensar a psicologia sob um viés comportamental, tendo como base a analogia entre o comportamento animal e o humano, entendendo que ambos estavam sujeitos não só a reflexos inatos, mas ao aprendizado condicionado. Assim, nasceu o Behaviorismo - do inglês behavior e cuja tradução literal é "comportamentalismo" - que teve sua primeira expressão explícita no texto de John Watson intitulado A Psicologia como a vê um behaviorista, manifesto publicado em 1913, opositor da Psicologia tradicional, voltada aos estudos da mente (também conhecida como mentalismo) e cujo método consistia na introspecção, na contemplação dos pensamentos dos próprios psicólogos e pacientes.

Assim, ele diz:

A Psicologia como o behaviorista a vê é um ramo puramente objetivo e experimental das ciências naturais. Seu objetivo teórico é a predição e o controle do comportamento. A introspecção não faz parte dos seus métodos essenciais, nem o valor científico dos seus dados depende da facilidade com que se prestam a interpretação em termos de consciência. O behaviorista, em seus esforços para conseguir um esquema unitário da resposta animal, não reconhece linha divisória entre o homem e a força bruta. O comportamento do homem, com todo o seu refinamento e complexidade, constitui apenas uma parte do esquema total da investigação behaviorista ${ }^{83}$ (WATSON, 1913, p.1).

Ao behaviorista, portanto, interessava o que era possível de ser observado no homem: o comportamento. Este era passível, por sua vez, de ser condicionado, moldado, ajustado e previsto. Watson acreditava, ao contrário dos geneticistas de seu tempo, que vínhamos ao mundo como "tabulas rasas", para sermos preenchidos por conteúdo, em conformidade com o que já havia sido defendido por John Locke (16321704). Para ele, tudo poderia ser aprendido pelo homem e pouca coisa se daria em função de reflexos inatos. Por isso, John Watson conduzia seus experimentos utilizando

\footnotetext{
${ }^{83}$ No original: "Psychology as the behaviorist views it is a purely objective experimental branch of natural science. Its theoretical goal is the prediction and control of behavior. Introspection forms no essential part of its methods, nor is the scientific value of its data dependent upon the readiness with which they lend themselves to interpretation in terms of consciousness. The behaviorist, in his efforts to get a unitary scheme of animal response, recognizes no dividing line between man and brute. The behavior of man, with all of its refinement and complexity, forms only a part of the behaviorist's total scheme of investigation". Tradução sugerida pela autora.
} 
bebês, pois acreditava que o aprendizado "correto" deveria ser iniciado desde os primeiros dias de vida.

Simplificando o pensamento pavloviano, John Watson desenvolveu o modelo behaviorista, segundo o qual a cada estímulo corresponde uma resposta $(E \rightarrow R)$ e essa resposta é manifestada pelo comportamento, não por estados de consciência.

A princípio, o manifesto de Watson não encontrou muita repercussão entre seus pares, mas a partir da década seguinte, a sua publicação e a atuação de Watson em diversos media, suas ideias foram popularizadas (o psicólogo prestava uma espécie de consultoria em diversos veículos, ensinando como educar crianças).

No que diz respeito à visão sobre o funcionamento dos meios de comunicação, a forma como John Watson entendia o condicionamento do comportamento em sua psicologia behaviorista foi decisiva diante do contexto das Guerras Mundiais e representou a primeira entrada do Behaviorismo no campo da Comunicação.

A questão-chave, então, era: como aglutinar as populações em torno dos ideais da guerra? A resposta unia problemas sociais e psicológicos e é bem expressa por DeFleur e Ball-Rockeach (1993), quando estes afirmam que as populações

Não eram sociedades de Gemeinschaft, mas eram deveras mais sociedades de massa, carecendo desses vínculos eficazes [...] tornou-se essencial mobilizar sentimentos e lealdades, instilar nos cidadãos ódio e medo contra o inimigo, manter elevado seu moral diante das privações e captar-lhes boas energias em uma efetiva contribuição para sua nação. O meio para alcançar essas metas urgentes foi a propaganda (p.179).

Dessa forma, propagandas foram cuidadosamente construídas, buscando alcançar uma resposta positiva aos estímulos oferecidos pelos propagandistas - um Behaviorismo aplicado. Não tardou, então, para que essas propagandas cuidadosamente planejadas se tornassem alvo de estudos. Assim, as primeiras conjecturas que aparecem como pesquisas em Comunicação, sobretudo a partir da década de 1920, após o término da Primeira Grande Guerra, compreendem o modelo da propaganda sob uma ótica behaviorista, pois era justamente isso o que eram: uma aplicação prática do esquema estímulo-resposta, na qual se mostrava também a compreensão da sociedade de massa oferecida pelas teses sociológicas desenvolvidas entre o século XIX e XX. Compreendia-se a propaganda como elemento de um maquiavelismo triunfante: os fins justificavam os meios e o público dos meios de comunicação, chamado de massa, era composto por indivíduos incultos, incapazes de um julgamento crítico. Era o período hipodérmico, assim chamado por acreditar-se que a ação dos meios de comunicação era 
similar à da agulha hipodérmica. O público (a massa) recebia a mensagem (estímulo) e a compreendia de maneira similar, sendo levado a agir de acordo com o estímulo (resposta).

\section{3) A Escola de Chicago}

Gerada, como o próprio nome indica, na Universidade de Chicago, em Illinois, nos Estados Unidos, a Escola de Chicago designa o mais forte grupo de pesquisas e cientistas sociais surgidos até então naquele país, cujas diretrizes foram dominantes entre, pelo menos, 1915 a 1940. A Universidade de Chicago foi fundada em 1892 por John D. Rockefeller, magnata do petróleo, na última década do século XIX, a qual viu florescer de maneira desbravadora as Ciências Sociais, que garantiram um lugar de honra na instituição, primeiramente, pelas mãos da Sociologia. Nesse campo, Albion Small foi o pioneiro, responsável não só pela implantação do primeiro departamento de tal disciplina nos Estados Unidos, como também pela criação, em 1895, da sua primeira revista de Sociologia, ainda hoje publicada, The American Journal of Sociology. Cercando-se dos nomes emergentes da pesquisa sociológica estadunidense, Small começou a formar um grupo sólido, que passou a ministrar aulas na Universidade de Chicago e a publicar em The American Journal of Sociology, dando origem a um rol de pesquisas que giravam em torno da cidade que os acolhia.

Insignificante em 1840, quando possuía somente 4.470 habitantes, Chicago entrou nos anos 1900 com mais de 1 milhão e meio de habitantes. Como descrito por Bulmer (1986, p.13), "Em 1890, Chicago era uma cidade relativamente nova, borbulhante, turbulenta, uma metrópole industrial que sabia o que era ser grande, mas teve tempo para absorver o conhecimento. Era uma cidade de paradoxos" ${ }^{\text {" }}$. A Chicago do início do século XX, portanto, era um verdadeiro caldeirão social, prato cheio para as ciências que se preocupavam com a sociedade industrial.

Entre os nomes acolhidos pela cidade, e que expressavam o paradoxo de Chicago, estava William I. Thomas, que, junto a Small, começou a produzir uma série de pesquisas que privilegiavam estudos voltados para a compreensão das classes mais baixas e as comunidades de imigrantes que muitas vezes representavam o lado "escuro" da vida na cidade. A Thomas e a Small, em seguida, veio se somar o nome de Florian Znanieck, que publicou, alguns anos mais tarde, com a co-autoria de Thomas, a

\footnotetext{
${ }^{84}$ No original: "In 1890 Chicago was a relatively new city, a boiling, turbulent, industrial metropolis that knew what it meant to be great, but had time to absorb the knowledge. It was a city of paradoxes". Tradução sugerida pela autora.
} 
primeira grande obra da geração de pesquisadores que ali se formava, um estudo empírico de fôlego: The Polish Peasant in Europe and America (O Camponês Polonês na Europa e na América), composta de cinco volumes, escritos entre 1918 e 1920. The polish peasant in Europe and America reunia um número impressionante de entrevistas com imigrantes poloneses, buscando compreender de que forma a vida nessas comunidades se organizava. Muitos estudos seguiram a mesma direção: The Gang (A gangue), de Frederic Trashers, publicado em 1927, e The Ghetto (O Gueto), de Louis Wirth, publicado em 1928, são bons exemplos.

Todavia, é o nome de Robert Ezra Park que marca, definitivamente, a Escola de Chicago sociológica, cujas ideias já aparecem em um artigo do autor anterior a The Polish Peasant in Europe and America, intitulado "A Cidade: Sugestões para a Investigação do Comportamento Humano no Meio Ambiente Urbano”, publicado em 1916 no American Journal of Sociology. Nele, Park sugere a aplicação na cidade dos mesmos métodos de observação utilizados por antropólogos na observação das culturas indígenas: observação direta, a pesquisa de campo, a análise estatística, os estudos de caso, entre outros. A cidade surge aí como "'laboratório social', com seus signos de desorganização, de marginalidade, de aculturação, de assimilação" (MATTELLART, 2002, p. 30).

No título do artigo de Park, uma palavra se revela peça-chave na compreensão de uma das mais fortes bases para a corrente sociológica da Escola de Chicago: "comportamento", ligado, por seu turno, à psicologia behaviorista. O Behaviorismo vai ser uma influência na corrente sociológica da Escola de Chicago e, posteriormente, como sabemos, marcará a fase inicial da pesquisa em comunicação (por conseguinte, a obra de Lasswell).

A Escola de Chicago também vai sofrer uma forte influência do interacionismo simbólico desenvolvido por George Herbert Mead, que "por muitos anos foi ' $o$ psicólogo social para os sociólogos" ",85 (BULMER, 1986, p.30), derivado do Pragmatismo deweyniano. De acordo com Mead, os indivíduos são produtos sociais e partilham, por meio do interacionismo simbólico ${ }^{86}$, os significados das coisas, sendo estes, portanto, também sociais - o que levou a teoria de Mead a ser conhecida como Psicologia Social. Igualmente, a Escola de Chicago vai ser a responsável pela importação do Funcionalismo, advinda da Sociologia (sob influência durkheimiana), aos Estados

\footnotetext{
${ }^{85}$ No original: "for many years became 'the social psychologist for sociologists". Tradução sugerida pela autora.
}

86 É Herbert Blumer quem nomeia, anos mais tarde, a teoria de Mead como interacionismo simbólico. 
Unidos. O Funcionalismo afirma que todas as instituições sociais exerciam funções (conceito-chave do Funcionalismo, donde seu nome) que contribuem para a manutenção do sistema no seio do qual ela está inserida, estando em interação com outras. Essa noção permitia "conceptualizar a interdependência dos fenômenos sociais e explicar efeitos de retroacção dentro de um sistema” (BOUDON, 1990, p.100).

A ideia de função foi valorizada pelo trabalho de Ernest Burgess, que ao elaborar um diagrama da cidade de Chicago no qual distinguia as concentrações humanas por zonas bem delimitadas, o influencia no sentido de pensar uma "ecologia humana", aproximando sociologia e biologia, entendendo a cidade como um organismo vivo, no qual as diversas partes estavam em cooperação. O Funcionalismo vai ter um impacto maior nos estudos de comunicação durante e após a Segunda Guerra Mundial, quando a pesquisa empírica estadunidense privilegiou esta abordagem.

No universo da Escola de Chicago, é o trabalho de Robert Ezra Park que assume mais peso quando se trata de pensarmos as influências dessa corrente sobre as pesquisas em Comunicação. Tendo trabalhado como jornalista por 11 anos, Park nutria um interesse genuíno nos fenômenos de comunicação de massa. Em 1903, quando conquistou o título de Doutor pela Universidade de Heildelberg, na Alemanha, Park já estava atento aos novos processos de comunicação que se colocavam na sociedade de massa, como demonstra sua tese "Multidões e Públicos: uma Investigação Metodológica e Sociológica". No intuito de pensar a sociedade contemporânea, a cidade, os grupos sociais, nada mais natural que Park, à frente da Escola de Chicago, deslocasse suas atenções ao fenômeno emergente da comunicação de massa, que passou a ser entendido como um importante sistema a compor o meio ambiente urbano. Dessa maneira, o tema perpassa diversos trabalhos seus como, por exemplo, o livro The Immigrant Press and Its Control (A Imprensa dos Imigrantes e seu Controle, 1922) e os famosos artigos "A História Natural do Jornal” (1925) e "A Notícia como Forma de Conhecimento" (1940).

São essas tradições apresentadas acima que, somadas a visão negativa sobre a atuação dos meios, vão permear, de uma forma ou de outra, os primeiros anos da pesquisa científica em Comunicação nos Estados Unidos. Mas, antes disso, há que se pensar aquilo que se costuma chamar de teoria hipodérmica. 


\subsection{Hipodérmica: a primeira teoria?}

Talvez, na história das pesquisas estadunidenses sobre a comunicação, não exista um período mais obscuro e submerso em equívocos que aquele que compreende o que chamamos de teoria hipodérmica, teoria da bala mágica ou, de modo menos metafórico, teoria dos efeitos ilimitados. Tachada de ingênua e simplista, entretanto, a teoria hipodérmica desenvolve um papel importante na historiografia do campo quando nos remetemos à Mass Communication Research (Cf. BERELSON, 1986; DEFLEUR \& BALl-RoCKEACH, 1993; KATZ \& LAZARSFELD, 2005; Wolf, 2002, por exemplo). Aí, aparece muitas vezes como o marco zero, o primeiro passo rumo a uma aproximação entre o impacto dos meios de comunicação na sociedade de massa e o conhecimento científico - período que se estende desde a terceira década até meados da década de 1940 do século XX.

Normalmente voltadas para o estudo da propaganda, a intenção dessas pesquisas era identificar de que forma os propagandistas políticos manipulavam a massa através de suas mensagens, levando, assim, essa mesma massa a agir. A propaganda, tomada como uma arma política, incentivava os pesquisadores a centralizar suas forças, especialmente na propaganda de fundo político, assim como Lasswell. Todas essas obras tinham como pontos de partida, que acabam por unificá-las, os seguintes motes:

a) A percepção do fenômeno da comunicação a partir da noção de sociedade de massa;

b) A maior parte desses estudos privilegiava a dimensão quantitativa da pesquisa, sob um viés empiricista;

c) A influência da psicologia behaviorista, como já vimos, no intuito de perceberque efeito - decorrente de um estímulo - os meios de comunicação tinham na sociedade.

Esse período costuma ser situado entre o fim da Primeira Grande Guerra e os anos que antecedem a década de 1940. É a partir dessa época, também, que o governo estadunidense e uma série de instituições privadas (o Fundo Payne e a Fundação Rockfeller, entre outras) começam a investir maciçamente nas pesquisas sobre comunicação, entendendo-a como peça estratégica. 
É emblemática dessa fase o texto do cientista político Charles Merriam (18741953), orientador de Lasswell, intitulado American Publicity in Italy, de 1919. O texto é muito mais uma grande reportagem do que um trabalho científico e coloca a propaganda como uma arma poderosa de persuasão, como fica claro no seguinte trecho:

A Grande Guerra criou muitas armas - o submarino, o aeroplano, a arma de longo alcance, o tanque, o gás mortal; mas, a mais curiosa e mortal das armas foi a propaganda, o trabalho psicológico na guerra ${ }^{87}$ (MERRIAM, 1919, p.541).

Quanto a ela, conseqüentemente, não haveria defesa, pois esta atuaria "hipodermicamente". "Hipodérmico" é um termo médico que designa o subcutâneo. O motivo da utilização desse termo, nos é há muito tempo conhecido. Como explicam Comstock e Scharrer, a expressão foi utilizada no sentido de entender a ação dos meios de comunicação como “[...] análoga à injeção de uma substância química com propriedades conhecidas na corrente sanguínea de um indivíduo" ${ }^{88}$ (2005, p. 55) e foi empregado como metáfora à ação super poderosa que se acreditava ser característica desses meios. Erroneamente creditado a Lasswell, a primeira utilização do vocábulo aparece na obra Voting (1944), de Bernard Berelson, Paul Lazarsfeld e William N. McPhee, quando estes afirmam que "[...] os debates típicos sobre o papel dos media comumente implicam em que estes oferecem uma influência simples, direta - como um estímulo hipodérmico num sujeito inerte" ${ }^{\circledR 9}$ (1986, p. 234). Esse "estímulo hipodérmico" seria, por conseguinte, o primeiro modelo elaborado sobre o processo de comunicação de massa. A teoria hipodérmica, ao contrário de seus antecedentes europeus, não tinha como foco a imprensa, mas a propaganda, sob o viés

[...] de uma teoria da acção elaborada pela psicologia behaviorista. $\mathrm{O}$ seu objectivo é o estudo do comportamento humano com os métodos de experimentação e observação das ciências naturais e biológicas. O sistema de acção que distingue o comportamento humano deve ser decomposto, pela ciência psicológica, em unidades compreensíveis, diferenciáveis e observáveis. Na relação complexa que existe entre o organismo e o ambiente, o elemento crucial é representado pelo estímulo; esse estímulo inclui os objectos e as condições exteriores ao sujeito, que produzem uma resposta. 'Estímulos e resposta parecem ser as unidades naturais em cujos termos pode ser descrito $\mathrm{o}$ comportamento' (Lund, 1933, 28). A unidade estímulo/resposta

\footnotetext{
${ }^{87}$ No original: "The Great War developed many weapons - the submarine, the aeroplane, the long rage gun, the tank, the deadly gas; but one of the most novel and deadly was the propaganda, the psychological working on the war". Tradução sugerida pela autora.

${ }^{88}$ No original: "““ [...] analogous to the injection of a chemical substance with known properties into the bloodstream of an individual". Tradução sugerida pela autora.

${ }^{89}$ No original: "[...] typical debates about the role of the media too often imply a simple, direct, ,influencee - like a hypodermic stimulus of an inert subject". Tradução sugerida pela autora.
} 
exprime, por isso, os elementos de qualquer forma de comportamento (WOLF, 2002, p.).

É possível, segundo essa perspectiva, percebermos um alinhamento em relação ao pensamento hipodérmico nos trabalhos

[...] que chamavam a atenção para os factores retóricos e psicológicos utilizados pelos propagandistas. Alguns títulos: Public Opinion de Lippmann, The Rape of the Masses de Chakhotin, Psychology of Propaganda de Doobs, Psychology of Social Movements de Cantril, Propaganda Techniques in World War de Lasswell, Propaganda in the Next War de Rogerson (SMITH apud WOLF, 2002, p. 23).

Segundo Bineham (1988), a teoria hipodérmica surgiu a partir de quatro ideias principais: a primeira diz respeito ao fato de que para os primeiros pesquisadores, a produção massiva de comunicações criou uma "audiência de massa", um conglomerado de milhões de indivíduos a receber a mesma mensagem. Em segundo lugar, essa audiência só poderia estar localizada nos espaços urbanos, num estado de alienação e passividade, suscetível à manipulação. A terceira ideia era decorrente da segunda: as massas eram presas fáceis dos meios de comunicação. Por fim, “[...] a ideia de que as pessoa tinham sofrido uma 'lavagem cerebral' pelas mensagens dos media durante a Primeira Guerra Mundial serviu para validar as primeiras três "doutrinas",90 (BINEHAM, 1988, p. 232).

Resumimos, assim, a narrativa sobre a teoria hipodérmica mais regularmente estabelecida pela bibliografia da área de comunicação. Essa historiografia tradicional, entrementes, não acabou com a dúvida sobre a existência ou não de uma teoria hipodérmica e de seu impacto na formação do campo comunicacional, quando buscamos evidências teóricas que legitimem todos esses estudos como verdadeiramente pertencentes a uma teoria homogênea. Afinal, quais estudos podemos identificar durante o período hipodérmico? O modelo hipodérmico foi, realmente, elaborado por esses estudos a fim de dar conta do fenômeno da comunicação de massa?

É na pouca consistência das possíveis respostas a essas perguntas que repousam as críticas que se contrapõem à ideia de uma teoria hipodérmica, presentes nos trabalhos de Ellen Wartella e Byron Reeves (1985) e Steven Chaffee e John Hochheimer (1985), a despeito da história contada nos parágrafos anteriores. Bineham resume da seguinte maneira a posição dos autores, assinalando que, para eles, “[...] o modelo hipodérmico

\footnotetext{
${ }^{90}$ No original: "[...] the Idea that people has been 'brainwashed' by mass mediated messages during World War I served to validate the first three tenets". Tradução sugerida pela autora.
} 
nunca existiu, mas a noção de meios todo-poderosos foi criada por Katz e Lazarsfeld para justificar o seu trabalho e chamar atenção as suas descobertas" (1988, p. 233).

O processo de definição da teoria hipodérmica como a primeira teoria da comunicação na tradição da Mass Communication Research passa, a propósito, pelo fato mesmo de definir o que é uma teoria. Ora, se os pesquisadores hipodérmicos recebem esse nome numa avaliação posterior à sua produção, não nos parece que exista um modelo hipodérmico explícito em suas formulações sobre a comunicação de massa. Como pode existir teoria sem intencionalidade, já que esta é produto de esforços metodológicos no âmbito do saber cientifico? Parece-nos que há, sim, uma aproximação com a ciência nesses estudos ${ }^{91}$, mas não no sentido de constituir um arcabouço teórico que possibilite o desenvolvimento de um campo de conhecimento novo, direcionado à comunicação como objeto - e que eles comportam uma ideia que entende o processo de comunicação de massa como poderoso e cujos efeitos são sentidos diretamente pelos indivíduos da massa.

Pode-se ainda perceber que o que se encontra expresso no que seria a teoria Hipodérmica representa ainda uma continuidade com seus antecedentes, não uma ruptura.

Destarte, não se trata exatamente de uma teoria nem de um modelo, mas uma suposição que parte do senso comum (os meios de comunicação têm uma poderosa ação sobre a massa). A teoria hipodérmica poderia, na verdade, ser entendida mais como "uma atitude mental" (GOMES, 2005, p. 29) que perpassaria os trabalhos científicos de diversos autores (é sempre importante lembrar que, ao afirmarmos que o período hipodérmico se constitui como o marco zero do campo da Comunicação, estamos falando de autores provenientes de outras áreas, que não possuem o compromisso de elaborar uma teoria da Comunicação, mas utilizam a comunicação como elemento para resolver os problemas de suas próprias áreas de origem). A teoria hipodérmica, deste modo, se configura muito mais como um período que um conjunto de conhecimentos suficientemente gerais para que possam ser aplicados em situações análogas, num contexto científico - como comumente definimos uma teoria. Mas é durante esse período, contudo, que Harold Lasswell desenvolve suas primeiras pesquisas em Comunicação.

\footnotetext{
${ }^{91}$ Que, algumas vezes, não são apenas uma “aproximação” da ciência, mas são, eles mesmos, científicos, como a obra de Lasswell, Técnica de Propaganda na Guerra Mundial, de 1927.
} 


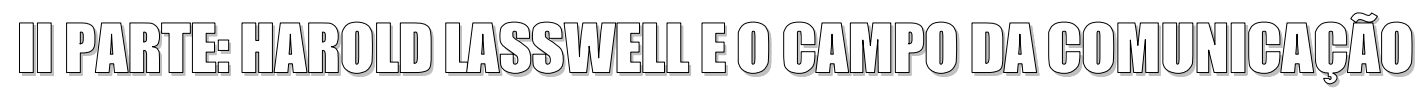




\section{PANORAMA BIOGRÁFICO E INTELECTUAL}

O sociólogo polonês Zygmunt Bauman escreveu certa feita que “[...] Histórias são como holofotes e refletores - iluminam parte do palco enquanto deixam o resto na escuridão" (2005, p.26). Esta observação nos parece particularmente justa quando se trata da vida de autores que se destacam por suas contribuições teóricas: os bastidores são comumente ignorados. Parece-nos pouco plausível abordar e discutir a obra de Lasswell sem conhecermos sua trajetória pessoal. Certamente se poderia colocar em dúvida a necessidade deste empreendimento, sobretudo quando visamos focar a compreensão histórica e epistemológica de um campo de estudo, mas adotamos o ponto de vista de que a trajetória de vida e o contexto histórico que cercam o trabalho de um cientista ajudam a complementar o trabalho do epistemólogo, oferecendo um material rico e fértil sobre as relações que se estabeleceram entre um cientista e seu campo de estudo.

Narrar a vida de cientistas não é um recurso recente. Pelo menos desde a era vitoriana, na Inglaterra, já podiam ser encontrados trabalhos biográficos no estilo "vida e cartas" $"$. Contudo, a biografia nem sempre grassou de prestígio nas ciências, ocupando mesmo muitas vezes uma posição de "aleijão" (FERRO, 1989). Como afirmou Joshua Lederberg ao fazer um retrospecto da situação do gênero,

Os relatos sobre a vida dos cientistas têm sido apenas uma acanhada moda nas últimas décadas, tanto no âmbito profissional quanto na cultura popular. Assim, "aquilo que alguém faz" é evocado para justificar suas descobertas e constituiu a literatura científica principal, enquanto "aquilo que alguém é" é omitido como um potencial contaminador do julgamento científico objetivo. Na ciência, a vida pessoal tem sido considerada muito menos relevante para a busca da verdade do que em campos mais auto-expressivos, tais como a literatura e as artes. É por esse motivo que a tradição da escrita científica desencorajou o uso de pronomes pessoais e outras manifestações do $\operatorname{self}(1990, \text { p.31 })^{93}$.

Com certeza, é uma idéia bastante simplista que os pronomes pessoais sejam "eliminados" somente por desconsiderar a biografia. Mas a afirmação nos leva a pensar

\footnotetext{
${ }^{92}$ Life and letters. Estilo literário em que a biografia se baseia na análise das correspondências dos biografados (LEDERBERG, 1990).

${ }^{93}$ No original: "Accounts of the lives of scientists have enjoyed only a limited vogue in recent decades, both within the profession and in popular culture. Thus "what one does," adduced to justify one's findings, comprises the primary scientific literature, while "who one is" is omitted as a potential contaminant of objective scientific judgment. In science the personal life has been considered far less relevant to the search for truth than in more self-expressive fields such as literature and arts. Hence tradition in scientific writing has discouraged use of personal pronouns and other manifestations of self".
} 
até que ponto podemos suprimir por completo a vida de um cientista de um estudo voltado para uma obra em particular. Lederberg escreveu a assertiva acima em 1990, quando a biografia nas ciências começava a desfrutar de uma atenção maior, resultado especialmente do amplo projeto do Dicionário de Biografias Científicas, iniciado em 1960 nos Estados Unidos, pelo American Council of Learned Societies, e que veio a público em 1970. O Dicionário foi elaborado a partir do pressuposto de que o conhecimento da história das ciências também se dá pelo conhecimento da vida de seus autores.

Falar em biografia, contudo, não significa que estejamos de posse de um gênero bem delimitado, com regras básicas bastante claras, nem mesmo com finalidades convergentes. É grande a variedade de tipos de biografia e "[...] aquela que talvez seja a forma mais apropriada para um crítico literário ou um historiador diplomático pode não ser a mais adequada para um historiador da ciência" (HANKINS, 1979, p.1) ${ }^{94}$.

Qual seria o teor, então, de uma biografia que convém a um trabalho interessado em epistemologia? De que modo a abordagem da vida de um determinado cientista pode esclarecer aspectos da produção científica de um determinado campo? E particularmente para nós, de que maneira conhecer Harold Lasswell pela perspectiva de sua biografia nos ajuda a compreender sua obra voltada à comunicação?

Em primeiro lugar, é necessário examinar o tipo de texto que trabalharemos aqui, a chamada biografia científica ou intelectual ${ }^{95}$. Para defini-la, iremos destacar um ponto de divergência entre a biografia literária, de maneira mais geral, direcionada ao que Lederberg chamou de vida pessoal, e a biografia intelectual, que se debruça sobre a vida de um cientista com o intuito de fornecer conexões entre sua produção e sua história. Enquanto a primeira concentra sua narrativa mais fortemente nos meandros da personalidade do biografado e sua vida "pessoal", a segunda "[...] tenta ver através da personalidade para obter uma melhor compreensão de eventos e ideias contemporâneas" ao autor (Idem, ibidem, p. 2) ${ }^{96}$. Adotar este segundo posicionamento não significa negligenciar por completo as pequenas crônicas e anedotas que fazem parte da intimidade dos indivíduos que escolheram a ciência como vocação. Mas, voltando-se para o passado de um campo de conhecimento - e sem perder de vista a trajetória

\footnotetext{
${ }^{94}$ No original: "[...] what may be the proper form for a literary critic or a diplomatic historian may not be proper at all for the historian of science".

${ }^{95}$ Os dois termos são igualmente válidos. Contudo, biografia científica é mais comumente empregado em países anglo-saxões, enquanto biografia intelectual é mais utilizado por países de línguas latinas.

96 No original: "[...] tries to see through the personality to obtain a better understanding of contemporary events and ideas".
} 
singular do biografado -, a biografia científica quer esquadrinhar os traços da influência do coletivo, bem como, de outra parte, a influência do biografado na formatação das ideias que constituíram sua época.

Deste modo, interessa ao estudo epistemológico o gênero de biografia que traça o contexto no qual uma obra se forma e se desenvolve, relacionando-a com as especificidades e demandas do campo. Em que momento, por exemplo, Lasswell se aproximou da comunicação como problema de pesquisa? Qual o papel de outros pesquisadores no desenvolvimento de seus estudos sobre propaganda? De que forma seus estudos ajudaram a constituir a Comunicação como um campo de pesquisa? O que está presente em sua obra que o torna importante para este campo? Quando Lasswell começa o seu distanciamento da Comunicação? São a perguntas como estas as quais se espera que o aporte biográfico possa trazer alguma luz, ou renovar as compreensões que temos atualmente.

É necessário dizer que encontramos, aqui, as mesmas dificuldades enfrentadas quando se trata de outros tipos de historiografia: o passado do indivíduo pertence a um lugar ao qual não podemos mais ir, um lugar que, mesmo nas fotografias e documentos, se apresenta bastante acidentado. Como saber, de fato, o que aconteceu? É impossível dar conta da totalidade da vida de um indivíduo, estabelecer uma narrativa sem fissuras, sem lags, assim como é inviável estabelecer todas as conexões entre a existência de um indivíduo e seu vínculo com a ciência.

Uma biografia que fosse escrita com a intenção de fornecer a história total de um determinado indivíduo e que se propusesse a ligar todos os pontos entre sua atividade enquanto cientista e o contexto social e cultural de sua época, certamente seria uma fantasia retórica, como bem notou o sociólogo Pierre Bourdieu, em A Ilusão Biográfica, (2005, p.185). Toda biografia é, portanto, incompleta por natureza.

Não obstante as críticas, a biografia intelectual se faz necessária e se tornou um verdadeiro consenso neste tipo de trabalho (FoURNIER, 2003). Por quê? Joshua Lederberg (1990) lista cinco motivos pelos quais a biografia científica se justifica:

1) Conteúdo substantivo da ciência: a biografia ajuda a divulgar o trabalho científico, torna a figura de determinado autor mais conhecida e fornece "um background para assimilar melhor sua pesquisa original" 
(LEDERBERG, 1990, p. 33) ${ }^{97}$. Todavia, segundo Lederberg, não se pode confiar na premissa de que, ao conhecermos o autor, teremos acesso àquilo que representa o campo científico ao qual ele pertence, à "substância" desse campo. Pelo contrário, esse é um ponto bastante problemático, que não se pode aceitar sem críticas. É verdade que um cientista representa muito do coletivo, mas dificilmente pode caracterizar um campo inteiro. O que se vislumbra são fragmentos, não uma soma que leva à compreensão do que seria um campo científico como um todo.

2) Processo de descoberta e verificação: relacionado diretamente à filosofia da ciência, está arrolado ao fato de que, ao tomarmos contato com a vivência dos cientistas, aprendemos também algo sobre seu processo de descoberta e verificação, resultante das ações subjetivas do cientista, que se combinam aos métodos objetivos de toda ciência.

3) A ciência como instituição social: Nesta perspectiva própria à sociologia da ciência, a biografia nos mostra

[...] como a comunidade científica é formada por normas de funcionamento e instituições, bem como por redes fraternas e de intergeracionais [...] A biografia retrata diretamente as relações pessoais entre os cientistas, as suas dívidas recíprocas, suas etiquetas e, às vezes, seus ciúmes e transgressões (Idem, ibidem, p. 34$)^{98}$.

Ou seja, a biografia nos fornece dados importantes sobre as condições sociais da produção científica e nos mostra o quão as atividades extracientíficas influenciam as decisões de um autor.

4) Psicologia do cientista: para Lederberg (1990, p. 35), neste ponto, a biografia científica provê subsídios acerca das motivações que levam os indivíduos a optar pela ciência como profissão, além dos fatores que influenciaram suas escolhas acadêmicas mais particulares. Essa é uma questão deveras delicada, e já havia sido criticada por Thomas Hankins, em seu clássico artigo In Defence of Biography: the use of biography in the history of science (1979). O enfoque psicológico oferece o risco de resvalar em "psicologismo" barato, vendo aqui e ali ecos de um pai

\footnotetext{
${ }^{97}$ No original: "[...] how the scientific community is shaped by its operating norms and institutions, as well as by its fraternal and intergenerational networks [...]Biography depicts directly the persona! relationships among scientists, their mutual debts, their etiquettes, sometimes their jealousies and transgressions"

${ }^{98}$ No original: "[...] how the scientific community is shaped by its operating norms and institutions, as well as by its fraternal and intergenerational networks [...] Biography depicts directly the personal relationships among scientists, their mutual debts, their etiquettes, sometimes their jealousies and transgressions".
} 
rigoroso na infância, por exemplo. É necessário cautela e deve-se evitar ser psicólogo do cientista biografado. Primeiro, por não ser o intuito da biografia intelectual desvendar a psique do autor estudado. Segundo, por a análise psicológica requerer uma formação bastante específica: a de psicólogo.

5) História da ciência: a biografia intelectual procura integrar o cientista ao seu campo, e vice-versa. E, mesmo de modo superficial, é essencialmente história. Como afirma Lederberg, "nenhum cientista contemporâneo tem trabalhado no vácuo; a apresentação e a solução de problemas são parte de uma história das ideias" (1990, p. 36) ${ }^{99}$. Sob essa perspectiva, a biografia é uma das maneiras de se fazer história das ciências, uma história que se apóia na constância de um nome próprio (Bourdieu, 2005). Assim, a biografia é um elemento possível para a compreensão da história de um campo, e ressitua “[...] o lugar dos seres humanos, com todas as suas peculiaridades maravilhosas e excêntricas, no desenvolvimento da grande empresa humana que é a ciência" (RICHARDS, 2006, p. 305) ${ }^{100}$.

Em nosso caso, trata-se de dimensionar historicamente Harold Lasswell, concentrando maior peso exatamente no último item listado por Lederberg, focando em sua relação com o campo da comunicação. A biografia, com esse intuito, não aparece como objetivo final, mas como uma paragem que deve ser atravessada para se chegar até ele. Ela funciona como um mapa, que nos mostra o percurso vivido pelo cientista na relação com determinado saber. Dificilmente conseguiríamos manter todos os dados biográficos do cientista político num capítulo estanque, separado do resto. Até porque não é exeqüível apartar inteiramente a obra de Lasswell sobre comunicação de seu contexto. O que faremos aqui é um corte que serve à investigação central desta tese, nos dando a conhecer o autor da obra a ser analisada. Para isso, começaremos pelo começo: a infância e a adolescência de Harold Lasswell.

\footnotetext{
${ }^{99}$ No original: "No contemporary scientist has worked in a vacuum; the presentation and solution of problems are part of a history of ideas".

${ }^{100}$ No original: "[...] the place of human beings, with all their wonderful quirks and cranckniness, in the development of the great human enterprise that is science".
} 


\title{
4.1. Os primeiros anos: de 1902 a 1918
}

Este é o período menos documentado da vida de Harold Lasswell. Há quatro principais textos biográficos sobre o cientista político (The mystifying intellectual history of Harold D. Lasswell, de Bruce Lannes Smith, publicado em 1969; Harold Lasswell: a Memoir, de 1969, de autoria de Leo Rosten; a biografia escrita por seu discípulo Gabriel Almond, Harold D. Lasswell, em 1985; Harold Dwight Lasswell: a Biographical Profile, escrito por Rodney Muth em 1989) - e todos eles são bastante breves sobre sua infância e adolescência, limitando-se ao ambiente da escola e da família. O pouco que se sabe corrobora a imagem de um intelectual precoce.

Filho de Linden Lasswell (1868-1943), pastor da igreja presbiteriana local, e de Anna Prather Lasswell (1868-1943), professora de high school, Lasswell teve nos pais seus primeiros modelos para uma vida devotada ao estudo.

Linden e Anna lhe ofereceram uma formação que encorajava o desenvolvimento intelectual, ainda que numa região pouco desenvolvida, como o centro-oeste dos Estados Unidos.

\begin{abstract}
É certo que o pastor e a professora estão perto do cume ou "nível da elite" da pirâmide socioeconômica de uma cidade pequena como Donnellson. Além disso, os pais de Lasswell eram "especialistas em símbolos", como ele mesmo viria a colocar: ambos passaram a vida pensando, falando e dando conselhos. Ambos tinham um grande respeito pela educação e viam nela o meio de se chegar a índices sociais e éticos impositivos e legítimos. Eles deram ilustração e receberam respeito ${ }^{101}$ (SMITH, 1969, p.42).
\end{abstract}

Tendo vivido sozinho com os pais, Lasswell recebeu atenção redobrada e, logo que ficou um pouco mais velho, começou a participar intensamente das atividades de Linden e Anna e a conviver mais com adultos do que com crianças, o que despertou nele curiosidade por assuntos variados, não exatamente infantis, como a política.

A família Lasswell não raramente passava o verão em Salem, também em Illinois, acompanhando o Chautauqua, movimento popular no final do século XIX e início do século XX. A palavra iroquesa ${ }^{102}$ possui vários significados, mas está mais associada à ideia de "ensinar a pescar os peixes" (expressa na tradução para o inglês

\footnotetext{
${ }^{101}$ No original: "Admittedly, the minister and the schoolteacher are near the summit or 'elite level' of the socioeconomic pyramid of a small town like Donnellson. Moreover, Lasswell's parents were 'symbol specialists,' as he was later to put it: both made their livings by thinking, talking, and giving advice. Both had a high regard for education and saw in it the means of arriving at social and ethical prescriptions that were both authoritative and legitimate. They gave enlightenment and received respect".

${ }^{102}$ Os iroqueses eram uma grande nação indígena que habitava a parte mais ao norte de Nova York, estado no qual surgiu o primeiro Chautauqua, em 1874.
} 
"where the fish are taken out" - "de onde se tiram os peixes"). O Chautauqua estava voltado para a educação de adultos das áreas rurais e entre a série de apresentações culturais, os discursos políticos tinham destaque.

Foi assim que Lasswell assistiu ainda muito novo a políticos proeminentes, como William Jennings Bryan (candidato três vezes à presidência dos Estados Unidos pelo Partido Democrata e secretário de Estado no governo de Woodrow Wilson, entre 1913 e 1916), e Robert La Follette (governador do estado de Wisconsin, entre 1901 e 1906, e senador republicano, de 1906 a 1925).

Portanto, apesar de ter nascido num lugarejo obscuro, Lasswell acabou crescendo em um ambiente intelectualmente rico. As constantes transferências de cidade pelas quais foi obrigado a passar, em função do ofício paterno, também fizeram com que Lasswell tivesse contato com diferentes realidades. De acordo com o próprio $(1951)^{103}$, antes de completar 16 anos, ele já havia morado em cinco cidades/vilas diferentes: Donnellson, Enfield, Good Hope, Toledo e Mount Zion. Nesta última, Lasswell passou boa parte da adolescência.

Mount Zion fica próxima a Decatur, cidade na qual Lasswell cursou a Decatur High School. Foi nessa escola que ele começou a se destacar e onde conseguiu o reconhecimento que lhe daria, alguns poucos anos depois, uma bolsa para a Universidade de Chicago ${ }^{104}$, em 1918 - mesmo ano em que terminou seus estudos na Decatur, logo após ter passado um período vendendo livros de porta em porta, em Bay City, Michigan ${ }^{105}$. Na Decatur, Lasswell editou o jornal escolar e foi o valedictorian de sua turma - título que identifica não só o orador na cerimônia de formatura, mas o aluno mais destacado da escola.

Nos anos de high school, Lasswell conheceu a obra de Sigmund Freud, influenciado por um tio médico, que havia lido a obra do austríaco, e presenteou Lasswell com uma cópia das conferências ministradas por Freud na Universidade Clark, em 1909; os livros de Karl Marx e Havellock Ellis, indicados por Lucy H. Nelson ${ }^{106}$, sua professora de inglês; o trabalho de uma série de sociólogos europeus, pelas mãos de seu

\footnotetext{
${ }^{103}$ Em memorial (affidavit) exigido como documento para que tomasse posse como professor de Ciência Política na Universidade de Yale. O documento é uma pequena autobiografia, com 23 páginas. 23 de outubro de 1951.

${ }^{104}$ Lasswell conseguiu a bolsa para a Universidade de Chicago após vencer uma competição sobre história moderna e inglês (ALMOND, 1987).

${ }^{105}$ Lasswell fez sua primeira viagem a Europa com o dinheiro obtido com a venda destes livros e com um empréstimo pessoal de um benfeitor, Morton D. Hull, congressista republicano.

${ }^{106}$ Lucy foi a responsável por apresentar Lasswell a John Dewey, que se tornou uma das grandes referências do cientista político. A admiração de Lasswell por Lucy é reforçada em uma série de cartas a seus pais, Linden e Anna.
} 
professor de Civismo, William Corney Casey, que mais tarde se tornaria professor da Universidade de Columbia ${ }^{107}$.

Esse cabedal de autores (muitos deles contemporâneos de Lasswell) fomentaram na jovem mente do menino interiorano um interesse crescente pelas Ciências Sociais, "recém-chegadas" a seu país. Ao entrar para a Universidade de Chicago no outono de 1918, aos 16 anos, o contato precoce com as tendências européias que vinham sendo debatidas naquela instituição possibilitou a ele uma rápida identificação e aprovação entre seus pares acadêmicos.

${ }^{107}$ Lasswell agradece especialmente a Casey, no prefácio de World Politics and Personal Insecurity (1934). 


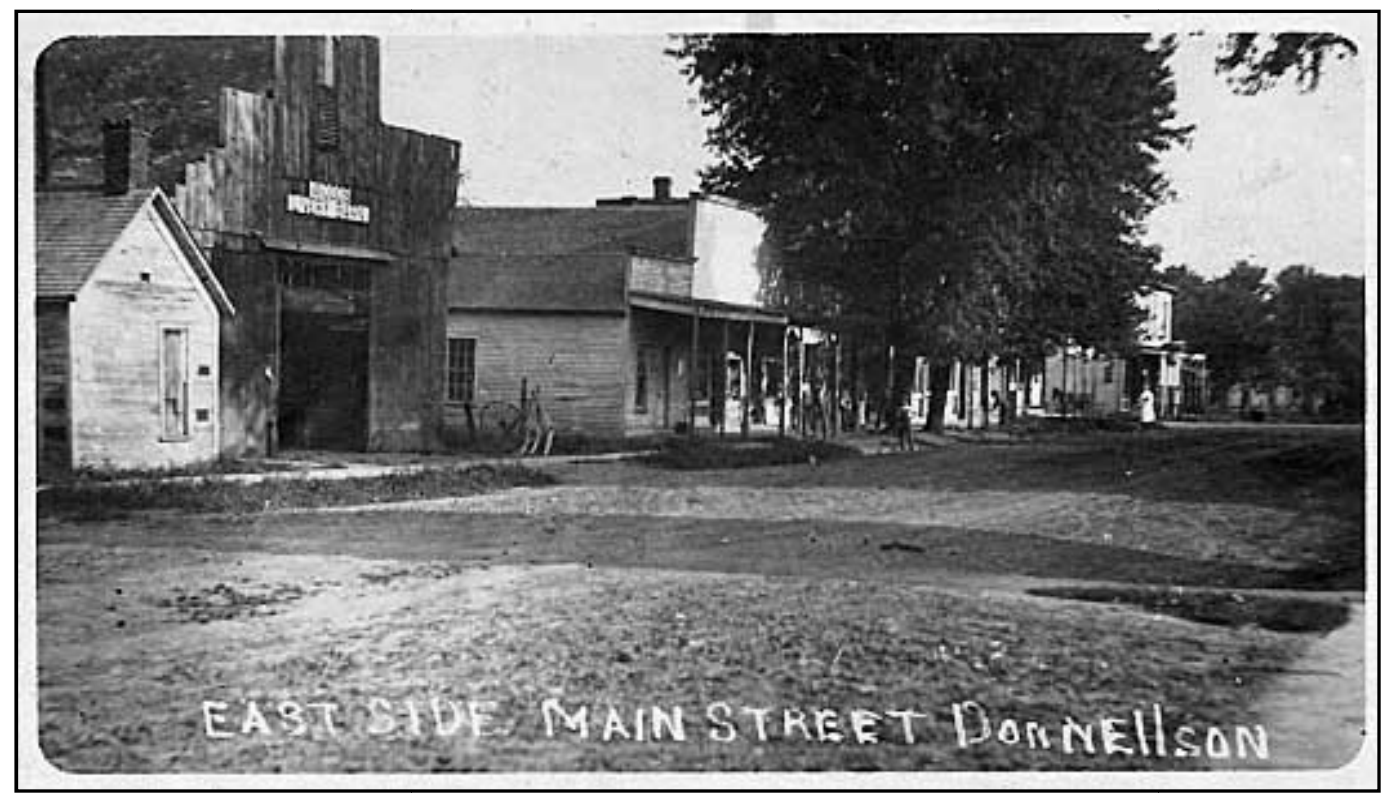

Figura 3. Rua de Donnellson na primeira metade do século XX.

Fonte: Montgomery County Illinois Historical Photo Archive.

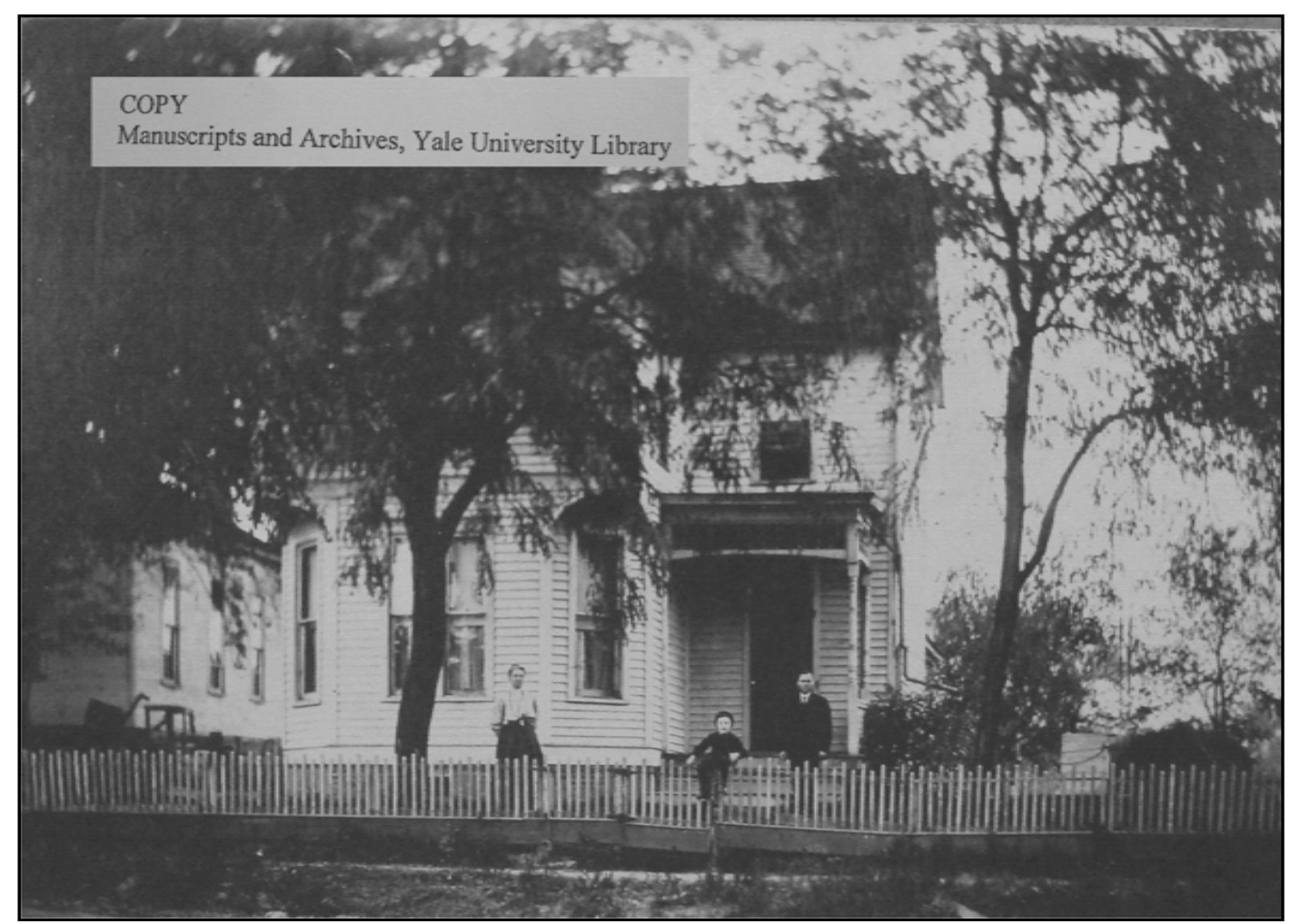

Figura 4. Residência dos Lasswell em Enfield. Fonte: Harold Lasswell's Papers, Yale Manuscripts and Archives, Sterling Memorial Library, Universidade de Yale. 


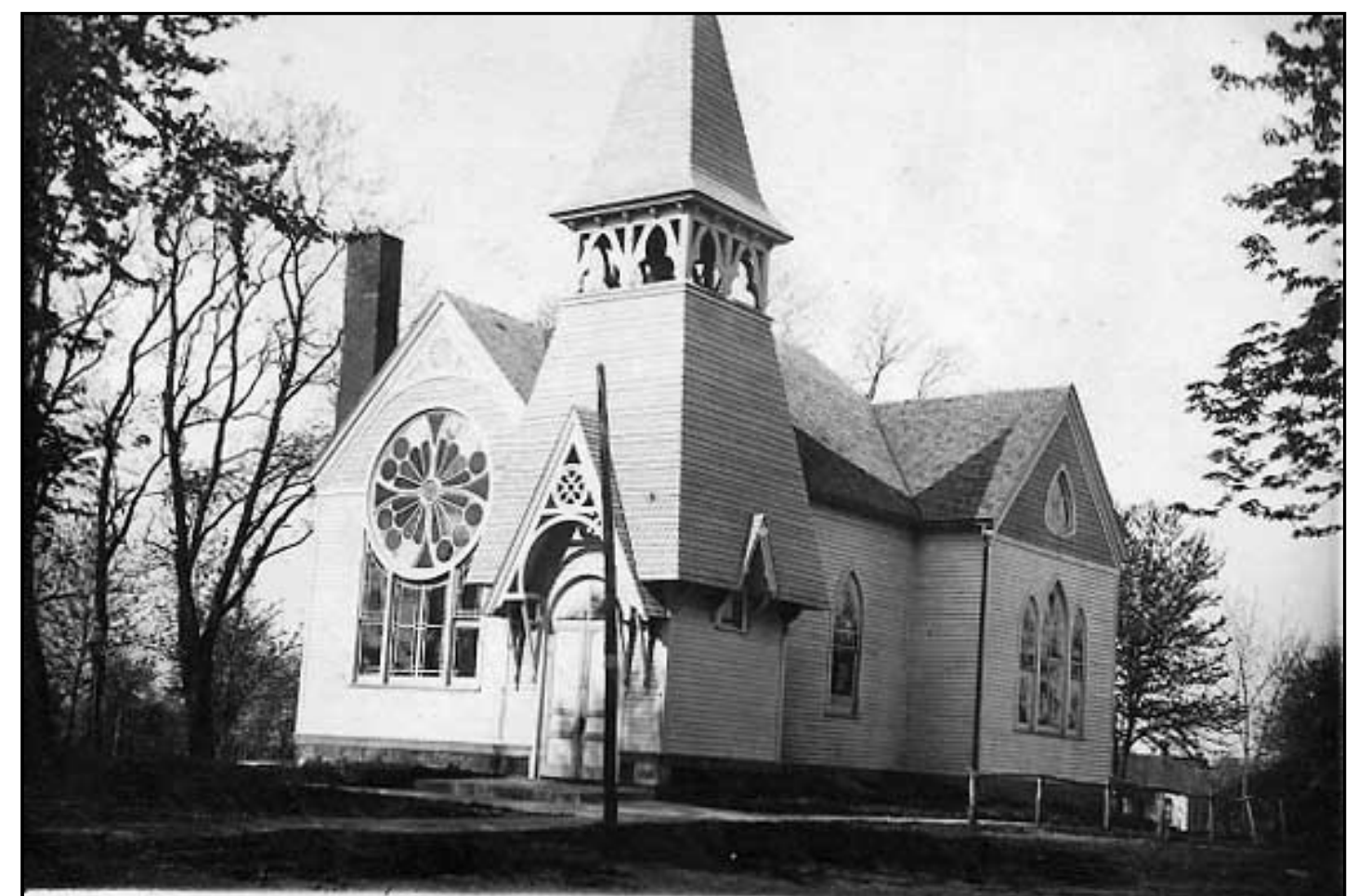

Figura 5. Igreja Presbiteriana de Donnellson, onde Linden Lasswell era pastor. O prédio é o mesmo ainda hoje. Foto da primeira metade do século XX. Fonte: Montgomery County Illinois Historical Photo Archive.

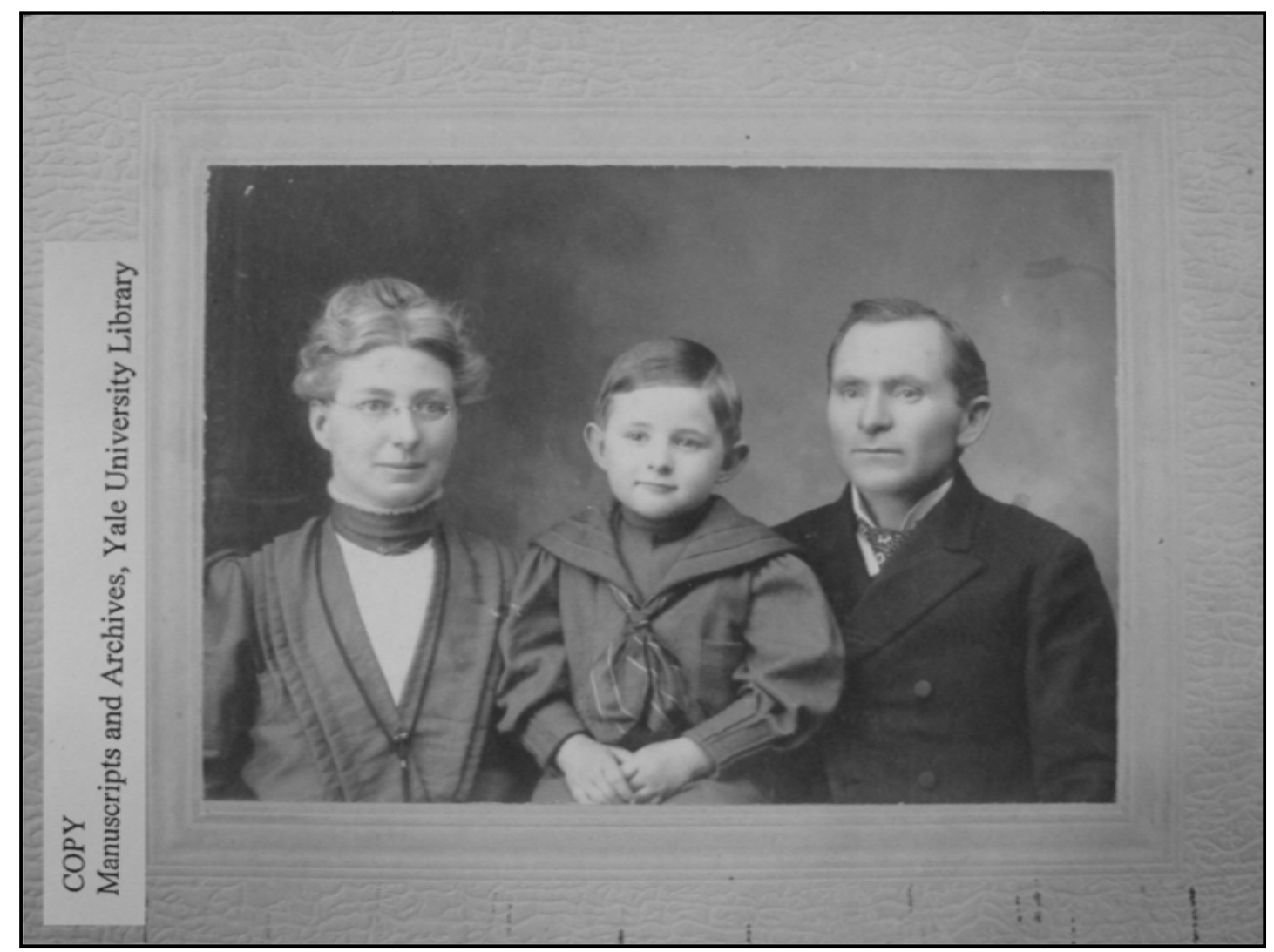

Figura 6. Harold Lasswell e os pais. Fonte: Harold Lasswell's Papers, Yale Manuscripts and Archives, Sterling Memorial Library, Universidade de Yale. 


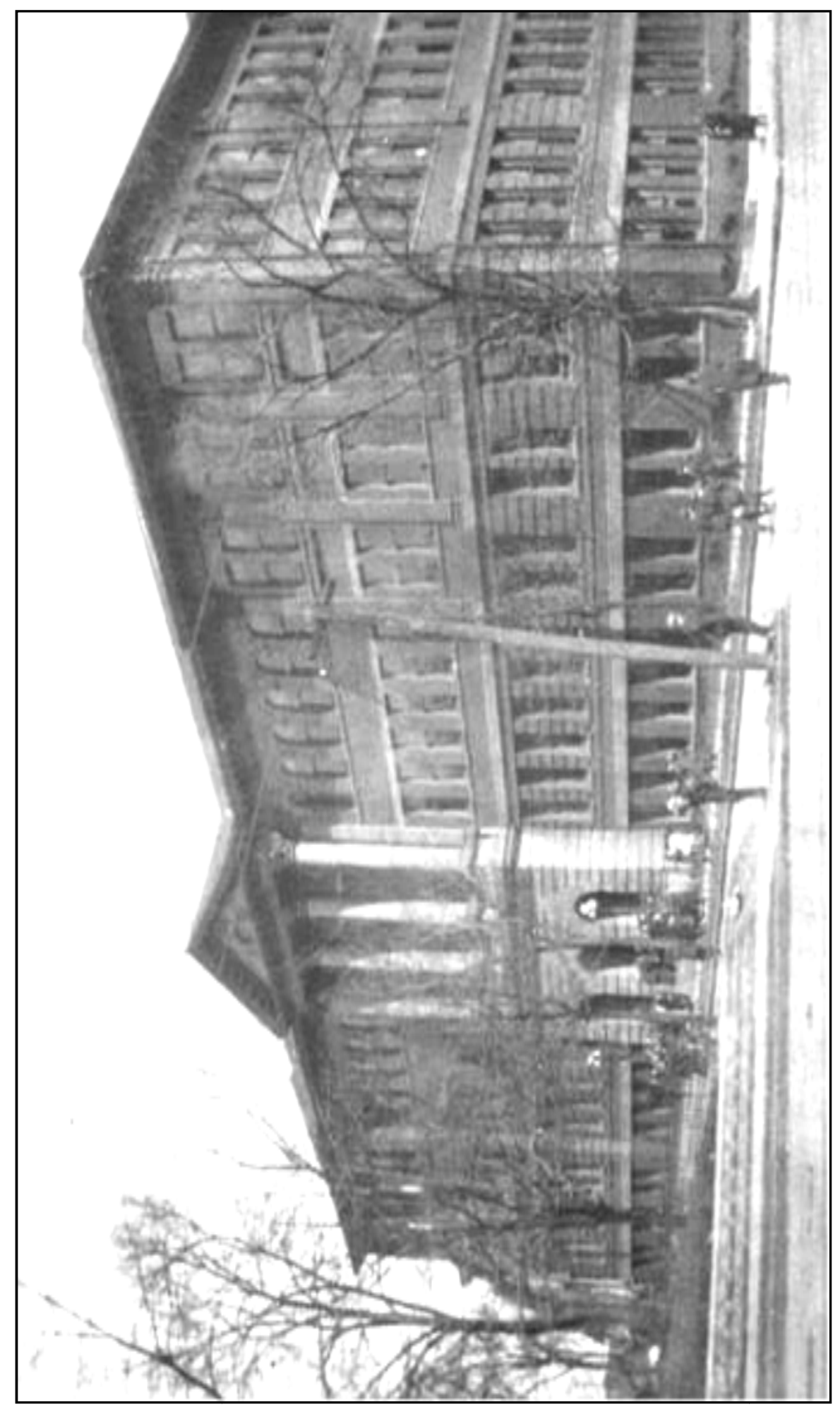

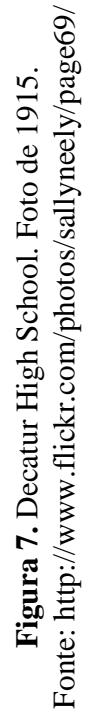




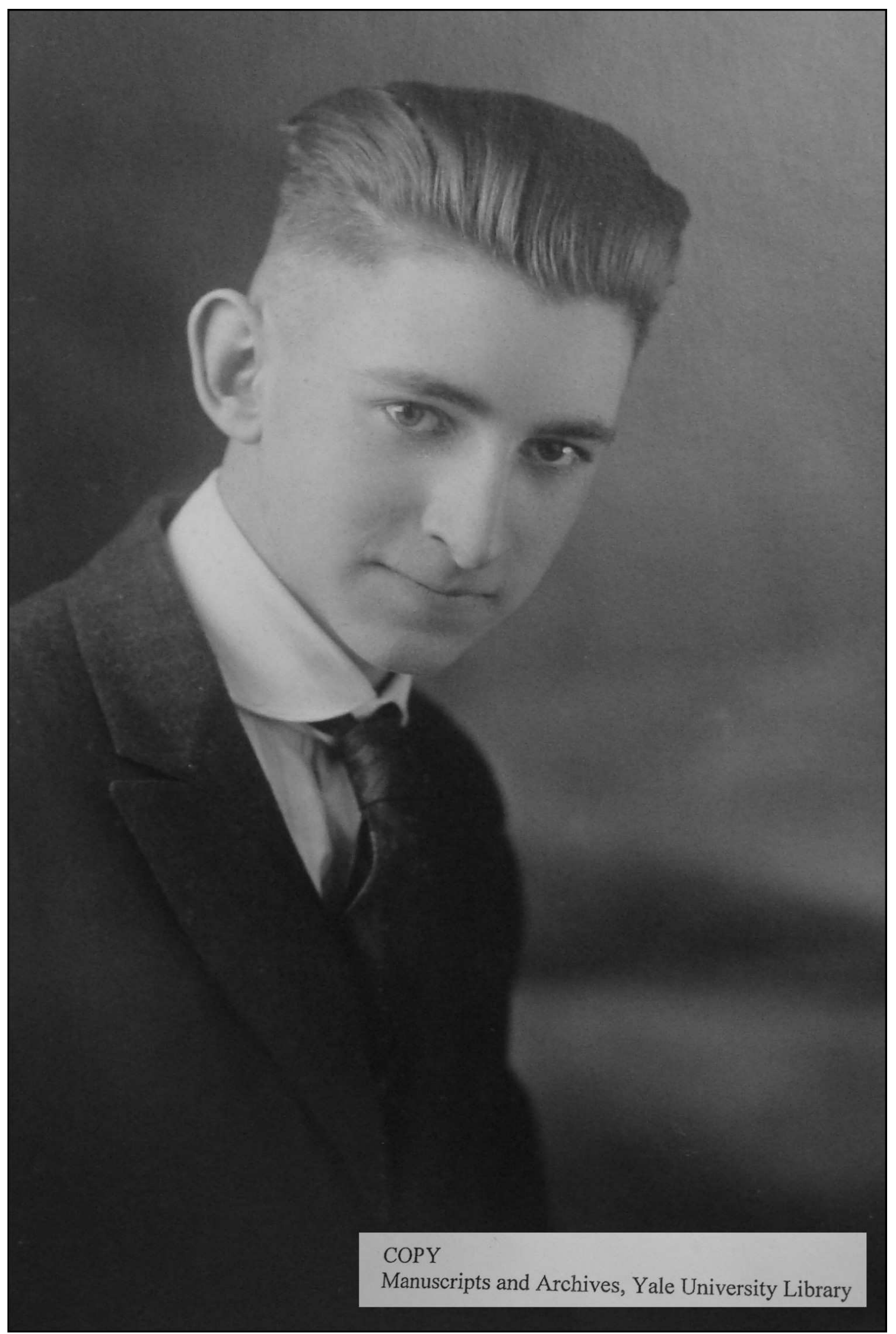

Figura 8. Fotografia de formatura na Decatur High School, em 1918, ano em que ingressou na Universidade de Chicago. Lasswell tinha 16 anos. Fonte: Harold Lasswell's Papers, Yale Manuscripts and Archives, Sterling Memorial Library, Universidade de Yale. 


\subsection{Os anos "mistificadores": de 1918 a 1946}

Um dos retratos mais contundentes sobre o acadêmico e a personalidade em que Harold Lasswell se tornaria, a partir de sua entrada na Universidade de Chicago, foi escrito por Bruce Lannes Smith. Em The Mystifying Intellectual History of Harold D. Lasswell, Smith afirma:

Em Harold D. Lasswell, temos um homem muito mistificador: um bon vivant animado, com uma consciência social puritana; um narcisista surpreendentemente modesto, um prolífico escritor sobre as "elites", publicamente comprometido com a partilha generalizada de valores atualmente mal distribuídos, como renda, saúde, respeito e educação; um gigante intelectual brilhante, que tolera suavemente o cientista social típico; um pensador extremamente lúcido, que às vezes divaga (ainda que de forma intermitente) numa convulsão de longas palavras; um excelente construtor de teorias puras e de elevados quadros teóricos, que defende alternar "horas de alta abstração e dias de contato paciente com o detalhe humilde" - e que, de fato, segue seu próprio conselho. Um incansável quantificador que também lê incansavelmente história e filosofia inquantificáveis, um homem que combina amizades bastante calorosas a um comportamento muitas vezes descrito como "gelado". Temos, na verdade, uma espécie de Leonardo da Vinci das ciências do comportamento: o autor de mais de quarenta volumes importantes em áreas tão variadas como a antropologia, relações internacionais, filosofia política, ciência política empírica, política econômica, relações de trabalho, psiquiatria, semânticas quantitativas, e mesmo em campos pouco convencionais como a lei (se houver) do espaço sideral ${ }^{108}$ (SMITH, 1696, p.41).

A descrição feita por Smith se ampara no adjetivo mistificador - que neste caso pode ser entendido de forma mais adequada como "intrigante" -, para dar ideia da pouca obviedade e controvérsia presentes em Lasswell e sua obra. Mostra como o cientista político transitou por diversas áreas do conhecimento, produzindo até mesmo sobre as possíveis viagens e migrações espaciais (como no artigo Men in space, de 1958). O adjetivo mistificador pode identificar também os anos em que Lasswell deixou de ser apenas um menino prodígio, do atrasado centro-oeste dos Estados Unidos, para

\footnotetext{
${ }^{108}$ No original: "In Harold D. Lasswell we have a very mystifying man: a lively bon vivant with a somewhat puritanical social conscience; a surprisingly modest narcissist; a prolific writer on "elites" who is publicly committed to the widespread sharing of such currently ill-distributed value as income, health, deference, and education; a scintillating intellectual giant who tolerates the typical social scientist suavely; an extremely lucid thinker who sometimes verbigerates (intermittently, though) with hypersesquipedalian anfractuosity; a topflight builder of pure theories and towering theoretical frameworks who advocates alternating "hours of high abstraction and days of patient contact with humble detail" - and actually follows his own advice; a tireless quantifier who also reads tirelessly in unquantified history and philosophy; a man who combines with many a warm friendship a detachment often described as "icy". We have, in fact, a kind of Leonardo da Vinci of the behavioral sciences: author of some forty volumes of substantial works in such assorted areas as anthropology, international relations, political philosophy, empirical political science, economic policy, labor relations, psychiatry, quantitative semantics, and even such far-out fields as the law (if any) of outer space".
} 
ocupar um lugar pioneiro nas Ciências Sociais e na pesquisa em Comunicação daquele país. Esses anos vão de 1918 a 1946, até a ida de Lasswell para Yale, onde foi contratado como professor do curso de Direito, na Yale Law School. Esses são os anos em que Lasswell firma, para muitos, seu nome como "[...] o mais fértil catalisador e teorizador de sua geração [...] um gerador fenomenal de ideias" (ROSTEN, 1969, pp.811) ${ }^{109}$. Anos em que consolidou sua carreira transitando, mistificadoramente, entre várias disciplinas - o que levou Margareth $\operatorname{Mead}^{110}$ a afirmar, na ocasião do $50^{\circ}$ aniversário de Lasswell, que o problema com o cientista político "[...] é que ele pensa precisamente na linguagem de, pelo menos, 12 disciplinas" $" 111$.

Em 1918, a Universidade de Chicago estava na segunda geração de professores (SHILS, 1991) e contava com um bom investimento financeiro, crescendo num ritmo impressionante. O trabalho dos scholars e cientistas não se limitava a estabelecer o prestígio da Universidade. Pelo contrário, a Universidade de Chicago agregava grandes nomes da pesquisa nos Estados Unidos e no campo das Ciências Sociais e da Filosofia, como vimos no capítulo anterior. Muito antes, em 1903, William James já reconhecia a importância da universidade e afirmava em carta à senhora Henry Whitman:

A Universidade de Chicago durante os últimos seis meses deu à luz o fruto de dez anos de gestação de John Dewey. O resultado é maravilhoso - uma verdadeira escola, e um pensamento real. Um pensamento importante também! Você já ouviu falar de uma cidade assim ou de uma tal universidade? Aqui nós temos o pensamento, mas nenhuma escola. Em Yale, uma escola, mas não um pensamento. Chicago tem os dois... ${ }^{112}$ (JAMES, 2003, pp.201-202).

Com o término da Primeira Guerra Mundial, contudo, a Universidade de Chicago passou a ter muitos competidores. Essa situação reforçou ainda mais o estímulo ao desempenho intelectual de seus membros, gerando comparação com instituições mais antigas da Europa, principalmente germânicas. "Seriedade intelectual”, como disse

\footnotetext{
${ }^{109}$ No original: "[...] the most fertile catalyst and theorist of his generation [...] a phenomenal generator of ideas".

${ }^{110}$ Antropóloga estadunidense. Contribuiu para a consolidação da teoria cibernética e trabalhou com vários pesquisadores associados hoje ao campo da comunicação.

${ }^{111}$ No original: "the problem with Harold Lasswell is that he thinks precisely in the language of about 12 different disciplines”. A frase de Margareth Mead é citada em carta escrita pelo cientista político Louis T. Olom ao Washington Post, em 27 de dezembro de 1978, alguns dias após a morte de Lasswell. Disponível em Harold Lasswell's Papers, Yale Manuscripts and Archives, Sterling Memorial Library, Universidade de Yale.

${ }^{112}$ No original: "Chicago University has during the past six months given birth to the fruit of its ten years of gestation under John Dewey. The result is wonderful - a real school, and real thought. Important thought too! Did you ever hear of such a city or such a University? Here we have thought, but no school. At Yale, a school, but no thought. Chicago have both...".
} 
Shils, "era a marca distintiva da Universidade de Chicago" $\left(1991\right.$, p.XII) ${ }^{113}$. Foi nessa atmosfera que Lasswell amadureceu como pesquisador.

De 1918 a 1922, Lasswell formou-se em Economia, tendo sido bastante ativo na Universidade durante os anos de graduação. Como ele próprio relata ${ }^{114}$, foi

[...] presidente da minha Fraternidade (Tau Kappa Epsilon), [...] marshal student ${ }^{115},[.$.$] representante estudantil no Conselho de$ Capela. [...] membro da equipe de debates, [...] líder de um clube de meninos no Casa de Assentamento da Universidade, e [...] membro do então recém-organizado Clube Liberal. Quando a Sociedade Intercolegiada Socialista fundiu-se a um grupo de alunos liberais, não-socialistas, em 1921, para formar a Liga para a Democracia Industrial, eu me tornei membro. ${ }^{116}$

A intensa atividade social a que Lasswell se submeteu forneceu a ele elementos importantes para pensar a sociedade levando em conta sua experiência. Ajudar recémchegados a Chicago, por exemplo, na casa de Casa de Assentamento da Universidade, possibilitou a Lasswell um contato revelador com a situação de imigrantes.

Entre 1919 e 1922, Lasswell também lecionou cursos para sindicatos e para veteranos da Primeira Guerra Mundial sobre negócios e administração, na Mayo Business College, em Chicago (MUTH, 1989). As lições ensinadas renderam seu primeiro livro, em colaboração com Willard Atkins ${ }^{117}$, Labour Attitudes and Problems ${ }^{118}$, publicado em 1924. Enquanto Atkins encarregou-se mais de economia em Labour..., Lasswell contribuiu com questões de psicologia - além de ter iniciado, segundo ele próprio, a maior parte das ideias originais (Idem, ibidem).

Mas a parceria mais importante que Lasswell começaria a desenvolver, nos anos de bacharelado em Economia, foi com seu futuro orientador de doutorado, iniciado imediatamente após a graduação: Charles Edward Merriam, "o fundador e o líder da 'Escola de Chicago' de Ciência Política"119 (Almond, 1991, p.338). Foi Merriam,

\footnotetext{
${ }^{113}$ No original: "Intellectual gravitas was the distinctive mark of University of Chicago".

${ }^{114}$ Em memorial (affidavit) exigido como documento para que tomasse posse como professor de Ciência Política na Universidade de Yale. 23 de outubro de 1951. Disponível em Harold Lasswell's Papers, Yale Manuscripts and Archives, Sterling Memorial Library, Universidade de Yale.

${ }^{115}$ A mais alta distinção estudantil dada pela Universidade de Chicago.

${ }^{116}$ No original: [...] president of my fraternity chapter (Tau Kappa Epsilon), [...] a student marshal, [...] a student representative on the Chapel Council. [...] a member of the debating team, [...] the leader of a boys' club at the University Settlement House, and [...] a member of the then recently organized Liberal Club. When the Intercollegiate Socialist Society merged with non-socialist liberal student group, in 1921 to form the League for Industrial Democracy, I became a member".

${ }^{117}$ Atkins era economista, professor na Universidade da Carolina do Norte. Foi assistente de Lei Comercial no Exército dos Estados Unidos durante a Primeira Guerra Mundial.

${ }^{118}$ Em carta aos pais, em fevereiro de 1924, Lasswell se demonstrava pouco satisfeito com este primeiro trabalho, pois considerava não haver nenhuma contribuição de pesquisa nele. Disponível em Harold Lasswell's Papers, Yale Manuscripts and Archives, Sterling Memorial Library, Universidade de Yale.

${ }^{119}$ No original: "the founder and the leader of the 'Chicago School' of political science".
} 
enfim, a principal ponte entre a Política e a Comunicação, nos estudos que Lasswell viria a desenvolver.

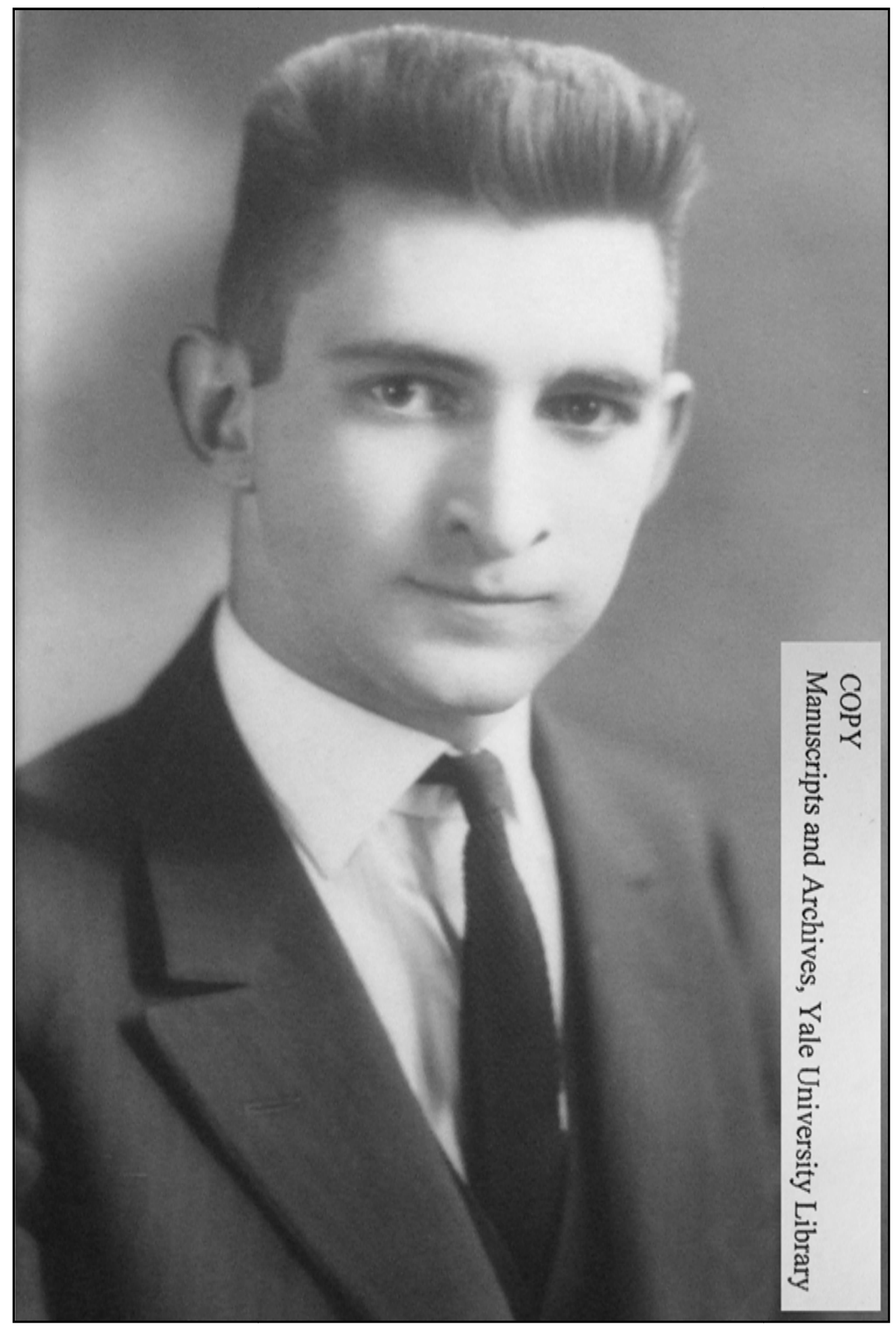

Figura 9. Fotografia de formatura em Economia na Universidade de Chicago, em 1922. Lasswell tinha 20 anos. Fonte: Harold Lasswell's Papers, Yale Manuscripts and Archives, Sterling Memorial Library, Universidade de Yale. 


\subsubsection{De Política e Propaganda}

Em 1922, Lasswell resolveu migrar do estudo das relações econômicas para o estudo da política, pois considerava este último mais desafiador. Desse modo, Lasswell iniciou em seu doutorado a formação pela qual ficaria mais conhecido: a de cientista político. Em carta aos pais, justificava a mudança: “[...] a economia é um campo que, infelizmente, necessita de uma reorganização geral do lado teórico"120.

Ao chegar ao departamento de Ciência Política, Lasswell encontrou em Charles Edward Merriam, não apenas um orientador para sua tese, mas um aliado. Então chefe do departamento que Lasswell escolheu para se doutorar, Merriam o empregou rapidamente como professor assistente e facilitou suas idas à Europa durante os anos de doutoramento, para realizar suas pesquisas.

Merriam merece uma atenção maior de nossa parte, pois é ele quem, sem sombra de dúvidas, direciona Lasswell a pensar sobre o problema da propaganda - e o seu papel nessa decisão é poucas vezes lembrado. Foram os primeiros anos com Merriam que fomentaram a aproximação de Lasswell com o campo da Comunicação, sob o viés político. E são esses mesmos anos que dimensionam a figura de Lasswell como a principal autoridade nos estudos de propaganda, no período que se estende de 1924 a 1938 (PETERS; SiMONSON, 2004, p.47).

Charles Merriam nasceu em Hompkton, Iowa, em 15 de novembro de 1874, e teve uma formação inicial em Direito, obtida pela Universidade do Estado de Iowa profissão que rapidamente abandonou. Em seguida, Merriam optou pelo estudo de Ciências Sociais, obtendo doutorado pela Universidade de Columbia, em 1900, sob o título de History of the Theory of Sovereignty since Rousseau (História da Teoria da Soberania desde Rousseau). O tema de Merriam era voltado para a compreensão das teorias do poder, o que o levou a iniciar uma carreira prolífica como professor de história das doutrinas políticas nos Estados Unidos, não em Columbia, mas na Universidade de Chicago. Sua principal obra do período, além de sua tese, é o livro American Political Theories (1903).

Merriam havia escrito, em 1921, o manifesto decisivo para a consolidação do departamento de Ciência Política na Universidade de Chicago: The present state of the

\footnotetext{
${ }^{120}$ No original: "[...] economics is a field which is sadly in need of general reorganization on the theoretical side, although in research work it is farther along than political science, much farther". Carta a Anna e Linden Lasswell, 16 de abril de 1926. Disponível em Harold Lasswell's Papers, Yale Manuscripts and Archives, Sterling Memorial Library, Universidade de Yale.
} 
study of politics, publicado na revista American Political Science Review. Foi um esforço consciente, que projetou a Escola de Chicago, já forte na Sociologia, também no campo da política.

Desde seu inicio na Ciência Política, Merriam foi tomado por uma forte convicção, que o acompanhou até o fim da vida: para entender a política, é necessário participar ativamente dela. Dessa forma, chegou a pertencer ao Conselho da Cidade de Chicago (em 1909 e entre 1913 e 1917), além de concorrer em 1911, pelo partido Republicano, a prefeito da cidade.

Durante seus anos como professor de Ciência Política, Merriam participou ativamente dos processos políticos que eram foco de suas pesquisas acadêmicas. Merriam acreditava que, de muitas maneiras, as teorias sobre os processos políticos precisavam estar relacionadas à atividade política prática ${ }^{121}$

Essa forte relação com o poder possibilitou a Merriam angariar muitos recursos para o departamento de Ciência Política da Universidade de Chicago e possibilitou, também, o alinhamento desse departamento com o de Sociologia da mesma instituição, já que Merriam principia uma abordagem da política associada à pesquisa de campo, ao entendimento do comportamento político como principal foco de estudo da Ciência Política (a partir de uma abordagem behaviorista), e a percepção de que as Ciências Sociais poderiam, sim, funcionar adotando os modelos das Ciências Naturais.

Além disso, sob o comando de Merriam, o vínculo entre o departamento de Ciência Política da Universidade de Chicago e o governo dos Estados Unidos se estreitou de tal maneira que, entre 1930 e 1940, a maior parte dos professores do departamento desenvolvia alguma função relacionada ao governo estadunidense e mesmo nos anos anteriores ofereceram a ele algum suporte.

Merriam foi chefe da propaganda americana em Roma durante a Primeira Guerra Mundial, averiguando os efeitos e a composição da propaganda dos Estados Unidos na Itália, e embora não tenha produzido muito a respeito de propaganda, era Merriam a pessoa mais indicada a conduzir a pesquisa do jovem Lasswell. Pouco antes, Merriam havia escrito o artigo American Publicity in Italy (Publicidade Americana na Itália), em 1919, que contém uma série de pressupostos que embasarão o trabalho de

\footnotetext{
${ }^{121}$ No original: "During his years as a political science professor at the University of Chicago, Merriam actively participated in the political process that was the focus of his academic research. Merriam believed that at some point theories of political process needed to be linked to practical political activity". Disponível em: The University of Chicago Centennial Catalogues. http://www.lib.chicago.edu/e/spd/centacat;fac/facch15_01.html. Acessado em 09/03/2009.
} 
Lasswell. E, embora Merriam tenha ficado muito mais próximo de outro orientando seu, Harold Gosnell ${ }^{122}$, sua influência não deixou de ser sentida de maneira intensa nos primeiros anos de Lasswell como cientista político. Isso ocorreu por uma série de razões:

\begin{abstract}
Merriam lançou dois desafios para o brilhante e ambicioso jovem cientista político. O primeiro veio da experiência de Merriam durante a guerra, como chefe da propaganda americana em Roma. O segundo surgiu do interesse de Merriam sobre as características de líderes políticos e os usos do estudo do anormal e do psicopatológico para explicar o comportamento normal e típico. O primeiro interesse de Merriam - a importância da moral, da propaganda e da formação cívica na explicação do comportamento político - conduziu a tese de doutorado de Lasswell em 1927 [...] e, finalmente, à invenção pelo cientista político da análise de conteúdo sistemática e seus usos na Segunda Guerra Mundial. O segundo interesse de Merriam - os aspectos psicológicos da liderança e os usos do anormal na explicação do normal -, levou a uma série de artigos de Lasswell sobre psicologia política e a personalidade política, culminando na obra Psicopatologia e Política (ALMOND, 1987, p.252) ${ }^{123}$.
\end{abstract}

Como fundador do SSRC, Social Science Research Council (Conselho de Pesquisa em Ciências Sociais), criado em 1923, Charles Merriam agregava ainda uma proposta de inclusão da pesquisa em comunicação aos objetivos desta instituição, que serviu a maioria das grandes fundações estadunidenses, como a Fundação Ford, a Fundação Rockefeller e a Fundação Russel Sage ${ }^{124}$.

Com esse intuito, Merriam buscou se aproximar do mais proeminente nome a falar sobre os media na época: Walter Lippmann (1889-1974), cujo livro Opinião Pública, de 1922, é muitas vezes citado como o primeiro livro-texto da pesquisa em comunicação nos EUA (cf. CAREY, 1989, por exemplo). Nascido em Nova York,

\footnotetext{
${ }^{122}$ Merriam e Gosnell produziram juntos o importante livro Non-voting (1924), um dos primeiros grandes trabalhos empíricos dedicados ao estudo de eleições (BULMER, 1986).

${ }^{123}$ No original: "Merriam threw out two challenges to the brilliant and ambitious young political scientist. The first came out of Merriam's wartime experience as chief American propagandist in Rome; the second arose from Merriam's interest in the characteristics of political leaders and the uses of the study of the abnormal and the psychopathological in explaining normal and typical behavior. Merriam's first interest- the importance of morale, propaganda, and civic training in the explanation of political behavior-led to Lasswell's 1927 doctoral dissertation, [...] and ultimately to his invention of systematic content analysis and its uses in World War II. Merriam's second interest - the psychological and personality aspects of leadership and the uses of the abnormal in the explanation of the normal-led to a series of articles by Lasswell on political psychology and personalityin politics, culminating in his Psychopathology and Politics".

${ }^{124}$ O Conselho ainda existe e hoje está sob a presidência de Craig Calhoun, sociólogo e professor a Universidade da Cidade de Nova York.
} 
Lippmann entrou aos 17 anos na Universidade de Harvard, onde cursou Filosofia e foi aluno de George Santayanna e William James. Walter Lippmann tinha, de fato, uma envergadura intelectual impressionante e seus livros traziam uma arguta reflexão sobre a época em que vivia, o que levou o presidente Theodore Roosevelt a declarar o jornalista ${ }^{125}$ como o "mais brilhante jovem da sua idade em todo os Estados Unidos"126 (STEEL apud JANSEN, 2010, p.131).

Merriam trocou correspondência com Lippmann, especialmente entre os anos de 1921 e 1927, ávido por absorver as possíveis contribuições do último para formação das metas do SSRC, sobretudo no que tange à "[...] análise das notícias, cidadania e inteligência organizada" (JANSEN, 2010, p.132).

Em 1924, o SSRC aprovou um projeto de pesquisa direcionado ao estudo de notícias internacionais, "uma investigação científica completa e objetiva dos instrumentos envolvidos na difusão de notícias e opiniões de interesse internacional, e das atitudes subjacentes aos assuntos internacionais"127 (MERRIAM apud JANSEN, 2010, p.135). Lippmann foi convidado a participar do projeto, mas declinou. Mesmo assim, o SSRC investiu na proposta, que gerou o Comitê de Notícias Internacionais e Comunicação, sob a presidência de Walter S. Rogers, que havia sido diretor da Divisão de Serviços a Cabo e Sem Fio do Comitê de Informação Pública (Comissão Creel) na Primeira Guerra Mundial - e Lippmann continuou a ser uma influência no trabalho de Merriam e no trabalho de seu discípulo Lasswell ${ }^{128}$.

Todo esse envolvimento com problemas ligados à comunicação, contudo, tinha como foco final o papel desta nas relações políticas. Merriam foi o pioneiro em pensar a possibilidade do estabelecimento de um caráter cientifico ao estudo da política e de uma aproximação deste aos métodos das Ciências Naturais. Como foi notado por Heaney e Hansen, "Mesmo em 1921, Charles Merriam não era o único defensor de uma abordagem cientifica no estudo da política"129 (2006, p. 591).

\footnotetext{
${ }^{125}$ Lippmann foi condecorado duas vezes com o prêmio Pulitzer, em 1958 e 1962.

${ }^{126}$ No original: "most brilliant young man of his age in all of the United States". De fato, comparado a Lasswell, Lippmann possuía um espectro de observação mais filosófico e crítico diante dos problemas que o século XX colocava.

${ }^{127}$ No original: "a thoroughly scientific and objective investigation of the instrumentalities involved in the world wide gathering and dissemination of current news and opinion of international concern, and of the underlying attitudes on international affairs".

${ }^{128}$ No que diz respeito à análise das notícias e suas consequiências na sociedade. Em relação ao futuro da democracia, contudo, prevaleciam as diretrizes deweyanas, opostas à visão de Lippmann.

${ }^{129}$ No original: "Even in 1921, Charles Merriam was hardly the only advocate for a scientific approach to the study of politics".
} 
De acordo com Merriam, três seriam as diretrizes básicas para uma "nova Ciência Política”:

Primeiramente, a Ciência Política deveria mergulhar em práticas semelhantes às das Ciências Naturais - especialmente no que diz respeito à Biologia -, para o desenvolvimento das teorias políticas contemporâneas (uma idéia que revela claramente a influência da "ecologia urbana" no pensamento de Merriam, cujo contato particular com Ernest Burgess era intenso);

Em segundo lugar, a Ciência Política também deveria se voltar às Ciências Naturais para o desenvolvimento de métodos similares. Tais métodos já estavam presentes na Escola de Chicago sociológica e estavam relacionados à observação sistemática, à percepção da cidade como laboratório, à criação de laboratórios nas universidades, ao uso de estatística e assim por diante. Era necessário, também, observar o comportamento humano, e para isso era importante a importação dos preceitos psicológicos desenvolvidos pelo behaviorismo e o interacionismo simbólico. Essa última aproximação produziu mais tarde a Psicologia Política, especialidade na qual Lasswell foi um dos principais representantes;

Por fim, a Ciência Política deveria se voltar às Ciências Naturais com o objetivo de tomá-las como exemplo daquilo que o estudo da política deveria ser: uma ciência com fins práticos.

Vê-se que muitos dos pressupostos que estavam presentes na Escola de Chicago da Sociologia permeavam as propostas de Merriam para a Ciência Política e eram, em grande parte resultado da forte cooperação entre os departamentos das Ciências Sociais na Universidade de Chicago, pouco afeitos a fronteiras disciplinares. Concomitantemente, reforçavam a principal crença de Merriam: participar da vida política ativamente seria um dos pré-requisitos para exercer a pesquisa no campo da Ciência Política.

Nessa tentativa de alinhar ciência e prática política - e apesar de ser um dos seus raros textos sobre comunicação, além de não poder ser considerado mais que uma reportagem -, American publicity in Italy acabou sintetizando o momento vivido pelos estudos políticos e pelos estudos sobre Comunicação na época. Representa um estágio pré-científico nas discussões acadêmicas acerca dos temas que aborda, mas também simboliza o início da pesquisas com base nos preceitos da Escola de Chicago sobre a propaganda. Merriam, contudo, estava mais interessado nos processos de formação de voto que não estavam diretamente relacionados à ação dos meios de comunicação de 
massa, como as festas dos partidos políticos, e a definição mais geral dos estatutos epistemológicos da Ciência Política.

Coube a Lasswell desenvolver a semente lançada por Merriam em American publicity in Italy, cujo início é uma síntese do pensamento do começo do século XX sobre a propaganda.

De muitas maneiras, American publicity in Italy condensava as diversas faces e a importância que os estudos sobre a propaganda, nos Estados Unidos, iriam assumir a partir de então, tendo como auge a criação do Instituto de Análise da Propaganda, em 1937. Todavia, há poucos escritos de Merriam sobre comunicação além desse relato resultante de sua atuação como alto comissário no Comitê de Informação Pública. É Lasswell que, na interface entre Comunicação e Política, passa a entender a primeira como objeto de estudo científico.

A escolha da propaganda como tema fundamental de sua pesquisa se deu em uma de suas viagens à Europa. É o próprio Lasswell quem conta que

De janeiro a março de 1924, eu estava na Sorbonne, em Paris. Nesta altura, eu tinha definitivamente escolhido como tema para minha tese de doutorado as táticas de propaganda empregadas na Primeira Guerra Mundial, e passei a maior parte do meu tempo em Paris numa biblioteca especial do governo dedicada ao material de propaganda de guerra. Meus estudos com o professor Merriam, que foi particularmente ativo, neste momento, no campo geral da formação cívica e como fonte de lealdade cívica, tinham centrado o meu próprio interesse na propaganda política, suas origens, efeitos e (sobretudo) sua psicologia, o que acabou se tornando o assunto da minha vida profissional. ${ }^{130}$

Assim, em junho de 1926, após passar um período em universidades de Londres, Berlim, Paris e Genebra, Lasswell defendeu Técnica de Propaganda na Guerra Mundial, dando prosseguimento às idéias de Merriam na Ciência Política e avançando sobre o novo campo de estudo ainda não institucionalizado que era a Comunicação. Técnica de Propaganda na Guerra Mundial concretizou o caráter mais científico que Merriam esperava da Ciência Política - e que ele próprio, em função da carreira no governo, não conseguira materializar.

\footnotetext{
${ }^{130}$ No original: "From January to March of 1924, I [he] was at the Sorbonne, in Paris. By this time, I had definitely chosen as the subject-matter for my doctoral thesis the propaganda tactics employed on World War I, and I spent most of my time in Paris at a special government library devoted to war propaganda material. My studies with professor Merriam, who was particularly active at this time in the general field of civic training and the source of civic loyalty, had focused my own interest on political propaganda, of which the origin, effects and (particularly) the psychology were to became the subject matter of my life work". Memorial de 23 de outubro de 1951, disponível em Harold Lasswell's Papers, Yale Manuscripts and Archives, Sterling Memorial Library, Universidade de Yale.
} 
A tese de Lasswell é um marco pelo menos em duas outras frentes: é o primeiro trabalho científico sobre a propaganda nos Estados Unidos, além de ser considerada a obra pioneira na utilização da análise de conteúdo (WOLF, 2002). O trabalho possui um corpus bastante extenso para os padrões atuais, abarcando propagandas de guerra americanas, inglesas, francesas e alemãs durante a Primeira Guerra Mundial. O objetivo não era apenas descrever essas campanhas, mas entender os efeitos políticos e psicológicos das ideias veiculadas por esse material. Esse direcionamento foi também fruto das indicações de Merriam, que deu a Lasswell a atribuição de desenvolver os aspectos clínicos, psicológicos e sociológicos da pesquisa em Ciência Política (Cf. ALMOND, 1987). A recorrência a análise psicológica e sociológica vai ser, desde essa época, uma constante na obra lasswelliana.

Lasswell afirmava, logo no primeiro capítulo de Técnica de Propaganda, que sua intenção era escrever uma teoria explícita e geral sobre as estratégias da propaganda utilizadas na Primeira Guerra Mundial, não só escrever uma história da propaganda - o que já era um tema razoavelmente comum nos Estados Unidos e em outras partes do mundo. Para ele, a propaganda era uma forma de unificar a mente dos cidadãos, uma sugestão direta, capaz de manipular as crenças, atitudes e ações do público. É assim que Lasswell oferece uma das primeiras definições de propaganda, cuja acepção "se refere unicamente ao controle da opinião pública por símbolos significativos, ou, para falar mais concretamente, por histórias, boatos, relatórios, retratos e outras formas de comunicação social"131 (LASSWELL, 1938, p. 8-9).

A tese foi publicada no ano seguinte e, se por um lado causou certa polêmica ${ }^{132}$, por outro consolidou o nome de Lasswell como o de principal especialista em propaganda - visto que, mesmo que outros estudos sobre o assunto passassem a ser mais freqüentes (como The Propaganda Menace, de Frederick Elmore Lumley, de 1933), ainda careciam de uma base científica mais estruturada. De fato, quando Lasswell defendeu Técnica de Propaganda, estava praticamente falando sozinho. Apesar da enxurrada de livros sobre propaganda que já circulavam na época, a maior parte dos trabalhos estava voltada ou para uma história da propaganda ou a ensinar como produzi-la; não estavam interessados em teorizar e analisar a propaganda a partir de um método mais sistemático.

\footnotetext{
${ }^{131}$ No original, "Refers solely to the control of public opinion by significant symbols, or, to speak more concretely and less acurately, by stories, rumors, reports, pictures and other forms of social communication".

${ }^{132} \mathrm{O}$ historiador Foster R. Dulles, por exemplo, afirmou ser um texto maquiavélico, que deveria ser destruído (MUTH, 1989)
} 
Portanto, Lasswell se torna um dos poucos, ou o único, a tratar a propaganda de forma mais científica e passa a ser reconhecido como uma referência nesses estudos, dado o caráter pioneiro de Técnica de Propaganda na Guerra Mundial.

Ocupando esse lugar, na altura da publicação de sua tese, Lasswell já era “[...] uma LENDA no CAMPUS" ${ }^{\prime 33}$, como pesquisador e professor. Como cientista devotado, destacava-se nele a incrível erudição, que, por vezes, impedia o pensamento original (ROSTEN, 1969), mas que o fazia transitar com desenvoltura por entre os muitos departamentos da universidade. Como docente,

Para 90 por cento dos barbudos que enfiavam os dedos dos pés em suas águas furiosas, Harold não era um professor, mas uma torrente, para resistir, ressentir, suportar e sobreviver. [...] Ele era impaciente com a mediocridade [...] para 5 por cento de seus alunos, Lasswell era uma galvanização, enervante, um cometa sedicioso que tinhavindo de algum planeta alienígena do intelecto [...] Ele exigia cérebro aos alunos, disciplina, bibliografia apavorante [...] E para os últimos 5 por cento, Harold era um abrir de olhos, um libertador da mente, um ampliador de horizontes, alguém como nunca veriam outra vez, neste mundo ou no próximo. Ele era original, perturbador, desafiador ${ }^{134}$ (Idem, ibidem, p.12).

Como pesquisador, Lasswell era também uma torrente. Entre 1926 e 1927, Lasswell já havia trabalhado com grande parte dos importantes nomes da Universidade de Chicago: Edward Sapir, Elton Mayo, Robert Park, George Herbert Mead, Harold Gosnell. Em 1928, retornou a Europa, onde

[...]se encontrou e conversou com Adolf Adler, Anna Freud, Hans Kelsen, Edouard Hitschmann, e Wilhelm Stekel, entre muitos outros. Além disso, ele visitou Viena e outras sociedades psicanalíticas e foi analisado por Theodor Reik ${ }^{135}$ (MUTH, 1989, p.10).

Ainda em 1927, mais afeito ainda à abordagem psicológica, deu início ao seu primeiro curso especializado, um seminário sobre propaganda política. Dois anos depois, escreveu seu trabalho mais importante desde sua tese de doutorado:

\footnotetext{
${ }^{133}$ No original: "[...] a LEGEND on CAMPUS”. Memorial sobre Harold Lasswell escrito por Luis Kutner, advogado e ativista de direitos humanos norte-americano. Kutner ajudou a criar a Anistia Internacional, em 1961. Documento de 7 de abril de 1979. Disponível em Harold Lasswell's Papers, Yale Manuscripts and Archives, Sterling Memorial Library, Universidade de Yale.

${ }^{134}$ No original: "For 90 percent of the unshaven who dipped their toes on his raging waters, Harold was not a teacher but a torrent, to be resisted, resented, endured, and survived. [...] He was impatient with mediocrity [...] for another 5 percent of his students, Lasswell was a galvanizing, unnerving, seditious comet who had roared in from some alien planet of the intellect [...] He required in students brain, discipline, fearful bibliography [...] And to the final 5 percent, Harold was an eye-opener, a mind-liberator, a horizon-widener unlike anyone they would ever run into again, in this world or next. He was original, disruptive, challenging, derisive".

${ }^{135}$ No original: "[...] he met and talked with Adolf Adler, Anna Freud, Hans Kelsen, Edouard Hitschmann, and Wilhelm Stekel, among many others. In addition, he visited the Vienna and other psychoanalytic societies and was analyzed by Theodor Reik".
} 
Psicopatologia e Política, publicado em 1930. A grande influência nesta obra é, sem dúvida, a de Elton Mayo. A intenção de Lasswell era adaptar os métodos mais gerais de Mayo, voltados às questões das relações humanas, ao estudo das personalidades políticas. O envolvimento com a psicologia levou Lasswell a procedimentos bastante controversos, analisando voluntários ${ }^{136}$. A experiência resultou numa série de artigos e ajudou a estabelecer o campo da psicologia política, do qual Lasswell é considerado o fundador (Idem, ibidem, p.11).

A década de 1930, aliás, representa um ponto de virada na carreira de Lasswell. Ele inicia uma série de contribuições originais ao campo da Ciência Política, ao mesmo tempo em que suas pesquisas sobre propaganda avançam e o transformam numa peçachave para os estudos sobre comunicação. Soma-se a isso o próprio desenvolvimento do campo comunicacional.

\footnotetext{
${ }^{136}$ A proximidade de Lasswell com os estudos de Psicologia vai culminar com sua efetiva eleição para compor o quadro de Diretores da Escola de Psiquiatria em Washington, de 1936 a 1938.
} 


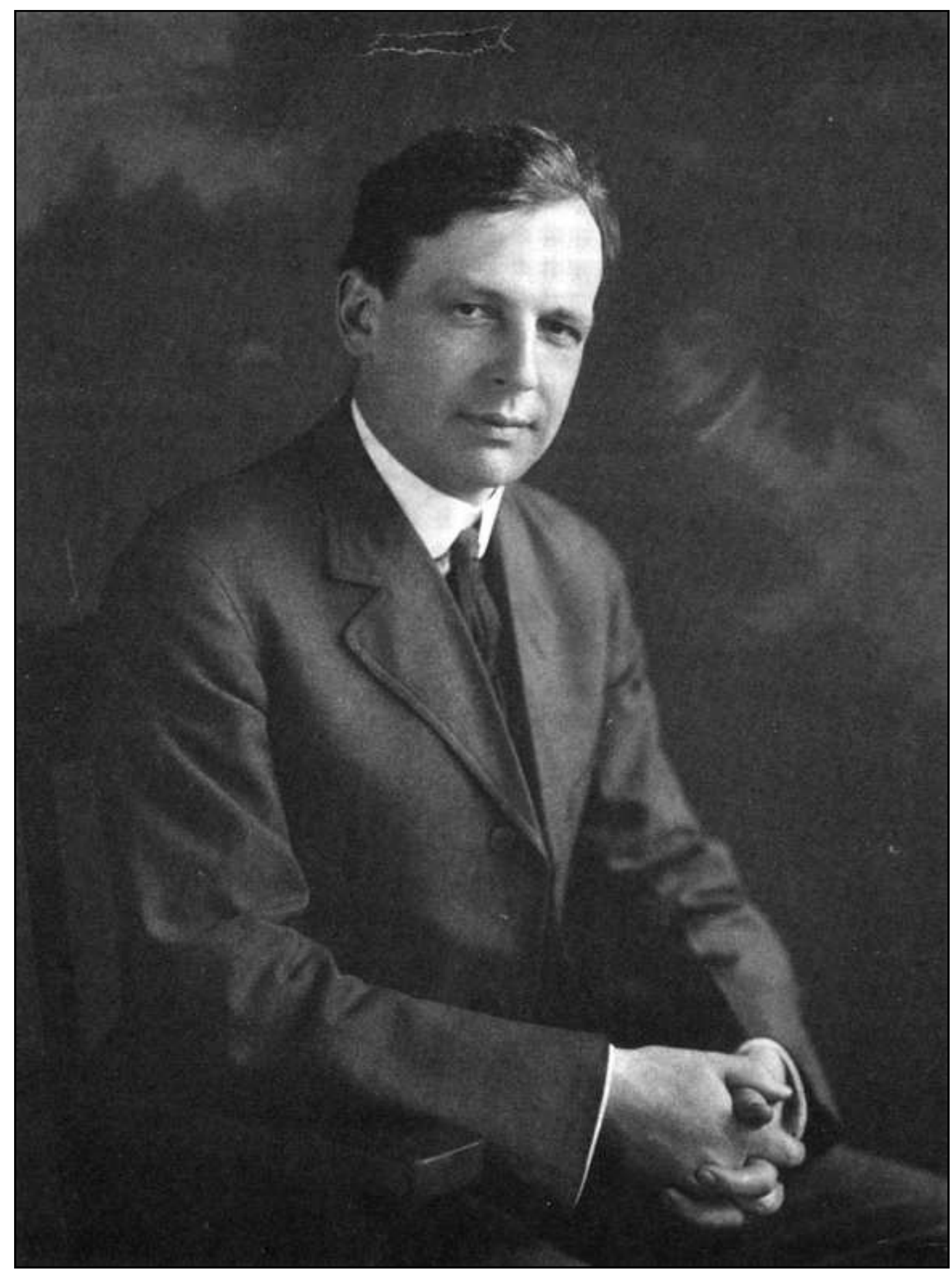

Figura 10. Charles Edward Merriam, orientador de doutorado de Lasswell. Foi ele o principal responsável pela aproximação do cientista político e o tema da propaganda. Fonte: The University of Chicago Centennial Catalogues. 


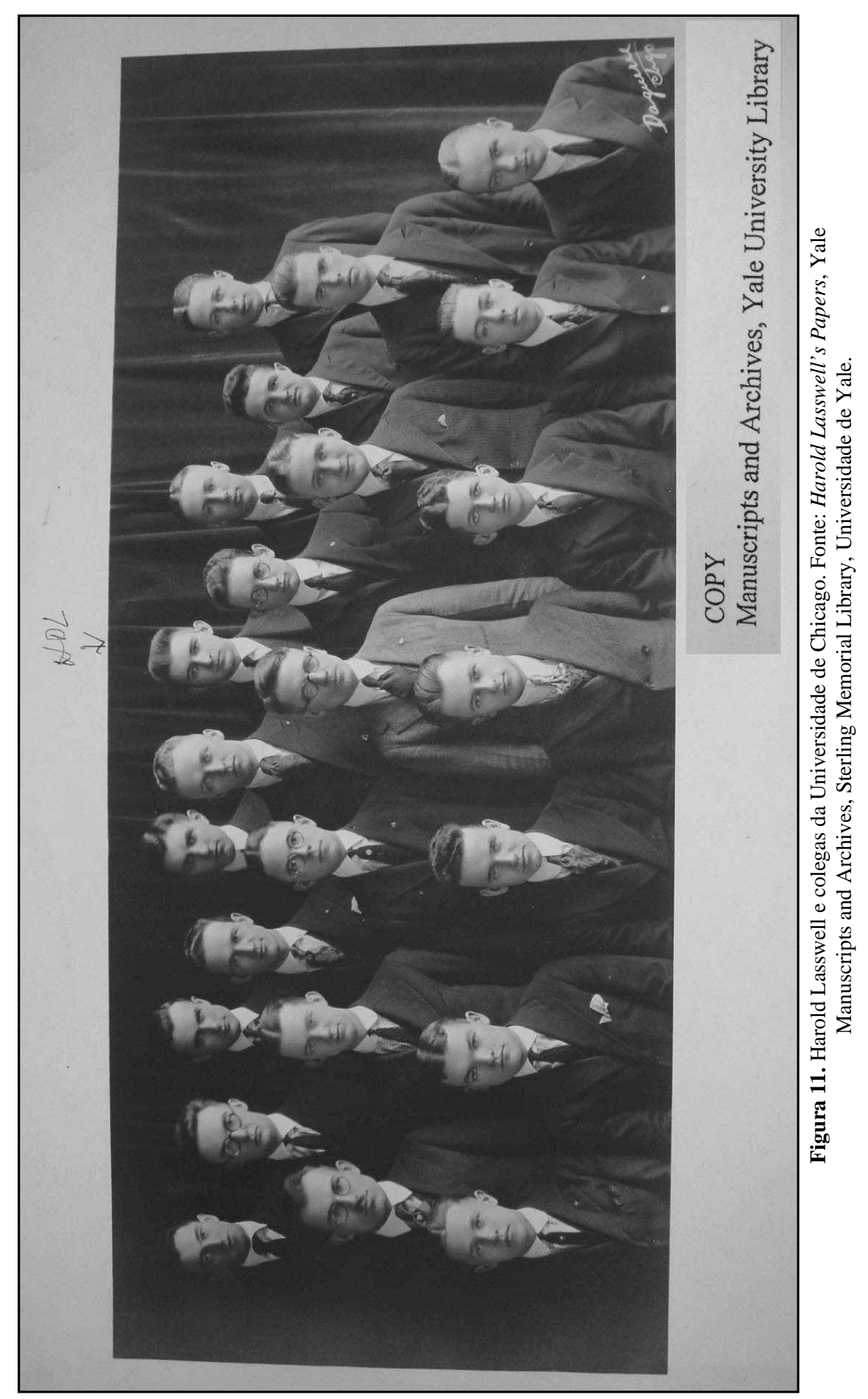




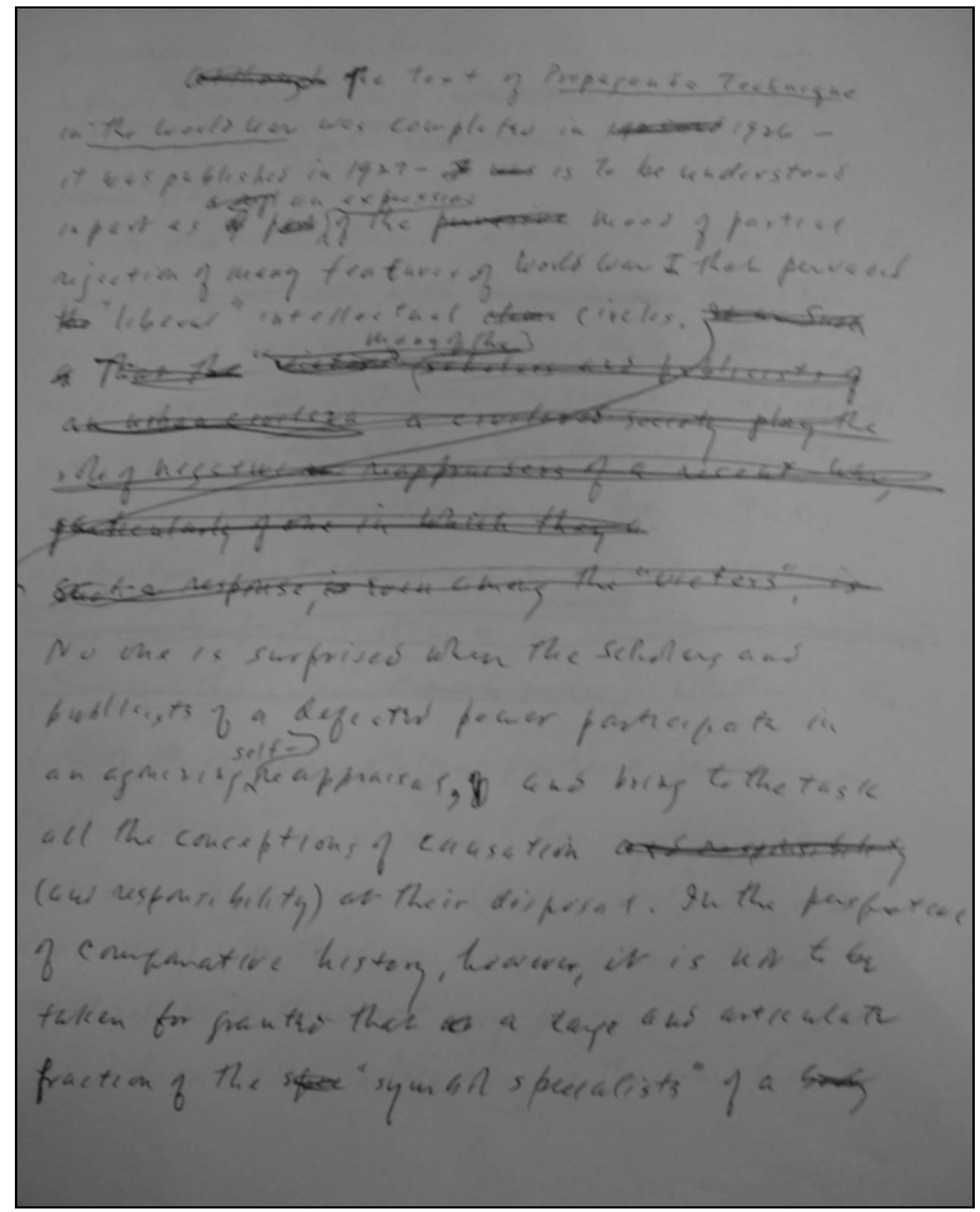

Figura 12. Manuscrito de Lasswell sobre Técnica de propaganda na Guerra Mundial. Fonte: Harold Lasswell's Papers, Yale Manuscripts and Archives, Sterling Memorial Library, Universidade de Yale. 


\subsubsection{De Propaganda e Comunicação}

Os anos 1920 representaram para Lasswell o início da longa relação que o cientista político estabeleceria com problemas ligados ao fenômeno da comunicação. Em Técnica de Propaganda na Guerra Mundial, a propaganda apareceu como objeto de estudo válido para o campo da Ciência Política, e Lasswell passou a ser reconhecido como uma importante autoridade sobre "a propaganda como parte do sistema de comunicação, mobilização social e organização da sociedade" (PAVARINO, 2011, p.21), que se tornou mais evidente nesse período. Mas foram os anos 1930 que consolidaram Lasswell como autor respeitável nos estudos de comunicação.

Entre a sua entrada na Universidade de Chicago e seu doutoramento, a influência dos meios de comunicação de massa nos Estados Unidos se tornou gigantesca, e seria bastante difícil não se questionar sobre os seus efeitos. Essa influência acabou, para usar uma expressão já bastante conhecida, "fermentando" o campo da comunicação (com o aumento do número de obras sobre os media massivos), gerando, posteriormente, sua institucionalização na década de 1940. Para se ter uma ideia, quando a década de 1920 chegou ao fim, 20 milhões de estadunidenses utilizavam o serviço telefônico, mais de 40 milhões de ingressos de cinema eram vendidos semanalmente, a publicidade já era a principal mantenedora econômica das estações de rádio, os primeiros aparelhos experimentais de TV haviam chegado aos lares.

Esses anos prepararam o terreno para o desenvolvimento da pesquisa comunicacional nas décadas de 1930 e de 1940, que também vão selar, definitivamente, o vínculo entre a obra lasswelliana e o campo da Comunicação. Essa ligação fica mais clara ao fazermos uma comparação entre o volume de publicações de Lasswell, antes e depois das décadas citadas. Enquanto na década de 1920, Lasswell produziu apenas quatro trabalhos sobre propaganda (The Status of Research on International Propaganda and Opinion, de 1925; The Theory of Political Propaganda, de 1927; The Function of the Propagandist, de 1928 - além de Técnica de Propaganda na Guerra Mundial), entre os anos de 1930 e 1950, foram produzidos 48 textos sobre comunicação e/ou propaganda, incluindo o verbete "Propaganda" da Enciclopédia de Ciências Sociais.

Houve, portanto, um interesse progressivo, que transformou a propaganda no principal objeto de pesquisa de Lasswell, e que ficou mais evidente a partir do ano de 
1931, quando iniciou estudo sobre a propaganda comunista em Chicago. Conforme relata o cientista político,

No início de 1931, eu elaborei planos para uma série de estudos sobre grupos de pressão e propaganda na área de Chicago. Em um memorando ao Professor Merriam, [...] Eu sugeri que o programa Local Chicago Community Studies, então em curso, poderia ser estendido para incluir um exame das pressões da propaganda sobre os grupos em Chicago mais suscetíveis a essas influências, como resultado da grande depressão ${ }^{137}$.

É importante percebermos que o crescente interesse e valorização do tema por Lasswell é também fruto de um contexto histórico no qual a propaganda continuava a ser alvo de grande curiosidade e recebia cada vez mais investimento por parte dos governos e instituições mundiais, que a julgavam como elemento fundamental nos rumos que a sociedade tomou a partir da Primeira Grande Guerra. Essa discussão já se fazia presente antes e durante o combate - como vimos ao falarmos de teoria hipodérmica -, e se torna mais intensa a partir de seu término. De acordo com Rosana Pavarino, citando Melvin Defleur e Sandra Ball-Rockeach, “[...] a Primeira Guerra Mundial foi a primeira em uma sociedade de massa a demandar 'devotamento total de todos os recursos da nação",, de modo que o termo propaganda adquiriu, definitivamente, um caráter ideológico, pois era o momento em que "Comodidades materiais tinham que ser sacrificadas; o moral tinha que ser mantido elevado; as pessoas tinham que ser persuadidas a deixar as famílias e alistarem-se; o trabalho nas fábricas tinha que ser realizado com vigor inabalável; e, não menos importante, era preciso conseguir dinheiro para financiar a guerra" (PAVARINO, 2011, p.21).

A Revolução Russa de 1917, que empregou a propaganda ostensivamente, também fez com que o assunto fosse alvo de mais investigações, até porque se tornava necessário combater o "fantasma" do comunismo. Acreditava-se que sua expansão se daria especialmente pelo uso da propaganda, idéia cujo peso pode ser visto numa afirmação do próprio Lasswell, segundo a qual "o comunismo é sempre propaganda" (LASWELL, 1935, p.189).

\footnotetext{
${ }^{137}$ No original: "Beginning early in 1931, I developed plans for a series of studies of pressure groups and propaganda in Chicago area. In a memorandum for Professor Merriam, [...] I suggested that the program of Local Chicago Community Studies then under way may be extended to include an examination of propaganda pressures on the groups on Chicago most susceptible to such influences, as a result of the great depression". Memorial de 23 de outubro de 1951, disponível em Harold Lasswell's Papers, Yale Manuscripts and Archives, Sterling Memorial Library, Universidade de Yale.
} 
Outro ponto fundamental a ser lembrado é que com a ascensão e organização dos regimes totalitários pós Primeira Guerra, a propaganda tem seu caráter bélico potencializado, com a criação de uma série de departamentos e cargos destinados a produção e controle das comunicações.

Embora alguns desses departamentos e cargos houvessem sido instituídos ainda durante a Primeira Guerra, seu papel se fortalece no intercurso até 1942, a despeito das terminologias adotadas (propaganda, comunicação, informação). Com isso,

[...] Os nazistas tiveram seu Ministério do Esclarecimento Popular e da Propaganda e os Soviéticos o seu Comitê de Propaganda do Partido Comunista, mas os britânicos tinham um Ministério da Informação e os americanos um Departamento da Informação de Guerra ${ }^{138}$ (TAYLOR, 2003, p.14).

Apesar, portanto, de ser comumente mais aceito que os nazistas possuíssem uma propaganda agressiva e inescrupulosa (personificada na figura de seu ministro da propaganda Joseph Goebbels e na fala de Adolf Hitler sobre a propaganda em sua autobiografia Mein Kampf, de 1925), certo é que todas as nações que assumiam algum poder no cenário internacional desenvolveram uma crença no poder da propaganda e a partir dessa ideia criaram seus próprios sistemas de produção e controle de conteúdo propagandístico. Não seria inadequado dizer que a interpretação de $\operatorname{Hitler}^{139}$ sobre a propaganda pode ser entendida como sendo mais que uma visão particular, ela é um reflexo de uma compreensão geral:

Para quem a propaganda deve apelar? Para a intelectualidade científica ou às massas menos instruídas? Tem que apelar para sempre e só para as massas! [...] A tarefa da propaganda não está em uma formação científica do indivíduo, mas sim no direcionamento das massas para certos fatos, acontecimentos, necessidades, etc., o objetivo é o de construir sua importância no campo de visão das massas [...] Esta é apenas a arte da propaganda: compreender as idéias e sentimentos das grandes massas; encontrar uma forma psicológica correta de alcançar o caminho para a atenção, e ainda mais para o coração, das grandes massas ${ }^{140}$ (HITLER, 1941, pp.230-233).

\footnotetext{
${ }^{138}$ No original: “[...] The Nazis had their Ministry of Popular Enlightenment and Propaganda and the Soviets their Propaganda Committee of the Communist Party, but the British had a Ministry of Information and the Americans an Office of War Information".

${ }^{139}$ O livro foi escrito em 1925, e é bastante alinhado ao que se costuma identificar como o modelo hipodérmico dos efeitos dos meios de comunicação.

${ }^{140}$ No original: "To whom has propaganda to appeal? To the scientific intelligentsia or to the less educated masses? It has to appeal forever and only to the masses! [...] The task of propaganda lies not in a scientific training of the individual, but rather in directing the masses towards certain facts, events, necessities, etc., the purpose being to move their importance into the masses' field of vision. [...] This is just the art of propaganda that it, understanding the great masses' world of ideas and feelings, finds, by a correct psychological form, the way to the attention, and further to the heart, of the great masses"
} 
E ainda: “A vitória de uma idéia será mais viável quanto mais intensa for a ação da propaganda sobre as pessoas na sua totalidade" (Idem, ibidem, p. 850) ${ }^{141}$.

Compartilhando a crença no poder da propaganda, era natural que as demais nações se interessassem por desenvolvê-la de maneira cada vez mais profissional e mais "científica", nos anos posteriores à Primeira Guerra Mundial, para assegurar o controle e o aperfeiçoamento (eficácia) das atividades de comunicação.

Nos Estados Unidos, a crença nesse poder da propaganda e a noção de que ela seria fundamental em outros conflitos armados que porventura pudessem surgir (o que era iminente), fizeram com que se investisse alto nas pesquisas sobre o assunto. E embora o jornalismo representasse um nicho importante das pesquisas sobre os fenômenos comunicacionais, foi a propaganda que suscitou o maior debate. Assim, é possível perceber que, no período entre-guerras, há um aumento significativo no número de obras devotadas à propaganda, que culmina no período da Segunda Guerra Mundial. Uma boa amostragem pode ser vista no gráfico seguinte ${ }^{142}$.

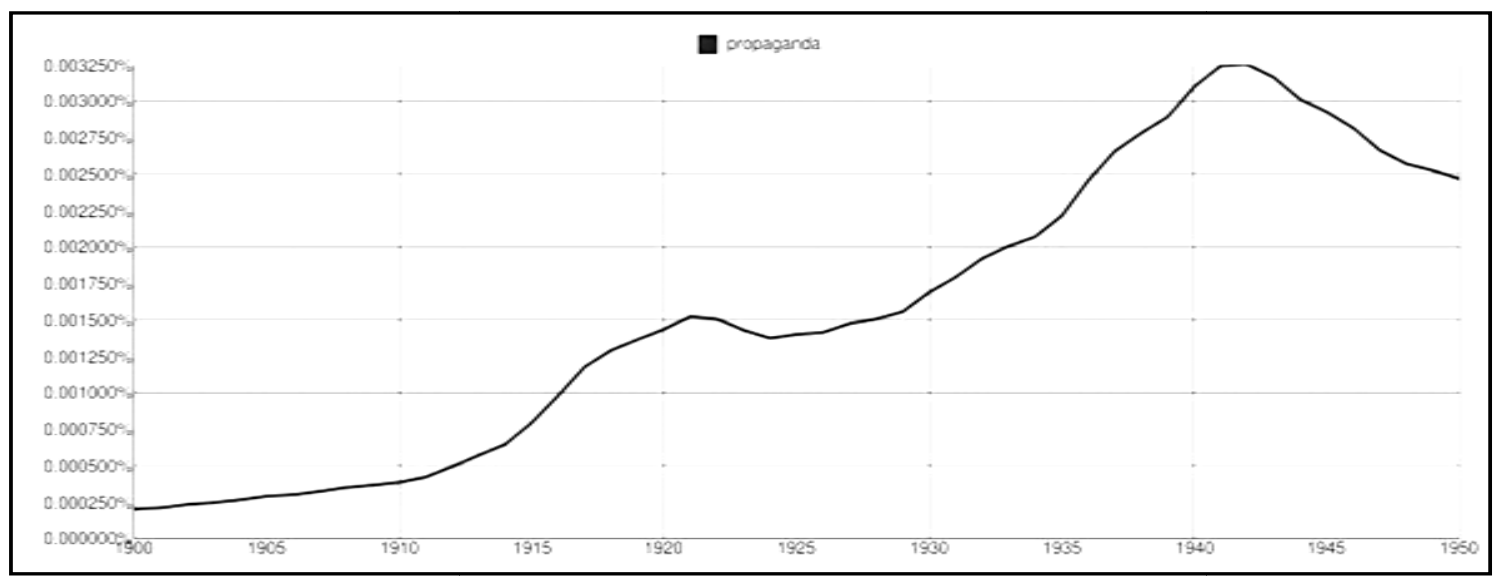

Figura 13. Curva de obras sobre propaganda entre 1900 e 1950. Fonte: GoogleNgram.

Com esse crescimento, já em 1935 foi possível que Lasswell organizasse um livro que seria essencial neste período, Propaganda and Promotional Activities: an Annotated Bibliography, em parceria com Ralph D. Casey e Bruce Lannes Smith, com uma larga bibliografia sobre propaganda. São 372 páginas só de obras sobre propaganda e temas correlatos, menos de 10 anos depois da tese de Lasswell ter sido publicada.

\footnotetext{
${ }^{141}$ No original: "The victory of an idea will be the more possible the more extensively propaganda works on people in their entirety".

${ }^{142} \mathrm{O}$ gráfico é gerado automaticamente pelo site Google Books NGram Viewer (http://ngrams.googlelabs.com) e representa a quantidade de livros sobre propaganda entre os anos de 1900 e 1950, apenas dentre aqueles que estão listados no endereço eletrônico do site Google Books (http://books.google.com) em língua inglesa. Contudo, é um importante indicativo do interesse progressivo no tema propaganda - e seu declínio posterior.
} 
Na segunda metade da década de 1930, a pesquisa em comunicação nos Estados Unidos já estava bem mais forte que nos primeiros anos do século XX, e já se desenvolvia em linhas gerais ainda que estivesse longe de comportar uma unidade explícita. Isso decorre sobremaneira do trabalho de figuras-chave no desenvolvimento de estudos mais institucionalizados sobre a propaganda e outras formas de comunicação. Podemos elencar aí, notadamente, os autores que se seguiram a Lasswell e aqueles da Universidade de Chicago, além daqueles que iriam despontar na Universidade de Columbia, como Paul Lazarsfeld (que conduziu o Escritório da Pesquisa em Rádio ${ }^{143}$, a partir de 1937) e aqueles que se aglutinaram em torno dos institutos do governo, com destaque para Carl Hovland, vindo de Yale, que trabalhou para o Exército estadunidense, pesquisando os efeitos psicológicos da persuasão nos produtos de comunicação. Há todo um cabedal de autores que passam a expressar referências mútuas e, de fato, trabalham em conjunto para as fundações estadunidenses, preocupadas em entender e aperfeiçoar o uso dos meios de comunicação. As abordagens variavam entre construções mais filosóficas (como a de Walter Lippmann); perspectivas interessadas em identificar o impacto dos produtos comunicacionais na psicologia da audiência (como os estudos do Fundo Payne sobre o cinema e as crianças, e o trabalho desenvolvido por Hovland para o governo estadunidense); e estudos mais focados nos resultados sociológicos da exposição dos públicos aos meios de comunicação de massa. A partir dessas linhas de investigação, a pesquisa estadunidense ancorava suas bases numa percepção de que o conjunto dos meios de comunicação era uma parte importante do sistema social (mesmo que ainda não possamos falar exatamente da presença de uma teoria estrutural-funcionalista acerca dos media), abordado de forma interdisciplinar. Mas sobre o que se perguntavam esses estudos? Sobretudo, a questão que se fazia presente era: que efeitos os meios de comunicação têm sobre os membros de uma sociedade (pergunta que já era feita desde o final do século XIX)?

Junto a esse questionamento, alinhavam-se as perguntas mais específicas sobre a propaganda.

\footnotetext{
143 O instituto foi depois renomeado como Bureau de Pesquisa Social aplicada, em 1944. Lazarsfeld fundou o instituto em parceria com Hadley Cantril (1906-1969), da Universidade de Princeton, e Herta Herzog (1910-2010), então esposa do pesquisador austríaco. Cantril foi o principal nome na pesquisa sobre a transmissão radiofônica realizada por Orson Welles em 1938, baseada na Guerra dos Mundos, livro de Herbert George Orwell (1866-1946). A transmissão de Welles, ao narrar a história da invasão da Terra por marcianos, deixou boa parte da audiência em pânico, por acreditar que se tratava de uma informação verídica e não de uma encenação para o rádio. O trabalho de Cantril analisando o pânico causado por essa transmissão, A invasão vinda de Marte, de 1938, teve importante participação de Herta Herzog.
} 
[...] Poderia um governo democrático se engajar legitimamente em programas de propaganda para influenciar a sua população e ainda manter seu status de democracia? O que acontece com o significado local e as iniciativas quando novas tecnologias de comunicação tornam difícil ou impossível obter uma resposta efetiva de volta, e quais são as implicações sociológicas e psicológicas do desenvolvimento dessas tecnologias? Deve a propaganda substituir a educação como função da escola ou deve a escola ter como objetivo desenvolver as capacidades críticas para se expor à propaganda? Até que ponto a propaganda perturba o ideal da igualdade de opinião, dando as classes endinheiradas que controlam as redes de comunicação uma vantagem injusta por terem suas opiniões ouvidas e, em última instância, sua concepção da realidade imposta? Estas e outras questões semelhantes de legitimidade estiveram no centro do debate sobre a propaganda ${ }^{144}$ (GLANDER, 2000, p.2-3).

A lista de autores que buscavam responder a essas perguntas nesse momento é extensa, e embora Mauro Wolf intitule os anos 1930 como a "época de ouro" (WOLF, 2000, p.29) da teoria hipodérmica, é perceptível que a pesquisa começou a substituir a análise dos meios de comunicação de massa e da propaganda pelo viés “oferecido" pelo senso comum e cedeu espaço a propostas que tentavam avançar na compreensão do fenômeno, mais científicas. O próprio Wolf (Idem, p.29) aponta que a "superação" da teoria hipodérmica tem seu início nos anos 30, com a elaboração do esquema de Lasswell, cujas variáveis teriam organizado os setores específicos da pesquisa:

Qualquer uma dessas variáveis define e organiza um setor específico da pesquisa: a primeira caracteriza os estudos dos emissores, ou seja, a análise do controlo sobre o que é difundido. Quem, por sua vez, estudar a segunda variável, elabora a análise do conteúdo das mensagens, enquanto o estudo da terceira variável dá lugar à análise dos meios. Análises da audiência e dos efeitos definem os restantes sectores de investigação sobre os processos comunicativos de massas. A fórmula de Lasswell, ordenando, aparentemente o objecto de estudo segundo variáveis bem definidas, sem omitir nenhum aspecto relevante dos fenômenos em causa, na realidade depressa se transformou - e assim permaneceu durante muito tempo - numa verdadeira teoria da comunicação (WOLF, 2000, p.30)

\footnotetext{
${ }^{144}$ No original: "Could a democratic government legitimately engage in propaganda programs to influence its populace and still retains its status as a democracy? What happens to local meaning and initiative when new communication technologies make it difficult or impossible to effectively answer back, and what are the sociological and psychological implications of this development? Should propaganda replace education as the function of school or should the school aim to develop the critical capacities by which this propaganda might be exposed? To what extent does propaganda upset the ideal of equality of opinion by giving the monied classes who control the communication networks an unfair advantage in having their views heard and, ultimately, their conception of reality enforced? These and similar questions of legitimacy were at the heart of the propaganda debate".
} 
Normalmente identificado como o grande norteador da pesquisa em comunicação (por exemplo: NARULA, 2006; REDDI, 2009; STEINBERG, 2007), o esquema costuma ser referenciado a partir do seguinte modelo, delimitando cada área de estudo que teria se formado no campo da comunicação:

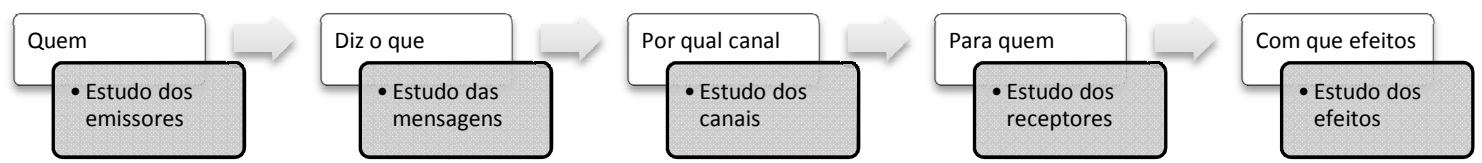

Gráfico 6. Representação gráfica do esquema de Lasswell, com as respectivas áreas de pesquisa segmentadas por sua divisão. Fonte: elaboração própria, baseada nos modelos mais comuns encontrados em livros de Teorias da Comunicação.

Contudo, ao tomarmos contato com o material produzido pela Divisão Experimental para o Estudo das Comunicações em Tempo de Guerra ${ }^{145}$, onde o esquema de Lasswell foi desenvolvido mais amiúde, verifica-se a ausência de intenção nessa segmentação apontada acima. Pelo contrário, a utilização do esquema servia a uma compreensão "totalizante" do processo de comunicação, alinhada com a pretensão de domínio desse mesmo processo, como se todas as suas variáveis, ao serem conhecidas pudessem também ser previstas e controladas ao máximo. Para que se conseguisse tal efeito, o próprio Lasswell conta que foram recrutados e treinados mais de 50 funcionários para a Divisão Experimental para a Comunicação em Tempos de Guerra $^{146}$, os quais se orientavam por documentos que ensinavam precisamente como utilizar o esquema de Lasswell (ver figura 13). Mesmo que a coleta de dados fosse realizada tendo por base as categorias do esquema, a finalidade era a somatória das informações referentes a cada pergunta-chave, possibilitando a compreensão global das mensagens (foco central dos estudos), desde seu produtor até os efeitos pretendidos ou alcançados.

De qualquer maneira, foi o esquema de Lasswell que organizou o trabalho em comunicação que se seguiu aos anos 1930, exercendo grande influência na percepção desenvolvida na pesquisa comunicacional nos anos da Segunda Grande Guerra.

Os anos 1930 também trouxeram outros elementos aos estudos de comunicação, que mais tarde poderiam sair da rota estabelecida pelos pesquisadores estadunidenses,

\footnotetext{
145 Disponíveis em Harold Lasswell's Papers, Yale Manuscripts and Archives, Sterling Memorial Library, Universidade de Yale.

${ }^{146}$ Em memorial (affidavit) exigido como documento para que tomasse posse como professor de Ciência Política na Universidade de Yale. Disponível em Harold Lasswell's Papers, Yale Manuscripts and Archives, Sterling Memorial Library, Universidade de Yale.
} 
adotando uma metodologia menos quantitativa. Em 1935, a Escola de Frankfurt aportou em Nova York, vindo a constituir "a contracorrente de muita communication research" (Idem, ibidem, p.82). A Escola de Frankfurt e sua teoria crítica se tornaram, a partir da década de 1940, o contraponto mais corriqueiro à forma como a pesquisa em comunicação nos Estados Unidos se desenvolvia - e que em grande parte era capitaneada por Lasswell.

Fundada em 1923, sob a liderança de Félix Weil (1898-1975), cientista político argentino, a Escola de Frankfurt é o "apelido" dado ao Instituto de Pesquisa Social, vinculado a Universidade de Frankfurt. O instituto possuía uma forte inspiração marxista e tinha como objetivo a elaboração de uma teoria que possibilitasse a compreensão da sociedade capitalista de uma forma geral. Aqui, também aparecem diversos pesquisadores interessados na comunicação de massa e que, hoje representam clássicos nos estudos comunicacionais: Max Horkheimer (1895-1973), Theodor Adorno (1903-1969), Sigfried Kracauer (1889-1966), Herbert Marcuse (1898-1979), Walter Benjamin (1892-1940) e Erich Fromm (1900-1980).

Trabalhando a partir de uma visão kantiana de esclarecimento, segundo a qual "a possibilidade de esclarecimento existe, mas a vontade não" (BORGES, NUNES \& VARÃO, 2008, p.2), a compreensão dos frankfurtianos sobre a ação dos meios de comunicação era bastante negativa, especialmente quando se levava em consideração a relação meios/governo. De início "marginal” (HARDT, 1992, p.123), a teoria crítica passa a ter uma importância maior nas décadas seguintes, não afetando diretamente a produção lasswelliana, nem mesmo a de outros estudiosos da comunicação nos anos iniciais de sua presença nos Estados Unidos. Contudo, pela filiação ao pensamento alemão, é possível encontrar na depreciação dos meios de comunicação de massa e na forma de encarar a audiência, semelhanças pontuais com o pensamento hipodérmico.

Nos anos seguintes a sua chegada em Nova York, não se vê nenhuma influência significativa da teoria crítica na pesquisa conduzida nos Estados Unidos, que só vai obter maior repercussão na década de 1940, após a tentativa de colaboração entre Theodor Adorno e Paul Lazarsfeld ,no Departamento de Pesquisa em Rádio, e a criação do conceito de indústria cultural por Adorno e Max Horkheimer na obra Dialética do Esclarecimento, de 1947, que se traduz na cultura transformada em mercadoria.

O trabalho de Lasswell seguiu realizando o balanço entre política e propaganda, centrado nos ideais democráticos referenciados por Dewey e na metodologia que já era empregada nos Estados Unidos, sem uma interferência mais expressiva da proposta 
frankfurtiana. Em 1936, o cientista político lançou Política: Quem Consegue o Quê, Quando, Como, livro em que o modelo de Lasswell para o processo de comunicação de massa parece ter sido adaptado ao processo de formação de votos.

Em 1937, apesar de passar um ano como professor visitante na Universidade de Yenching, na China, Lasswell manteve-se produzindo incansavelmente material sobre a propaganda política, como Propaganda and the Channels of Communication $e$ Propaganda in a Planned Society, e ajudou a fundar a revista Public Opinion Quartely, uma das mais importantes e tradicionais da área de Ciências Sociais.

De volta a Chicago, entretanto, Lasswell tomou uma atitude inesperada: demitiuse da universidade e partiu rumo à capital dos Estados Unidos, aparentemente sem

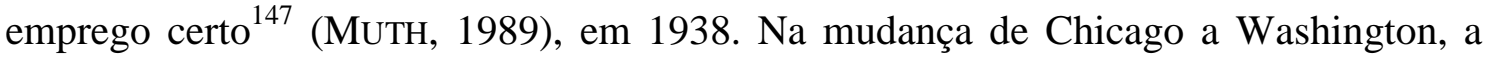
caminhonete em que Lasswell viajava sofreu um acidente que teve algumas conseqüências desastrosas.

Em primeiro lugar, suas ideias foram de alguma forma reorientadas, pois suas notas de pesquisa foram perdidas. Por outro lado, alguns materiais de pesquisa aparentemente criaram um pequeno desconforto quando foram encontrados após o acidente. Estes incluíam livros de Marx, que, como Freud, influenciou o pensamento de Lasswell, e panfletos sobre o comunismo, um detalhe observado numa matéria de jornal sobre o acidente. Como resultado, Lasswell foi mais tarde perseguido por agências federais, questionado sobre seu patriotismo, e foi forçado, durante a era McCarthy, a desenvolver um relatório extenso para provar o seu amor à democracia, sua lealdade aos Estados Unidos, e seu ferrenho anticomunismo. Embora seus esforços tenham sido bem sucedidos, a checagem o perseguiu durante toda sua carreira $^{148}$ (Idem, Ibidem, p. 14).

Marx e Freud eram influências antigas, dos anos de high school, e embora Marx tenha sido uma leitura que fundamentou boa parte da pesquisa de Lasswell sobre as elites, isso não seria o suficiente para caracterizá-lo como um comunista. Mas Lasswell teve que recorrer constantemente a amigos e conhecidos, que escreveram dezenas de cartas ao governo dos Estados Unidos, atestando o patriotismo do cientista político e

\footnotetext{
${ }^{147}$ Segundo o próprio Lasswell (Affidavit), ele planejou a saída da Universidade de Chicago para assumir um lugar na Escola de Psiquiatria de Washington. Mas, de fato, não há nada que comprove que Washington já o esperava.

${ }^{148}$ No original: "First, his intellectual pursuits were refocused somewhat since his research notes were lost. Second, some of his resource materials apparently created a small sensation when they were found after the crash. These included books by Marx -who, like Freud, had influenced Lasswell's thinking -and pamphlets about Communism, a detail noted in a newspaper report ofthe accident. As a result, Lasswell was later hounded by federal agencies about his patriotism and was forced, during the McCarthy era, to develop a copious dossier? To substantiate his love for democracy, his loyalty to America, and his staunch anticommunism. While his efforts were successful, background, checks followed him throughout his career".
} 
reforçando seu anti-comunismo, até a década de 1950. Em 1951, Lasswell, cansado de importunar seus colegas, escreveu o seguinte ao governo:

Eu não quero incomodar as muitas pessoas que me conheceram e trabalharam comigo por tantos anos, pedindo a elas para escreverem cartas em meu favor. Acredito que o material contido neste documento será suficiente a quem quer que seja para provar que não há verdade na afirmação de que eu sou, ou fui, um comunista ou um simpatizante do comunismo. Minha preocupação é com os valores tradicionais que os americanos têm sorte em possuir, a saber: a dignidade da personalidade humana ${ }^{149}$.

Isso repercute em algumas obras ao longo de sua carreira, que reforçam a defesa da democracia estadunidense e dos meios de comunicação como agentes democráticos, como The Volume of Communist Propaganda em Chicago (1939), Can we defeat the Propaganda of International Communism? (1950), Symbols of Democracy (1952). Apesar do constrangimento sofrido por Lasswell durante todo esse tempo, seu lugar como principal especialista em propaganda dos Estados Unidos fez com que esse mesmo governo o oferecesse cargos importantes (ainda que sob suspeita de ter inclinações comunistas). Dessa maneira, ao chegar a Washington, Lasswell desenvolveu uma série de trabalhos relacionados à educação e comunicação (como membro do Quadro Geral de Educação da Fundação Rockefeller).

Como consultor da National Broadcasting Company, desenvolvi uma série de transmissões, a convite do Dr. James Rowland Angell, Presidente Emérito da Universidade de Yale e consultor educacional para a NBC, intitulada "Human Nature in Action", destinada a comunicar os ensinamentos da psicologia moderna para uma ampla audiência de rádio. Como consultor da Enciclopédia Britannica Educational Films, ajudei a desenvolver uma série de filmes educativos. Também lecionei na Yale Law School durante este período, e na New School for Social Research, em Nova York, e continuei a contribuir para diversos periódicos ${ }^{150}$.

\footnotetext{
${ }^{149}$ No original: "I do not want to bother the many persons who have known and worked with me for these many years, asking them to write letters on my behalf. I believe that the material contained in this statement ought to be enough for anyone to satisfy himself that there is no truth in the assertion that I am, or have, been either a Communist or a sympathizer with Communism. My concern is for the traditional values which were Americans are fortunate in having: namely, the dignity of human personality". Declaração original disponível na Sterling Memorial Library, em Yale.

${ }^{150}$ No original: "As a consultant for the National Broadcasting Company, I developed a series of broadcasts, at the invitation of Dr. James Rowland Angell, President-Emeritus of Yale University, and Educational Adviser to NBC, entitled "Human Nature in Action", intended to communicate the teachings of modern psychology to a wide radio audience. As a consultant to Encyclopedia Britannica Educational Films, I helped to develop a series of educational films. I also lectured at the Yale Law School during this period, and at the New School for Social Research in New York City, and continued to contribute to various periodicals". Em declaração juramentada (affidavit) exigida como documento para que tomasse posse como professor de Ciência Política na Universidade de Yale. 23 de outubro de 1951.
} 
Entre 1938 e 1939, com o início da Segunda Guerra Mundial e com o envolvimento cada vez maior dos Estados Unidos em esforços de defesa, as atividades de consultor acabaram sendo requisitadas mais fortemente pelo governo estadunidense. Em 1939, Lasswell, juntamente com outros cientistas sociais ${ }^{151}$, foram reunidos pela Fundação Rockefeller para considerar “[...] o atual estado no campo da comunicação de massa e dos estudos de opinião pública"152, o The Rockfeller Foundation Communication Seminar. Além dessa discussão, aventou-se a possibilidade de se desenvolver um projeto para a comunicação de guerra, o qual deveria ser submetido por Lasswell.

Foi assim que, em 1940, Lasswell tornou-se o chefe da Divisão Experimental para o Estudo das Comunicações em Tempo de Guerra, da Biblioteca do Congresso, em Washington ${ }^{153}$. A divisão foi inteiramente sustentada pela Fundação Rockefeller, e garantiu o aprofundamento dos estudos de Lasswell sobre propaganda.

A Divisão Experimental para o Estudo das Comunicações em Tempo de Guerra tinha como objetivo mais amplo “[...] fornecer novas abordagens para refinar o conhecimento na promissora área da comunicação, cujo objetivo maior era levar essa informação aos gestores públicos relevantes" (PARK \& POOLEY, 2008, p.164-165) ${ }^{154}$. A divisão fomentou aquilo que passou a ser conhecido como pesquisa administrativa estadunidense em comunicação, de base empírica, que terá em Paul Félix Lazarsfeld seu maior nome depois de Lasswell.

Sob a direção deste último, a divisão trabalhava, primeiro, no desenvolvimento da análise de conteúdo quantitativa. Em segundo lugar, o grupo encabeçado por Lasswell deveria aplicar o método da análise de conteúdo para análise imediata de organizações e treinar pessoal para a análise de propaganda e inteligência, sempre sob a responsabilidade de Lasswell, que devia se manter disponível em Washington ${ }^{155}$. O projeto foi criado para ser administrado inteiramente pela Biblioteca do Congresso, mas

\footnotetext{
${ }^{151}$ A pesquisa em Comunicação era uma grande frente nas pesquisas sociais, embora os programas das universidades estadunidenses ainda não reconhecessem, estando sempre filiada aos departamentos já existentes. Contudo, grandes nomes da sociologia, como Paul Lazarsfeld, e da Psicologia, como Carl Hovland já eram vinculados a pesquisas sobre os fenômenos da comunicação de massa.

${ }^{152}$ No original: "[...] the existing state in the field of mass communication and public opinion studies". Em declaração juramentada (affidavit) exigida como documento para que tomasse posse como professor de Ciência Política na Universidade de Yale. 23 de outubro de 1951.

${ }^{153}$ Entre 1930 e 1940, Lasswell ainda exerceu a função de lecturer na New School of Social Research em Nova York e em Yale. A função é comumente desempenhada por acadêmicos em estágio inicial da carreira, conduzindo pesquisas e grupos de estudo.

${ }^{154}$ No original: "[...] refine new approaches to knowledge in the promising area of communication, which the further objective was bringing this information to the attention of relevant government administrators".

${ }^{155}$ Em declaração juramentada (affidavit) exigida como documento para que tomasse posse como professor de Ciência Política na Universidade de Yale. 23 de outubro de 1951.
} 
os esforços do grupo que o compunha fizeram com que suas atividades fossem vinculadas ao Departamento de Justiça, "[...] particularmente quando da acusação de agentes comunistas, nazistas e fascistas" ${ }^{\text {156 }}$. A Divisão forneceu ainda pessoal para o Escritório de Fatos e Figuras; o Serviço de Inteligência para Transmissões Estrangeiras; o Escritório para Censura; o Escritório de Serviços Estratégicos; o Departamento Psicológico do Exército; o Departamento de Estado.

O resultado mais opulento da Divisão Experimental para o Estudo das Comunicações em Tempo de Guerra foi o estudo World Attention Survey, uma análise colossal do conteúdo dos meios ao redor do mundo que interessava então: Estados Unidos e Europa. Boa parte do material produzido pelo Escritório de Informação de Guerra para a geração de World Attention Survey, está disponível na Coleção de Papéis de Harold D. Lasswell, na seção de manuscritos e arquivos da Sterling Memorial Library, em Yale. Esse material revela, sobremaneira, o foco no quantitativo e na precisão matemática presentes na pesquisa da Divisão Experimental para o Estudo das Comunicações em Tempo de Guerra; a colaboração interdisciplinar entre seus membros; o rigoroso controle pelo qual os meios de comunicação de massa passavam nos Estados Unidos; a crença em uma propaganda poderosa e onipresente; e, por fim, a presença constante do esquema de Lasswell na organização dos materiais analisados.

A pesquisa da Divisão de Guerra representou o maior esforço coletivo para a consolidação de um cabedal teórico-metodológico para a compreensão da comunicação de massa nos Estados Unidos e gerou uma base para as pesquisas posteriores, inclusive no sentido de se construir uma teoria da comunicação - expressão que aparece mais marcadamente a partir das suas atividades. $\mathrm{O}$ arquivo Termos-chave para uma Teoria da Comunicação ${ }^{157}$, de 1941, com 361 palavras, é um importante exemplo de como a ideia de uma teoria da comunicação se fazia presente. Segundo Park e Polley (2008), o papel de Lasswell foi crucial para a emergência do termo comunicação nos estudos da Divisão. A mudança de terminologia nos institutos não se deu ocasionalmente, apesar dos estudos ainda se concentrarem na propaganda.

A opção de Lasswell pela rubrica comunicação está diretamente relacionada à confluência das condições de guerra, em consequência das quais outorgantes, administradores e acadêmicos buscavam distanciar seu trabalho (o estudo da

\footnotetext{
${ }^{156}$ No original: “[...] particularly in its prosecution of Communist, Nazi, and Facist agents". Em declaração juramentada (affidavit) exigida como documento para que tomasse posse como professor de Ciência Política na Universidade de Yale. 23 de outubro de 1951.

${ }^{157}$ Anexo I. Disponível na Sterling Memorial Library, Universidade de Yale.
} 
"comunicação") do inimigo (cuja produção era "propaganda"). Aqui, o consultor Lasswell atuou como um acadêmico construindo "teoria básica no campo da comunicação." (2008, p.165)

Embora o próprio Lasswell tenha continuado a usar ostensivamente a expressão propaganda, comunicação começa a ser mais freqüente em seus textos, como demonstram os títulos de seus trabalhos em 1942, ano em que produziu sete títulos devotados ao assunto: Analyzing the Content of Communication: a Brief Introduction, The Communications Front: Strategies of Political and Moral Warfare, Communication Research and Politics, An Experimental Comparison of Four Ways of Coding Editorial Content, The Pollitically Significant Content of the Press: Coding Procedures, Propaganda Good and Bad, Radio in Wartime.

O emprego do termo "comunicação" em substituição como um guarda-chuva para os demais vocábulos presentes nos estudos da área, como "propaganda", "publicidade" e "opinião pública", cresceu enormemente nos anos que se seguiram a ação da Divisão. Um bom exemplo do aumento do uso da palavra "comunicação" em relação às demais expressões mostra que:

O estudo da comunicação estava em andamento em 1930, mas foi somente em 1942 que os índices da Psychological Abstracts passaram a incluir regularmente "comunicação" como uma entrada, e o total de tais entradas entre 1942 e 1947 foi de apenas 22 artigos. No entanto, em 1948, o número anual subiu para dezesseis, daí para 32 em 1949, e 48 em 1950. As médias anuais, posteriormente, tinham entre cinquenta e cem artigos durante a década de 1950, chegando a mais de cem nas décadas de 1960 e 1970, indicando o crescimento e a estabilidade do termo como um conceito focal importante na pesquisa em ciências sociais ${ }^{159}$ (PARK \& POOLEY, 2008, pp.164)

Tendo gerado um mapeamento gigantesco dos meios de comunicação no mundo, a Divisão Experimental para o Estudo das Comunicações em Tempo de Guerra encerrou suas atividades em 1944 (Lasswell permaneceu no cargo até 1943). Mas seus ecos continuaram a ser ouvidos, não só nos trabalhos de Lasswell que se seguiram, mas no

\footnotetext{
${ }^{158}$ No original: "Lasswell's turn to the rubric of communication was directly related to the confluence of wartime conditions whereby grantors, administrators, and academicians all sought to distance their work (the study of "communication") from that of the enemy (whose output was "propaganda"). Here consultant Lasswell continued to function as an academician building up "basic theory in the field of communication."

${ }^{159}$ No original: "Communication study was afoot in the 1930s, but it was not until 1942 that the bounds indices of Psychological Abstracts regularly included "communication" as an entry, and the total of such entries between 1942 and 1947 was but twenty-two articles. Yet by 1948, the annual number has risen to sixteen, thence to thirty-two in 1949, and forty-eight in 1950. Yearly averages thereafter were between fifty and one hundred articles in the 1950s, increasing typically to the upper 100 s in the 1960 s and 1970 s, indicating the growth and stability of the term as a major focal concept in social science research".
} 
domínio que, passados os anos do conflito, consolidava-se cada vez mais como campo da Comunicação.

Quando o funcionamento da Divisão Experimental se encerrou, as abordagens ingênuas e pouco científicas sobre o fenômeno da comunicação já eram uma realidade um pouco distante. E embora se possam fazer muitas críticas à pesquisa estadunidense em comunicação, que ficou conhecida por sua corrente administrativa, é inegável o seu esforço na implantação de uma teoria da comunicação (ou, pelos menos, sobre a comunicação ${ }^{160}$ ) e o extenuante uso da quantificação com o objetivo se aproximar mais e mais do conhecimento científico.

Durante a chefia da Divisão, Lasswell ainda desenvolveu a ideia que transformaria em um de seus principais projetos: o "cultivo" de uma "policy science", cuja tradução é equivalente a Ciência Política. Na verdade, Lasswell está falando de "ciências políticas", no plural, entendendo o estudo da política como uma conjunção de múltiplas disciplinas. Segundo o cientista político,

Meu objetivo final no campo da ciência está longe de ser modesto. Proponho-me a contribuir para uma teoria sistemática das ciências políticas. As ciências políticas incluem as ciências sociais e psicológicas, em geral, todas as ciências que fornecem fatos e princípios de importância direta para a tomada de decisões importantes na vida dos negócios, governo e cultural ${ }^{161}$ (MUTH, 1990, p.17).

Claramente, a noção pretendida por Lasswell foi resultado da sua experiência na Divisão Experimental para Comunicação em Tempos de Guerra, uma vez que se vislumbrou, na prática, a possibilidade de se unir as diversas áreas das Ciências Sociais em torno de ideais políticos, no bem descrito cenário abaixo:

A chefia da época da guerra, a mais importante, permitiu a Lasswell desenhar em torno dele um grupo de jovens brilhantes cientistas políticos "na prática", incluindo Lerner, Abraham Kaplan, Bruce Lannes Smith, Heinz Eulau, Gabriel Almond, David Truman, Itiel de Sola Pool, Nathan Leites, Edward Shils, Morris Janowitz, Irving Janis, e Sebastian de Grazia. Eles colaboraram com outros especialistas a serviço da inteligência em Washington, como Samuel Stouffer, Paul Lazarsfeld, Kurt Lewin, Bernard Berelson, Wilbur Schramm, Hans Speier, Carl Hovland, Hadley Cantril e

\footnotetext{
${ }^{160}$ A distinção é feita por Martino: “[...] teorias sobre comunicação e teorias da comunicação, ou seja, teorias que se ocupam de fenômenos comunicacionais no sentido amplo e teorias propriamente comunicacionais, que se caracterizam por um certo tipo de aproximação ou recorte da realidade" (2007, p.30).

${ }^{161}$ No original: "My ultimate objective in the field of science is far from modest. I propose to contribute to the systematic theory of the policy sciences. The policy sciences include the social and psychological sciences; in general, all the sciences that provide facts and principles of direct importance for the making of important decisions in government, business and cultural life".
} 
Ralph Casey (ver Sproule, 2008). Dificilmente teríamos um grupo de cientistas sociais mais famosos ou promissores atuando como cientistas políticos. Reunidos pela guerra, eles defenderam a democracia, aconselharam os tomadores de decisão, analisaram pesquisas políticas, inventaram métodos como a análise de conteúdo, escreveram de forma rápida e longamente sob prazos apertados, e criaram um interdisciplinar "corpo de estudiosos experientes guiados pela responsabilidade" (1951, 133), inventaram a pesquisa em comunicações como um campo e fomentaram uma revolução comportamental nas ciências sociais (FARR, HACKER \& KAZEE, 2006, p.581) ${ }^{162}$.

O approach interdisciplinar que marcou a época da Divisão Experimental também legou a mesma possibilidade de abordagem interdisciplinar ao campo comunicacional. Ele marcou uma série de discursos mais apressados sobre a possibilidade de se unir o conjunto de conhecimentos de disciplinas variadas para se entender a comunicação, que deveria ser compreendida como um objeto estudado por perspectivas de análise que passaram a ser bastante ampliadas desde então. No ínterim entre a ameaça e o fim da Segunda Grande Guerra, novas frentes de investigação foram abertas, em parte, por conta da colaboração que se estabeleceu nessa época entre as diferentes Ciências Sociais. E, por outra parte, também pelo reconhecimento de outras contribuições que haviam sido negligenciadas (por exemplo, a semiótica de Pierce, a crítica de Lippmann, as análises de Cooley), porque não foram vistas como diretamente operacionais para as finalidades de guerra e controle. Talvez mesmo a contribuição da própria Escola de Chicago (particularmente em comunicação), normalmente mais identificada com Robert Park que exatamente com Lasswell ou Dewey.

Em 1944, ainda sob o efeito do reconhecimento que o trabalho na divisão havia lhe rendido, Lasswell tornou-se membro da Comissão para a Liberdade de Imprensa, convidado para ajudar a organizá-la em sua fase inicial, mas a comissão só funcionou por dois anos. Com o fim da guerra em 1945, sua finalidade não era mais tão útil quanto parecia ser no momento da sua criação.

\footnotetext{
162 No original: "The war-time chiefdom, most important, allowed Lasswell to draw around him a brilliant group of young policy-scientists-in-the-making, including Lerner, Abraham Kaplan, Bruce Lannes Smith, Heinz Eulau, Gabriel Almond, David Truman, Ithiel de Sola Pool, Nathan Leites, Edward Shils, Morris Janowitz, Irving Janis, and Sebastian de Grazia. He and they collaborated with other intelligence specialists on duty in Washington, like Samuel Stouffer, Paul Lazarsfeld, Kurt Lewin, Bernard Berelson, Wilbur Schramm, Hans Speier, Carl Hovland, Hadley Cantril, and Ralph Casey (see Sproule 1997). There could hardly have been a more famous or promising group of social qua policy scientists. Brought together by war, they defended democracy, advised decision-makers, analyzed policy, devised research, invented methods like content analysis, wrote quickly and at length under deadline, and created an interdisciplinary "corps of scholars seasoned by responsibility" (1951a, 133) who would invent communications research as a field and foment a behavioral revolution in the social sciences"
} 
Em 1946, Lasswell transfere-se para Yale, onde assumiu o cargo de professor de Direito, na Yale Law School. Contudo, mesmo migrando para uma área distinta de suas formações, Lasswell permaneceu durante muito tempo norteando a pesquisa em comunicação, resultado do amplo trabalho desenvolvido nas décadas de 1930 e 1940. Gradativamente, seu nome vai ser substituído em importância pelo de Lazarsfeld, que se firma especialmente ao final dos anos 1940 e durante toda a década de 1950. 


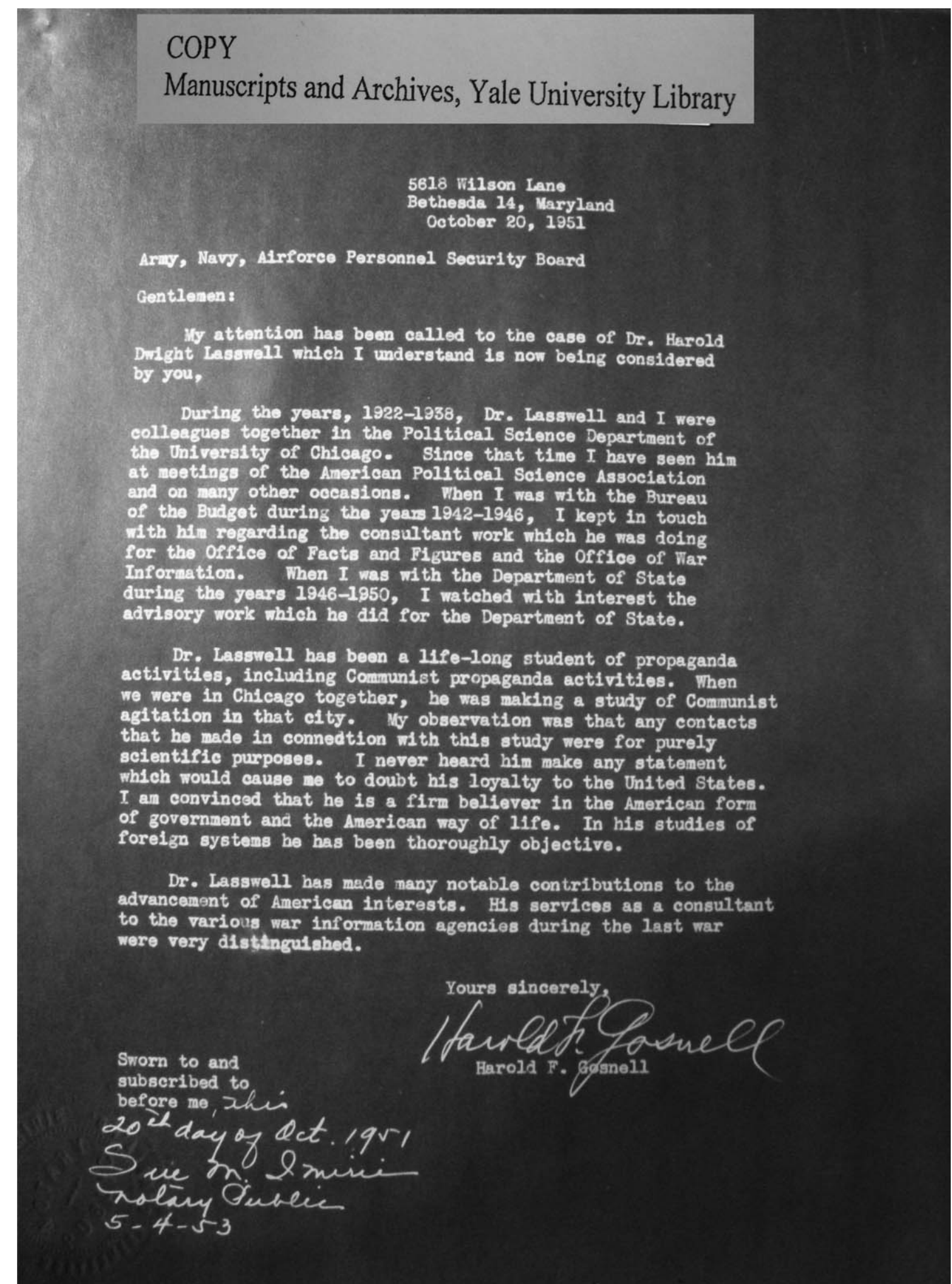

Figura 14. Carta de Harold Gosnell ao governo estadunidense, atestando desconhecer ligações de Lasswell com o comunismo. Fonte: Harold Lasswell's Papers, Yale Manuscripts and Archives, Sterling Memorial Library, Universidade de Yale. 


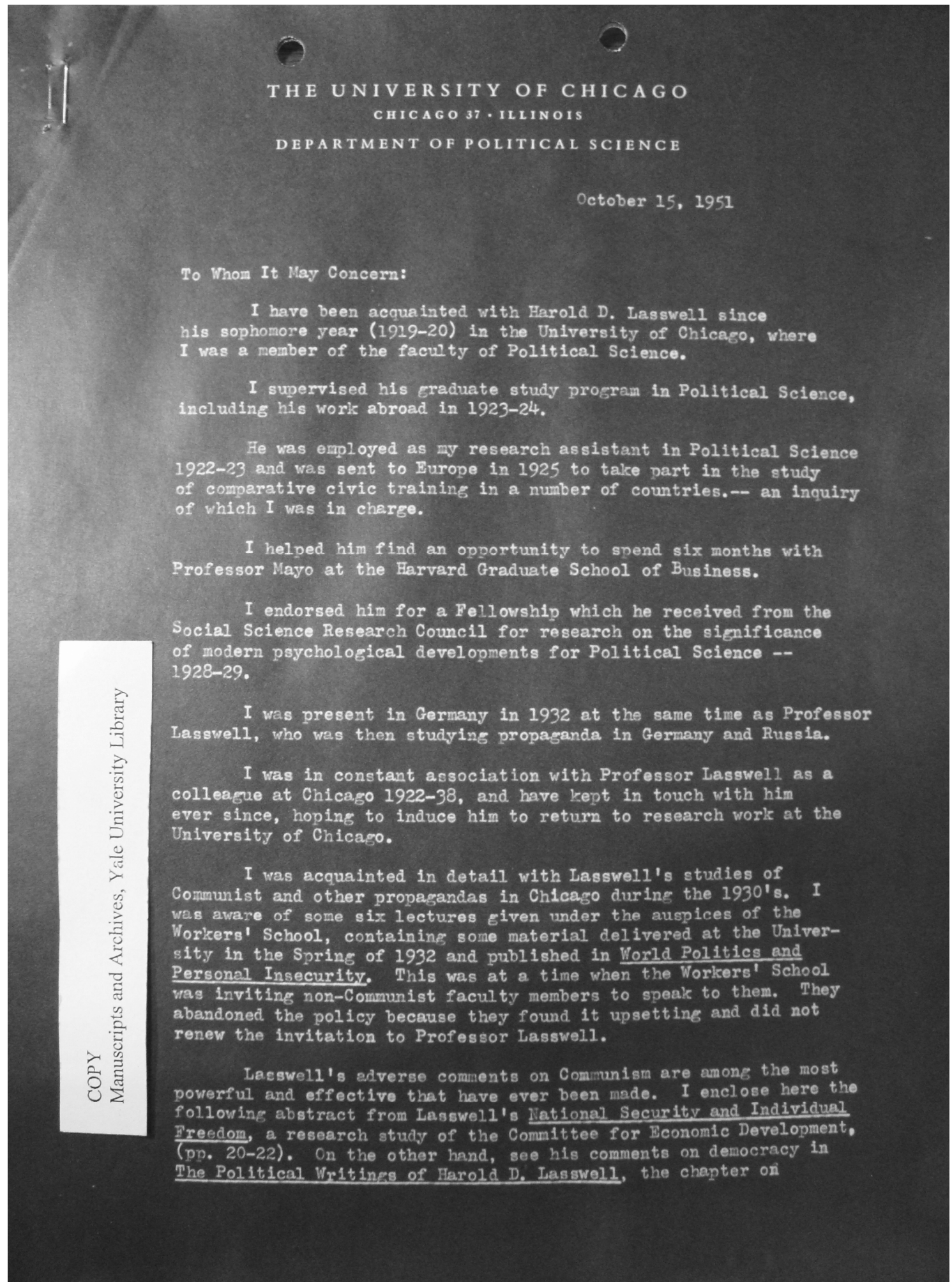

Figura 15. Carta de Charles Merriam ao governo estadunidense, atestando desconhecer ligações de Lasswell com o comunismo, página 1. Fonte: Harold Lasswell's Papers, Yale Manuscripts and Archives, Sterling Memorial Library, Universidade de Yale. 


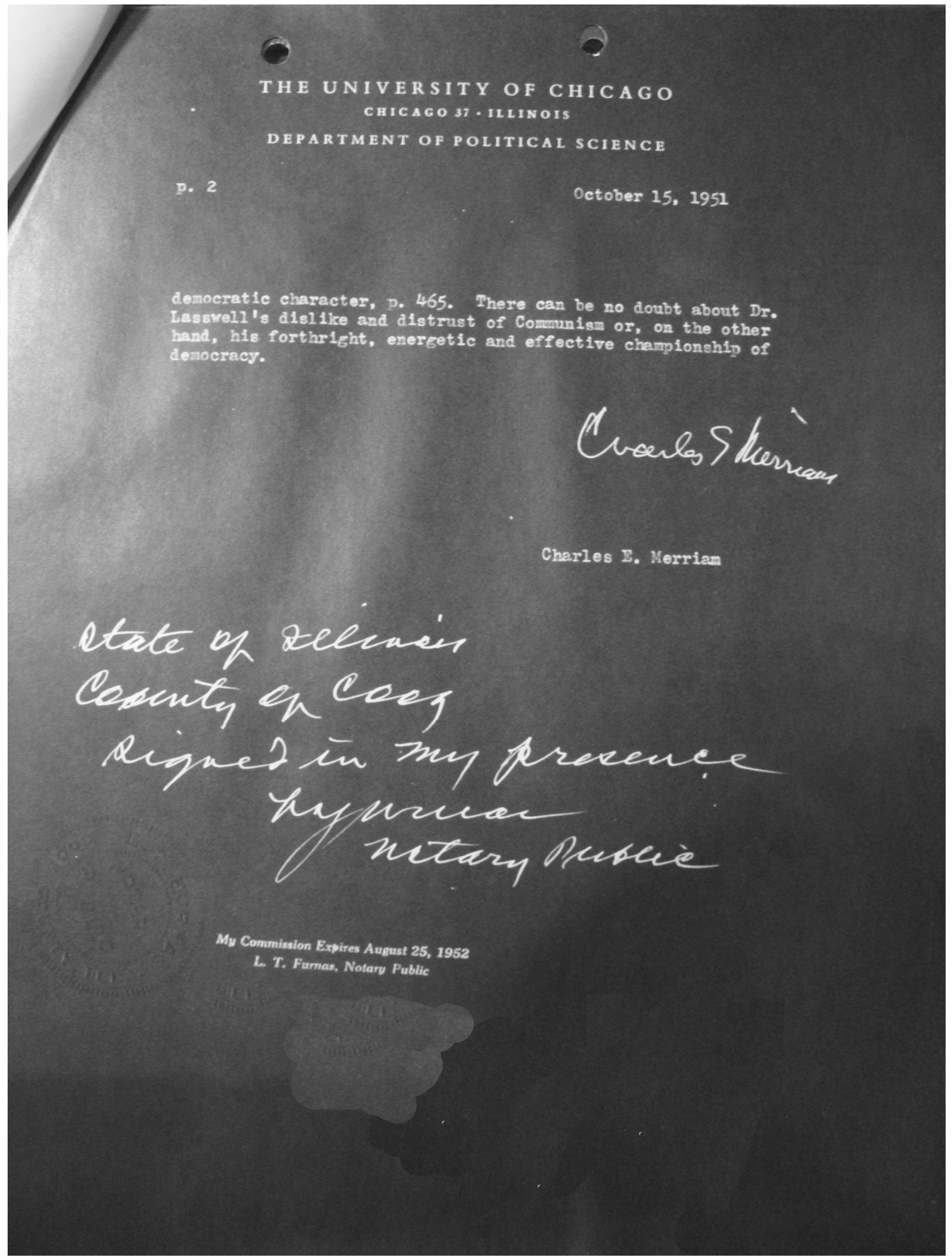

Figura 16. Carta de Charles Merriam ao governo estadunidense, atestando desconhecer ligações de Lasswell com o comunismo, página 2. Fonte: Harold Lasswell's Papers, Yale Manuscripts and Archives, Sterling Memorial Library, Universidade de Yale. 


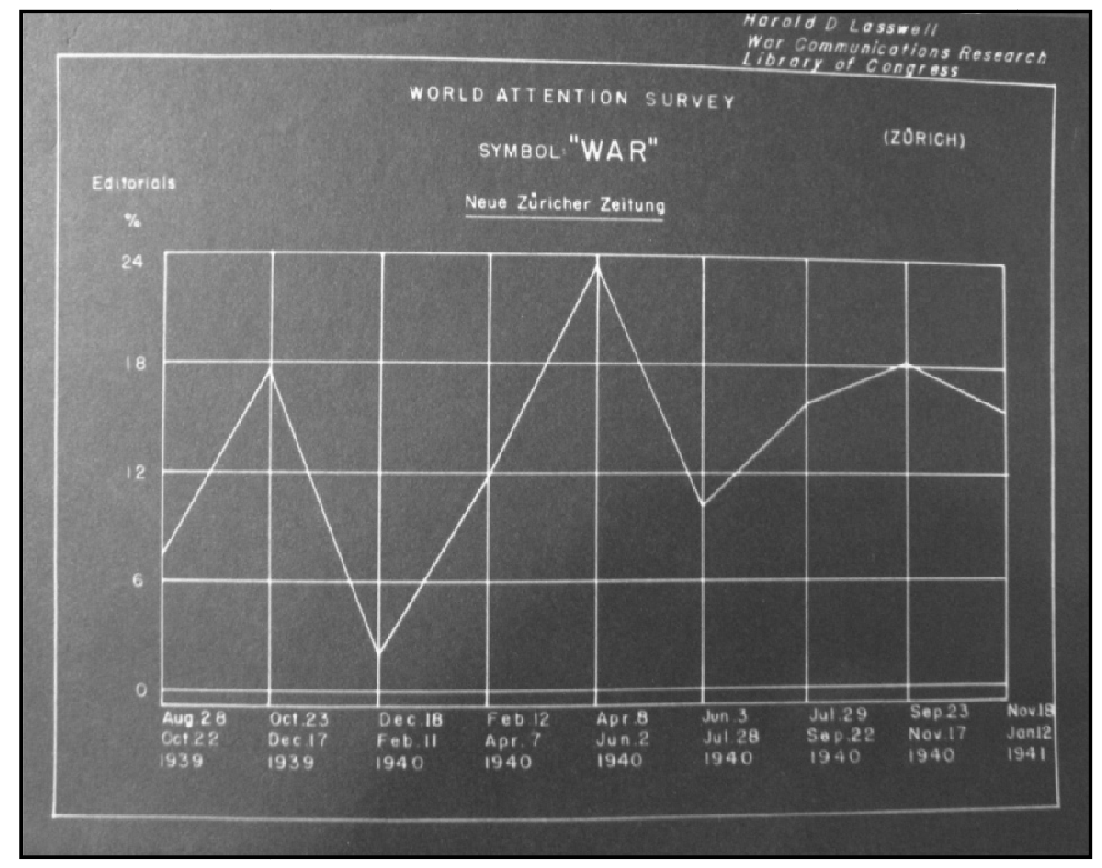

Figura 17. Gráfico que mostra a frequiência do símbolo "Guerra" no jornal Neue Züricher Zeitung, de 1939 a 1941. O gráfico é, ao mesmo tempo, um exemplo da aplicação da análise de conteúdo proposta por Lasswell e do trabalho meticulosamente quantitativo da Divisão Experimental para o Estudo das Comunicações em Tempo de Guerra. A Divisão produziu centenas desses gráficos, que serviam para análise simbólica das comunicações. Fonte: Harold Lasswell's Papers, Yale Manuscripts and Archives, Sterling Memorial Library, Universidade de Yale.

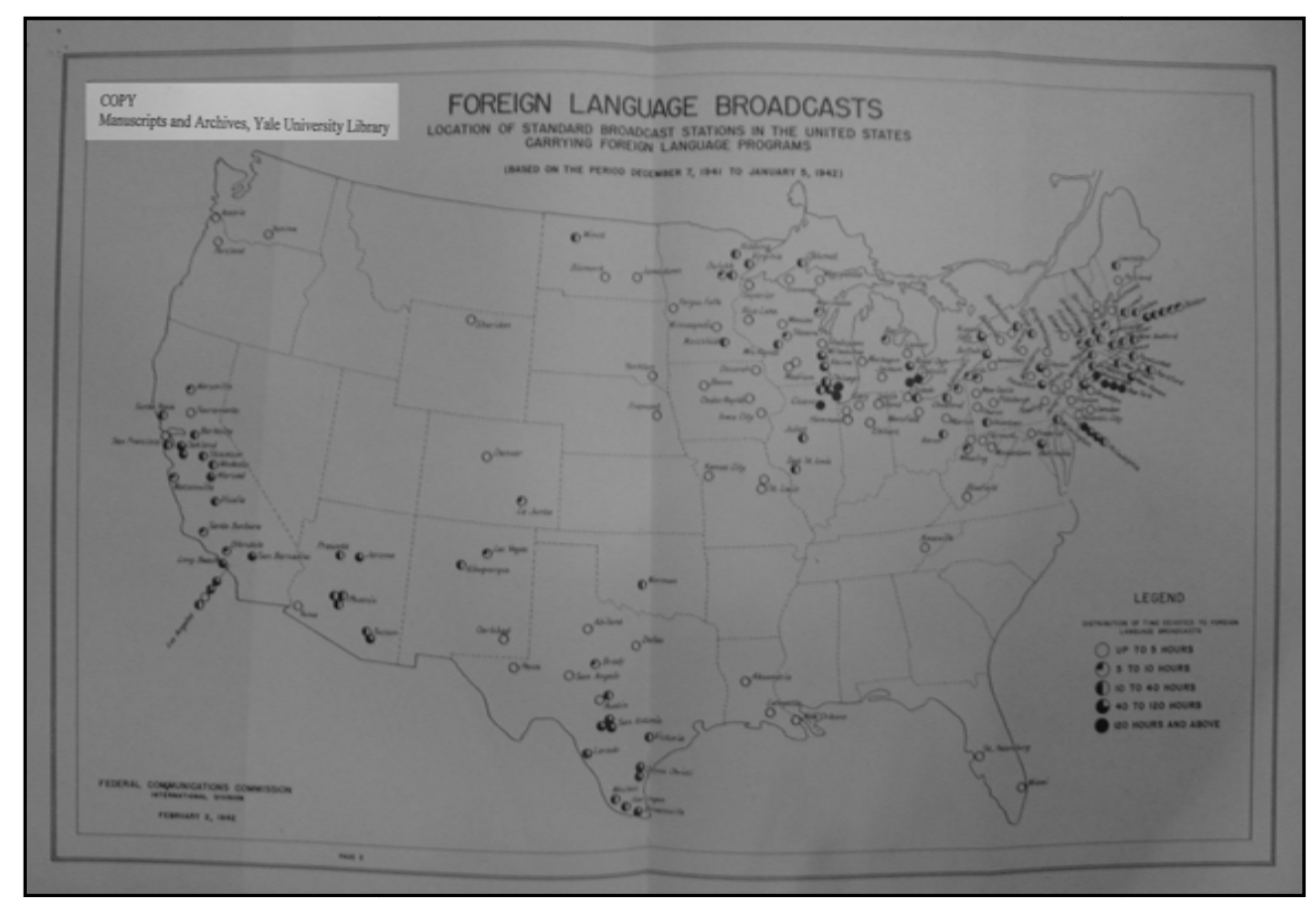

Figura 18. Mapa elaborado pela Divisão Experimental para o Estudo das Comunicações em Tempo de Guerra mostrando emissoras de rádio em língua estrangeira nos EUA em 1942. O mapa deixa claro a tentativa de controle das emissões radiofônicas pelo governo estadunidense. Fonte: Harold Lasswell's Papers, Yale Manuscripts and Archives, Sterling Memorial Library, Universidade de Yale. 


$$
-10-
$$

TYPES OF SYMBOLS AT THE FOCUS OF ATTENTION OF LA PRENSA
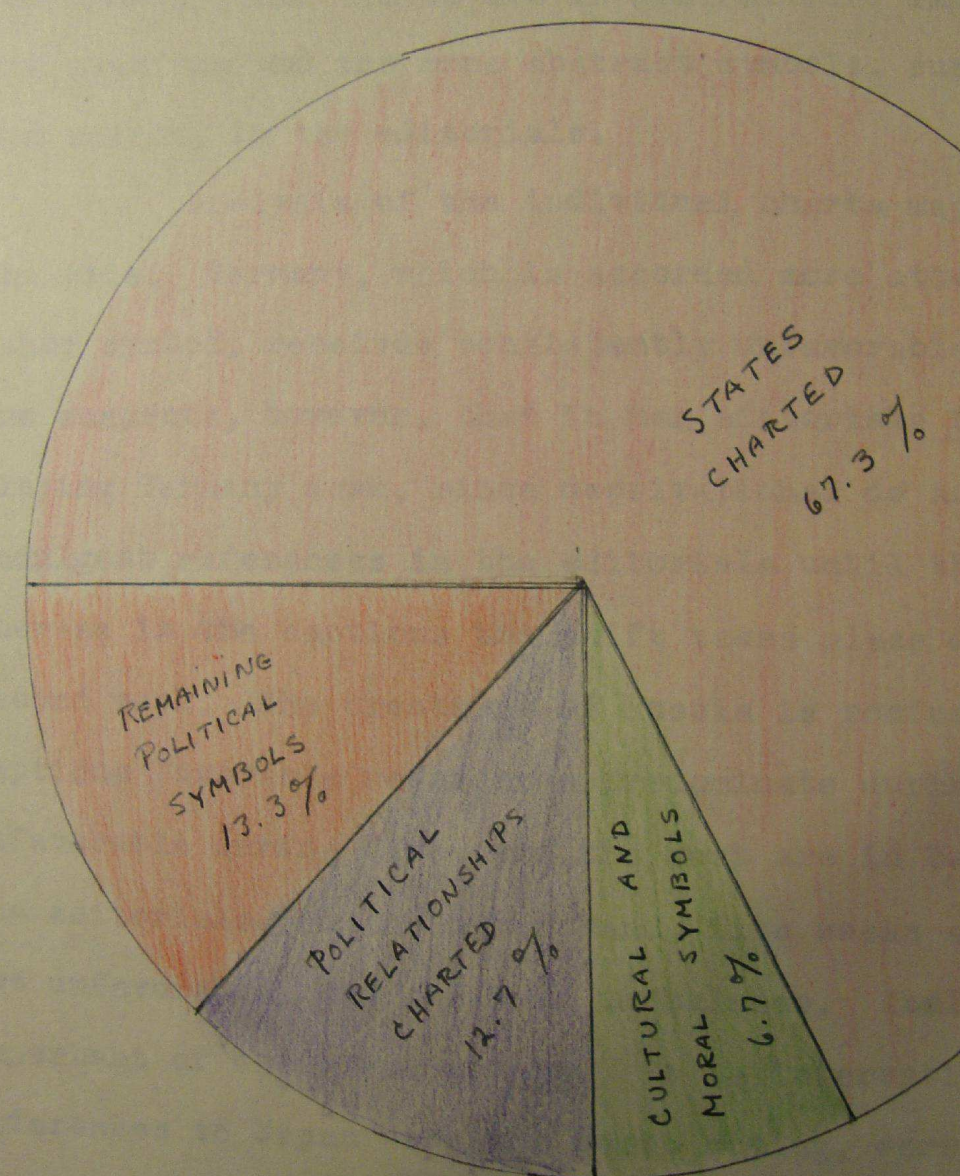

Note:

The percentages given above include the additions made in footnote * on page 7 .

Figura 19. Gráfico produzido pela Divisão Experimental para a Comunicação em Tempos de Guerra. Fonte: Harold Lasswell's Papers, Yale Manuscripts and Archives, Sterling Memorial Library, Universidade de Yale. 


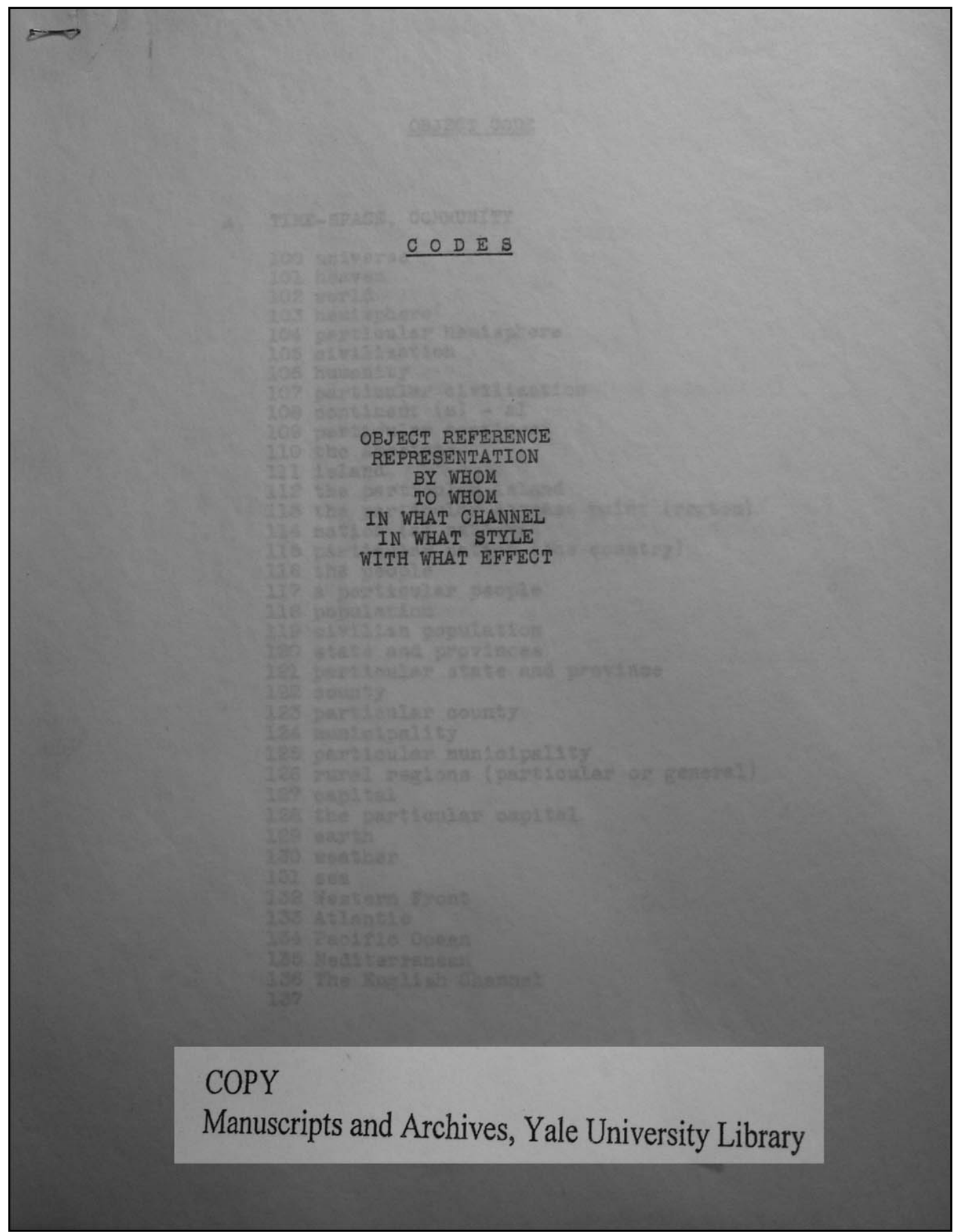

Figura 20. Manual para utilização do esquema de Lasswell na Divisão Experimental para o Estudo das Comunicações em Tempo de Guerra. Fonte: Harold Lasswell's Papers, Yale Manuscripts and Archives, Sterling Memorial Library, Universidade de Yale. 


\section{KEY TERMS FOR A THEORY OF COMKUNICATION}

1. EVENT: Whole or part.

2. SYBBOL (EVENT): An event that refers.

3. RETEREN: Bvents referred to by a symbol.

4. MOVBMEN (EVINT): A non-referring event.

5. EOO: A symbol user.

6. THING: Non-ogo,

7. STATBNENT: Series of Interrelated symbols.

8. SIGI: Movement correlated with a symbol.

9. PRIMARY EGO: Ego of the aaker of a statement.

10. IDSNTIFICATION (STATANENT): Delinits the events to be inoluded with and excluded from ego.

11. LANGUAG:; System of symbols in whloh statements are made.

12. SCIENTIFIC LANCUAGE: Language among selent1sts* for solentifle purposes.

13. ALPHA LANGOAG: Non-selentiple langugge.

14. BETA LANGUAG: Solentifle language for alpha language and for non-selentifie movements.

- Underlined terne derined leter.

COPY

Manuscripts and Archives, Yale University Library

Figura 21. Primeira página do arquivo "Termos-chave para uma Teoria da Comunicação". Fonte: Harold Lasswell's Papers, Yale Manuscripts and Archives, Sterling Memorial Library, Universidade de Yale. 


\subsection{Os anos finais: 1946 a 1978}

Lasswell chegou a Yale com um grande reconhecimento como cientista social, mas o desafio de recomeçar em uma área cuja pesquisa ainda era bastante restrita, o Direito. Contudo, os anos em Yale ofereceram uma estabilidade maior ao cientista político, que deu início a um trabalho mais voltado às relações internacionais, ao estudo das leis, e, ainda, uma continuidade às frentes abertas pelos anos anteriores, reforçando a pesquisa em Ciência Política e Comunicação. Contudo, ao firmar base em Yale, Lasswell sai dos holofotes aos quais estava acostumado em Washington, e há poucos registros sobre os bastidores de sua produção após a liderança da Divisão Experimental para o Estudo das Comunicações em Tempo de Guerra. Isso não significa que Lasswell tenha deixado de trabalhar para o governo. Pelo contrário,

Durante o período da Guerra Fria [...] a interação de Lasswell com o governo continuou. Com analistas de sua "loja de propaganda" - nomeadamente Lerner, Pool, e Eulau - ele continuou a estudar elites e símbolos no Instituto Hoover e para a RAND Corporation (FARR, HACKER \& KAZEE, 2006, p.582) ${ }^{163}$

Mas as pesquisas que se seguiram não alcançavam tanta repercussão, nem tinham a mesma importância que possuíam quando estavam diante do desafio de vencer a guerra juntamente com as forças armadas estadunidenses. Talvez por isso, acredita-se comumente que Lasswell teria abandonado por completo os estudos de Comunicação após o fim da Divisão. Entretanto, até 1970, quando se aposenta pela universidade de Yale, a produção de Lasswell consegue equilibrar os seus diversos interesses de estudo - o que justifica a afirmação de Margareth Mead no início deste capítulo. A comunicação (que aparece sob a rubrica "Symbols appeals") nunca deixa de ser presente nesta produção, que se configura de maneira impressionante, conforme mostra a figura a seguir:

\footnotetext{
${ }^{163}$ No original: "During the period in which the Cold War [...] Lasswell's interaction with the government continued. With analysts from his propaganda shop — notably Lerner, Pool, and Eulau — he continued to study elites and symbols at the Hoover Institute and for the RAND Corporation".
} 


\begin{tabular}{lcccc|}
\hline Focus of Attention & $\begin{array}{c}\text { Early Period } \\
(1923-38)\end{array}$ & $\begin{array}{c}\text { Middle Period } \\
(1939-54)\end{array}$ & $\begin{array}{c}\text { Late Period } \\
(I 955-72)\end{array}$ & Totals \\
\hline 1. Contemporary problems & 48 & 14 & 5 & 18 \\
2. Human psyche & 18 & 13 & 17 & 15 \\
3. Symbol appeals & 19 & 51 & 11 & 27 \\
4. Methods of inquiry & 13 & 18 & 39 & 26 \\
5. Options for the future & 2 & 4 & 28 & 14 \\
Totals & 100 & 100 & 100 & 100 \\
6. Wordage (in thousands) & 900 & 1,300 & 1,700 & 3,900 \\
\hline SOURCE: From Harold D. Lasswell: On Political Sociology (p. 11), edited by D. Marvick, 1977, Chicago: \\
University of Chicago Press. Copyright 1977 by University of Chicago Press.
\end{tabular}

Figura 22. Produção de Harold Lasswell em quantidade de palavras.

E entre o que Marwick chama de "período intermediário" e "período tardio", Lasswell produziu 45 trabalhos que de alguma maneira abarcavam o fenômeno da comunicação, incluindo obras como Propaganda, Communication and Public Opinion: a Comprehensive Reference Guide (1946), The Structure and function of Communication in Society (1948), Propaganda and Mass Insecurity (1950), Communication as an Emerging Discipline (1958), Political Communication: the Public Language of Political Elites in India and the United States (1969). Há também um reconhecimento que leva Lasswell a ministrar cursos de teoria da comunicação até o fim da vida.

Dessa forma, percebe-se que, longe de abandonar a comunicação enquanto problema, Lasswell retorna a ela constantemente, agregando a realidade vivida em Yale a seus estudos, que em New Haven ${ }^{164}$ começam a perder o vínculo estabelecido na Segunda Guerra Mundial com as exigências do governo estadunidense. Nesta fase, as colaborações com Myres McDougal, professor da Yale Law School, são constantes e acabam gerando obras fundamentais de Lasswell no estudo da Lei, como Power and Personality (1948), seu mais importante escrito sobre o assunto. Juntamente com McDougal, Lasswell ainda propôs a reforma de todo o currículo da escola de Direito, para que a formação do jurista estivesse voltada em favor de uma ordem pública e, nas palavras do próprio, para a garantia da dignidade humana. Além disso, Lasswell continuava a elaborar o projeto de "ciências políticas", criando uma revista (Policy Sciences) e dois institutos (a Fundação para as Ciências Políticas e o Centro de Ciências Políticas, com escritórios em Nova York e em New Haven, ambos fundados em 1948).

Essas instituições suprimiram as fronteiras tradicionais entre a academia e as empresas de consultoria, oferecendo bases independentes de operações para seus membros. Seus

\footnotetext{
${ }^{164}$ Cidade em que a Universidade de Yale está situada, no estado de Connecticut.
} 
fundadores empreenderam uma série de atividades para promover as ciências políticas, como a Biblioteca de Ciências Políticas (inicialmente editada por Lasswell). A partir dessa concepção, essas novas organizações "casaram” o centro de pesquisa com o escritório de advocacia - não por acaso, porque os fundadores originais eram todos da Escola de Direito de Yale (a qual Lasswell tinha sido associado desde 1938 e para a qual ele foi eleito professor em 1946). No entanto, os fundadores não apenas emprestaram a perspectiva legal, eles a modificaram (FARR, HACKER \& KAZEE, 2006, p.582) ${ }^{165}$.

A princípio contratado como professor de Direito, Lasswell assumiu em 1952 o posto definitivo de professor de Ciência Política, ano em que se torna também vicepresidente da Associação Americana de Ciência Política. A partir de 1952 também, Lasswell começa a ser homenageado por seu trabalho, além de ter sido professorvisitante de diversas instituições. É assim que se torna Fellow visitante do Centro Avançado de Pesquisa em Ciências do Comportamento, em Stanford (1954); professor visitante na Universidade de Tóquio (1955); presidente da Associação Americana de Ciência Política (1956); Fellow da Academia Americana de Artes e Ciências (1957); consultor do Escritório dos Estados Unidos de Administração de Pessoal (1964); consultor do Corpo de Paz, Doutor Honoris Causa em Direito pela Universidade de Illinois, Doutor Honoris Causa em Letras, pelo Seminário Teológico Judeu da América (1965); professor visitante da Universidade de Patna, na Índia, Doutor Honoris Causa em Direito pela Universidade de Chicago (1967); professor visitante do John Jay College of Criminal Justice, fundador da revista Policy Sciences (1969); Fellow da Academia de Ciências de Nova York, consultor da RAND Corporation, Professor Emérito de Ciência Política do John Jay College of Criminal Justice, em Nova York (1970).

É ainda nos anos entre 1946 e 1978 que Lasswell passa a ser um dos principais personagens na narrativa dominante, nos Estados Unidos, sobre a formação do campo da Comunicação, conhecida como "mito dos quatro fundadores". Em 1947, o primeiro curso de doutorado em Comunicação havia sido criado na universidade de Illinois, por

\footnotetext{
${ }^{165}$ No original: "These institutions elided traditional boundaries between academic and advisory enterprises, while providing independent bases of operations for their members. They undertook a number of activities to promote the policy sciences, like the Library of Policy Sciences (which Lasswell initially edited). In conception, these new organizations married the research center with the law firm - not incidentally, because the original founders were all from the Yale Law School (with which Lasswell had been associated since 1938 and in which he was made professor in 1946). Yet the founders did not just borrow the legal perspective; they changed it".
} 
Wilbur Schramm. A história ofereceu legitimidade a um campo que possuía muitos autores, mas nunca havia chegado a se constituir de fato.

Nesses anos,

A pesquisa relacionada aos efeitos dos meios de comunicação estava bem consolidada, sendo, inclusive, patrocinada pelo governo estadunidense e por diversas instituições, como a Fundação Rockefeller e o Fundo Payne. As relações entre governo, comunicação e guerra estavam desde muito estabelecidas. As escolas de jornalismo pululavam nos Estados Unidos. Os frankfurtianos já haviam descido em solo americano e partido, tendo, inclusive colaborado com os "pais fundadores", que não eram mais pesquisadores iniciantes, mas cientistas de renome. A primeira metade do século XX havia se despedido e o campo da Comunicação já havia dado seus primeiros passos rumo a um estatuto mais científico, que, no final das contas, foi o resultado final de um interesse crescente no impacto dos meios de comunicação na sociedade e de uma sistematização do conhecimento gerado a partir desse questionamento (VARÃO, 2010, p. 80).

Relembremos esse ponto: a ideia dos pais fundadores foi sugerida primeiramente por Berelson (1959), no seu famoso artigo The State of Communication Research (Public Opinion Quarterly), e reafirmada por Schramm ${ }^{166}$ algum tempo depois, em 1963, na obra Human Communication Research. Essa ideia coloca a fundação do campo sob a forma de narrativa de uma disciplina ainda não constituída, mas em gestação, e introduz uma legitimação baseada na busca por aqueles que o historiador da Antropologia George Stocking chama de the firsts (os primeiros): "grandes homens que deixaram grandes 'escritos' pioneiros para a história de um campo" (STOCKING apud PoOlEy, 2007, p. 2) ${ }^{167}$. "Os primeiros" se referem àqueles que, parafraseando Alexandre Koyré, viram coisas que "ninguém nunca viu antes" e tiveram "pensamentos que ninguém nunca teve", representando o marco-zero de uma determinada ciência. No artigo de Berelson eles estão representados por Lasswell, pelo sociólogo Paul Felix Lazarsfeld (1901-1976), e os psicólogos Carl Iver Hovland (1912-1961) e Kurt Zadek Lewin (1890-1947).

O artigo nos coloca no âmbito de uma revisão do campo em 1959, véspera, para o seu autor, da comemoração dos 30 anos da pesquisa em Comunicação. Berelson faz, com The State of Communication Research, a primeira elaboração de um estado da arte do saber comunicacional.

\footnotetext{
166 Já em seus primeiros escritos, Schramm apresenta Lasswell, Hovland e Lazarsfeld como importantes precursores. Só em 1963, Kurt Lewin passa a integrar a quadríade.

${ }^{167}$ No original "a great men/great deeds approach and writings to history of a field". Tradução livre.
} 
Berelson, que trabalhava diretamente com Lazarsfeld, situou o início das pesquisas em comunicação na década de 30, com o seminário promovido pela Fundação Rockfeller $^{168}$, cujo escopo era acadêmico e comercial, mas que focava a comunicação de massa de maneira nunca antes vista e serviu de importante fermento aos trabalhos de então. Quando traçou esse quadro, vinha de uma demorada experiência no Iowa, trabalhando no Instituto de Informação da Guerra dos Estados Unidos (OWI), no qual Schramm também se encontrava, e onde ambos tiveram contato com um amplo comitê de cientistas sociais, entre eles os próprios pais fundadores e nomes como Stouffer, Maccoby, Likert, Nafziger, Gardner, Gallup, Roper e Stanton ${ }^{169}$. Quando Schramm replica a ideia de Berelson nos anos seguintes, Lasswell, Hovland, Lazarsfeld e Lewin aparecem não só como responsáveis pela organização das linhas principais da pesquisa em Comunicação, mas como os reais fundadores do campo.

Dos quatro autores, é Lazarsfeld, no entanto, quem vai assumir uma envergadura maior, deixando para trás em importância o próprio Lasswell. Hovland ganha notória importância no que diz respeito à análise e desenvolvimento das técnicas de persuasão, mas sua morte aos 48 anos (em decorrência de um câncer na glândula parótida) e sua preocupação maior em desenvolver uma teoria da psicologia, fizeram com que poucas de suas obras fosse referência para o campo comunicacional. Lewin, recrutado para servir aos institutos de pesquisa na Segunda Guerra Mundial, acabou não representando uma grande influência no campo por não ter deixado nenhuma obra mínima em comunicação, o que confirma seu foco primário na sua área de origem.

Lazarsfeld, por outro lado, construiu uma história diferente. Com uma reputação bem erigida durante os anos da Segunda Guerra, Lazarsfeld lançou poucos anos antes do artigo de Berelson, que o lista como um dos fundadores do campo comunicacional, um dos mais influentes livros da pesquisa em comunicação: Personal Influence - the Part Played by People in the Flow of Mass Communication, de 1955, escrito em parceria com Elihu Katz.

A obra não só estabelecia uma nova forma de se fazer pesquisa em comunicação - com o que ficou conhecido como teoria do líder de opinião -, como a opõe em relação a tudo o que veio antes, logo nas suas primeiras quinze páginas. De acordo com Pooley (2006), as quinze primeiras páginas de Personal Influence não só resumiram a

\footnotetext{
168 O mesmo seminário que promoveu a adoção do nome "comunicação" em substituição a "propaganda" nesses estudos.

${ }^{169}$ Muitos desses cientistas, após a Segunda Guerra Mundial, acabaram por se tornar uma elite no campo da pesquisa social.
} 
história do campo sob a ótica de Lazarsfeld, mas instituíram o reconhecimento de Lazarsfeld como o pesquisador a superar, de fato, a teoria hipodérmica. Assim, Pooley resume as conseqüências da história contada por Lazarsfeld:

Em um capítulo curto, o passado sem unidade do campo estava bem resumido. Uma pré-história naif, intuitiva - escrita sobre a crença equivocada de que de rádio e filme empunhavam enorme poder - foi substituída por uma avaliação científica mais calma: estes meios, de acordo com as novas evidências, têm apenas efeitos "limitado". Esta história contida em Influência Pessoal é simples, direta e deficiente em fontes. Sua narrativa limpa é resolvida pelo segundo ato. E acreditada: cinquenta anos depois, o enredo de "poderosos efeitos limitados" permanece como clichê em livros didáticos e como dogma em revisões de literatura. As quinze páginas de Katz e Lazarsfeld tiveram mais influência sobre a auto-compreensão histórica do campo do que qualquer coisa publicada antes ou depois.

Todos os clichês historiográficos das décadas por vir - a "teoria da bala mágica" do entre-guerras, por exemplo, ou a idéia de um modelo de "agulha hipodérmica" - traçam suas origens até essas quinze páginas ${ }^{170}$ (POOLEY, 2006, p.2).

Dessa maneira, aparentemente toda a pesquisa anterior se ajuntaria sob o rótulo de hipodérmica, com um status negativo. Era necessário repensar uma série de questões pertinentes ao estudo da comunicação, inclusive o esquema de Lasswell, citado logo na primeira página de Personal Influence.

A teoria do líder de opinião explicitada no livro buscava inserir nos estudos de comunicação a importância do grupo primário $^{171}$ no processo de comunicação de massa, alegando que os meios não atingiam diretamente o destinatário, mas antes passavam por uma espécie de "filtro": o líder de opinião. O líder era o setor da população mais ativo politicamente também mais próximo dos meios de comunicação. Assim, importava mais a influência do líder de opinião sobre a audiência do que a mensagem propriamente dita dos meios de comunicação. Focando no líder de opinião, a chance das mensagens terem seus objetivos alcançados seria muito maior. O contexto social deveria ser, portanto, mais valorizado nas análises de comunicação, tendo sido ignorado por muito tempo, de acordo com a visão de Lazarsfeld.

\footnotetext{
${ }^{170}$ No original: "In one short chapter, the field's untidy past was neatly emplotted. A naïve, intuitive prehistorygiven over to the mistaken belief that radio and film wield enormous power-got displaced by a calmer, scientific appraisal: These media, according to the new evidence, have only "limited" effects. This Personal Influence history is simple, direct, and meagerly sourced. Its clean narrative is resolved by the second act. And it was believed: Fifty years later, the 'powerful-to-limited-effects' storyline remains textbook boilerplate and literature review dogma. Katz and Lazarsfeld's fifteen pages have had more influence on the field's historical self-understanding than anything published before or since.

All of the historiographical cliches of the decades to come-the interwar 'magic bullet theory', for example, or the idea of a 'hypodermic needle' model-trace their origins to those fifteen pages"

${ }^{171}$ Sob inspiração de Edward Shils (PoOLEY, 2006).
} 
Para Pooley, grande parte das intenções de Lazarsfeld ao construir essa pequena história não eram cientificas.

A melhor maneira de entender as escolhas de Lazarsfeld em Personal Influence é, em primeiro lugar, reconhecer que a busca da distinção científica - para obter respeito de seus pares - foi o estímulo acadêmico fundamental de Lazarsfeld. Esta motivação coexistiu provetiosamente com dois interesses intelectuais genuínos, a metodologia e psicologia da tomada de decisões - interesses que foram, no entanto, bem adequados à geração que clama pela novidade em função dos créditos oferecidos à reputação acadêmica (POOLEY, 2006, p.15) ${ }^{172}$.

Independente dos motivos, fato é que Personal Influence divide a pesquisa em comunicação em um antes e um depois de suas propostas. Com isso, grande parte da pesquisa realizada em fases anteriores passou a ser em larga medida desacreditada - o que talvez explique a progressiva perda de status de referência da obra lasswelliana.

Entrementes, pela história de Berelson e sua importância reconhecida por longos anos, Harold Lasswell tem seu lugar assegurado na memória do campo. Se sua enorme produção acerca de comunicação e propaganda pode não ser suficiente para demonstrar o caráter de pai fundador, pelo menos aponta uma preocupação incomum para aquela época, com problemas inerentes à área. Além disso, não se pode deixar de reconhecer que é da autoria de Lasswell, um dos primeiros textos a identificar a Comunicação como uma possível disciplina: Communications as an Emerging Discipline, de 1958.

Ao se aposentar de Yale, em 1970, Lasswell ainda se manteve bastante ativo, e continuou a aliar comunicação e política, deixando pelo menos três obras importantes em seus últimos seis anos de vida, ainda que mais voltadas a Ciência Política: Communications Research and Public Policy, de 1972, Communication in a Divided World: Opportunities and Constraints e Building as Political Communication, ambas de 1977.

Harold Lasswell morreu em 18 de dezembro de 1978, em Nova York, vítima de um acidente vascular cerebral, que primeiro o deixou paralisado por meses, sem fala, até derrotá-lo por completo. Na época, já não era mais uma figura proeminente, viva nas pesquisas dos cientistas sociais - nem mesmo na Ciência Política.

Naquele tempo, a estrela de Lasswell - e com isso, o cientista político da democracia - já estava desaparecendo. Segundo uma análise

\footnotetext{
${ }^{172}$ No original: "The best way to understand Lazarsfeld's choices about Personal Influence is, first, to recognize that the quest for scientific distinction-for peer respect-was Lazarsfeld's fundamental academic stimulus. This motivation coexisted profitably with two genuine intellectual interests, methodology and the psychology of decisionmaking-interests that were, however, well-suited to the generation of the claims to novelty that underwrite scholarly reputation"
} 
recente (Eulau e Zlomke, 1999), Lasswell foi citado mais de 200 vezes nas principais revistas de ciência política nos 17 anos antes de sua morte, mas apenas 70 vezes nos 17 anos depois. [...] Apesar de Lasswell ter se tornado uma figura imponente na crescente literatura sobre a história da disciplina, seu trabalho é apenas esporadicamente citado (FARR, HACKER \& KAZEE, 2006, p.6) ${ }^{173}$.

Para Rodney Muth (1989), isso pode ser explicado pelo fato de Lasswell e suas teorias seriam compreendidas inadequadamente no campo da Ciência Política. Poderíamos dizer que o mesmo aconteceu na Comunicação. Mas não podemos. Na Comunicação, o ilustre desconhecido que apresentamos aqui ainda requer que conheçamos suas teorias para além da caricatura que o seu esquema do processo de comunicação se tornou. É o que faremos no próximo capítulo.

\footnotetext{
${ }^{173}$ No original: "By then, Lasswell's star - and with it, the policy scientist of democracy - was already fading. According to a recent analysis (Eulau and Zlomke 1999), Lasswell was cited more than 200 times in major political science journals in the 17 years before his death, but just 70 times in the 17 years after. [...] Although Lasswell has become an imposing figure in the growing literature on the history of the discipline, his work is only sporadically cited".
} 


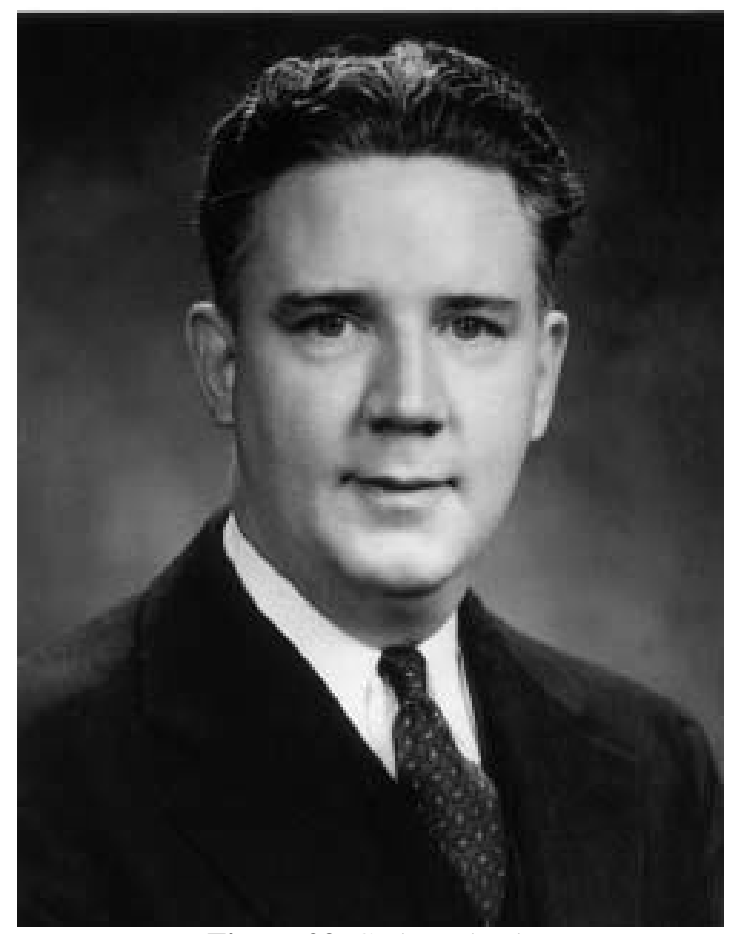

Figura 23. Carl Hovland.

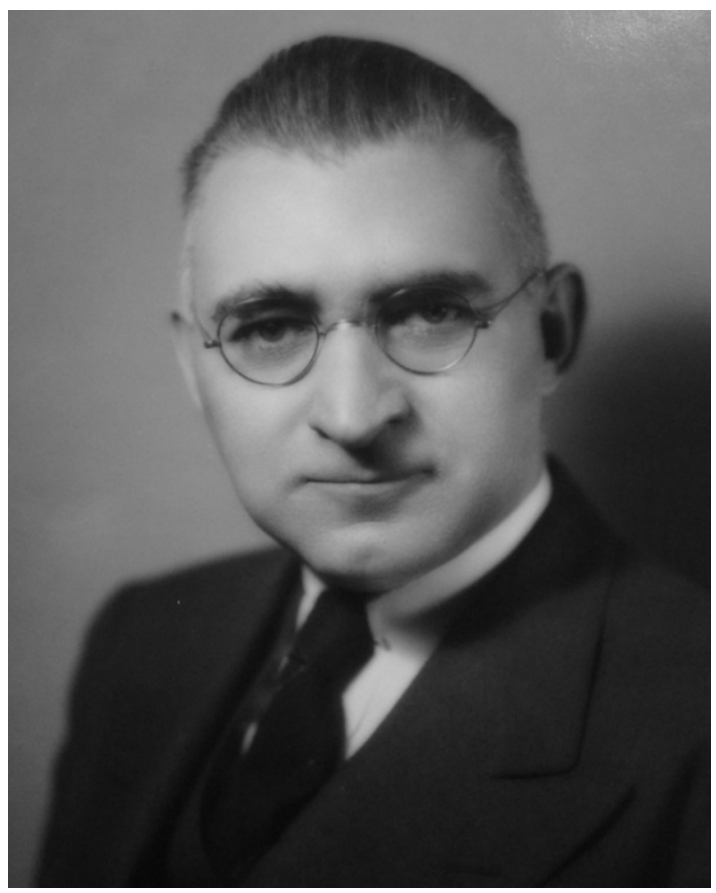

Figura 25. Harold Lasswell.

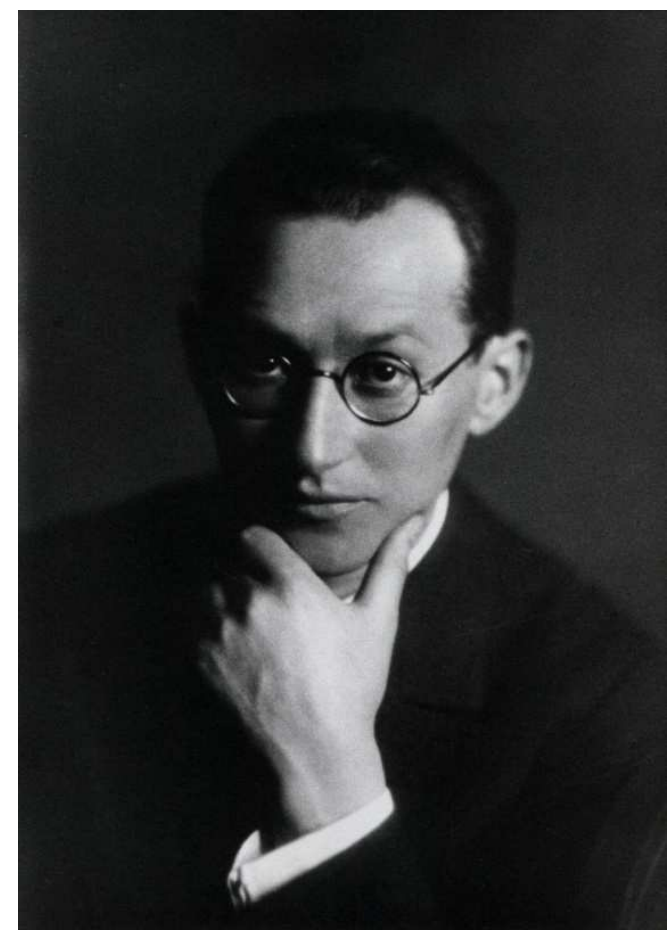

Figura 24. Kurt Lewin.

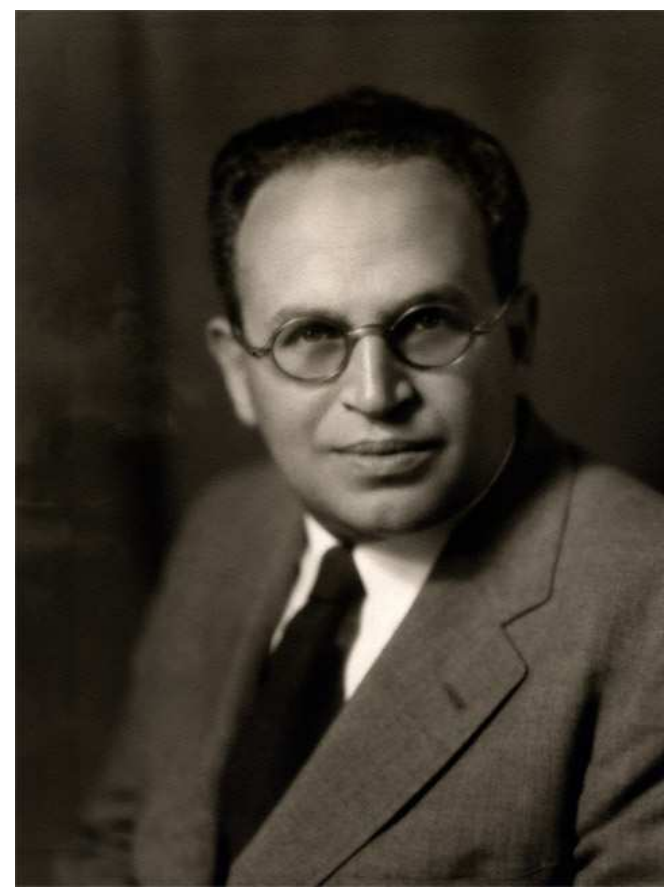

Figura 26. Paul Lazarsfeld 


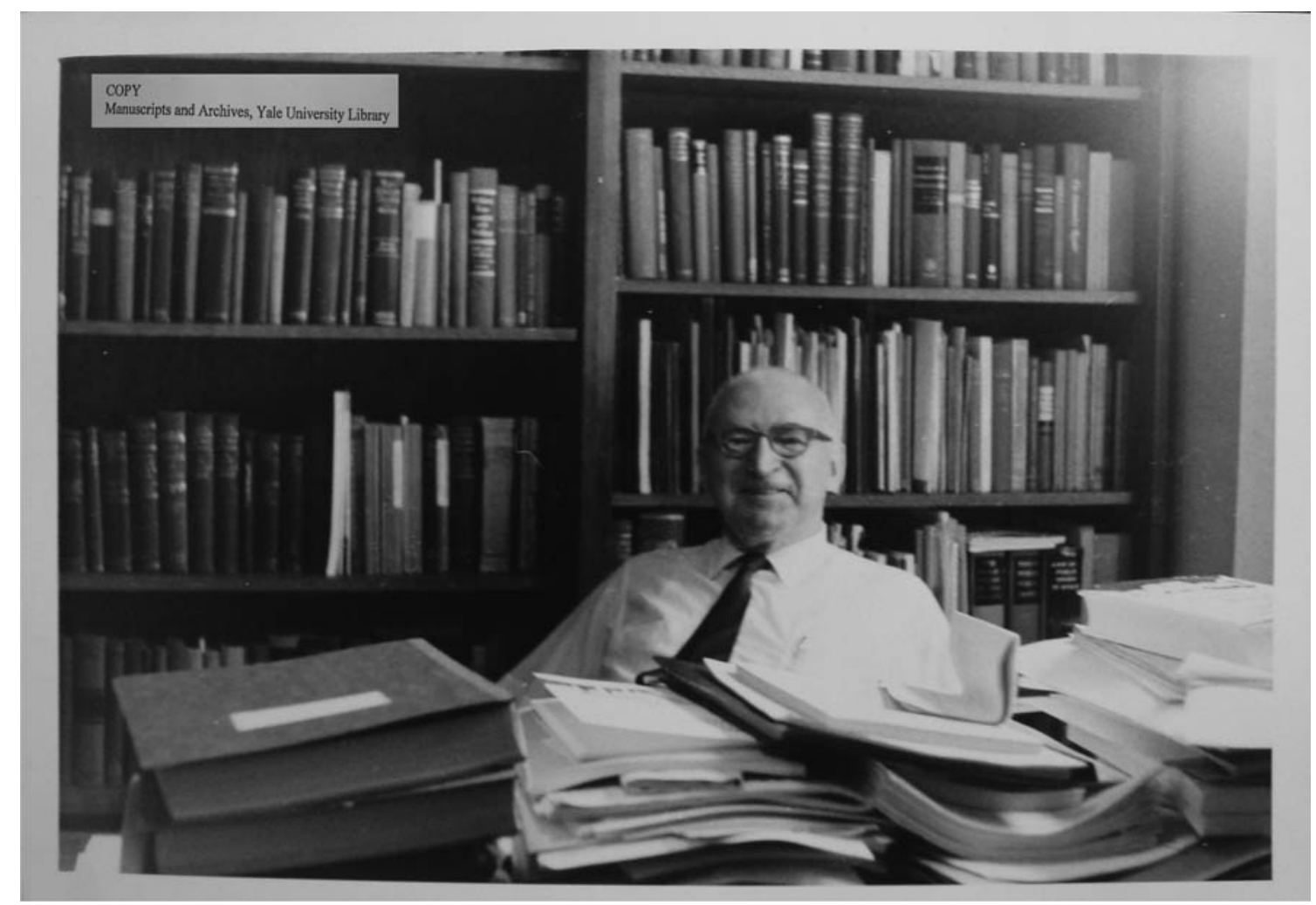

Figura 27. Lasswell em seu escritório em Yale. Fonte: Harold Lasswell's Papers, Yale Manuscripts and Archives, Sterling Memorial Library, Universidade de Yale.

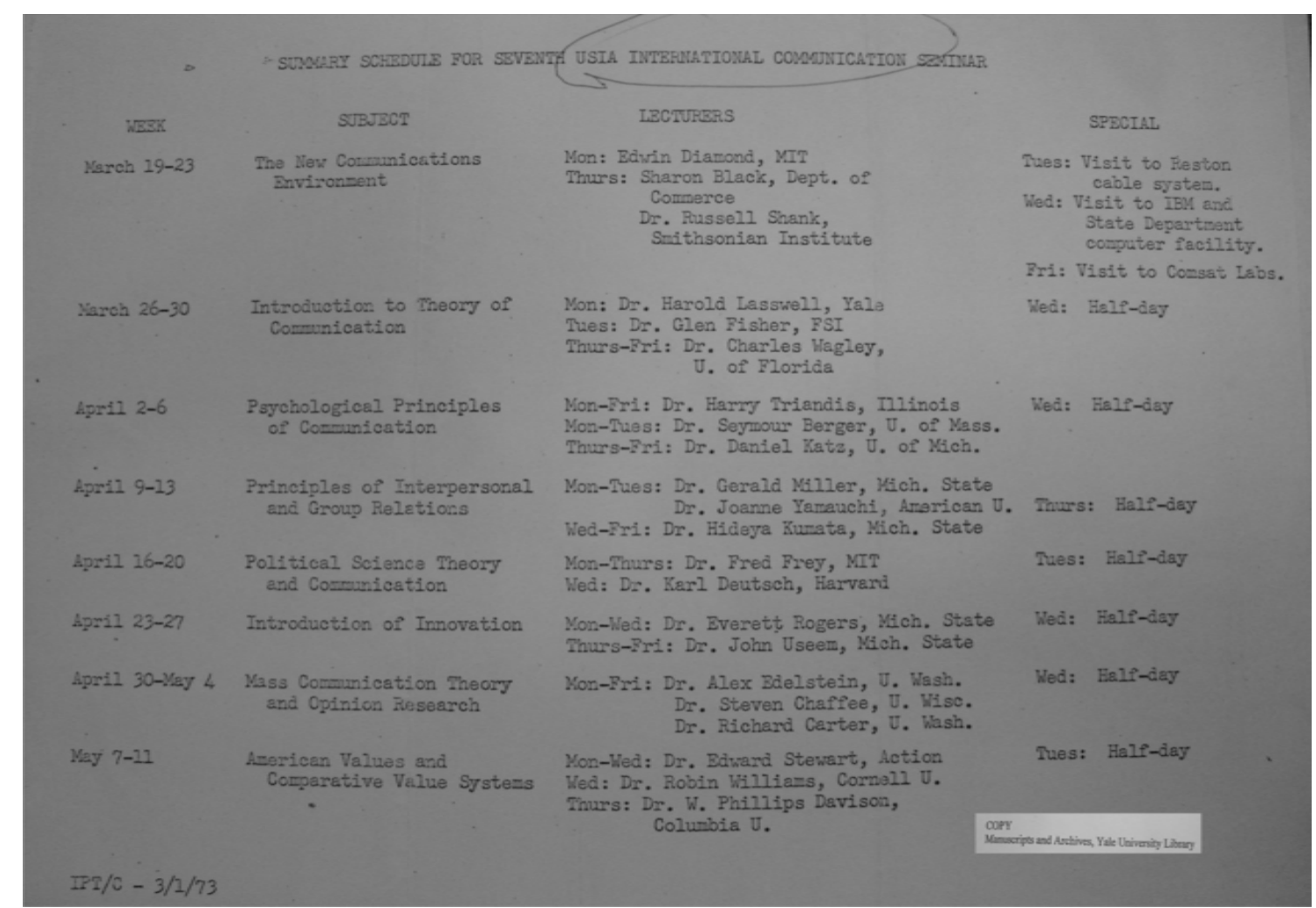

Figura 28. Lasswell ministrou cursos de Teoria da Comunicação até próximo da sua morte. Fonte: Harold Lasswell's Papers, Yale Manuscripts and Archives, Sterling Memorial Library, Universidade de Yale. 


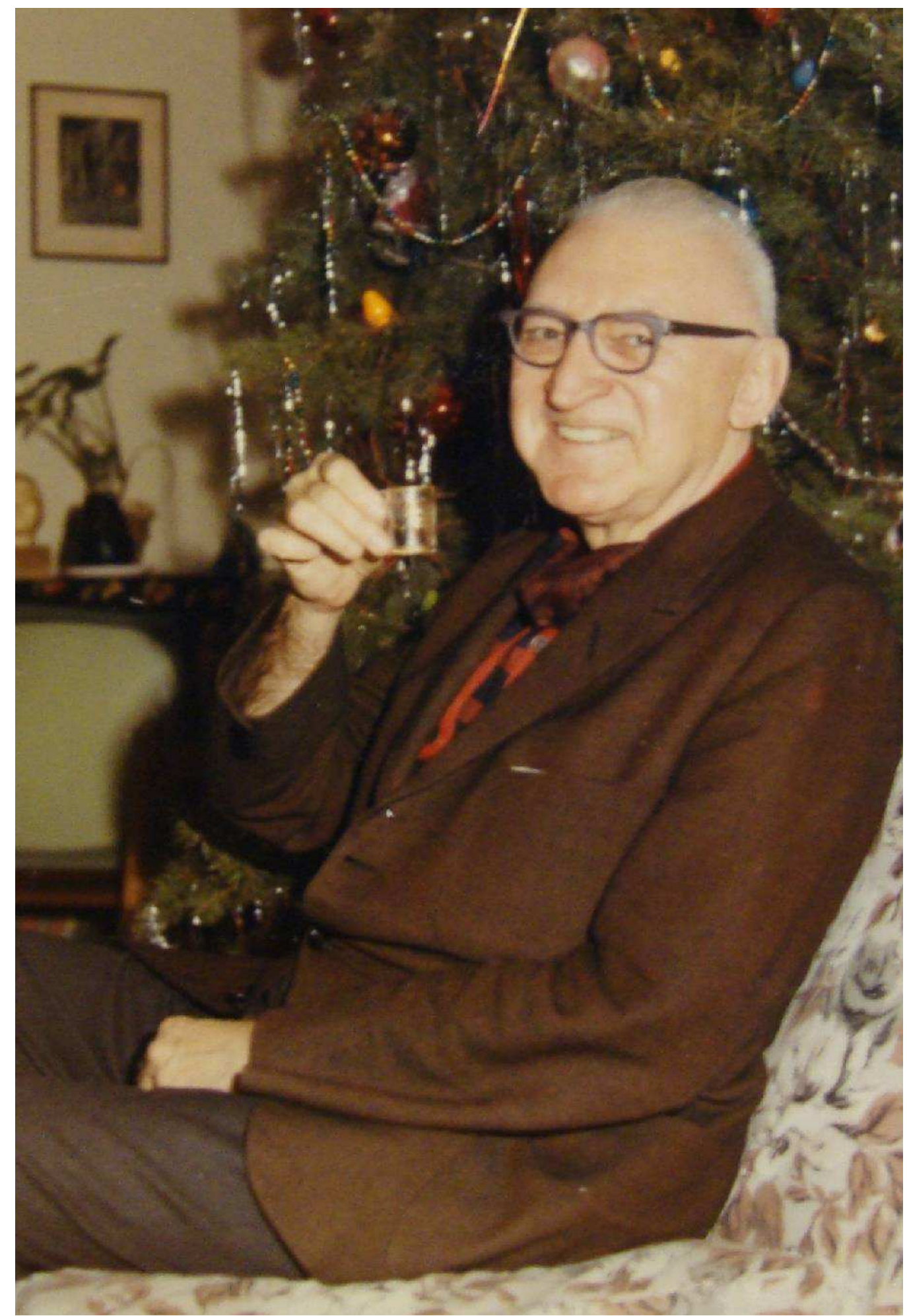

Figura 29. Uma das raras fotos coloridas de Lasswell, já no final da vida. Fonte: Harold Lasswell's Papers, Yale Manuscripts and Archives, Sterling Memorial Library, Universidade de Yale. 


\section{A OBRA COMUNICACIONAL DE HAROLD LASSWELL}

Os capítulos anteriores ofereceram uma visão geral de como Harold Lasswell se vinculou ao campo da Comunicação, e de como esse autor se encontra numa posição ambígua, sendo referenciado e ignorado. O que foi visto também, embora não nos ofereça uma compreensão da produção lasswelliana sobre comunicação, permite enxergar para além dessa ambiguidade: seja de que maneira for, Harold Lasswell e sua obra possuem uma representatividade no campo comunicacional. Mas, quais são as contribuições de Lasswell ao campo da Comunicação?

A resposta, esboçada com traços leves no panorama biográfico e intelectual que antecede este capítulo, encontra-se em parte nas relações históricas com o campo da Comunicação, mas se sobressai no que está contido no que chamaremos de obra comunicacional de Harold Lasswell. É esse conteúdo que determina mais incisivamente as histórias e os posicionamentos no campo da Comunicação em relação ao seu trabalho, mesmo que o conhecimento desse conteúdo seja superficial. É aqui que faremos um mergulho no pensamento lasswelliano sobre a comunicação, procurando compreender de que maneira ele se organiza, tanto no que diz respeito às formulações teóricas, quanto no que tange a horizontes metodológicos.

A análise epistemológica, contudo, requer também a definição de seus limites. A epistemologia é comumente definida como "o saber sobre a maneira como os saberes se constroem" (FOUREZ, 2002, p.23), centrada na formação do conhecimento. Todavia, não há apenas uma forma de se posicionar quanto à epistemologia. Segundo Martino (2003), há hoje cinco formas majoritárias de se abordar o conhecimento, que são confundidas com o trabalho epistemológico:

1) História das ciências: já comentada no segundo capítulo deste trabalho, a história das ciências é uma das vias do conhecimento epistemológico e fornece as bases históricas da evolução do pensamento científico;

2) Filosofia das ciências: A filosofia da ciência designa a forma como a ciência é tomada como objeto pela filosofia, de maneira muito ampla, colocando questões que não podem ser resolvidas dentro do universo científico, como, por exemplo, “[...] problemas éticos surgidos da produção e da aplicação do conhecimento científico [...] problemas de definição, possibilidade, origem e natureza do conhecimento humano em geral" (MARTINO, 2003, p. 79). Ou seja, 
trata de assuntos que pertencem mais às indagações filosóficas do que às perquirições científicas;

3) Psicologia das ciências: A psicologia das ciências é uma área menos desenvolvida e se aplica, sobretudo, à “[...] evolução ontogenética, no acompanhamento da evolução da criança, ou seja, ela se concentra nas estruturas psicológicas responsáveis pela aquisição do conhecimento" (Idem, ibidem, p. 76-77).

4) Gnosiologia: também chamada de Teoria do Conhecimento, designa o estudo geral do conhecimento, seja sua natureza qual for - e como tal constitui um ramo da filosofia. A gnosiologia tem como problema geral "a realidade das coisas ou, em geral, do mundo externo"” (ABBAGnANO, 2003, p.183). Na contemporaneidade, a gnosiologia perdeu bastante de sua importância, sendo substituída pela metodologia, como "a análise das condições e dos limites de validade dos procedimentos de investigação e dos instrumentos linguisticos do saber científico" (Idem, ibidem, p.183).

5) Sociologia das ciências: desenvolvida por marxistas como Karl Mannheim (que utiliza o termo sociologia do conhecimento), tem como objetivo destacar até que ponto e de que forma o conhecimento está enraizado no social ${ }^{174}$. Sob esse ponto de vista, o desenvolvimento de um campo científico está muito mais atrelado a fatores externos à produção de conhecimento científico. "Seu objeto de estudo não é o conhecimento científico como tal, mas tudo aquilo que envolve a comunidade científica e acaba influenciando na produção do conhecimento científico" (MARTINO, 2003, p.78).

Todas essas são extensões importantes relacionadas ao conhecimento e podem auxiliar, de muitas maneiras, ao estudo epistemológico, mas não as entendemos aqui como sinônimo de epistemologia. Cada um desses tratamentos, de fato, se apresenta de forma diversa da epistemologia, que "[...] se caracteriza por certas questões específicas e não por toda e qualquer relação com o conhecimento" (Idem, ibidem, p. 71).

A princípio, a epistemologia encontra suas raízes na filosofia. Num sentido mais amplo (epistemologia geral), está relacionada às seguintes perguntas: o que é conhecer, o que podemos conhecer, como podemos conhecer, o que nos motiva a conhecer? Num 
sentido mais estrito, o de epistemologia aplicada, integra cada disciplina científica, sendo "condicionada pelos limites, pelos procedimentos e finalidades do trabalho científico" (MARTINO, 2003, p. 82). Com isso, as perguntas gerais se assentam nas particularidades de cada disciplina.

Voltando-nos a Comunicação, então, os interrogantes são transmutados nos seguintes: o que é o conhecimento (saber, pensamento) comunicacional?. Qual é o seu objeto de estudo? Quais são suas teorias? Quais são seus métodos? Ou,

Em termos esquemáticos, a investigação epistemológica refere quatro problemas ao saber comunicacional: 1) Como definir o saber comunicacional? (em que condições podemos apontar um certo estudo como sendo um trabalho em Comunicação?, ou o que faz de uma pesquisa uma pesquisa em Comunicação?). 2) Quais os fundamentos desse saber? 3) Qual o estatuto do conhecimento comunicacional? (ciência?, arte?, técnica?, senso comum?, estratégia social?...). 4) Qual a relação desse saber com outros saberes? (por exemplo, como a Comunicação se relaciona com os saberes das ciências sociais?) (Idem, ibidem, p.85).

Entendida como descrita acima, a epistemologia não tem como alvo qualquer forma de conhecimento, mas se volta ao conhecimento científico produzido por uma área específica, às suas teorias. Quando se trata de pensar a obra de um autor, as questões epistemológicas se recortam ainda mais. Deslocando-as em relação ao nosso objetivo, elas se convertem em: o que é o pensamento lasswelliano sobre a comunicação? Existe a delimitação de um objeto de estudo na obra de Lasswell que possa ser considerado comunicacional? Que teorias e métodos presentes em Lasswell comportam contribuições ao que identificamos como campo da Comunicação?

Todos esses questionamentos abriram espaço para a reflexão sobre o que seria uma contribuição científica. O termo é uma constante em estudos cujo objetivo é meditar sobre um determinado cientista e um campo de atuação específico, provavelmente por seu significado parecer bastante óbvio. Por isso, não há uma definição explícita de seu sentido, mas referências contínuas aos "feitos" de um cientista como "contribuições".

Uma bibliografia variada nos mostra facilmente essa identificação. É como aparece, em BetTi \& Lemmi (2008), StARbuck (2006) e Cullen (2009), por exemplo. Todavia, essa mesma bibliografia não elucida que dimensões devem ser abrangidas no entendimento de uma contribuição, se a participação do cientista na criação de um instituto de pesquisa, a criação de um equipamento ou se o desenvolvimento de uma teoria chave numa disciplina. Se as contribuições são relembradas para assinalar a 
relevância de um autor, sem dúvida, dependendo da maneira como compreendemos a epistemologia, uma ou outra perspectiva prevalecerá.

No caso desta tese, o interesse se debruça sobre a obra teórica constituída por Harold Lasswell acerca do fenômeno da comunicação e que nos revelam aspectos importantes da fundação e fundamentação do campo comunicacional ${ }^{175}$. Trata-se de entender a contribuição não como um evento, mas como um processo que está ligado à constituição de um saber. Afinal, “[...] O objeto da epistemologia não é o fenômeno, mas as teorias, de modo que ela não pode ser 'ultrapassada' pelos fatos" (MARTINO, 2003, p.91).

Portanto, se dizemos que Lasswell foi importante para o campo da Comunicação, não o fazemos porque este obteve uma autoridade outorgada pelo governo dos Estados Unidos para dirigir a Divisão Experimental para Comunicação em Tempos de Guerra. Se assim fosse, poderíamos elencar outros nomes igualmente indicados pelo governo estadunidense para suas instituições de comunicação e afirmar que eles também foram importantes para o campo pelos seus feitos administrativos. Não. Se colocamos Lasswell numa posição de destaque em relação do campo comunicacional é porque levamos em consideração seu papel para a construção e/ou consolidação de um conhecimento científico sobre a comunicação. É assim, portanto, que nossa bússola se orienta em direção à interrogação: que teorias, conceitos e métodos estão presentes na obra lasswelliana sobre comunicação?

Fundamentalmente, nos argüirmos sobre o que buscar na obra lasswelliana, tomando também como baliza o problema de pesquisa desta tese - quais foram as contribuições de Harold Lasswell ao campo da Comunicação? - e, justamente, o entendimento de que essa resposta se dá pelas vias da epistemologia, conforme colocado acima.

Para arrazoar uma resposta, empreendemos a identificação do que seria a obra comunicacional de Harold Lasswell. Se Lasswell escreveu tanto e em tantas disciplinas, que obras seriam pertinentes ao estudo de suas contribuições ao campo da Comunicação?

Partiu-se de um procedimento basilar: a seleção de um corpus, constituído por obras de Harold Lasswell, delimitando, entre estas, aquelas que discutem temas diretamente ligados à comunicação. Para esse levantamento, o livro Harold Lasswell:

175 Podemos não estar falando de uma disciplina científica no sentido mais estrito, mas de algo que "caminha" para a elaboração de seus próprios pressupostos e objeto de estudo. 
an annotated bibliography (1990), organizado por Rodney Muth ${ }^{176}$, Mary M. Finley e Marcia F. Muth, foi fundamental. O livro, como o próprio nome indica, é uma bibliografia comentada, trazendo não só a listagem das obras produzidas por Lasswell ao longo de sua vida, mas um breve resumo sobre o conteúdo de cada uma delas. O trabalho de reunir uma espécie de "referência completa" das obras de Lasswell começou em 1982, três anos e meio após a morte do cientista político. Harold Lasswell: an annotated bibliography demorou sete anos para ficar pronta e é a maior listagem de referências sobre a produção acadêmica lasswelliana, apesar de não ter conseguido a integralidade das informações que era tida como objetivo no início do projeto. Como o próprio Muth reconhece,

Procedimentos normais de catalogação e indexação não são projetados para alguém tão produtivo ou com uma obra tão variada como a de Lasswell. Apesar dos nossos anos de pesquisa e os nossos esforços para seguir pistas numerosas na correspondência de Lasswell e em seus papéis, estamos confiantes de que obras complementares de Lasswell ainda vão aparecer (MUTH, 1990, p.VII) ${ }^{177}$

Mesmo assim, a obra coordenada por Muth é surpreendente e cataloga 570 trabalhos, excluindo-se desse número as resenhas publicadas por Lasswell. Dessa quantidade, extraímos os títulos selecionados para análise em nosso estudo, divisados pelos seguintes critérios: 1) título indicativo de conteúdo sobre comunicação (com as palavras-chave "comunicação", "propaganda", "mensagem", "meios de comunicação", “jornalismo”, "imprensa”, "notícias”, “opinião pública” e correlatos - todos eles temas que aparecem no capítulo anterior e que permearam nossa apresentação da trajetória intelectual de Lasswell); 2) comentários dos organizadores de Harold Lasswell: an annotated bibliography que demonstrassem conteúdo relacionado às palavras-chave acima. O resultado final foi uma sequiência de 73 obras, às quais acrescentamos apenas mais um título, Describing the Effects of Communications (1946), conforme o desenrolar da pesquisa sobre Lasswell. Dessa forma, as obras de Lasswell selecionadas para análise foram as seguintes:

176 Rodney Muth trabalhou diretamente com Lasswell durante cinco anos no Mershon Center, na Universidade de Ohio, na década de 1970, pouco antes do cientista político morrer.

177 No original: "Normal cataloging and indexing procedures are not designed to account for someone as productive or as far ranging as Lasswell. Despite our years of research and our efforts to follow numerous clues in Lasswell's correspondence and papers, we are confident that additional works by Lasswell will yet tum up". 
"The Status of Research on International Propaganda and Opinion"

"The Theory of Political Propaganda"

"The Function of the Propagandist"

Propaganda Technique in the World War.

"The Strategy of Revolutionary and War Propaganda"

"Propaganda." Encyclopaedia of the Social Sciences.

"The Person: Subject and Object of Propaganda"

Propaganda' and Promotional Activities: An Annotated Bibliography

"The Scope of Research on Propaganda and Dictatorship"

"Propaganda and the Channels of Communication"

"Propaganda in a Planned Society"

"The Propaganda Technique of the Pamphlet on Continental Security "

\begin{tabular}{l|l} 
Artigo & 1933 \\
\hline
\end{tabular}

"The Technique of Slogans in Communist Propaganda"

"The Propaganda Technique of Recent Proposals for the Foreign Policy of the U.S.A."

"The Propagandist Bids for Power"

"The Volume of Communist Propaganda in Chicago"

World Revolutionary Propaganda: A Chicago Study

"Radio as an Instrument of Reducing Personal Insecurity"

"The Communications Front: Strategies of Political and Moral Warfare"

Verbete

"Communications Research and Politics"

"An Experimental Comparison of Four Ways of Coding Editorial Content"

"The Politically Significant Content of the Press: Coding Procedures"

"Public Opinion in War and Peace: How Americans Make Up Their Minds"

"New Rivals of the Press: Film and Radio"

"The Science of Communication and the Function of Libraries"

"Describing the Contents of Communications"

"Describing the Effects of Communications"

Propaganda, Communication, and Public Opinion: A Comprehensive Reference Guide.

"Freedom of the Press: A Summary Statement of Principle." Apêndice.

A Free and Responsible Press: A General Report on Mass Communication: Newspapers,

Radio, Motion Pictures, Magazines, and Books

"Summary of Principle: A Statement of the Commission"

"The Structure and Function of Communication in Society"

"Detection: Propaganda Detection and the Courts"

"Trend: May Day Slogans in Soviet Russia, 1918-1943"

"Why Be Quantitative?"

"Propaganda and Mass Insecurity"

"The Theory of Political Propaganda"

"The Strategy of Soviet Propaganda"

"Propaganda"

"Key Symbols, Signs and Icons"

Symbols of Internationalism

"Symbols of Democracy"

"Educational Broadcasters as Social Scientists"

\begin{tabular}{l|l} 
Artigo & 1935
\end{tabular}

Livro

Artigo 1936

Artigo 


\begin{tabular}{|c|c|c|}
\hline "The "Prestige Papers": A Survey of Their Editorials" & Artigo & 1952 \\
\hline $\begin{array}{l}\text { "Research in International Communication: An Advisory Report of the Planning } \\
\text { Committee" }\end{array}$ & Artigo & 1953 \\
\hline "The Impact of Public Opinion Research On Our Society" & Artigo & 1957 \\
\hline "Communications as an Emerging Discipline" & Artigo & 1958 \\
\hline $\begin{array}{l}\text { Introduction. Road of Propaganda: The Semantics of Biased Communication. By Karin } \\
\text { Dovring. New York: Philosophical Library }\end{array}$ & Introdução & 1959 \\
\hline Foreword. Public Relations and Management & Posfácio & 1960 \\
\hline "Communication and the Mind" & Artigo & 1961 \\
\hline "The Role of Communication Arts and Sciences in University Life" & Artigo & 1965 \\
\hline "Freedom and Responsibility" & Artigo & 1966 \\
\hline "Toward World Community Now" & Artigo & 1968 \\
\hline Introduction (1969): What Next? [New in this edition] & Introdução & 1969 \\
\hline $\begin{array}{l}\text { Political Communication: The Public Language of Political Elites in India and the United } \\
\text { States. }\end{array}$ & Livro & 1969 \\
\hline The Prestige Press: A Comparative Study of Political Symbols & Livro & 1970 \\
\hline "The Continuing Survey and Appraisal of Public Attention" & Artigo & 1971 \\
\hline Introduction. Propaganda Technique in World War I & Introdução & 1971 \\
\hline "Communications Research and Public Policy" & Artigo & 1972 \\
\hline "Future Systems of Identity in the World Community" & Artigo & 1972 \\
\hline The Future of World Communication: Quality and Style of Life & Artigo & 1972 \\
\hline Foreword. 1938. Allied Propaganda and the Collapse af the German Empire in 1918 & Prefácio & 1972 \\
\hline "Research in Policy Analysis: The Intelligence and Appraisal Functions" & Artigo & 1975 \\
\hline "The Future of World Politics and Society" & Artigo & 1975 \\
\hline "Building As Political Communication: The Signature of Power on Environment" & Artigo & 1977 \\
\hline Communication in a divided world: opportunities and constraints & Artigo & 1977 \\
\hline The Signature of Power: Buildings, Communication, and Policy & Livro & 1979 \\
\hline The Symbolic Instrument in Early Tunes & Livro & 1979 \\
\hline "The Future of World Communication and Propaganda" & Artigo & 1980 \\
\hline Emergence of Public Opinion in the West & Livro & 1980 \\
\hline
\end{tabular}

Tabela 14. A obra comunicacional de Harold Lasswell

Essas 70 obras constituem o corpus a ser analisado por nossa pesquisa. Todavia, como Lasswell não concentrava todas as definições necessárias para a compreensão de suas proposições em único texto, nem mesmo em uma única área de atuação, foi necessário agregar textos cujo escopo central era a ciência política em nossas análises $^{178}$. Esses textos não fazem parte do nosso corpus de análise, mas complementam a sua compreensão (um exemplo é A Linguagem da Política, utilizado não só pelos artigos sobre propaganda, mas também por conter textos importantes sobre análise de conteúdo e componentes que possibilitam a compreensão da teoria política de Lasswell). Outro ponto importante a ser ressaltado é que a escolha das obras por palavra-chave não nos eximiu de uma observação "intuitiva" de que, ao final de nossa análise, talvez uma parte dos textos escolhidos não fosse de fato focada em problemas de comunicação. Mas isso apenas a leitura poderia confirmar.

178 A tabela nos mostra como a produção de Lasswell sobre comunicação é bastante fragmentada, com uma presença mínima de livros-texto (apenas 12) e uma maioria de artigos (61). 
Definido o escopo da pesquisa, chegamos ao último trajeto a ser vencido, o da própria análise, que implica a interpretação qualitativa dos dados coletados. Novamente, o método escolhido foi a análise de conteúdo. Entretanto, há diferenças substanciais quanto ao emprego da análise de conteúdo efetuada neste capítulo e aquela elaborada no primeiro capítulo.

Em primeiro lugar, o objetivo anterior era identificar de que maneira o campo comunicacional representa Lasswell, no universo bastante amplo das obras de teoria da comunicação, num espraiamento "horizontal". Agora trata-se de mergulhar "verticalmente" no universo das obras lasswellianas, a procura de elementos que possibilitem a compreensão de como Lasswell entendia a comunicação não só como fenômeno, mas também como área. Neste caso, estamos trabalhando com uma hipótese: há nas obras de Lasswell o desenvolvimento de um conhecimento acerca da comunicação.

Em segundo lugar, a obra de Lasswell será analisada neste capítulo a partir de um esquema temporal, que substitui as unidades temáticas. Dessa forma, um mesmo período pode conter vários temas, nos importando o conjunto de conceitos e suas interrelações.

Selecionamos dois grandes vetores de análise para nos guiar na análise da obra lasswelliana: 1) teoria e 2) método. Essas duas categorias nortearam a leitura dos trabalhos de Lasswell, sendo mesmo as categorias que estão implícitas sob a designação "obra comunicacional de Harold Lasswell".

Após essa leitura interessada e engajada já num posicionamento sobre o que é o campo da Comunicação (delimitado em nosso segundo capítulo) e sobre o objeto da epistemologia que realizamos a pouco, dividimos a obra de Lasswell em três períodos, tomando como inspiração a proposta de Marwick (1977) exposta no quarto capítulo. Para a Comunicação, entretanto, fizemos uma modificação nas datas, de forma a ajustar melhor os períodos à realidade da produção lasswelliana sobre os fenômenos comunicacionais, alinhando os ciclos ao exposto no panorama biográfico e intelectual.

Assim, a obra comunicacional de Harold Lasswell será apresentada de acordo com a seguinte divisão:

1) Período inicial (1925-1939);

2) Período intermediário (1940-1950);

3) Período tardio (1951-1978). 


\subsection{Período inicial: 1925 a 1939}

O período inicial tem seu começo com o primeiro trabalho de Harold Lasswell publicado sobre comunicação, The Status of Research on International Propaganda and Opinion, de 1925, indo até o Seminário da Fundação Rockefeller promovido para se discutir o estado do campo da Comunicação, em 1939. Corresponde a 14 anos na produção de Harold Lasswell e compreende 17 obras que falam especialmente sobre propaganda. Dessas, apenas duas são livros: Propaganda Technique in the World War, de 1927, e World Revolutionary Propaganda: A Chicago Study, de 1939, escrito em parceria com Dorothy Blumenstock ${ }^{179}$. O restante são artigos e um verbete (propaganda) escrito para a primeira edição de Encyclopaedia of the Social Sciences, em 1934.

As obras desse período são:

\begin{tabular}{|l|c|}
\hline Título & 1925 \\
\hline "The Status of Research on International Propaganda and Opinion" & 1927 \\
\hline "The Theory of Political Propaganda" & 1928 \\
\hline "The Function of the Propagandist" & 1927 \\
\hline Propaganda Technique in the World War & 1933 \\
\hline "The Strategy of Revolutionary and War Propaganda" & 1934 \\
\hline "Propaganda" & 1935 \\
\hline "The Person: Subject and Object of Propaganda" & 1935 \\
\hline Propaganda and Promotional Activities: An Annotated Bibliography. & 1936 \\
\hline "The Scope of Research on Propaganda and Dictatorship" & 1937 \\
\hline "Propaganda and the Channels of Communication" & 1937 \\
\hline "Propaganda in a Planned Society" & 1938 \\
\hline "The Propaganda Technique of the Pamphlet on Continental Security" & 1939 \\
\hline "The Technique of Slogans in Communist Propaganda" & \\
\hline "The Propaganda Technique of Recent Proposals for the Foreign Policy of the U.S.A." & \\
\hline "The Propagandist Bids for Power" & \\
\hline & \\
\hline & \\
\hline & \\
\hline & \\
\hline & \\
\hline & \\
\hline & \\
\hline & \\
\hline & \\
\hline & \\
\hline
\end{tabular}

179 Pesquisadora hoje quase desconhecida. Suas únicas obras conhecidas são, justamente, os artigos e o livro elaborado em parceria com Lasswell. 
Tabela 15. Obras do Período Inicial de Harold Lasswell.

Por sua vez, o período inicial pode ser dividido em dois momentos: de 1925 a 1934, quando o objetivo principal de Lasswell ao falar sobre propaganda é delimitar o fenômeno conceitualmente e descrever suas técnicas, analisando, sobretudo, a propaganda de guerra e de 1935 a 1939, quando Lasswell se dedica mais a avaliação da propaganda comunista.

\subsubsection{Conceituando a propaganda, suas técnicas e organização (1925 a 1934)}

Esse é um período claramente devotado à delimitação do conceito de propaganda, cujas publicações se iniciam no ano de defesa do doutorado de Lasswell (1925) e se prolongam até 1934 - na mesma época em que se costuma demarcar a teoria hipodérmica, na esteira das obras sobre propaganda do início do século XX, que não eram raridade. De fato, como o próprio Lasswell avisa na introdução de sua tese, ela não é o primeiro trabalho sobre o tema.

Há sinais abundantes de interesse na propaganda internacional desde a Guerra de 1914. Muitos livros foram publicados por homens que tiveram postos importantes ligados a propaganda durante a Guerra. Creel nos Estados Unidos, Stuart na Inglaterra, Nicolai na Alemanha, e Waitz e Tonnelet na França, publicaram grande parte de suas memórias para o mundo. Agentes individuais de propaganda do mais alto ao mais baixo nível escreveram suas memórias, e a propaganda internacional é mencionada sempre cada reminiscência e apologia dos tempos pós-armisticio.

Os professors e os estudantes universitários e os publicistas tem incentivado o fluxo da especulação sistemática e o exame sistemático sobre o assunto.

[...]

Há muitas razões pelas quais o papel da propaganda na política internacional, e especialmente na Guerra, vem recebendo análises mais cuidadosas agora do que antes. Há novos questionamentos no mundo de hoje. Muitas das pessoas que nos anos antes da guerra costumavam aceitar as mudanças na animosidade e amizade internacional como manifestações inevitáveis da ordem cósmica, que comandava o nascer do sol e o cair da chuva, começaram a suspeitar do caráter sobrenatural ou impessoal desses eventos. Uma palavra apareceu, que passou a latejar em muitas mentes - Propaganda. Nós vivemos juntos de mais pessoas do que em qualquer outra época, que estão perplexas, inquietas ou aborrecidas com uma astúcia desconhecida que parece tê-las enganado e degradado. A propaganda 
é uma hora objeto de vituperação, e, portanto, de interesse, discussão, e, finalmente, de estudo ${ }^{180}$ (LASSWELL, 1938, p. 1-2).

A lista dos autores citados por Lasswell nesta passagem indica o tipo de obras com a qual se relacionava e que também era o material disponível naquele momento. São quatro funcionários de governo, cujo principal trabalho era fomentar e compreender a propaganda, e um historiador. George Creel $^{181}$ (que comandava o Comitê de Informação Pública dos Estados Unidos, centrado na propaganda, por vezes chamado de Comitê Creel); Campbell Stuart (magnata canadense das comunicações, que auxiliou o governo britânico no serviço de propaganda em países inimigos); Walter Nicolai (alto funcionário do Serviço de Inteligência Alemã); Jean Jacques Waitz e Ernest Tonnelet (o primeiro, conhecido com "Tio Hansi" ou simplesmente "Hansi"182, era um artista francês e propagandista cujos desenhos criticavam severamente a Alemanha. O segundo, historiador germanista e crítico literário).

As obras dos autores apresentados por Lasswell são, como o próprio cientista político afirma, "relatos" de experiências particulares, vivenciadas por aqueles que as escreveram. Não há intenção científica nesses escritos. Dessa forma, George Creel registra seu trabalho em How we advertised America (1920); Campbell Stuart detalha a atuação da Casa Crewe ${ }^{183}$ em Secrets of the Crewe House: a History of Famous Campaign (1920); Walter Nicolai relembra os anos de 1914 a 1918 em Der Grosse Krieg (1924) e dedica algumas páginas a propaganda; e, por fim, Hansi e Tonnelet registram a ofensiva francesa contra a Alemanha em $\grave{A}$ Travers les lignes ennemies: trois années d'offensive contre le moral allemand (1922).

Exceção feita a How we advertised America, os livros não focam especialmente a questão da propaganda, mas analisam a guerra de uma forma mais ampla. Contudo, e

\footnotetext{
180“'There are abundant signs of interest in international propaganda since the War of 1914. Several books have been published by men who held responsible propaganda posts during the War. Creel in the United States, Stuart in England, Nicolai in Germany, and Waitz and Tonnelet in France, have published much of their record to the world. Individual propaganda agents of high and low degree have written their memoirs, and international propaganda is alluded to in every reminiscence and apology of post-armistice times.

The professors and the graduate students and the publicists have swollen the flood of systematic speculation about, and systematic examination of the subject. [...] There are many reasons why the role of propaganda in international politics, and especially in war-time, is receiving more careful scrutiny today than heretofore. There is a new inquisitiveness abroad in the world. Some of the people who in the years before the War were disposed to accept the changing tides of international animosity and friendship as inevitable manifestations of the cosmic fate, which commanded the sun to rise or the rain to fall, have became suspicious of the supernatural or the impersonal character of these events. A word has appeared, which has come to have an ominous clang in many minds - Propaganda. We live among more people than ever, who are puzzled, uneasy, or vexed at the unknown cunning which seems to have duped and degraded them. It is often an object of vituperation, and therefore, of interest, discussion and, finally, of study".

${ }^{181}$ Cuja primeira atividade havia sido a de repórter.

${ }^{182}$ Hansi é considerado um herói de guerra francês, tendo lutado nas duas grandes guerras.

${ }^{183}$ Patrocinada por Lord Northcliffe (Alfred Harmsworth), britânico fundador do Daily Mail e do Daily Mirror.
} 
é Lasswell quem nos chama a atenção em Propaganda Technique, são todos marcados pelos

[...] mistérios da propaganda com esse misto de admiração e desgosto com o qual as vítimas de um novo truque querem que este seja explicado. Essa utopia crédula, que explora a experança das massas na guerra, levou muitas mentes ao cinismo e ao desencantamento, e para essas almas pioneiras a propaganda é um porblema muito mais sério do que se pensa. Muitos daqueles que acreditaram piamente e odiaram passionalmente empregaram suas mãos para matar homens, mutilaram a outros e talvez tenham sido mutilados em retorno, encorajaram outros a empunhar a espada, e tem ridicularizado e denegrido aqueles que se recusam a ter raiva como eles tiveram ${ }^{184}(1938$, p.2-3).

A principal ideia presente nessas obras é que a propaganda foi um dos elementos fundamentais da Primeira Grande Guerra, sendo utilizada como arma "psicológica" - o que está em plena concordância com o que expusemos sobre a teoria hipodérmica e também se faz presente nas observações de Lasswell nas produções aqui analisadas. Mas How we advertised America merece um pouco mais de nossa atenção. De saída, fica claro, pelo título, que George Creel evita a utilização da palavra "propaganda". De forma que não nos parece impensada, Creel utiliza o vocábulo em inglês advertise (de "tornar público") e tem a intenção de não confundi-lo com "propaganda". O que Creel busca com o emprego do termo é evidenciado com a leitura de seu subtítulo: The first telling amazing story of the Committee of Public Information that carried the gospel of americanism to every corner of the globe (a primeira e incrível história do Comitê de Informação Pública que levou a mensagem do americanismo a todos os cantos do mundo).

Como se vê, a intenção de Creel é mais uma elogio ao trabalho americano, que "tornou público" o modo de ser dos Estados Unidos (visto como um país em que a democracia e o respeito ao povo eram reinantes), o que fica claro no prefácio da $1^{a}$ edição, quando Newton D. Baker, então Secretário de Guerra, afirma:

Mas foi esse interminável fluxo invisível, mas persuasivo, de ideias que conseguiu uma apreensão correta do verdadeiro espírito e do idealismo da América na guerra, e quando o armistício foi assinado e a paz voltou ao mundo, conduzida por um lado pelas mãos do poderio militar de pessoas livres, foi conduzida, por outro lado, pela idéia

\footnotetext{
184 " [...] mysteries of propaganda with that compound of admiration and chagrin with which the victims of a new gambling trick demand to have the thing explained. That credulous utopianism, which exploited the hopes of the mass in war, has in many minds given way to cynicism and disenchantment, and with these earnest souls propaganda is a far more serious matter. Some of those who trusted so much and hated so passionately have put their hands to the killing of man, they have mutilated others and perhaps been mutilated in return, they have encouraged others to draw the sword, and they have derided and besmirched those who refused to rage as they did.".
} 
conquistadora de justiça e liberdade como expressada no idealismo americano $^{185}$ (BAKER apud CREEL, 1920, p. XVI).

Deste modo, How we advertised America é um obra não só sobre propaganda, mas essencialmente propaganda e revela um pouco sobre as diversas posições que já se construíam no período sobre os efeitos desse tipo de mensagem.

Sua preocupação é preservar a moral do governo americano (e a do próprio Creel) após a Primeira Grande Guerra e desdemonizar o trabalho de propagandista diante de um público que questionava o uso da propaganda por seus administradores - o que joga por terra a noção de que todos os autores do período anterior à Segunda Grande Guerra percebessem a audiência a partir do modelo hipodérmico ${ }^{186}$. Um exemplo da não aceitação passiva da propaganda no período e que envolvia George Creel é o episódio relatado George G. Buntz, em Allied Propaganda and the Collapse of the German Empire in 1918 (1939), livro prefaciado por Lasswell:

[...] Seu entusiasmo o afastou da verdade algumas vezes. O jornal Daily Bulletin de 28 de março de 1918 tinha quatro fotografias ilustrando a construção e a embarcação de aviões para a França. O Bulletin dizia: "esses aeroplanos, o auge da engenharia, estão prontos para serem despachados para a França. Apesar de milhares já terem sido enviados, nossas fábricas chegaram a um nível alto de produção e centenas e centenas serão enviados." A verdade é que as fotos foram tiradas nas fábricas de aviões, as partes não estavam prontas para serem embarcadas, e apenas uma vião havia sido enviado a França naquela época. Rubel, chefe da divisão de imagens da CPI foi levado perante o Comitê de Assuntos Militares do Senado, e, junto com George Creel, foi severamente criticado por fazer essas declarações falsas ${ }^{187}$ (BUNTZ, 1939, p.63).

Creel acabou criando uma reação oposta às suas intenções e contribuiu para o crescimento da rejeição à propaganda (CULL, CULBERT \& WELCH, 2003, p. 99), pois se tratava do governo defendendo a si próprio. Mas, porque estendermos o exemplo de Creel? Conhecido como um propagandista ofensivo, sua atuação traz as marcas da

\footnotetext{
${ }^{185}$ "But it was this unseen but persuasive and unending flood of ideas that aroused a correct apprehension of the true spirit and idealism of America in the war, and when the armistice was signed and peace came back into the world, it came, led by one hand by the military prowess of the great free peoples, and led by the other hand by the conquering idea of justice and freedom as expressed in America's idealism".

${ }^{186} \mathrm{Na}$ verdade, há uma oposição nos Estados Unidos ao uso ostensivo de propaganda pelos governos, uma vez que o país é marcado na época por uma ideologia deweyana de democracia, que se opõe à manipulação de informações, que se acreditava ser o trabalho do propagandista.

${ }_{187 ،[\ldots]}$... His enthusiasm carried him away from the truth at times. The Daily Bulletin of March 28, 1918, had four photographs illustrating the building and shipment of airplanes to France. Said the Bulletin: These aeroplane bodies, the acme of engineering ar, are ready for shipment to France. Though hundreds have already been shipped, our factories have reached quantity production and thousands and thousands will soon follow." The truth of the matter was these pictures had been taken in the airplane factories, the parts not yet ready for shipment, and that only one airplane had been shipped to France at that time. Mr. Rubel, head of the division of pictures of the C.P.I., was brought before the Senate Military Affairs Committee, and, together with George Creel, was severely criticized for making these false statements".
} 
teoria hipodérmica. Contudo, sua relação com o público mostra que, de muitas maneiras, o que se coloca normalmente sobre a passividade da audiência é apenas um dos lados da moeda e mesmo autores do início do século XX enxergavam a diversidade quanto à recepção da propaganda. Afinal, como afirmar que as teorias do período colocavam um público que obedecia cegamente ao esquema estímulo-resposta (Wolf, 2002) se, mesmo os autores menos criteriosos, já reconheciam que a mensagem da propaganda por vezes era rejeitada? Não é a toa que Lasswell, ao buscar constituir um estado da arte da pesquisa sobre propaganda, consegue perceber a ausência de estudos mais consistentes sobre o tema - e é nessa seara que ele avança.

Identificando a construção da opinião pública como objetivo da propaganda, Lasswell não cita Creel de maneira ingênua, mas o coloca no rol de autores que merecem uma leitura crítica (apresentados com maiores detalhes no artigo The Status of Research on International Propaganda and Opinion ${ }^{188}$, de 1925). Para o próprio Lasswell, as obras que falavam sobre a propaganda na Primeira Guerra Mundial careciam de uma base científica. É assim que ele diz:

As pessoas que provam os mistérios da opinião pública devem, no presente, pelo menos, confiar em algo além das medições exatas para confirmar ou desacreditar suas especulações. Generalizações acerca da opinião pública convencem porque são plausíveis e não porque foram experimentalmente estabelecidas. Elas caem no esquecimento queando outros, que tiveram a experiência direta com aquilo que elas tentaram descrever, entram em desacordo com o observador original. Algumas vezes, esse desacordo é nítido e enfático, pois vem de pessoas que tentaram utilizar as noções existentes sobre opinião pública nos seus esforços de controlá-la. Esse é o teste de engenharia. É empregado por propagandistas e publicitários de todos os tipos e formas.

Conjecturas no campo da opinião pública são particularmente suscetíveis aos testes de engenharia. Mas muito da literatura sobre opinião pública é tão obtusa e de carater indefinido que desafia a verificação empírica. Há uma infinidade de teorias sobre algo chamado opinião pública, em geral, e uma escassez de hipóteses sobre a opinião pública, em particular. Quando o campo da opinião pública está dividido entre o problema de explicar e controlar as opiniões políticas, e as atitudes em torno dos vários modos de participação política, um progresso um pouco mais tangível deves ser esperado ${ }^{189}$ (LASSWELL, 1938, p.6).

\footnotetext{
${ }^{188} \mathrm{O}$ artigo é basicamente o primeiro estado da arte realizado por um pesquisador sobre propaganda e opinião pública, cujos dados foram levantados justamente para a elaboração de Propaganda Technique in the World War.

189 "The people who probe the mysteries of public opinion in politics must, for the present, at least, rely upon something other than exact measurement, to confirm or discredit their speculations. Generalizations about public opinion stick because they are plausible and not because they are experimentally established. They fall by the wayside, when others, who have had experience with the kind of fact which they purport to describe, disagree with the original observer. Sometimes, this disagreement is sharp and emphatic, because it cames from people who have tried to use existing notions about public opinion in their efforts to control it. This is the engineering test. It is employed by propagandists and publicity-men of all sorts and shapes.
} 
Aí, temos algumas indicações valiosas que contrariam o que vimos em nosso primeiro capítulo: não há em Lasswell uma ligação insolúvel com a teoria hipodérmica, nem mesmo uma ausência de consciência sobre as variáveis que se apresentam na análise dos fenômenos comunicacionais - aqui representados pelo campo da opinião pública. O que temos é um autor que revê o que já fora produzido sobre seu tema e tenta se posicionar de maneira crítica, mesmo que isso não faça de Lasswell prontamente um autor imune às idéias de sua época.

É importante notar que Lasswell traz uma visão mais completa e crítica acerca da pesquisa sobre opinião pública. Outra questão importante é que Lasswell, comumente identificado como um pesquisador "quantitativo", no sentido pejorativo do termo, assinala a pertinência de procedimentos que não sejam apenas o mensuramento numérico dos dados. Isso também não quer dizer que Lasswell se afaste da idéia de uma propaganda com super poderes. Mas a observação sobre o campo da opinião pública nos revela a tentativa do autor de alcançar um nível maior de cientificidade nesses estudos, e que vai levá-lo a empregar a sua maior força nesses anos iniciais propondo uma teoria sobre a propaganda - e não exatamente reforçando ou elaborando preceitos hipodérmicos, como boa parte da bibliografia de teorias da comunicação supõe.

Tal objetivo, obviamente, não era (e ainda não é) fácil. Deve-se lembrar que nesse primeiro momento encontramos um Lasswell falando quase sozinho, apesar da quantidade de livros sobre o tema não ser irrisória. Constituindo-se a maior parte de relatos, a falta de compromisso com a análise científica do fenômeno da propaganda pouco poderia auxiliar a Lasswell.

Restava a Lasswell, portanto, o recurso aos trabalhos desenvolvidos de forma pouco sistematizada pelos autores das Ciências Sociais, que começam a perceber um mundo marcado e estruturado pela comunicação. De qualquer maneira, não sendo a propaganda o ponto focal das Ciências Sociais, o que Lasswell mais vai sugar dos teóricos da sociedade complexa é a interpretação que se dá aos fenômenos sociais, em relação aos quais a comunicação de massa passa a cumprir um papel determinante. Um mundo novo, que, como diz Lasswell, estava "testemunhando o crescimento de um

Conjectures in the field of public opinion are particularly susceptible to engineering tests. But much of the literature of public opinion is of such abstruse and indefinite character that it defies empirical verification. There is a plethora of theories about something known as public opinion in general and a paucity of hypothesis about public opinions in particular. When the field of public opinion is split into the problems of explaining and controlling opinions about policies, attitudes towards persons and groups, and attitudes toward the various modes of political participatio9n, some more tangible progress may be expected 
público mundial, e esse público havia surgido em parte porque a propaganda internacional o agitou e o organizou"190 (1938, p.6).

Em Propaganda Technique in the World War, então, temos de fato a estreia de uma pesquisa com intenções científicas sobre o assunto, mas o pioneirismo tem o custo do diálogo limitado e é Lasswell quem vai acabar definindo de que base teórica ele irá partir para analisar a propaganda. Entendendo que a construção da opinião pública passa pela propaganda e que esta última deve ser considerada, sobretudo, em sua dimensão política, Lasswell designa um propósito ambicioso para sua tese: a produção de uma teoria sobre a propaganda de guerra (o que fica explícito também em todos os trabalhos dessa primeira fase). O resultado é um trabalho que se contradiz em muitas passagens, contaminado pelo senso comum de sua época, mas, ao mesmo tempo, com algumas lúcidas passagens teóricas.

Dividido em nove capítulos ("The matter in hand"; "Propaganda organization"; "War guilty and war aims"; "Satanism"; "The illusion of victory"; "Preserving friendship"; "Demoralizing the enemy"; "Conditions and methods of propaganda: a summary"; "The results of propaganda"), Propaganda Technique é a pedra fundamental para a compreensão dos trabalhos posteriores, mesmo se seu autor o caracterize como incipiente:

Este é um estudo preliminar e uma análise altamente provisória do grupo de problemas sobre propaganda conectado ao controle das antipatias e atrações durante a guerra. Quantos devem ser mobilizados contra o inimigo? Quanto ódio deve ser mobilizado contra o inimigo? Como o inimigo pode ser desmoralizado pela manipulação astuta? Como é possível fomentar a amizade entre os neutros e os aliados?

Não é nosso propósito escrever história, mas descrever a técnica. Quando a guerra for um fenomeno do passado, sera possível escrever pelo menos uma história fragmentada da propaganda internacional desse tempo. O objetivo da presente pesquisa é ao mesmo tempo mais modesto e mais ambicioso que isso. É mais modesto porque teve que escolher poucos fatos que serão incluídos numa história compreensiva. É mais ambicioso porque tem como meta dsenvolver uma teoria explícita de como a propaganda internacional pode ser conduzida com sucesso $^{191}$ (LASSWELL, 1938, p.12).

\footnotetext{
190“witnessing the growth of a world public, and this public has arisen in part because international propaganda has at once agitated and organized it".

191،"This study is a preliminary and highly provisional analysis of the group of propaganda problems connected with the control of international antipathies and attractions in wartime. How may hate be mobilized against an enemy? How may the enemy be demoralized by astute manipulation? How is it possible to cement the friendship of neutral and allied peoples?

It is not purposed to write history, but to describe technique. When the war has receded further into the past, it will be possible to write at least a fragmentary history of the international propaganda of the time. The aim of the present inquiry is at once more modest and more ambitious than this. It is more modest in that it has chosen but a few of the facts which will be included in a comprehensive history. It is more ambitious in that it has undertaken to evolve an explicit theory of how international propaganda may be conducted with success".
} 
Notadamente, há uma preocupação de Lasswell (advinda especialmente de sua formação na Escola de Chicago) de se aproximar de seu objeto de pesquisa (a propaganda de guerra americana, francesa, italiana e alemã) de maneira mais cientifica possível. O caminho para isso é delimitado por ele pela construção de uma teoria sobre a propaganda internacional (restringida à propaganda de guerra), a formulação de conceitos e análise do fenômeno, que vai requerer o desenvolvimento de um método.

Nessas delimitações, Lasswell está apoiado substancialmente em questões políticas, mas, ao mesmo tempo, constrói uma apreciação de detalhes da propaganda que não são apenas políticos: a conceituação da propaganda, seus possíveis efeitos, os aspectos da profissão de propagandista, a relação sociedade/propaganda. Além disso, Lasswell se vale do aprendizado na Europa junto a estudiosos da mente como Anna Freud e Theodor Reik, além dos estudos do próprio Freud, para somar às suas análises um viés psicológico, pois para ele, o controle da opinião pública se dava especialmente pelo manuseio de elementos que fossem capazes de afetar a "psicologia das nações" 192 (LASSWELL, 1938, p.4).

A guerra, como principal problema da política internacional e como fenômeno político e psicológico, é vista (e aí temos claramente a influência de Dewey em Lasswell) como um episódio que coloca em jogo o moral das nações, com a propaganda tendo um papel relevante na construção dessa moral, mas não sendo o único modo de elevá-lo - o que fica claro quando Lasswell define o objetivo da propaganda:

[...] Os sinais convencionais de um moral alto são entusiasmo, determinação, autoconfiança, ausência de culpa e ausência de descontentamento. Quase todos os fatos devem ter essas implicações para o moral. As calorias da ração official, o suprimento de cigarros, a oportunidade de recreação, a confiança dos oficiais nos homens públicos, o comportamento inteligente das tropas, o modo de inflingir disciplina; tudo isso, e mais, afetam a vontade de lutar e a tenacidade da população civil e militar.

O problema da manutenção do moral é apenas em parte problema da propaganda, pois a propaganda é apenas uma dos muitos dispositivos que devem ser utilizados para esse fim. Propaganda não siginifca o controle dos estados mentais pela mudança das condições objetivas, como o suprimento de cigarros ou a modificação química da composição da comida. Propaganda também não inclui a elevação do moral por um comportamento confiante. $\mathrm{O}$ termo se refere somente ao controle da opinião por símbolos significantes, ou, para falar mais concretamente e de forma menos precisa, a estórias, rumores, relatórios e outras formas de comunicação social. A propaganda é preocupada com a adminsitração das opiniões e atitudes pela manipulação direta das sugestões sociais mais do que a alteração de

${ }^{192}$ Lasswell é especialmente interessado nesse período pela união entre psicologia e política. 
outras condições de ambiente ou do organismo ${ }^{193}$ (Idem, ibidem, p.89).

Portanto, apesar de identificar a propaganda como um fenômeno bastante poderoso, Lasswell não a reconhece como único fator decisivo numa operação de guerra, o que realmente seria bastante ingênuo. Na verdade, a propaganda tem sua importância na política internacional em tempos de guerra, mas relativamente menor se comparada à pressão militar, ao "poder coercivo das forças armadas de ar, mar e terra", e, ainda, à pressão econômica e sua "interferência com acesso a fontes de matéria prima, mercados, capital e força de trabalho". A esses três fatores, soma-se ainda a negociação, entendida como "[...] um método de influenciar os estados estrangeiros a identificar qual deles não está em combate ativo. Por negociação, entende-se as trocas oficiais que procuram o acordo. A mediação entre partidos opostos e a submissão a arbitragem são comumente evocadas nesse caso"194 (LASSWELL, 1938, p.9).

A definição dos objetivos da propaganda também é perpassada, mesmo que sutilmente, pela influência de Herbert Mead. A compreensão da propaganda como manipulação de símbolos é elaborada tomando-a como um fator responsável pela criação de um comportamento social (termo cunhado por Mead), desencadeado pelo propagandista. Lasswell reforça essa característica em todos os textos do período inicial, cuja súmula a esse respeito é bem representada pelo início de The Theory of Political Propaganda, no qual reforça:

Propaganda é a administração das attitudes coletivas pela manipulação de símbolos significantes. A palavra attitude é usada para significar uma tendência para agir de acordo com certos padrões de avaliação. A existência de uma attitude não é um dado direto da experiência, mas uma inferência de signos que possuem um sentido convencionalizado. [...] Os padrões de avaliação nos quais essa inferência se funda podem ser gestos primitives da face ou do corpo, ou gestos mais sofisticados da caneta e da voz. Colocados juntos, esses objetos que

\footnotetext{
193،The conventional signs of high moral are enthusiasm, determination, self-confidence, absence of carping criticism and absence of complaint. Almost every fact may have its implication for moral. The calories in the official ration, the supply of cigarettes, the opportunity of recreation, the confidence of officers and public men, the smart demeanour of the troops, the mode of inflicting discipline; all this, and more, affects the fighting vim and tenacity of the military and civil population.

The problem of maintaining moral is only in part a problem of propaganda, because propaganda is but one of the many devices which must be relied upon. Its scope is limited though important. By propaganda is no meant the control of mental states by changing such objective conditions as the supply of cigarettes or the chemical composition of the food. Propaganda does not even include the stiffening of moral by a cool and confident bearing. It refers solely to the control of opinion by significant symbols, or, to speak more concretely and less accurately, by stories, rumours, reports, pictures and other forms of social communication. Propaganda is concerned with the management of opinions and attitudes by the direct manipulation of social suggestion rather than by altering other conditions in the environment or in the organism".

194 "[...] a method of influencing foreign states with which one is not in active combat. By negotiation is meant the official exchanges which look toward agreement. Mediation between contending parties and submission to arbitration are both commonly invoked".
} 
tem um significado padrão num grupo são chamados de símbolos significantes. A sobrancelha elevada, o punho cerrado, a voz aguda, a frase pungente, tem suas referências estabelecidas na teia de uma cultura particular. Tais símbolos significantes são o aparato empregado na expressão de atitudes, e eles são capazes de serem empregados para reafirmar ou redefinir atitudes. Portanto, os símbolos significantes têm ao mesmo tempo uma função expresssiva e de propaganda, na vida pública ${ }^{195}$ (LASSWELL, 1927, p.627).

Dessa forma, a propaganda é colocada como um elemento essencial na construção da união nacional pelos governos, pois é responsável por criar símbolos partilhados pela sociedade e que geram atitudes coletivas. Para Lasswell, a propaganda como instrumento político, não pode deixar de existir em nenhum governo, sendo uma de suas partes constituintes - a despeito da rejeição que possa existir em países democráticos ${ }^{196}$.

Segundo Lasswell, portanto,

A verdade é que todos os governos estão engajados em algum tipo de propaganda como uma de suas funções comuns nos tempos de paz. Eles empregam a propaganda em nome de seus amigos diplomáticos ou contra seus antagonistas, e isso é inevitável. Portanto, embora exista uma presunção contra o trabalho de propaganda realizado por um governo democrático, essa idéia não deve ser levada tão a sério.

Durante o período de guerra a mobilização da opinião passou a ser reconhecida. $\mathrm{O}$ poder sobre a opinião, assim como sobre a vida e a propriedade, passou para mãos oficiais, por conta do perigo da licença ser tão grande quanto o perigo do abuso. De fato, não há dúvidas de que a adminsitração da opinião pelos governos é um corolário inescapável da moderna guerra em larga escala. A única questão é o grau em que essa conduta deve ser tomada abertamente ${ }^{197}$ (LASSWELL, 1938, p.14-15).

A propaganda não pode simplesmente ser demonizada, pois é elemento essencial para a política. Já que é assim, o que é a propaganda para Lasswell? A definição,

\footnotetext{
195 "Propaganda is the management of collective attitudes by the manipulation of significant symbols. The word attitude is taken to mean a tendency to act according to certain patterns of valuation. The existence of an attitude is not a direct datum of experience, but an inference from signs which have a conventionalized significance [...] The valuational patterns upon which this inference is founded may be primitive gestures of the face and body, or more sophisticated gestures of the pen and voice. Taken together, these objects which have a standard meaning in a group are called significant symbols. The elevated eyebrow, the clenched fist, the sharp voice, the pungent phrase, have their references established within the web of a particular culture. Such significant symbols are paraphernalia employed in expressing the attitudes, and they are also capable of being employed to reaffirm or redefine attitudes. Thus, significant symbols have both an expressive and a propagandist function in public life".

${ }^{196}$ O uso da termo "democrático" é mais ideológico do que conceitual.

197 "The truth is that all governments are engaged to some extent in propaganda as part of their ordinary peace-time functions. They make propaganda on behalf of diplomatic friends or against diplomatic antagonists, and this is unavoidable. While, therefore, the presumption exists against propaganda work by a democratic government, this statement should not be taken too literally.

During the war-period it came to be recognized that the mobilization of opinion. Power over opinion, as over life and property, passed into official hands, because the danger from license was greater than the danger of abuse. Indeed, there is no question that government management of opinion is an unescapable corollary of large-scale modern war. The only question is the degree to which it should conduct it openly
} 
bastante sintética e que vai acompanhar Lasswell até os seus últimos escritos, diz que a propaganda é "a administração das atitudes coletivas pela manipulação dos símbolos significantes" ${ }^{\prime 198}$. Nessa definição, que aparece quando Lasswell fala dos objetivos da propaganda em Propaganda Technique in the World War e vai se repetir em seus outros textos, encontra-se entre os termos-chave para a identificação do cientista político com o que se caracteriza como teoria hipodérmica: a administração das "atitudes" coletivas e a "manipulação" dos símbolos.

\section{Entretanto, Lasswell explica que}

A idéia de uma "atitude coletiva" não é super-orgânica, como uma entidade extra-natural. Fenômenos coletivos foram muitas vezes tratados como se estivessem em um plano para além da ação individual. A confusão surgiu principalmente porque os estudiosos têm sido lentos para inventar uma palavra capaz de suportar a conotação de uniformidade sem implicar também uma unidade biológica ou metafísica. Os antropólogos introduziram a noção de um padrão para designar as uniformidades da conduta em um determinado momento e lugar, e este é o sentido da palavra aqui pretendido. Assim, a atitude coletiva, como um padrão, é uma distribuição de atos individuais e não um espírito constante que alcançou realização transitória no bruto e grosseiro mundo dos sentidos ${ }^{199}$ (LASSWELL, 1927 , p.627-628).

A administração das atitudes e a manipulação dos símbolos também não implicam a ideia de mentira que permeia grande parte das interpretações acerca desses termos. E não há, na verdade, a garantia de que a manipulação dos símbolos terá como fim a certa administração das atitudes. Contudo, isso não exime Lasswell de perceber e até certo ponto, defender a utilização da propaganda como a sobrepujança da vontade dos governantes sobre os indivíduos da audiência, o que advêm de sua concordância coma teoria das elites. Mas o propagandista, o profissional da propaganda ${ }^{200}$, aparece não como um manipulador no sentido negativo do termo, mas como um interprete da cultura. Ele só pode intentar um determinado resultado a partir do conhecimento dos anseios do público. Comparado por Lasswell ao advogado e ao diplomata (1928, p.259),

\footnotetext{
198 "the management of collective attitudes by the manipulation of significant symbols".

199 "The idea of a "collective attitude" is not that of a super-organic, extra-natural entity. Collective phenomena have too often been treated as if they were on a plane apart from individual action. Confusion has arisen principally because students have been slow to invent a word able to bear the connotation of uniformity without also implying a biological or metaphysical unity. The anthropologists have introduced the notion of a pattern to designate the standard uniformities of conduct at a given time and place, and this is the sense of the word here intended. Thus the collective attitude, as a pattern, is a distribution of individual acts and not an indwelling spirit which has achieved transitory realization in the rough, coarse facts of the world of sense".

${ }^{200}$ Lasswell nos chama atenção para a péssima fama do propagandista, o que revela a não aceitação desse profissional pelo público.
} 
o propagandista deve estar atento às disposições psicológicas da audiência, que costuma, em certos aspectos, ser mais ou menos genéricas. Por isso, Lasswell afirma

[...] Disposições psicológicas profundas, o que facilita o trabalho do propagandista na fixação da culpa guerra contra o inimigo técnico [...] Isso permite que o escrupuloso mate com a consciência limpa, ou pelo menos, admoeste o mais jovem a fazê-lo [...] um propagandista deve estar sempre alerta para captar a frase sagrada que cristaliza aspiração do público ${ }^{201}$ (LASSWELL, 1938, p.54-66).

Outro aspecto importante a ser ressaltado é que Lasswell faz distinção entre propaganda e advertising, que em português foi traduzido para "publicidade". Contudo, para Lasswell, a publicidade (publicity) é uma categoria que engloba tanto a propaganda quanto o advertising. A propaganda é um tipo de publicidade que se diferencia do advertising por não ser um serviço pago. Dessa forma, a propaganda de guerra deve ser sempre governamental.

Basicamente, a propaganda de guerra segue seis passos, expressos no sumário de Propaganda Technique in the World War, que se alinham, a essas predisposições psicológicas do público: 1) a organização da propaganda; 2) a culpa da guerra e os objetivos da guerra; 3) a demonização do inimigo; 4) a ilusão da vitória; 5) a preservação das amizades; 6) a desmoralização do inimigo. Podemos resumi-los da seguinte forma:

1) A organização da propaganda: diz respeito, como o nome indica, a organização da propaganda, não só como mensagem, mas em relação às instituições governamentais de propaganda;

2) A culpa da guerra e os objetivos da guerra: a propaganda de guerra é organizada de forma tal que não reste dúvida de quem é o culpado pela guerra e o objetivo do propagandista deve ser fazer com que o público entenda a guerra como necessária apenas para por fim a atuação do culpado. Como afirma Lasswell,

Tão grandes são as resistências psicológicas contra a guerra em nações modernas que toda guerra deve parecer uma guerra de defesa contra um agressor ameaçador, assassino. Não deve haver nenhuma

\footnotetext{
201 “....] profound psychological dispositions, which facilitate the work of the propagandist in fastening war guilt upon the technical enemy [...] This permits the scrupulous to kill with a clean conscience; or at least, to admonish the younger to do so $[\ldots]$ a propagandist must always be alert to capture the holy phrase which crystallizes public aspiration".
} 
ambigüidade sobre quem o público deve odiar [...] Todos os culpados devem estar do outro lado da fronteira ${ }^{202}$ (LASSWELL, 1938, p.47).

3) A demonização do inimigo: segundo Lasswell, para a propaganda de guerra não basta que o inimigo seja visto como culpado pelo conflito, ele deve ser apresentado com tintas carregadas como intrinsecamente pérfido e satânico.

Quando o público acredita que o inimigo começou a guerra e bloqueia uma paz permanente, rentável e piedosa, o propagandista alcançou seu propósito. Mas como uma garantia dupla, é seguro para fortalecer a mente da nação com exemplos da insolência e depravação do inimigo. Qualquer nação que começou a guerra e bloqueia a paz é incorrigível, má e perversa. Insistir diretamente sobre essas qualidades é apenas uma precaução, e seu principal efeito é a de tornar mais certo que o inimigo poderia ser capaz de coisa tão monstruosa como uma guerra agressiva. Assim, por uma circularidade de reação psicológica, o culpado é satânico e satânico é o culpado ${ }^{203}$ (Idem, ibidem, p.77).

4) A ilusão da vitória: se o público não for convencido de que a vitória será da sua nação, a mobilização será impossível de ser efetivada, uma vez que, para Lasswell, o espírito de luta de uma nação só pode ser atingido pela propaganda em caso de confiança de que o lado "certo" da guerra prevalecerá. O lado "certo" corresponde à nação que deve ser mobilizada. Essa idéia é expressa pela frase religiosa que diz: “[...] se vencermos, Deus está do nosso lado. Se perdermos, talvez ele esteja do outro" (LASSWELL, 19308, p.102);

5) A preservação das amizades: outro aspecto relevante na constituição da propaganda de guerra é a preservação das relações cordiais entre os aliados, reforçando sentimentos de respeito e estima. A meta é fazer com que o inimigo seja um inimigo comum, e os objetivos na participação da guerra, os mesmos.

6) A desmoralização do inimigo: por fim, a propaganda de guerra ataca diretamente a moral do inimigo - e deve, por vezes, ser direcionada a ele, no intuito de abalar suas convicções.

\footnotetext{
202 "So great are the psychological resistances to war in modern nations that every war must appear to be a war of defence against a menancing, murderous aggressor. There must be no ambiguity about whom the public is to hate $[\ldots]$ All the guilty must be on the other side of the frontier".

203 "When the public believes that the enemy began the war and blocks a permanent, profitable and godly peace, the propagandist has achieved his purpose. But to make assurance doubly sure, it is safe to fortify the mind of the antion with examples of the insolence and depravity of the enemy. Any nation Who began the war and blocks the peace is incorrigible, wicked and perverse. To insist directly upon these qualities is merely a precaution, and its chief effects is to make it more certain that the enemy could be capable of so monstrous a thing as an agressive war. Thus, by a circularity of psychological reaction the guilty is satanic and the satanic is the guilty".
} 
Lasswell, deve-se lembrar, não é exatamente partidário dessas técnicas, mas as identifica entre os materiais de propaganda produzidos pelas nações beligerantes. Dessa forma, há uma série de críticas que permeiam Propaganda Technique in the World War. Essas objeções podem ser representadas pela passagem em que Lasswell fala do "disciplinado" exército alemão:

Os contos de atrocidade por atacado e destruição intencional são generalizações maliciosas de lamentáveis casos individuais, que acontecem em todos os exércitos, mas com menos frequência no exército disciplinado alemão do que em outros lugares. As necessidades da guerra, como todos sabem, pode mexigir atos que não são essenciais nos momentos silenciosos de paz, mas é um absurdo distorcer os fatos em uma denúncia de atacado contra uma nação inteira. Muitas das igrejas que os alemães deveriam ter destruído nunca foram destruídas, e muitas delas foram ilegitimamente utilizadas pelo inimigo ${ }^{204}$ (LASSWELL, 1927, p.168).

O livro não é, portanto, uma obra maquiavélica, ensinando a se praticar uma propaganda desleal, mas uma análise das técnicas empregadas pelas nações envolvidas na Primeira Grande Guerra que, por acaso, eram desleais e procuravam com o auxílio da propaganda, atingir o público e produzir como reação o comportamento esperado. Para alcançar seus desígnios, o propagandista tem como guia, exatamente como aponta a maior parte da bibliografia de teorias da comunicação, a sinalização do esquema estímulo-resposta behaviorista (o behaviorismo social de Mead). Como é exposto em The Theory of Political Propaganda,

A estratégia de propaganda, que foi formulada em termos culturais, pode ser facilmente descrita na linguagem do estímulo-resposta. Traduzindo o vocabulário, que é especialmente inteligível para alguns, o propagandista está preocupado com a multiplicação dos estímulos que são melhor calculados para evocar as respostas desejadas, e com a anulação dos estímulos que possam instigar uma resposta indesejada. Colocando a mesma coisa em termos de sugestão social, o problema da propaganda é multiplicar todas as sugestões favoráveis para as atitudes que ela deseja produzir e fortalecer, e restringir todas as sugestões que sejam desfavoráveis a essas atitudes ${ }^{205}$ (LASSWELL, 1927, p.630).

\footnotetext{
204،"The tales of wholesale atrocity and willful destruction are malicious generalizations from a regrettable individual instances, which happen in every army, but less often in the disciplined German army than elsewhere. The necessities of war, as everyone knows, may require acts which are not essential in the quiet times of peace, but it is absurd to distort the facts into a wholesale denunciation of an entire nation. Many of the churches which the Germans are supposed to have destroyed were never destroyed, and many of them were illegitimately used by the enemy"

205“"The strategy of propaganda, which has been phrased in cultural terms, can readily be described in the language of stimulus-response. Translated into this vocabulary, which is especially intelligible to some, the propagandist may be said to be concerned with the multiplication of those stimuli which are best calculated to evoke the desired responses, and with the nullification of those stimuli which are likely to instigate the undesired responses. Putting the same thing into terms of social suggestion, the problem of the propagandist is to multiply all the suggestions favorable to the attitudes which he wishes to produce and strengthen, and to restrict all suggestions which are unfavorable to them"
} 
Mas o prosseguimento da afirmação de Lasswell lança por terra a ideia de uma manipulação do indivíduo, que aceitaria a mensagem sem nenhum tipo de senso crítico. Assim, Lasswell explica que, "nesse sentido da palavra, sugestão não é usada como na psicologia individual para significar a aceitação de uma ideia sem reflexão; ela se refere ao material cultural com um significado reconhecível"206 (Idem, p.360-361). A atividade de propagandista é mais uma prática de conexão com o universo cultural da audiência do que exatamente uma imposição de um determinado comportamento.

O conceito de símbolo, que explica o exposto acima, está presente em toda a obra lasswelliana sobre propaganda, mas não é bem explicado pelo autor. Entretanto, a leitura contínua das obras do cientista político nos direciona para a compreensão de símbolo tal como delimitado por Herbert Mead. Por isso, faz-se necessário, agora, retomarmos com mais detalhes a contribuição de Mead ao pensamento lasswelliano. Vejamos, portanto, de que maneira Mead vai construir o conceito de símbolo.

O símbolo, para Mead, tem um sentido bastante próximo do signo saussuriano, definindo uma estrutura da cultura (ou da linguagem) que representa um significado coletivo, um significado compartilhado socialmente (e que Herbert Blumer mais tarde nomeou como “interacionismo simbólico”). Dessa maneira, o sentido de símbolo utilizado por Lasswell é "o símbolo significante é então o gesto, o sinal, a palavra que é endereçada a outro indivíduo, e a outro, e a todos os outros indivíduos, quando é endereçado a si mesmo"207 (MEAD, 1922, p.162).

Lasswell, portanto, tem uma visão mais neutra do propagandista e da propaganda do que aparentemente era colocado pelos autores de relatos já que os considera interpretes e administradores de símbolos. Em muitos momentos, o que se tem é uma defesa do propagandista e da propaganda, elementos que para ele são indispensáveis na sociedade moderna, pois "[...] deve haver alguma coisa na estrutura da nossa sociedade moderna que destina a propaganda uma função peculiarmente indispensável" (LASSWELL, 1938, p. 261).

Esse primeiro momento do período inicial nos revela as primeiras relações do cientista político com a propaganda e o campo da Comunicação. Temos, por um lado, um ator preocupado com a construção de um trabalho científico, mas ao mesmo tempo

\footnotetext{
206“'In this sense of the word, suggestion is not used as it is in individual psychology to mean the acceptance of an idea without reflection; it refers to cultural material with a recognizable meaning".

207 "The significant symbol is then the gesture, the sign, the Word which is addressed to another individual, and is addressed to another individual, and its addressed to another, in form to all other individuals, when it is addressed to the self".
} 
ainda confuso sobre suas proposições - o que é quase sempre característico em obras pioneiras. Lasswell traz preceitos hipodérmicos, tais como a percepção da propaganda como uma "arma" extremamente poderosa ou a utilização do esquema estímuloresposta behaviorista, mas não é exatamente hipodérmico. Acredita na propaganda como maneira de influenciar a audiência, mas percebe que ela só pode ser construída a partir de um conhecimento do universo cultural dessa mesma audiência (apesar de não indicar de que forma isso seria feito). $\mathrm{Na}$ verdade, como quase todo marco zero, Lasswell não é claro. Não só não consegue abarcar o fenômeno que estuda da maneira que pretende, como não consegue se desvencilhar das crenças circundantes a respeito da propaganda.

Contudo, em seu esforço, acaba se tornando o principal nome nos estudos de propaganda do início do século XX já nesse primeiro momento do período inicial, sendo convidado para escrever o verbete propaganda, da Encyclopaedia of Social Sciences, de 1934, que reforça o conceito já visto. No período seguinte, como veremos em seguida, Lasswell consolida essa posição.

\subsubsection{Analisando a propaganda (1935 a 1939)}

Dez anos após a defesa de sua tese na Universidade de Chicago, o pesquisador desfruta de prestígio em relação aos estudos sobre propaganda, sendo considerado o mais importante produtor de conhecimento sobre o tema. É um período em que Lasswell já tem a companhia de outros estudiosos que buscam a compreensão mais sistemática dos fenômenos da comunicação, como Edward Bernays e Jacques Ellul, por exemplo. Mas, como pioneiro, Lasswell leva vantagem por estar mais avançado em sua pesquisa.

São anos em que a perspectiva de uma segunda guerra envolvendo as nações do planeta se coloca de maneira mais forte, com a invasão da Etiópia pela Itália - com o conflito mundial se concretizando em 1939. O comunismo se apresentava como uma ameaça aos Estados Unidos que, ao mesmo tempo, para garantir sua ideologia de país livre, não poderia simplesmente impedir a existência de manifestações comunistas, nem de fundações partidárias também comunistas. Esses são os anos em que Lasswell estreita sua relação com o governo americano 
Nesta fase, chama atenção especial os estudos que, em meio a tantas questões relacionadas ao poder, se voltam para a análise da propaganda em regimes ditatoriais e comunistas, a partir de uma visão de que o caminho mais eficaz para disseminar uma ideologia de apoio a entrada dos Estados Unidos na guerra e a contenção da comunismo nos EUA, era a propaganda.

Com uma autoridade já instituída, o trabalho que abre a segunda fase do período inicial é uma extensa bibliografia sobre o tema propaganda, organizada em parceria com Ralph D. Casey e Bruce Lannes Smith. O livro é composto por 373 páginas ${ }^{208}$, com indicações bibliográficas que podem auxiliar o estudo da propaganda, segundo os autores. Lasswell, além de organizador, é responsável pelo capítulo de abertura, intitulado The Study and Practice of Propaganda.

A meta do capítulo é apresentar a propaganda e sintetizar aquilo que Lasswell já havia apresentado na primeira fase de seu trabalho. Desse modo, o que temos é a conceituação da propaganda, suas técnicas e possibilidades de análise, sendo que estas últimas vão ser norteadas pela análise de conteúdo, método creditado a Lasswell pela bibliografia de teorias da Comunição. Contudo, não encontramos elementos na obra lasswelliana que assegurem a "criação" do método por Lasswell, mas apenas seu desenvolvimento.

Quanto ao conceito de propaganda, Lasswell não apresenta modificações, e repete o já visto anteriormente:

\begin{abstract}
Nem bombas, nem pão, mas as palavras, imagens, músicas, desfiles, e muitos outros dispositivos semelhantes, são os meios típicos de fazer propaganda. Não é a finalidade, mas o método que distingue a propaganda do uso da violência pelos homens, do boicote, do suborno e outros meios semelhantes de controle social. A propaganda se baseia em símbolos para alcançar seus objetivos: a manipulação das atitudes coletivas [...], a propaganda é a transmissão de atitudes que são reconhecidas como controversas dentro de uma determinada comunidade $^{209}$ (LASSWELL, 1969, p.3).
\end{abstract}

Da mesma forma acontece com as reflexões sobre a organização da propaganda, o mester do propagandista é reconhecer os símbolos de uma comunidade e utilizá-los em seu trabalho.

\footnotetext{
${ }^{208}$ Na edição de 1969.

209 "Not bombs, nor bread, but words, pictures, songs, parades, and many similar devices are the typical means of making propaganda. Not the purpose but the method distinguishes propaganda from the manegement of men by violence, boycott, bribery, and similar means of social control. Propaganda relies on symbols to attain its ends: the manipulation of collective attitudes [...] propaganda is the transmission of attitudes that are recognized as controversial within a given community".
} 
O estado da arte, já enfocado no primeiro artigo publicado de Lasswell, é ampliado minimamente, mas se verifica com ele que o cientista político entende que apesar da propaganda ter sido um fenômeno que tomou proporções dignas de preocupação científica a partir do século XIX, considera origens bastante antigas para escritos sobre o assunto, identificando A Arte da Guerra, de Sun Tzu, como o possível primeiro estudo da matéria ${ }^{210}$.

A visão trans-histórica de Lasswell é justificada, em grande parte, pela ausência de delimitação do conceito de meios de comunicação. A percepção da ausência desse conceito em Lasswell é particularmente importante quando, inclusive, pensamos em seu modelo. O termo em inglês channel, que é traduzido como canal, não é utilizado por ele para designar meios técnicos de difusão da mensagem, mas qualquer forma de transmissão de mensagens, mesmo as baseadas na oralidade. Para Lasswell, não há diferença conceitual entre uma conversa e um impresso: os dois são canais de comunicação. A diferença é apenas de objetivos. Essa ausência de distinção já aparecia na primeira fase, mas não explicitamente. Em The Study and Pratice of Propaganda ela tornasse explícita.

Os canais de propaganda disponiveis para o propagandista devem ser classificados de acordo com a intimidade de contato entre aqueles que os utilizam e de acordo com o número de pessoas afetadas. Eles também podem ser classificados de acordo com sua adequação para propaganda anti-autoritária ou autoritária.

Formas intímas de comunicação são necesssariamente adotadas quando autoridades vigilantes ameaçam aplicar penalidades sérias ao disseminador de idéias subversivas da sua ascendência.

Muitos dos canais de contato mais geral se esforçam para manter o poder de convencimento dos mais íntimos tipos de conversa; daí a carta pastoral, a voz de boa vizinhanbça no rádio, o close-up informal no noticiário, o diálogo, e a importação de saudações informais direcionadas ao público ${ }^{211}$ (LASSWELL, 1969, p.14).

Apesar de Lasswell elaborar uma análise rápida sobre qual canal seria mais adequado a cada tipo de objetivo ${ }^{212}$, o resultado obtido pelo uso dos diversos canais,

\footnotetext{
${ }^{210} \mathrm{O}$ posicionamento trans-histórico é comum no período, não só em Lasswell, mas em praticamente todos os autores que estudam o fenômeno da propaganda.

211 “The channels of propaganda available to the propagandist may be classified according to the intimacy of contact among those who use them and according to the number of persons affected. They may also be classified according to their availability for anti-authoritarian or pro-authoritarian propaganda.

Intimate forms of communication are necessarily adopted when vigilant authority threatens to visit serious penalties on the disseminator of ideas subversive of its ascendancy.

Many of the channels of more general contac strive to retain the compelling power of the more intimate kinds of talk; hence the pastoral letter, the neighborly voice on the radio, the informal close-up on the newsreel, the dialogue, and the importation of informal salutations into public addresses".

${ }^{212}$ Por exemplo, o rádio é considerado por Lasswell um bom meio para comunicação a distância, em tempos de paz, ainda que conflituosos.
} 
orais ou mediáticos, é considerado bastante imprevisível por ele, sendo difícil avalizar o resultado da propaganda.

Mesmo assim, Lasswell já identifica a ligação entre a classe média e os meios impressos e indica a propaganda impressa como especialmente proeminente nesse setor, especialmente pelo fato de estar mais perto das decisões políticas do que as outras classes sociais e não obter mais o conhecimento somente pela experiência direta. Essa percepção nos mostra que Lasswell diferencia o poder da propaganda de acordo com a estratificação social. Ele, de forma alguma, ignora as diferenças entre os grupos que recebem a mensagem da propaganda. Isso fica mais perceptível ao final de The Study and Practice of Propaganda, quando Lasswell perscruta as conexões entre a propaganda e o desenvolvimento social. Segundo o cientista político,

A função da propaganda pode ser considerada também sob a luz das teorias das consequências do desenvolvimento social para a relativa à ascendência das classes, habilidades, personalidades e atitudes. Portanto, da Revolução Francesa a Revolução Russa, o efeito de rede da propaganda em relação à emergência do retardo da "revolução proletária", pode ser avaliado. Eventos contemporâneos, desde a revolução Russa devem ser construídos em termos de uma possível passagem entre a prevalência de trabalhadores intelectuais, que favorecem os sistemas burocráticos do Estado na sua prática atual, e uma possível próxima revolução mundial que marque a prevalência de trabalhadores braçais.

A propaganda é ela mesma uma habilidade, e os propagandistas devem ser vistos em competição com os profissionais de outras habilidades por renda, segurança, e deferência [...] propaganda, em comum com outros processos sociais, tem propaganda, tem sua influência na distribuição de valores, sobre quem consegue o que, quando, e como em termos de classe, habilidades, personalidade e atitude $^{213}$ (LASSWELL, 1969, p.27).

Vê-se que Lasswell não pode ser enquadrado, destarte, na afirmação de Elihu Katz, segundo a qual os estudiosos comumente associados à teoria hipodérmica consideravam “[...] O ponto não é que o estudioso das comunicações de massa não estava sabendo que os membros da audiência possuiam famílias e amigos, mas ele não acreditava que eles afetassem o resultado de uma campanha"214 (KATZ, 1960, p.435).

\footnotetext{
213،The function of propaganda may also be considered in the light of theories of the consequences of the social development for the relative ascendancy of classes, skills, personalities, and attitudes. Thus from the French to the Russian Revolution the net effect of propaganda upon the emergence of the retardation of the "proletarian revolution" could be appraised. Contemporary events since the Russian Revolution might be constructed in terms of a possible passage between the emergence of the intellectual workers who favored bureaucratic state systems in actual practice, and a possible next world revolution which marks the emergence of manual toilers.

Propaganda is itself a skill, and propagandists may be viewed as in competition with the wielders of other skills for income, safety, and deference [...] propaganda, in common with other social processes, has its bearing upon the distribution of values, upon who gets what, when, and how in terms of class, skill, personality, and attitude"

214 “"...] The point is not that the student of mass communications was unaware that members of audience have families and friends but that he did not believe that they might affect the outcome of a campaign".
} 
Pelo contrário, o contato persistente com os processos políticos vinham mostrando a Lasswell as variáveis envolvidas não só no processo político, mas também no processo de comunicação. É por isso que Lasswell cria o modelo quem consegue o que, quando e como para a pesquisa política sobre propaganda. Politics: who gets what, when, and how, de 1936, obra sobre o estudo da política que traz discussões interessantes acerca da propaganda. Nela, há pressupostos importantes para a compreensão dos textos que se seguem a Propaganda and Promotional Activities: an Annoted Bibliography. Em particular, assinalamos a definição de política e análise da influência.

a) Definição de política: "O estudo da política é o estudo da influência e dos influentes. A ciência da política define condições; a filosofia da política justifica as preferências"215 (1971, p.13);

b) Análise da influência: "Os influentes são aqueles que conseguem quase tudo que se tem para conseguir [...] Os que conseguem quase tudo são a elite; o resto são as massas" ${ }^{216}$ (Idem, p.13).

No jogo político, a propaganda se coloca como uma das formas de conseguir manter a influência das elites sobre as massas. Portanto, nada mais natural do que transportar o modelo criado para a análise da política para o campo da propaganda. Todavia, apesar de Lasswell já expressar o modelo em Propaganda and Promotional Activities: an Annoted Bibliography, a adaptação do esquema para o campo da Comunicação ainda demoraria dois anos, posto que o cientista vai se manter mais concentrado nesse período na análise da propaganda comunista.

$\mathrm{Na}$ verdade, Lasswell havia desenvolvido uma profunda pesquisa de campo no ano de 1932, que foi maturada ao longo desses anos, vindo a desembocar nas obras da segunda fase do período inicial, o que ele relata em seu affidavit:

Depois [...] da primavera de 1932, eu recebi uma bolsa de viagem da Universidade, para observer na Alemanha as importantes eleições de verão, e examinar na Rússia as fontes da propaganda comunista internacional. Na Alemanha, eu me juntei ao professor Merriam e ao professor Samuel Harper, o russianista da Universidade. Lá eu fui aos encontros dos mais importantes partidos politicos brigando por poder, incluindo Nazistas, Comunistas, Socialistas, Nacionalistas e Centristas. Depois das eleições, eu parti para Moscou. [...] Minha

\footnotetext{
215 "The study of politics is the study of influence and the influential. The science of politics states conditions; the philossophy of politics justifies preferences".

216 "The influential are those who get the most of what there is to get [...] Those who get the most are elite; the rest are masses".
} 
viagem, assim como meus encontros com oficiais da propaganda russa, foi organizada pelos canais usuais de uma agência para turistas. Mas naquela época a agência estava aparentemente orientada para receber bem os professores visitantes.

Dessa forma, eu pude visitor os escritórios de controle da propaganda do governo, e entrevistar muitos oficiais, incluindo correspondentes internacionais, eu não tive permissão para viajar pelo campo, por conta do sofrimento notório que ficaria evidente ao observador como resultado da política de coletivização forçada ${ }^{217}$ (LASSWELL, 1951, p.11-12).

Portanto, Lasswell desenvolve extensa pesquisa sobre a propaganda comunista nos Estados Unidos já sob uma perspectiva negativa e preconceituosa, ao contrário dos trabalhos da primeira fase sobre propaganda, no quais a regra é neutralizá-la como instrumento. Na segunda fase, a rejeição ao comunismo se mostra a tônica de suas análises, cuja síntese pode ser percebida no aforismo "o comunismo é sempre propaganda" (Lasswell, 1935, p.189), ditado em The Person: Subject and Object of Propaganda.

$\mathrm{Na}$ verdade, a propaganda como instrumento continua sendo neutra para Lasswell, mas a utilização da propaganda pelos comunistas acaba sendo colocada de maneira oposta aquela praticada em países “democráticos”. Para Lasswell, a propaganda comunista em países democráticos tem como principal objetivo "[...] enfraquecer as lealdades básicas das quais as instituições democráticas dependem, e preparar o caminho para uma revolta impulsiva contra elas"218 (LASSWELL, 1935, p.188).

A partir dos estudos da propaganda comunista, Lasswell sintetiza ainda mais sua definição do termo e adjetiva as atitudes que são alvo da propaganda. Segundo ele, propaganda passa a ser, então, “[...] a manipulação de símbolos para influenciar atitudes controversas"(Idem, 1939, p.63, grifo nosso).

Essa definição vai aparecer, com poucas modificações, nos outros textos do período, que passam a trabalhar com a ideia de persuasão das audiências mais claramente, e não com o conceito de manipulação (inclusive no verbete da

\footnotetext{
217 "After [...] the spring of 1932, I was given a travelling fellowship by the University, to observe in Germany the important Summer elections, and to examine in Russia the sources of international communist propaganda. In Germany I joined Professor Merriam, and Professor Samuel Harper ${ }^{217}$, the University's Russian expert. There I attended meetings of the most important political parties contending for power, including the Nazis, Communists, Socialists, Nationalists and Centrists. After the elections I left for Moscow [...] My trip, as well as my contests with Russian propaganda officials, was arranged through the usual channels of the "intourist" agency. But at that time the agency was apparently under instructions to humor the special interests of visiting scholars.

Accordingly, I was able to visit the control propaganda offices of the government, and interview several echncal officials, including even the foreign correspondents, I was not permitted to get out into the countryside, because of the widespread suffering which would be evident to my observer as a result of the government's policy of forced collectivization".

218 "[...] to undermine the basic loyalties upon which democratic institutions depend, and to prepare the way for impulsive revolt against them".
} 
Encyclopaedia of Social Sciences). A exceção é The Person: Subject and Object of Propaganda, no qual Lasswell define a propaganda como uma técnica de controle social ou como "uma espécie de movimento social”(LASSWELL, 1935, p.189).

O grande aprofundamento desse período se trata do aperfeiçoamento feito no método de análise, a análise de conteúdo, sobretudo nas obras escritas com Dorothy Bluemenstock, The Volume of Communist Propaganda in Chicago e World Revolutionary Propaganda: A Chicago Study, ambas de 1939. Como The Volume of Communist Propaganda in Chicago nada mais é do que uma síntese do livro de 1939, nos concentraremos aqui neste último, no qual Lasswell e Bluemenstock, como o nome indica, analisam a propaganda comunista em Chicago a partir da seguinte pergunta: será que o comunismo conquistará a América?

Lasswell retoma nesse estudo a idéia do propagandista como advogado de uma causa: a causa do comunismo. Não há uma modificação no conceito de propaganda, em World Revolutionary Propaganda: A Chicago Study, mas a agregação do termo "revolucionário" para se referir à propaganda comunista em Chicago, pois, para Lasswell e Bluemenstock, “[...] a propaganda comunista em Chicago é revolucionária porque demanda mudanças fundamentais (mais do que reformas) nas práticas institucionais na América"219 (1939, p.11).

As metas da propaganda comunista, destarte, são:

1) Direcionar os descontentes contra os símbolos e práticas da ordem estabelecida;

2) Organizar atitudes favoráveis em torno de símbolos que podem ser manipulados por uma contra-elite durante crises revolucionárias;

3) Prevenir a hiper concentração de influências hostis até que a probabilidade de uma ação revolucionária bem-sucedida seja alcançada.

Os símbolos, por sua vez, podem ser classificados em símbolos de demanda, símbolos de identificação e símbolos de fatos. Os símbolos de demanda são símbolos de preferências ou determinações para que certos eventos possam ocorrer. A definição é melhor explicada por Lasswell quando este coloca que "os padrões da propaganda revolucionária são distintos dos padrões da propaganda não-revolucionária, de acordo

\footnotetext{
219، “...] communist propaganda in Chicago is revolutionary because it demands fundamental changes (rather than reforms) in the institutional practices at America".
} 
com a presença ou ausência de demandas para mudanças fundamentais" ${ }^{220}$ (LASSWELL, 1939, p.103). Os símbolos de identificação, como o nome indica, são símbolos que fazem com que os padrões trabalhados se refiram mais a identidades do que a demandas, como Lasswell exemplifica: "algumas revoluções foram feitas em nome das classes (como o proletariado); outras em nome das nações" (Idem, ibidem, p.104). Por fim, os símbolos de fatos estão relacionados mais a objetos do que a pessoas ou grupos, "ou sentenças que afirmam algo sobre eventos sem afirmar preferências, e sem ser símbolos de identifdicação" (LASSWELL, 1939, p.104).

Novamente, Lasswell trabalha com uma definição de canais de comunicação bastante ampla, listando piadas, festas de partidos, uniformes, bandeiras, música, etc., como meios pelos quais a propaganda pode ser difundida. Mais uma vez também, Lasswell apresenta fatores psicológicos que podem interferir (para o bem e para o mal) na interpretação e composição da mensagem da propaganda. Assim, ele diz que é conveniente que se faça uma análise das predisposições levando em consideração às atitudes pré-organizadas e os níveis de reatividade.

Neste período também acontecem os seminários da Fundação Rockefeller e Lasswell adentra, enfim, na discussão mais ampla sobre a comunicação nos Estados Unidos, relatada por ele em seu affidavit:

Com o envolvimento progressivo dos Estados Unidos no esforço de defesa, minhas atividades como consultor se concentraram mais diretamente em torno de projetos diretamente relacionados a esse esforço. Desde 1939, eu participava de um grupo informal que se encontrava sob os auspícios da Fundação Rockefeller para avaliar o status da pesquisa no campo da comunicação de massa e dos estudos em opinião pública. A partir dessas discussões, cresceu a ideia de uma pesquisa sobre a comunicação de guerra, e eu fui convidado pela Fundação a submeter um projeto. Foi o que fiz, e recebi uma concessão de dois anos, depois extendida para que me compromissase com um programa em três frentes: 1) desenvolver os métodos da "análise de conteúdo" na pesquisa em comunicação, assim como da análise organizacional (como na Procuradoria Geral da República); 2) treinar pessoal para as agências do governo que se esperava serem mais ativamente envolvidas na propaganda e nos serviços de inteligência; 3) me manter disponível, em Washington, de modo que eu pudesse ser uma espécie de consultor dos oficiais públicos desenvolvendo várias propagandas do governo e o progresso da inteligência.

O projeto como um todo foi colocado sob a administração da Biblioteca do Congresso, apesar de muito do nosso trabalho ter sido em nome do Departamento de Justiça, particularmente nas acusações de agentes comunistas, nazistas e fascistas sob o Ato de Registro de

220 "[...] revolutionary propaganda symbol patterns are distinguished from non-revolutionary patterns according to the presence or absence of demands for fundamental changes". 
Agentes Estrangeiros. Eu mesmo testemunhei como especialista pelo Departamento na acusação bem sucedida da Boolmiga Corporation como agente russa não declarada, analisando o conteúdo das publicações distribuídas pela empresa, como forma de comprovar o quão proximamente eles seguiam a linha do partido comunista. Fui também testemunha especialista em casos envolvendo publicações nazistas e fascistas, e mais tarde no Departamento dos Correios, na audiência do periódico grosseiro "X-Ray" que desde então tem me dado uma série de epítetos ${ }^{221}$ (LASSWELL, 1951, p.17-18).

A entrada de Lasswell no trabalho da Divisão Experimental para a Comunicação em Tempos de Guerra marca o fim de seu período inicial. Ao final da década de 1930, Lasswell é não só a maior autoridade em propaganda nos Estados Unidos, mas o idealizador do projeto que colocou o termo "comunicação" em debate, e propôs uma área de pesquisa que poderia se desenvolver autonomamente.

\footnotetext{
221 "With the progressive involvement of the United States in the defense effort, my consultative activities turned more towards projects directly related to that effort. Since about 1939 I had participated in a informal group which met under the auspices of the Rockefeller Foundation to consider the existing status of research in the field of mass communication and public opinion studies. Out of this discussions there grow an idea for research on war communication, and I was invited by the Foundation to submit a project. I did so, and received a two-year grant, later extended to engage in a program on three fronts: 1) to develop the methods of "content analysis" in communication research, as well as organizational analysis (as in the Attorney General's List); 2) to train personnel for the agencies of the government that could be expected to become more actively involved in propaganda and intelligence activities; 3) to hold myself available, in Washington, so that I could set as a sort of raving consultant to public officials developing the government's various propaganda and intelligence progress.

The project as a whole was put under the administration of the Library of the Congress, although much of our efforts were on behalf of the O Departamento de JustiçaDepartment of Justice, particularly in its prosecution of Communist, Nazi and Fascist agents under the Foreign Agents Registration Act. I myself testified as an expert witness for the Department in the successful prosecution of the Boolmiga Corporation as an undeclared Russian agent, analyzing the content of the publications distributed by the Corporation, in order to show how closely they followed the party line. I was also an expert witness in cases involving Nazi and Fascist publications, and later appeared at a Post Office Department hearing banning from the nails scurrilous periodical called "X-Ray" which has since subjected me to a constant barrage of epithets".
} 


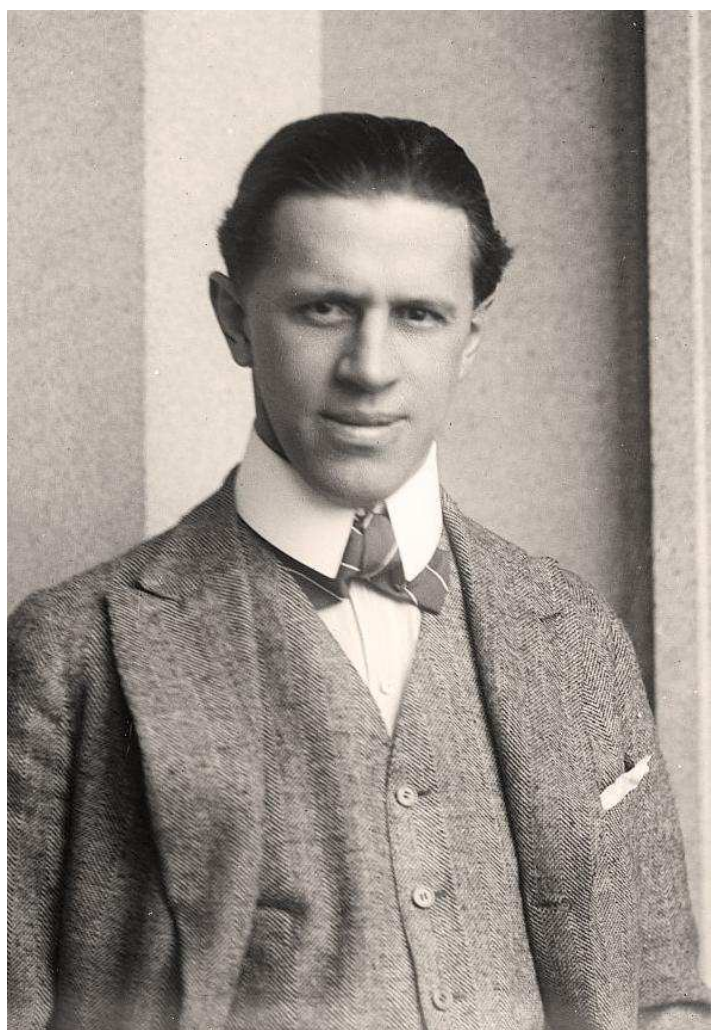

Figura 30. George Creel.

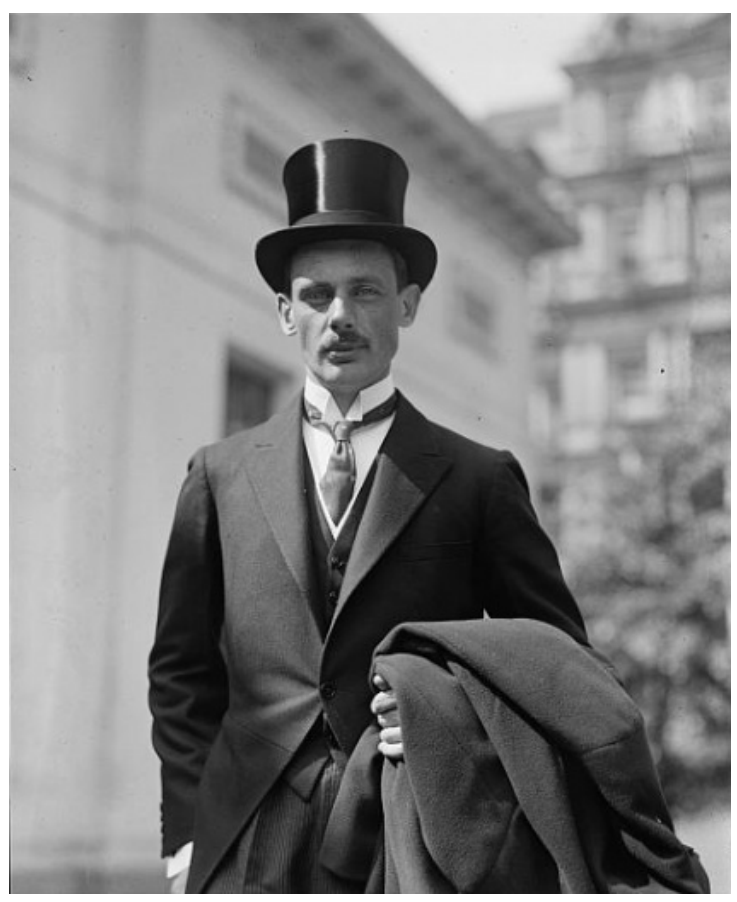

Figura 32. Stuart Campbell.

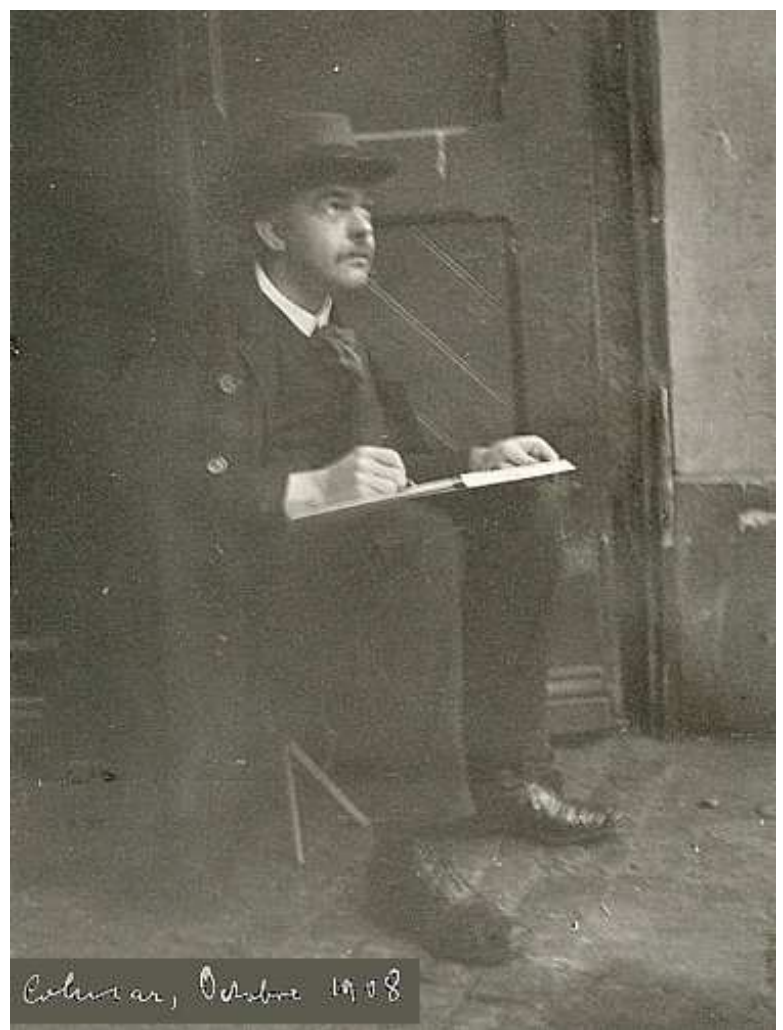

Figura 31. Hansi.

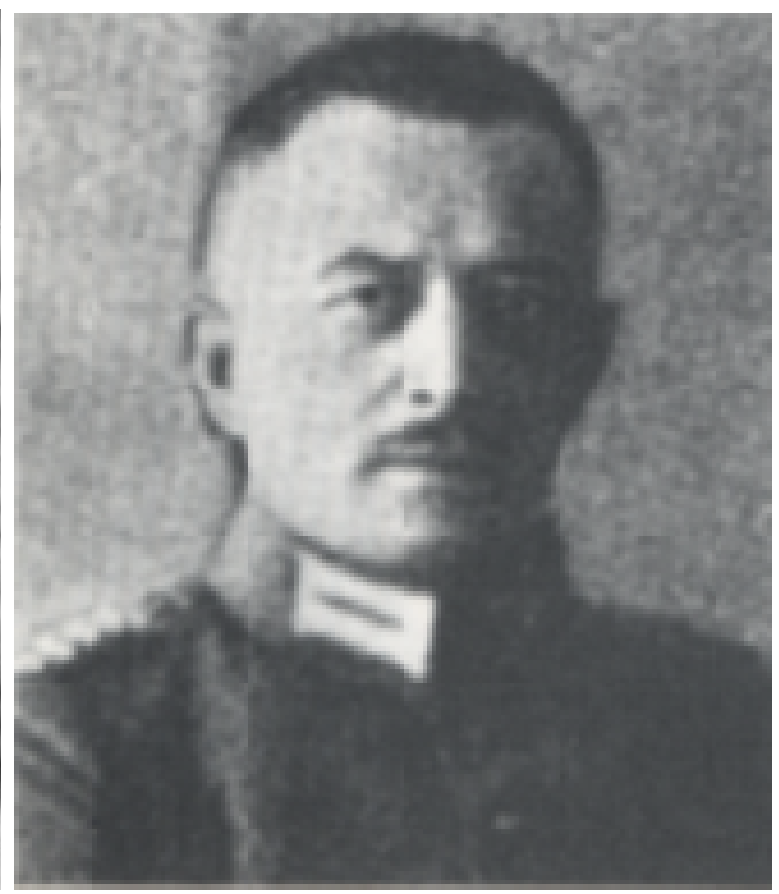

Figura 33. Walter Nicolai. 


\subsection{Período intermediário: de 1940 a 1950}

Este é o período mais produtivo de Harold Lasswell sobre questões comunicacionais e seu início coincide com a intensificação do trabalho na Divisão de Guerra. As obras do período são:

\begin{tabular}{|c|c|c|}
\hline Título & Tipo & Ano \\
\hline "Radio as an Instrument of Reducing Personal Insecurity" & Artigo & 1941 \\
\hline "The Communications Front: Strategies of Political and Moral Warfare" & Artigo & 1942 \\
\hline "Communications Research and Politics" & Artigo & 1942 \\
\hline "An Experimental Comparison of Four Ways of Coding Editorial Content" & Artigo & 1942 \\
\hline The Politically Significant Content of the Press: Coding Procedures" & Artigo & 1942 \\
\hline Public Opinion in War and Peace: How Americans Make Up Their Minds & Artigo & 1943 \\
\hline "New Rivals of the Press: Film and Radio" & Artigo & 1945 \\
\hline "The Science of Communication and the Function of Libraries" & Artigo & 1945 \\
\hline "Describing the Contents of Communications" & Artigo & 1946 \\
\hline "Describing the Effects of Communications" & Artigo & \\
\hline Propaganda, Communication, and Public Opinion: A Comprehensive Reference Guide & Livro & 1946 \\
\hline "Freedom of the Press: A Summary Statement of Principle" & Apêndice & 1947 \\
\hline $\begin{array}{l}\text { A Free and Responsible Press: A General Report on Mass Communication: Newspapers, } \\
\text { Radio, Motion Pictures, Magazines, and Books }\end{array}$ & Livro & 1947 \\
\hline "Summary of Principle: A Statement of the Commission" & Artigo & 1947 \\
\hline "The Structure and Function of Communication in Society" & Artigo & 1948 \\
\hline "The Rise of the Propagandist" ("The Propagandist Bids for Power") & Artigo & 1948 \\
\hline "Detection: Propaganda Detection and the Courts" & Artigo & 1949 \\
\hline "Trend: May Day Slogans in Soviet Russia, 1918-1943" & Artigo & 1949 \\
\hline "Why Be Quantitative?" & Artigo & 1949 \\
\hline "Propaganda and Mass Insecurity" & Artigo & 1950 \\
\hline
\end{tabular}

Tabela 16. Obras de Lasswell do Período Intermediário de Harold Lasswell.

São 20 trabalhos cujo escopo começa a não se concentrar mais unicamente no desenvolvimento de uma teoria da propaganda, mas se preocupa em conceber questões mais amplas em relação ao universo da comunicação de massa. A mudança de rubrica, 
de propaganda para comunicação $o^{222}$ já foi explicada aqui, mas é necessário considerarmos essa modificação para além da neutralidade do termo comunicação. Mas qual é o impacto epistemológico da mudança de vocábulo?

Ao optar pelo uso da palavra comunicação, Lasswell primeiro amplia o escopo de atuação da Divisão Experimental de Comunicação em Tempos de Guerra e acaba, ainda que de forma não muito intencional, congregando as diversas vertentes de pesquisas que se avolumavam desde o início do século $\mathrm{XX}$ tendo como objeto os processos de comunicação de massa. Em segundo lugar, ao agrupar essas diferentes pesquisas sob uma única insígnia, força-se a reflexão sobre o próprio termo. E, se Lasswell havia tentado desenvolver uma teoria da propaganda, a designação agora concebida pela Divisão Experimental para Comunicação em Tempos de Guerra traz a necessidade de uma teoria da comunicação também. O que antes se encontrava disperso, começa a ser agrupado.

Desse modo, Lasswell é responsável pela transição essencial que tornaria as pesquisas iniciais sobre comunicação elementos de um campo único, cuja base teórica precisava ser estabelecida. Evidentemente que este pioneirismo não exclui as influências que recebeu quando de sua participação das discussões do Seminário da Fundação Rockefeller, do qual é fruto seu projeto a esta mesma instituição. Lasswell tinha reunido suficiente prestígio para colocá-lo em uma posição privilegiada, pois grande parte das linhas que naquele momento estabeleciam esse campo iria ser delimitada por ele. Assim, enquanto está à frente da Divisão, Lasswell elabora uma série de preceitos teóricos para o estudo da comunicação. Alguns já haviam sido desenvolvidos por ele nos estudos sobre propaganda, como a noção de que a comunicação busca influenciar pela utilização de símbolos compartilhados. Outros vão germinar a partir das necessidades colocadas pela chefia da Divisão, como o modelo de Lasswell.

Os dois mais visíveis resultados desses anos, na obra lasswelliana, são a ênfase na ação dos meios de comunicação de massa, como jornais, rádio e cinema, e a aplicação extrema da análise de conteúdo, com um levantamento quantitativo ainda mais detalhado do que no período inicial. Os meios de comunicação começam a ser analisados na tentativa de compreender de que modo a audiência utiliza esses meios para sanar algumas necessidades, como no artigo Radio as an Instrument of Reducing

\footnotetext{
${ }^{222}$ A palavra propaganda praticamente desaparece dos títulos das obras de Lasswell. Quando presente, em geral vem acompanhada do termo comunicação.
} 
Personal Insecurity, de 1941, e no artigo New Rivals of the Press: Film and Radio, de 1945.

Por outro lado, o empenho de Lasswell em atribuir ao trabalho da Divisão Experimental o mesmo caráter científico que havia sido atrelado aos seus estudos individuais, vai fazer com que a idéia de uma teoria da comunicação gere textos importantes nos quais uma compreensão do processo de comunicação de massa e às formas de analisá-lo sejam difundidos de modo mais amplo.

O período intermediário também pode ser dividido em duas fases: de 1940 a 1946, anos que cobrem o trabalho de Lasswell na Divisão Experimental para o Estudo da Comunicação em Tempos de Guerra até sua ida para a Universidade de Yale; e de 1947 até 1950, quando Lasswell começa a reeditar seus artigos iniciais e passa a escrever textos mais ensaísticos, baseados na sua experiência como pesquisador em comunicação e propaganda.

\subsubsection{A Comunicação (1940 a 1946)}

A primeira fase do período intermediário lasswelliano é marcada pela transição entre a pesquisa sobre a propaganda e a pesquisa sobre a comunicação. Uma das principais características dessa transição aparece já no primeiro texto dessa fase, Radio as an Instrument of Reducing Personal Insecurity, de 1941. Pela primeira vez, Lasswell foca sua análise na ação de um meio de comunicação de massa específico, com a intenção de verificar de que maneira o rádio é utilizado como forma de "educar" a psicologia das massas, formada pela classe média.

Alinhado com a teoria psicanalítica freudiana, Lasswell tenta explicar de que maneira a classe média utiliza os programas radiofônicos que explicam a natureza humana, de modo científico ou não, para reduzir a sensação de insegurança do período de guerras, tipicamente um período de crise. Assim, ele coloca as características psicológicas da natureza do indivíduo de classe média para explicar os efeitos desse tipo de programa sobre a audiência. Iremos nos valer, aqui, de uma longuíssima citação, mas que consideramos essencial para compreender como Lasswell qualifica o ouvinte dos programas radiofônicos descritos acima.

Uma vez que o rádio reflete os interesses de uma sociedade individualista, existirão programas de fundo "psicológico", devotados a explicação e a manipulação da natureza humana. A criança que nasce numa sociedade individualista desenvolve uma consciência 
apurada de seu próprio ego, a partir do momento em que ela é treinada a comparar-se incessantemente aos rivais em potencial, ela é ensinada a disciplinar seus próprios impulsos no interesse do sucesso e, por sucesso, entenda-se o aperfeiçoamento do controle acerca de certos valores como poder, respeito e renda. Como retorno de um trabalho bem feito, o sucesso é tido como garantia.

O gosto pela psicologia pode ser encontrado em todos os lugares, mas apenas nas sociedades individualistas esse gosto se transformou numa fissura com a magnitude de um vício. No quadro geral de uma cultura como essa, há zonas especiais de ênfase relacionadas a relaização individualista. A criança que é criada em uma famíla de classe média comumente cresce para compartilhar a aspiração da classe média de "subir na vida". A criança de classe media é a quintessência do alpinista social numa sociedade de alpinistas.

[...] O padrão duplo de sucesso e serviço cria enormes dificuldades nas vidas dos meninos e meninas de classe média. Se a classe media é a cama em que germinam os alpinistas ambiciosos, é também a guardiã da moralidade e dos ideiais de sacrifício em nome de valores que transcendem os limites do ego individual. O conflito típico em relação a personalidade da juventude de classe média é entre "ambições" e "ideais"; o individual sofre com as ênfases contraditórias encontradas na estrutura total da sociedade individualista $^{223}$ (LASSWELL, 1948, p.246-247).

Em tempos de insegurança no futuro, numa sociedade em que a comunicação pela experiência direta começa a ter como concorrente a comunicação mediada, em que os conselheiros estão distantes, o rádio assume o papel de analisar e tranquilizar esse cidadão de classe média, formado para a competição, que se auto-avalia em termos de sucesso ou fracasso. Assim, Lasswell continua:

[...] Por isso, a promessa da "psicologia" na escala de interesses de pessoas inseguras; por isso, a verdade na predição de que, ao passo que os meios de comunicação de massa, na sociedade individualista refletem o sentimento popular, eles devem se preocupar com a psicologia - de alguma forma todos os momentos; de uma maneira

\footnotetext{
223 "As long as radio reflects the interests of an individualistic society, there will be "psychological" programmes, programmes devoted to the explanation and handling of human nature. The child who is born into an individualistic society develops acute consciousness of his own ego, since he is trained to compare himself incessantly with all potential rivals, he is taught to discipline his own impulses in the interest of success, and by success is meant the improvement of his control over such values as power, respect and income. In return for work well done, success is said to be sure.

The taste of psychology may be found among among all men everywhere, but only among individualistic societies does the taste become a craving approaches the magnitude of an addiction. Within the general framework of such a culture, there are zones of special emphasis upon individualistic achievement. The child who is reared in a middleclass family usually grows to share the middle-class aspiration to rise in the world. The middle-class child is the quintessential climber in a society of climbers.

[...] The double standard of success and service creates enormous difficulties in the lives of middle-class boys and girls. If the middle class is the germinating bed of ambitious climbers, it is also the custodian of morality, of ideals of sacrifice on behalf of values that transcend the limits of individual ego. The typical conflict within the personality of middle-class youth is between "ambitions" and "ideals"; the individual suffers from contradictory emphases that are found throughout the total structure of an individualistic society
} 
mais extensa, em tempos de insegurança geral ${ }^{224}$ (LASSWELL, 1948, p. 247).

Há indicações importantes nessas afirmações, pois começa a ser definida na obra publicada de Lasswell, uma noção de que a comunicação de massa cumpre certas funções em sociedade (o que vai ser completamente delimitado por ele no texto mais referenciado pelos teorógrafos da Comunicação: The Structure and Function of Communication in Society, na segunda fase do período intermediário). Com o campo da Comunicação se formando de modo mais consistente, Lasswell já cita seus interlocutores $^{225}$ e suas respectivas teorias (Lazarsfeld e o efeito pré-seletivo, por exemplo) e aprofunda a questão das diferenças do público, apesar de reconhecê-lo como de classe média.

Nós precisamos de investigações mais cuidadosas para determiner o efeito dos programas psicologicos em geral, e de padrões específicos em particular, em relação às várias audiências de ouvintes. $\mathrm{O}$ efeito vai depender, em parte, das predisposições latentes e ativas nas personalidades dos ouvintes. De fato, uma das mais interessantes perguntas a ser respondida em em relação às transmissões psicológicas é quem as escutam. Isso é o que Paul F. Lazarsfeld chama de efeito pré-seletivo, a seleção pessoal não apenas de um canal de rádio como um canal de comunicação, mas de tipos específicos de $\operatorname{programas}^{226}$ (LASSWELL, 1948, p. 255).

Lasswell chama a atenção para o fato de que muito pouco ainda é conhecido sobre a audiência desses programas, mas não se exime de expor uma hipótese que possa guiar trabalhos futuros, como ele mesmo afirma - ou seja, Lasswell apresenta uma suposição e não uma certeza de como a mensagem é recebida pelo público. Tendo como principal objetivo analisar a resposta da audiência (ou o efeito da mensagem), o cientista político recorre ao behaviorismo e sua teoria geral da resposta, segundo a qual toda resposta é composta por dois fatores: o ambiente externo e o ambiente interno (a sociedade e o eu interior). A resposta será mais positiva se a adequação desses ambientes apresentar mais ganhos do que perdas para a audiência.

\footnotetext{
224“[...] Hence the promise of "psychology" in the interest scale of insecure people; hence the truth in the prediction that as long as the media of mass communication in the individualistic society reflect popular sentiment, they Will concern themselves with psychology - to some extent at all times; to a greater extent in times of general insecurity". ${ }^{225}$ Apesar disso, deve-se ressaltar que as observações associadas aos interlocutores de Lasswell já estavam de certa forma presente nas discussões do cientista político no período inicial.

${ }_{226}^{22}$ We need much careful investigation to determine the effect of psychological programmes in general, and of specific patterns in particular, upon the various listening audiences. The effect Will depend, in part, upon the varied predispositions latent and active in the personalities of those who listen. Indeed, one of the msot interesting questions to be raised in connection with the psychological broadcasts is Who listens to them all. This is what Paul F. Lazarsfeld calls the pré-selective effect, the self-selecting not only of radio as a channel of communication, but of specific types of programme".
} 
Essa é a última contribuição notória do artigo, pois Lasswell oferece mais perguntas do que respostas em seu texto, que constitui mais um guia para futuras investigações sobre a audiência do rádio.

Nesta fase, logo após a publicação de Radio as an Instrument of Reducing Personal Insecurity, Lasswell retoma a análise do estado da arte nas pesquisas sobre comunicação e opinião pública, provavelmente pela necessidade de reavaliá-lo para as atividades da Divisão Experimental da Comunicação em Tempos de Guerra. Em Communications Research and Politics, Lasswell já fala em um campo da Comunicação, incluindo seu próprio trabalho na retrospectiva, e explicando a preferência pelo quantitativo.

A pesquisa moderna sobre opinião pública e comunicação se dessenvolveu como resposta a uma notável convergência de condições favoráveis. As ciências sociais estavam num espasmo de inferioridade quando eram comparadas a seus irmãos, irmãs e primos nas ciências físicas e biológicas. Muitas das suas principais figures estavam convencidas que, a menos que os especialistas fossem capazes de "quantificar" suas proposições, eles estavam condenados ao status permanente de segunda classe de cidadãos no universo do conhecimentos secular ${ }^{227}$ (LASSWELL, 1942, p. 302).

Trata-se um texto curto, ensaístico, com poucas passagens teóricas relacionadas à comunicação. $\mathrm{O}$ ponto crucial deste artigo, entretanto, é mesmo a percepção da necessidade de delimitação crescente de uma autonomia maior para o campo da Comunicação e a defesa de uma autonomia para o profissional da área.

A questão essencial sobre uma profissão não está relacionada com a afirmação tradicional de que esta possui uma literatura distintiva. Atualmente, praticamente todo ofício ou mercado cumpre esse critério. Mais relevante é a distinção entre o exercício de uma habilidade, e a união entre essa habilidade e o conhecimento do processo agregado ao qual a habilidade está intimamente relacionada.

[...] Não é suficiente aos especialistas em comunicação adquirirem habilidades em surveys, análise de conteúdo, ou outras operações técnicas. Uma profissão genuína é aquela que complementa a habilidade com o conhecimento. No caso da comunicação, isso implica um mapa comum de tendências, condições e projeções do processo inteiro. Isso também implica a capacidade de inventar e avaliar políticas para o cumprimento das metas pretendidas.

\footnotetext{
227“"Modern public opinion and communications research developed in response to a remarkable convergence of favoring conditions. The social sciences were in a spasm of inferiority when they compared themselves with their brothers, sisters, and cousins in the physical and biological sciences. Many of the leading figures were convinced that, unless the specialists on society were able to "quantify" their propositions, they were doomed to the permanent status of second class citizens in the universe of secular knowledge".
} 
[...] Nessa concepção está implicado um grau de autonomia ${ }^{228}$ (LASSWELL, 1942, p.306).

Essa afirmação mostra a percepção de Lasswell sobre o crescimento do campo comunicacional e sobre a necessidade deste se auto delimitar. Afiança também uma visão mais completa que o profissional dessa área deve ter do processo de comunicação.

Os artigos Public Opinion in War and Peace: how Americans Make up their Minds (1943), New Rivals of the Press: Film and Radio (1945) e Propaganda and Mass Insecurity (1950) seguem mais ou menos a mesma linha dos dois primeiros textos apresentados neste tópico, não avançando muito em termos de análise e propostas para a comunicação.

Os textos que trazem implicações para a compreensão da obra lasswelliana desse período são, portanto, aqueles que descrevem processos de análise dos meios de comunicação: An Experimental Comparison of Four Ways of Coding Editorial Content (1942), The Politically Significant Content of the Press: Coding Procedures (1942), Describing the Contents of Communication (1946) e Describing the Effects of Communication (1946), estes dois últimos publicados no livro Propaganda, Communication, and Public Opinion, a Reference Guide, em parceria com Bruce Lannes Smith e Ralph D. Casey.

An Experimental Comparison of Four Ways of Coding Editorial Content e The Politically Significant Content of the Press: Coding Procedures basicamente relatam os procedimentos para se realizar análise de conteúdo de editoriais de jornais impressos. Na verdade, os artigos são uma espécie de relatório expedido pela Divisão Experimental para o Estudo da Comunicação em Tempos de Guerra, e descrevem as práticas da instituição para análise dos meios impressos, com aplicação de métodos matemáticos bastante complexos - o que levou Heinz Elau a chamá-los de malucos em The madenning methods of Harold Lasswell (1969, p.15).

Escritos em parceria com Alan Grey e David Kaplan, os artigos apresentam o método de acordo com os seguintes passos:

\footnotetext{
228“"The important thing about a profession is not conveyed by the traditional assertion that it has a distinctive literature. Today, practically every craft or trade meets this criterion. More relevant is the distinction between the exercise of a skill, and the coupling of skill

with knowledge of the aggregated process to which the skill is intimately related.

[...] It is not enough for communication specialists to acquire skill in surveying, content analysis, or other technical operations. A genuine profession can be said to complement skill with enlightenment. In the case of communication, this implies a common map of the trends, conditions, and projections of the entire process. It also implies the capacity to invent and evaluate policies for the accomplishment of postulated goals.

[...] Implied in this conception of a profession is a degree of autonomy".
} 
1) Seleção da lista de símbolos, que podem ser palavras unitárias ou uma seqüência de símbolos (uma sentença) que se julgue válida de ser registrada;

2) Inclusão na lista de símbolos de variáveis desse mesmo símbolo. Por exemplo, “[...] o classificador deve ser deixado à vontade para anotar como 'Hitler' termos tais como 'Führer', 'Chanceler alemão', 'Nazista nº1' e assim por diante" (GREY, KAPLAN \& LASSWELL, 1982, p.105);

3) Selecionar a unidade de registro e o contexto;

4) Treinar os leitores para que os dados sejam consistentes e confiáveis;

5) Coletar e analisar os dados.

Cada símbolo foi classificado de acordo com as variações positivas (recebendo o símbolo +), negativas (recebendo o símbolo -) e neutras (recebendo o símbolo 0). A intenção era identificar os períodos favoráveis, desfavoráveis ou neutros em relação aos símbolos estudados, buscando, pela freqüência, uma apreciação da situação destes símbolos nos jornais.

Esse é um método ainda bastante utilizado em análise de conteúdo, especialmente quando se busca uma análise temporal que agregue uma interpretação da avaliação que se faz de um determinado símbolo.

Os dois últimos textos da fase inicial do período intermediário se desconectam e grande parte de seu trabalho na Divisão Experimental, pois se afastam do tom relatorial e se ocupam em fornecer as linhas teóricas mais gerais que podem ser aplicadas ao entendimento dos conteúdos da comunicação e aos efeitos da comunicação. Como dizem os autores, Propaganda, Communication and Public Opinion: a Comprehensive Reference Guide, obra no qual estão incluídos os referidos textos, é "direcionado para a estrutura da emergente ciência da comunicação" (CASEY, LASSWELL \& SMITH, 1946, p.3).

\section{Describing the Contents of Communication e Describing the Effects of} Communication, os capítulos sob responsabilidade de Lasswell, ao mesmo tempo em que resgatam seu aprendizado nos anos da Divisão, se afastam do tom relatorial dos artigos nos quais o cientista político tornava público os métodos utilizados para analisar os meios de comunicação, em seu trabalho, durante a guerra.

Lasswell descreve o trabalho de análise do conteúdo e dos efeitos da comunicação sob a responsabilidade de uma ciência da comunicação, que "[...] nos capacitaria para estudar o alcance da influência que passa do controle do conteúdo e do 
conteúdo a audiência" ${ }^{229}$ (LASSWELL, 1946, p.74). Percebe-se aí que Lasswell mantémse firme em suas convicções de formação na origem. Mesmo com a transição do estudo da propaganda para o estudo da comunicação, de maneira mais geral, Lasswell a vê como um processo político de influência sobre as massas.

Como se trata de um capítulo que faz às vezes de introdução ao estudo dos conteúdos dos meios, Lasswell não se prolonga em definições, posto que a maior parte delas pode ser encontrada em seus trabalhos anteriores. Entretanto, algumas assertivas neste capítulo, merecem atenção, ou porque apontam para caminhos que poderiam ser desenvolvidos posteriormente, ou porque modificam o sentido de algumas colocações do passado.

Em relação ao primeiro caso, temos a classificação da resposta da audiência, que para Lasswell pode se dar da seguinte maneira:

Sem entrar em detalhes sobre esse ponto, podemos classificar a resposta da audiência da seguinte forma: (1) atenção; (2) compreensão; (3) divertimento; (4) avaliação; (5) ação ${ }^{230}$ (LASSWELL, 1946, p.80).

Como ele próprio diz, não há maiores explicações sobre esses cinco tipos de respostas possíveis. O que se consegue perceber é que o nível de envolvimento da audiência com a mensagem dos meios de comunicação vai desde a simples atenção até um resultado comportamental, uma ação.

Já em relação ao segundo caso, os exemplos são mais pródigos. Temos a primeira publicação do modelo de Lasswell, ainda que de forma bastante breve, na introdução da bibliografia. Tendo sido desenvolvido na Divisão Experimental para a Comunicação em Tempos de Guerra, o modelo de Lasswell já era bastante conhecido nos bastidores da pesquisa em Comunicação.

Como desenvolvido nos últimos anos, o campo científico do estudo da comunicação está centrado nas quatro fases sucessivas de qualquer ato de comunicação: por quais canais a comunicação se dá? Quem comunica? O que é comunicado? Quem é afetado pela comunicação e como $?^{231}$ (LASSWELL, 1946, p.3).

É interessante notar que, se antes Lasswell considerava como canais as mais variadas formas de comunicação, em Propaganda, Communication and Public Opinion:

\footnotetext{
229

230"Without going into detail at this point, we may classify audience response as follows: (1) attention; (2) comprehension; (3) enjoyment; (4) evaluation; (5) action".

231 "As developed in the past few years, the scientific field of scientific study of communication centers around the four successive phases of any act of communication: In what channels do communication take place? Who communicates? What is communicated? Who is affected by the communication and how?".
} 
a Comprehensive Reference Guide ele considera apenas o estudo da comunicação de massa, o que se torna mais claro quando afirma: "[...] nossa preocupação é com a comunicação de massa, um ato de comunicação no qual uma grande quantidade de pessoas está envolvida como emissores, recpetores, ou ambos"232 (Idem, ibidem, p.83).

Nesta colocação, também devemos notar que a crítica ao "modelo unidirecional" de Lasswell está longe de fazer sentido. O próprio pesquisador considera a possibilidade de alternância (ou sobreposição?) dos papeis de emissor e receptor, ainda que na comunicação de massa tradicional, realmente emissor e receptor estejam isolados fisicamente.

Outro ponto importantíssimo a ser relatado aqui é a necessidade que Lasswell coloca em relação à definição do termo que dá nome à área, quando se pergunta afinal, "qual é a definição mesma de comunicação" (LASSWELL, 1946, p.114). Questão à qual ele mesmo responde, destacando a urgência de se refletir sobre ela.

\subsubsection{As funções da comunicação (1947 a 1950)}

A ida para Yale reduz a produção de Lasswell sobre comunicação, provavelmente não apenas pela ligação que começa a se desenvolver com outra área de estudo, a das leis, mas por questões de mudança de moradia, adaptação, etc. Então de 1947 a 1950, além de publicar novamente alguns de seus trabalhos, Lasswell também publica relatórios acerca de sua participação no Comitê de Liberdade de Imprensa nesses anos, um trabalho no qual tenta unir o estudo da propaganda e do Direito, intitulado Detection: Propaganda Detection and the Courts (1949), um texto sobre a importância da pesquisa quantitativa, Why be quantitative? (1949) e apenas um artigo que realmente vai ganhar destaque no campo da Comunicação. Trata-se do famosíssimo The Structure and Function of Communicaction in Society (1948).

De fato, The Structure and Function of Communicaction in Society, apesar de poder ser tomado como o grande clássico de Lasswell, se a definição de clássico passasse apenas pela quantidade de citações, traz poucas novidades às teorias desenvolvidas pelo cientista político sobre a comunicação.

O modelo de Lasswell surge mais "limpo" nesse texto, descrito conforme era aplicado na Divisão Experimental, como uma sequência de elementos. Lasswell repete,

232 "[...] our concern is with mass communication, an act of communication in which a great many persons are involved as senders, receivers or both". 
então, o que havia apresentado em Propaganda, Communication and Public Opinion: $a$ Comprehensive Reference Guide, de forma mais esquemática. Ele diz:

Um modo conveniente de descrever um ato de comunicação é responder às seguintes questões:

Quem

Diz o Quê

Por qual Canal

Para Quem

Com Qual Efeito? $?^{233}$

(LASSWELL, 1948, p.216).

Como vimos no primeiro capítulo, o modelo de Lasswell é o assunto mais citado pelos teorógrafos acerca do cientista político, ganhando uma relevância para o campo como organizador e divisor das áreas de pesquisa na Comunicação. Muito criticado, desconsidera-se o benefício da descrição do ato comunicacional como modelo, pois qualquer modelo científico serve à apreciação teórica de um dado objeto e, como tal, pode ser modificado e ajustado para a melhor adequação a determinadas condições. Mesmo diante das críticas de que o modelo de Lasswell não pode ser aplicado ao ambiente de comunicação virtual, essa definição do modelo teórico nos mostra que sim, bastando ajustar as variáveis às condições do fenômeno - bastando considerar que o próprio Lasswell já havia pensado na alternância de papeis entre emissores e receptores.

Mas Lasswell afiança, mais adiante, não ser intenção dele estudar esses elementos de forma isolada, mas utilizá-lo conforme já havia feito na Divisão Experimental: de maneira completa, em relação a todo o processo social. É com esse intuito que ele agrega ao estudo do ato de comunicação as funções do processo comunicacional.

A partir de uma analogia com o mundo biológico não-humano, Lasswell define as seguintes funções para a comunicação: (a) vigilância do ambiente, revelando ameaças e oportunidades que afetam a posição do valor da comunidade e dos componentes dentro dela; (b) correlação dos componentes da sociedade em fazer uma resposta para o ambiente; (c) transmissão da herança social. Todas essas funções colocam a comunicação de massa como essencial na formação da sociedade do século XX. Com esse texto, Lasswell fecha o ciclo de maior proximidade com o campo da Comunicação,

\footnotetext{
233 "Convenient way to describe an act of communication is to answer the following questions: Who

Says What

In Which Channel

To Whom

With What Effect?".
} 
mas mesmo em seu período final conseguimos encontrar obras que fazem com ele ainda seja um teórico a ser escutado.

\subsection{Período final: de 1950 a 1978}

O período final de Lasswell traz uma grande quantidade de obras relacionadas à comunicação, conforme mostra a tabela:

\begin{tabular}{|c|c|c|}
\hline Título & Tipo & Ano \\
\hline "Propaganda and Mass Insecurity" & Artigo & 1950 \\
\hline "The Theory of Political Propaganda" & Artigo & 1950 \\
\hline "The Strategy of Soviet Propaganda" & Artigo & 1951 \\
\hline "Propaganda" & Verbete & 1951 \\
\hline "Key Symbols, Signs and Icons" & Artigo & 1954 \\
\hline Symbols of Internationalism & Livro & 1951 \\
\hline Symbols of Democracy & Artigo & 1952 \\
\hline "Educational Broadcasters as Social Scientists" & Artigo & 1952 \\
\hline The "Prestige Papers": A Survey of Their Editorials & Artigo & 1952 \\
\hline Research in International Communication: An Advisory Report of the Planning Committee & Artigo & 1953 \\
\hline "The Impact of Public Opinion Research On Our Society" & Artigo & 1957 \\
\hline "Communications as an Emerging Discipline" & Artigo & 1958 \\
\hline $\begin{array}{l}\text { Introduction. Road of Propaganda: The Semantics of Biased Communication. By Karin } \\
\text { Dovring. New York: Philosophical Library }\end{array}$ & Introdução & 1959 \\
\hline Foreword. Public Relations and Management & Posfácio & 1960 \\
\hline "Communication and the Mind" & Artigo & 1961 \\
\hline "The Role of Communication Arts and Sciences in University Life" & Artigo & 1965 \\
\hline "Freedom and Responsibility" & Artigo & 1966 \\
\hline "Toward World Community Now" & Artigo & 1968 \\
\hline Introduction (1969): What Next? [New in this edition] & Introdução & 1969 \\
\hline $\begin{array}{l}\text { Political Communication: The Public Language of Political Elites in India and the United } \\
\text { States. }\end{array}$ & Livro & 1969 \\
\hline The Prestige Press: A Comparative Study of Political Symbols & Livro & 1970 \\
\hline "The Continuing Survey and Appraisal of Public Attention" & Artigo & 1971 \\
\hline Introduction. Propaganda Technique in World War I & Introdução & 1971 \\
\hline "Communications Research and Public Policy" & Artigo & 1972 \\
\hline "Future Systems of Identity in the World Community" & Artigo & 1972 \\
\hline The Future of World Communication: Quality and Style of Life & Artigo & 1972 \\
\hline Foreword. 1938. Allied Propaganda and the Collapse af the German Empire in 1918 & Prefácio & 1972 \\
\hline "Research in Policy Analysis: The Intelligence and Appraisal Functions" & Artigo & 1975 \\
\hline "The Future of World Politics and Society" & Artigo & 1975 \\
\hline "Building As Political Communication: The Signature of Power on Environment" & Artigo & 1977 \\
\hline Communication in a divided world: opportunities and constraints & Artigo & 1977 \\
\hline The Signature of Power: Buildings, Communication, and Policy & Livro & 1979 \\
\hline The Symbolic Instrument in Early Tunes & Livro & 1979 \\
\hline "The Future of World Communication and Propaganda" & Artigo & 1980 \\
\hline Emergence of Public Opinion in the West & Livro & 1980 \\
\hline
\end{tabular}

Tabela 17. Obras do período tardio de Harold Lasswell. 
Todavia, apesar da grande quantidade de obras produzidas por Lasswell no que chamamos aqui de período final (nada menos que 33), sua produção é resultado basicamente do status e prestígio adquiridos nos anos anteriores. A maior parte dos escritos desse período é formada por pequenos capítulos, livros organizados pelo cientista político, juntamente com outros autores, prefácios, introduções e artigos. Com a ida para Yale e a sua integração a escola de direito, Lasswell amplia ainda mais sua participação em outras áreas, que não a política (é nesse período, por exemplo, que ele vai receber o título de doutor em Letras) e os trabalhos sobre comunicação, embora sejam constantes, não trazem a formulação de novas ideias conceituais, mas permanecem, sob muitos aspectos, releituras com poucos diferenciais em relação ao que já havia sido estabelecido por ele.

Entretanto, os poucos trabalhos mais originais trazem questões comunicacionais importantes, como a definição da Comunicação como disciplina (Comunication as an Emerging Discipline) e a organização de uma ampla história da propaganda, contemplada tanto em aspectos teóricos quanto históricos (os três volumes de Propaganda and Communication in the World History). São esses dois trabalhos, basicamente, que fazem com que Lasswell, mesmo afastado do campo comunicacional,continue oferecendo importantes contribuições à área. Mesmo assim, suas análises são cada vez mais rápidas e ensaísticas e pouco temos a dizer sobre elas.

Em Propaganda and Communication in the World History, a garnde contribuição de Lasswell não se dá exatamente de uma maneira explícita. Ao organizar a obra, juntamente com Daniel Lerner e Hans Speier, o que Lasswell faz também é constituir os primeiros volumes sobre a história da propaganda, elaborada sob um viés teórico. Apesar das múltiplas visões sobre a propaganda que aparecem na obra, elas são organizadas a partir de um conjunto teórico oriundo da formação de seus autores.

Em segundo lugar, o único artigo de Lasswell presente em Propaganda and Communication in the World History, no terceiro volume, The Future of World Communication and Propaganda, aponta caminhos para investigações futuras sobre a comunicação com os olhos de quem viveu o passado. Apesar de não apresentar nenhum elemento teórico novo, Lasswell prevê uma "rede global de pesquisa" sobre a comunicação, devido, sobretudo, a uma sociedade inflacionada por questões de informação a que só os pesquisadores da comunicação poderiam responder.

Já em Comunication as an Emerging Discipline, Lasswell volta ao ponto da autonomia da área. De uma maneira pouco ortodoxa, Lasswell afirma que 
É conveniente que a parte da comunidade universitária nitidamente preocupada com o conhecimento deva se tornar um centro focal de estudo e inspiração para os estudos que continuam a abrir o novo mundo de conhecimento sobre a comunicação ${ }^{234}$ (LASSWELL, 1958, p.254).

Apesar do pouco dito por Lasswell no período final, acreditamos que esse pouco se soma ao muito produzido por ele no campo da Comunicação e adquire uma dimensão relevante: a dimensão de quem, mesmo que não tenha conseguido atingir plenamente seu objetivo, pensou a propaganda e a comunicação como campos científicos e que, dessa forma, nos ofereceu um pensamento teórico que não pode ser negligenciado.

Resta-nos, agora, refletir sobre as relações entre Lasswell e o campo comunicacional numa dupla via: o que o campo da comunicação diz sobre ele e o que sua obra diz sobre esse campo.

\footnotetext{
234“'It is appropriate that the part of the university community distinctly concerned with enlightenment should become a focal center of study and inspiration to studies that continue to open up the new world of communication knowledge".
} 


\section{CONCLUSÃO: HAROLD LASSWELL E O CAMPO DA COMUNICAÇÃO}

Uma das epígrafes deste trabalho refere-se a Harold Lasswell como uma lenda viva. Defini-lo dessa maneira traz implicações importantes para pensarmos a relação deste pesquisador com o campo da Comunicação. Em geral, uma lenda é caracterizada como uma história que mistura fatos fictícios com acontecimentos reais, no limite entre o pensamento mítico e o pensamento racional. Ao analisarmos a forma como Harold Lasswell foi associado ao campo da Comunicação, encontramos uma visão cujos fundamentos na realidade se ajuntaram à ficção de forma pouco refletida, como nas lendas.

Nos livros de teorógrafos da área de comunicação, Lasswell é apresentado de forma resumida como:

1) O criador do modelo que organizou e repartiu o campo da comunicação em áreas de investigação, o chamado "modelo de Lasswell";

2) Um dos principais estudiosos da propaganda, tendo sido pioneiro nesta área;

3) Um autor adepto ou próximo do modelo de comunicação da teoria hipodérmica, pois suas concepções sobre a propaganda trabalham com a ideia de meios de comunicação super poderosos e de uma audiência passiva;

4) O introdutor do Funcionalismo no campo da Comunicação, ao arrolar as funções da comunicação na sociedade;

5) A análise de conteúdo foi um método desenvolvido por Lasswell para o estudo das comunicações;

6) Um dos fundadores do campo da Comunicação, sendo um de seus primeiros teóricos - e um autor clássico;

7) Pesquisador cuja contribuição essencial para o campo comunicacional é o "modelo de Lasswell" - apesar das falhas desse mesmo modelo.

Por outro lado, nossa leitura da obra lasswelliana não compartilha dessas afirmações e nos permite examinar cada uma dessas colocações sob uma nova luz. De forma pontual, ela nos mostrou que: 
1) O modelo de Lasswell organizou e repartiu o campo da comunicação em áreas de investigação, mas isso não deve ser interpretado como uma fragmentação e desvirtuamento do processo ou do campo da comunicação. A fragmentação não foi o propósito que inspirou a criação do modelo. $\mathrm{Na}$ verdade, ele era utilizado de forma global nos anos em que foi mais aplicado (quando Lasswell estava à frente da Divisão Experimental para o Estudo da Comunicação em Tempos de Guerra). Não podemos esquecer que se trata de uma descrição visando identificar as partes de um processo único, a comunicação;

2) Lasswell foi, de fato, um dos principais estudiosos da propaganda, tendo sido pioneiro nesta área, no que diz respeito a trabalhos científicos acerca do tema. Antes de sua tese de doutorado, Propaganda Technique in the World War, os livros sobre propaganda já eram bastante correntes;

3) Não há muito na obra de Lasswell que facilite sua identificação como um autor adepto do modelo hipodérmico de comunicação. Embora alguns de seus conceitos possam ser alinhados à terminologia ligada à chamada teoria hipodérmica, isso não é suficiente para identificá-lo a ela.;

4) Também não há nada de substancial que justifique identificar Lasswell como o introdutor do Funcionalismo no campo da Comunicação. O simples emprego do termo "funções" aplicado à noção de meios de comunicação não é suficiente para caracterizá-lo como funcionalista. O termo está presente em grande parte dos trabalhos sobre comunicação desde os primeiros livros sobre propaganda, sendo empregado em trabalhos não científicos ou de diferentes escolas;

5) A análise de conteúdo foi o método mais aplicado por Lasswell no estudo das comunicações, mas não se consegue identificar a criação do método por ele. Em momento algum Lassell trata a análise de conteúdo como uma proposta sua, particular;

6) Realmente, Lasswell pode facilmente ser listado como um dos fundadores do campo da Comunicação, sendo um de seus primeiros teóricos, com textos fundadores, pois deixou textos sobre a formação de uma nova disciplina (embora não sejam citados);

7) O "modelo de Lasswell", embora seja o seu mais conhecido trabalho hoje, não pode ser considerado a contribuição essencial de Lasswell para a 
pesquisa em Comunicação. Em seus 76 anos de vida, Lasswell contribuiu para o campo tanto involuntariamente, ao expressar a necessidade de um aparato científico para o estudo da propaganda, em seus primeiros trabalhos, quanto na organização intencional da pesquisa em comunicação nos anos da Divisão Experimental para a Comunicação em Tempos de Guerra. Essa organização não se dá apenas pela utilização do modelo que leva seu nome. Lasswell, ao buscar a construção de uma teoria e de um método de análise das comunicações, forneceu grande parte dos fundamentos científicos da pesquisa em Comunicação, sendo o modelo apenas um item.

$\mathrm{Na}$ verdade, a comparação entre aquilo que dizem os livros de teorias da comunicação e aquilo que diz a obra lasswelliana nos revela, sobretudo, a superficialidade com que muitas vezes o campo trata os autores considerados fundamentais. Muito do que é dito a respeito de Lasswell, nas obras teorográficas, coloca em contradição a relevância que esse autor possui para o campo comunicacional e as críticas muito pouco abalizadas que lhe são feitas: a maior parte delas não resiste à leitura dos originais.

Lasswell não é um autor óbvio e está longe de ser um autor de fácil compreensão. Como testemunha direta da história, sua visão não poderia ser a mais acurada. Ele viveu a novidade da comunicação em larga escala, como um estudioso que estava no olho do furacão, mas isso não o impediu de reconhecer a importância do fenômeno que se delineava e, sobretudo, de perseguir um ponto de vista privilegiado para os estudos que se iniciavam.

Contemporâneo de uma série de cientistas políticos, sociólogos e psicólogos definidores dessas ciências, Lasswell consegue, de maneira muito eficaz, utilizar as teorias sociais como o grande auxílio em suas primeiras pesquisas. Esse fato é relevante por inserir um componente histórico em seus primeiros trabalhos - ainda que Lasswell às vezes assuma uma perspectiva trans-histórica sobre a comunicação e a propaganda. Nos estudos elaborados pelo cientista político, nunca se perde de vista a particularidade da comunicação que se dá a partir da multiplicação do público e das formas de se comunicar, que se difundem após a Revolução Industrial. Portanto, assim como a Psicologia, a Ciência Política e a Sociologia, os estudos em Comunicação surgem para Lasswell como decorrentes da configuração social implantada pela sociedade industrial. O grande problema que se coloca é a da comunicação desnaturalizada, centrada na 
técnica, e que passa a ser um dos componentes organizadores dos fenômenos sociais, como, por exemplo, a guerra. Essa base teórica mostra que o campo da Comunicação, antes mesmo de se consolidar, não se estrutura de modo aleatório, mas se constrói alinhado às ciências sociais. E, sendo assim, não nasce apenas pela pressão social de dar respostas sobre a comunicação de massa, mas tem um compromisso maior com a compreensão do homem e suas formas de se comunicar, a partir do século XIX.

Outro ponto importante é que, como pioneiro desse campo, Lasswell elabora suas próprias teorias sobre o fenômeno que mais lhe interessa (a propaganda) e, como consequiência dessa elaboração, vai delimitando um objeto de estudo para o campo em formação. Ao ser convocado para o Seminário Rockefeller e fazer a transição para o termo comunicação, a propaganda deixa de ser objeto da Ciência Política e passa a ser o objeto do novo campo. Mas, ao agrupar, sob o trabalho da Divisão Experimental para a Comunicação em Tempos de Guerra, as diversas vertentes que pensavam a comunicação social na época, na figura de seus pesquisadores, Lasswell abriu o campo para o estudo da Comunicação de Massa, o que já era sua característica, mesmo com considerando a dispersão em que se encontrava.

O modelo de Lasswell, que surge nessa época, não pode ser considerado uma contribuição maior e estanque, estando relacionado apenas à organização e classificação das pesquisas em Comunicação, por áreas. Na verdade, o modelo é fruto do amadurecimento teórico e metodológico que Lasswell conseguiu por, desde o início, ter perquirido qual seria a forma mais científica de se estudar a propaganda.

Não foi nosso objetivo aqui tratar a validade de suas idéias. O que nos intrigou ao longo de toda a pesquisa, foi o fato de Lasswell ter tentando construir para a propaganda e para a comunicação, uma teoria. E, no final das contas, propor um campo científico chamado Comunicação. Essa idéia, sim, está na origem do trabalho do cientista político. E não se resume a uma possível filiação à teoria hipodérmica ou sua redução ao modelo de Lasswell.

Em suma, se o campo da Comunicação o cita como autor fundamental, também o desconhece. A expressão "ilustre desconhecido" cai como uma luva para expressar esta situação paradoxal de Lasswell em relação ao campo da Comunicação. Temos aí um problema de proporções que não podem ser ignoradas. Como estabecer a história de um campo de conhecimento se valendo de lendas ou de afirmações pouco alicerçadas? 
Assim como Lasswell afirmou na introdução da sua tese de doutorado, consideramos que este estudo que ora apresentamos ainda vai sofrer muitas alterações ao longo dos anos que dedicaremos ao estudo desse pesquisador. Este é só um dos passos a serem dados para que, de fato, conheçamos os autores que o campo da Comunicação identifica como relevantes. 


\section{REFERÊNCIAS}

ABBAGNANO, Nicola. Dicionário de Filosofia. São Paulo: Martins Fontes, 2003.

ALEXANDER, Jeffrey. "The Centrality of the Classics". In Social Theory Today. GIDDENS, Anthony; TURNER, Jonathan (Orgs.). California: Stanford University Press, 1993, pp.11-53.

ALMOND, Gabriel A. Harold Dwight Lasswell (1902-1978): A Biographical Memoir. Londres: National Academy Press, 1987.

ALMOND, Gabriel. "Charles Edward Merriam". In: SHILS, Edward (Org.). Remenbering the University of Chicago. Chicago: University of Chicago Press, 1991.

ALSINA, Rodrigo Miquel. Teorías de la Comunicación: Ámbitos, Métodos y Perspectivas. Barcelona: Universitat Autònoma de Barcelona, 2001. 236 p.

ANDERSON, James Arthur. Communication Theory: Epistemological Foundations. Nova York: Guilford Press, 1996. 259 p.

ARAÚJO, Carlos Alberto (2001). “A Pesquisa Norte-americana”. In: HOHLFELDT, Antonio; MARTINO, Luiz C.; FRANÇA, Vera Veiga (org.). Teorias da Comunicação: Conceitos, Escolas e Tendências. Petrópolis: Vozes, pp. 119-130.

BACHELARD, G. A Noção do Obstáculo Epistemológico. In: A Formação do Espírito Científico. RJ: Contraponto, 1996. p. 17-28.

BAEHR, Peter. Founders, Classics, Canons. Nova Jersey: Transaction Publishers, 2002.

BAKER, Newton. "Foreword" in: CREEL, George. How We Advertised America. Nova York: Harper and Brothers, 1920.

BARAN, Stanley J.; DAVIS, Dennis K.. Mass Communication Theory: Foundations, Ferment, and Future. Satmford: Cengage Learning, 2011. 392 p.

BARDIN, Laurence. Análise de Conteúdo. Lisboa: Editora 70, 1979.

BARLOW, David M. \& MILLS, Brett. Reading Media theory: thinkers, approaches and contexts. Nova York: Longman Publishers, 2008.

BAUER, Martin W.. A Análise de Conteúdo Clássica: uma revisão in: BAUER, Martin W.. \& GASKELL, George. Pesquisa Qualitativa com Texto, Imagem e Som: um Manual Prático. Petropólis: Vozes, 2004.

BAUMAN, Zygmunt. Vidas Desperdiçadas. Rio de Janeiro: Jorge Zahar Editor, 2005.

BELLO, Edison Otero (Org.). Teorías de la comunicación (textos). Santiago do Chile: Editorial Universitaria, 1997. 245 p.

BELTRÃO, Luiz. Subsídios Para Uma Teoria da Comunicação de Massa. São Paulo: Summus, 1986. 
BERELSON, Bernard. Content Analysis in Communication Research. Nova York: Hafner, 1971.

BERELSON, Bernard. "The State of Communication Research". In: Public Opinion Quarterly. Nova York: Free Press, 1959, pp. 1-5.

BERELSON, Bernard et al. Voting: A Study of Opinion Formation in a Presidential Campaign. Chicago: University of Chicago Press, 1986.

BERGER, Arthur Asa. Media and Communication Research Methods: an Introduction to Qualitative and Quantitative Approaches. Thousand Oaks: Sage, 2010. 341 p.

BERGER, Arthur Asa. The Mass Comm Murders: Five Media Theorists Self-destruct. Lanham: Rowman \& Littlefield, 2002. 146 p.

BETTI, Gianni \& LEMMI, Achille. Advances on Income Inequality and Concentration Measures. Nova York: Taylor and Francis, 2008.

BINEHAM, Jeffrey L. "A Historical Account of the Hypodermic Model in Mass Communication". In: Communication Monographs, 55 (1988): 230-46.

BLUEMENSTOCK, Dorothy \&LASSWELL, Harold. "The Technique of Slogans in Communist Propaganda" in: Psychiatry 1, 1938.

BLUMENSTOCK, Dorothy \& LASSWELL, Harold. "The Volume of Communist Propaganda in Chicago" in: Public Opinion Quarterly 3, 1939.

BLUEMENSTOCK, Dorothy \& LASSWELL, Harold. World Revolutionary Propaganda: A Chicago Study. Nova York: Alfred A. Knopf, 1939.

BONI, Federico. Teorías de los Medios de Comunicación. Barcelona: Universitat Autònoma de Barcelon, 2008.

BOUGNOUX, Daniel. Introdução às Ciências da Informação e da Comunicação. Bauru: Edusc, 1999.

BOUNDS, Philip \& JAGMOHAN, Mala. Recharting Media Studies: Essays on Neglected Media Critics. Nova York: Peter Lang, 2008.

BOURDIEU, Pierre. A Ilusão Biográfica. In: AMADO, Janaína e FERREIRA, Marieta de Moraes. Usos e Abusos da História Oral: Rio de Janeiro: Editora FGV, 2005, p. 183-191.

BRADDOCK, Richard. “An Extension of Lasswell's Formula”. Malden: Journal of Communication, vol.8, p.88-93.

BRECHT, Bertolt. A Vida de Galileu. São Paulo: Abril, 1977.

BULMER, Martin (1986). The Chicago School of Sociology. Chicago: University of Chicago Press.

BUXTON, William. The Emergence of Communication Study - Psychological Warfare or Scientific Thoroughfare? In: Canadian Journal of Communication. Vancouver: Canadian Centre for Studies in Publishing, 1996, nº 4, pp. 204-216. 
CALVINO, Italo. Por Que Ler os Clássicos. São Paulo: Companhia das Letras, 2007.

CAMBRÓN, Alfons Medina \& JANÉ, Josep Sort. La Recerca en Comunicació. Què hem de saber? Quins passos hem de seguir?. Barcelona: Editorial UOC, 2006. 206 p.

CAMIC, Charles. Reclaiming the Sociological Classics: The State of the Scholarship. Boston: Blackwell Publishing, 1997.

CAREY, James. The Chicago School and the Mass Communication Research. In: CHAFFEE, Steven H. "Differentiating the Hypodermic Model From Empirical Research: A Comment on Bineham's Commentaries." Communication Monographs, 55 (1988): 247-49.

CASEY, Ralph D.; LASSWELL, Harold \& SMITH, Bruce Lannes. "Describing the Contents of Communications" in: Propaganda, Communication, and Public Opinion: A Comprehensive Reference Guide. Nova Jersey: Princeton University Press, 1946.

CASEY, Ralph D.; LASSWELL, Harold \& SMITH, Bruce Lannes. "Describing the Effects of Communications" in: Propaganda, Communication, and Public Opinion: A Comprehensive Reference Guide. Nova Jersey: Princeton University Press, 1946.

CASEY, Ralph D.; LASSWELL, Harold \& SMITH, Bruce Lannes. Propaganda and Promotional Activities: an Annotated Bibliography. Minneapolis: University of Minnesota Press, 1935.

CASEY, Ralph D.; LASSWELL, Harold \& SMITH, Bruce Lannes. Propaganda, Communication, and Public Opinion: A Comprehensive Reference Guide. Nova Jersey: Princeton University Press, 1946.

CASMIR, Fred L.. Building Communication Theories: a Socio/Cultural Approach. Mahwah: Lawrence Earlbaum Assosicates, 1994.

CHAFFEE, Steven H.; ROGERS, Everett M. The Stablishment of Communication Study in America. In: SCHRAMM, Wilbur. The Beginnings of Communication Study in America: A Personal Memoir. Thousand Oaks: Sage Publications, 1997.

CHAFFEE, Steven H. "Differentiating the Hypodermic Model From Empirical Research: A Comment on Bineham's Commentaries." Communication Monographs 55 (1988): 24749.

CHRISTIANS, Clifford G.; GLASSER, Theodore \& MCQUAIL, Denis. Normative Theories of the Media: Journalism in Democratic Societies. Champaign: University Of Illinois Press, 2009.

COHN, Gabriel. Para Ler os Clássicos. São Paulo: Azougue, 2006.

COMSTOCK, George A.; SCHARRER, Erica. The Psychology of Media and Politics. Saint Louis: Academic Press, 2005.

CORSON, David; HEATH, Robert Lawrence \& BRYANT, Jennings. Human Communication Theory and Research: Concepts, Contexts, and Challenges. Mahwah: Routledge, 2000. 
CRAIG, Robert T. \& MULLER, Heidi L.. Theorizing Communication: Readings Across Traditions. Thousand Oaks: Sage, 2007.

CREEL, George. How We Advertised America. Nova York: Harper and Brothers, 1920.

CROWLEY, David J.; MITCHELL, David \& MITCHELL, David. Communication Theory Today. Stanford: Stanford University Press, 1994.

CULL, Nicholas John; CULBERT, David Holbrook \& WELCH, David. Propaganda and Mass Persuasion: A Historical Encyclopedia, 1500 to the Present. Santa Bárbara: ABC-Clio, 2003.

CULLEN, Katherine E. Encyclopedia of Life Science. Vol.1. Nova York: Infobase, 2009.

DANCE, Frank E. X.. Human Communication Theory: Comparative Essays. Nova York: Harper \& Row, 1982.

DAVIS, Dennis K. \& BARAN, Stanley J.. Mass Communication and Everyday Life: a Perspective on Theory and Effects. Florence: Wadsworth Pub. Co, 1981.

DAVISON, Walter Phillips \&YU, Frederick T. C.. Mass Communication Research: Major Issues and Future Directions. Westport: Praeger, 1974.

DEFLEUR, Melvin \& BALL-ROKEACH, Sandra. Teorias da Comunicação de Massa. Rio de Janeiro: Jorge Zahar, 1993.

DEFLEUR, Melvin Lawrence \& BALL-ROKEACH, Sandra. Theories of Mass Communication. Nova York: Longman Publishers, 1989.

DELANTY, Gerard. Handbook of Contemporary European Social Theory. Nova York: Routledge, 2006.

DENNIS, Everett E. \& WARTELLA, Ellen . American Communication Research: The Remembered History. Mahwah: Lawrence Erlbaum Associates, 1996.

DOMINGUES, Ivan. O Grau Zero do Conhecimento: o Problema da Fundação e da Fundamentação das Ciências Humanas. São Paulo: Edições Loyola, 1991.

DOOB, Leonard. A Natureza da Propaganda. In: STEINBERG, Charles S. Meios de Comunicação de Massa. São Paulo: Cultrix, 1970. p. 483-503.

DURKHEIM, Émile. Pragmatismo e Sociologia. Santa Catarina: Editora UFSC, 2004.

FAUSTO NETO. A. PORTO. S.D.: Aidar Prado, J.L. (eds.). Campo da Comunicação: Caracterização, Problematização e Perspectivas. João Pessoa: Editora Universitária/UFPB, 2001.

FARR, James; HACKER, Jacob S. \& KAZEE, Nicole. "The Policy Scientist of Democracy: The Discipline of Harold Lasswell" in: American Political Science Review, 2006, p. 579-587.

FERREIRA, Ana C. Borges; VARÃO, Rafiza ; NUNES, Poliana. O Esclarecimento na Dialética de Adorno e Horkheimer: A Presença de Kant no Clássico Frankfurtiano. 
In: XXXI INTERCOM - Congresso Brasileiro de Ciências da Comunicação, 2008, Natal. Anais do XXXI Congresso Brasileiro de Ciências da Comunicação, 2008.

FERREIRA, Giovandro Marcus; HOHLFELDT, Antonio; MARTINO, Luiz C. \& MORAIS, Osvando J. Teorias da Comunicacao: Trajetórias Investigativas. Porto Alegre: EDIPUCRS, 2010.

FERRO, Marc. La Biographie: Cette Handicapée del Histoire. Magazine Littéraire, Paris, n. 264, p.185-186, abr. 1987.

FOUCAULT, Michel.. O Que é um Autor? Lisboa: Nova Vega, 1992.

FOUREZ, Gérard. A Construção das Ciências. Lisboa: Instituto Piaget, 2002.

FOURIE, Pieter J.. Media Studies: Media History, Media and Society. Cidade do Cabo: Juta And Company, 2010.

FRENETTE, Micheline. La Recherche en Communication: Un Atout Pour les Campagnes Sociales. Quebec: Presses de l'Université du Québec , 2010.

GELLER, A.; KAPLAN, D. \& LASSWELL, Harold. "An Experimental Comparison of Four Ways of Coding Editorial Content" in: Journalism Quarterly 19, 1942.

GELLIUS, Aullus. Attic Nights. Roman texts. http: //Penelope.uchicago.edu/Thayer/L/Roman/Texts/Gellius/19.html. Acessado em 10/02/2009.

GIDDENS, Anthony; TURNER, Jonathan (Orgs.). "Of What Use are the 'Classics'?". In: Social Theory Today. GIDDENS, Anthony; TURNER, Jonathan (Orgs.). California: Stanford University Press, 1993.

GLANDER, Timothy Richard. Origins of Mass Communications Research During the American Cold War. Mahwah: Taylor and Francis, 2000.

GOMES, Itania Maria Mota. Efeito e Recepção: a Interpretação do Processo Receptivo em Duas Tradições de Investigação Sobre os Media. Rio de Janeiro: E-papers Serviços Editoriais, 2004.

GRIFFIN, Em. A First Look at Communication Theory. Nova York: Mcgraw-hill, 1991.

HAMELINK, Cees J.; LINNÉ, Olga. Mass Communication Research on Problems and Policies: the Art of Asking the Right Questions. Norwood: Greenwood Publishing Group, 1994.

HANKINS, Thomas L.. In defence of Biography: the Use of Biography in the History of Science. Dispinível em: http://adsabs.harvard.edu/abs/1979HisSc..17....1H. Acesso em 15 de julho de 2010.

HARDT, Hanno. Critical Communication Studies: Communication, History, and Theory in America. Thousand Oaks: Routledge, 1992.

HARDT, Hanno. "Introduction: Communication and the Question of History". In: Communication Theory. Montreal: University de Montreal, 2002, n.29, pp.130-136. 
HEANEY, Michael T.; HANSEN, John Mark. "Building the Chicago School". American Political Science Review. Novembro, 2006.

HEANEY, Michael T.. “The Chicago School That Never Was”. Political Science and Politics. Outubro, 2007.

HEINDERYCKX, , François. Une Introduction aux Fondements Théoriques de l'Étude des Médias. Liege: Éditions du CÉFAL, 2002.

HOHLFELDT, Antonio; MARTINO, Luiz C.; FRANÇA, Vera Veiga. (orgs.). Teorias da Comunicação. Petrópolis: Editora Vozes, 2001.

HOLMES, David. Communication Theory: Media, Technology and Society. Michigan: Pearson Longman. 2009.

HOLT, Jennifer \& PERREN, Alisa. Media Industries: History, Theory, and Method. Hoboken: John Wiley \& Sons, 2011.

INFANTE, Dominic A.; RANCER, Andrew S. \& WOMACK, Deanna F.. Building Communication Theory. Long Gorve: Waveland Press, 2003.

JENKINS, Keith. A História Repensada. São Paulo: Contexto, 2001.

JENSEN, Klaus Bruhn. A Handbook of Media and Communication Research: Qualitative and Quantitative Methodologies. New Featter Lane: Routledge, 2002.

KAID, Lynda Lee. Handbook of Political Communication Research. Mahwah: Routledge, 2004.

KANT, Immanuel. Resposta à Pergunta: Que é Esclarecimento? In: KANT, Immanuel. Textos Seletos, Edição Bilíngüe. Trad. Floriano de Sousa Fernandes. Petrópolis: Vozes, 1974.

KATZ, Elihu. "A Propôs des Médias et de Leurs Effets", in SFEZ, L. (org.) Technologies et Symboliques de la Communication. Colloque de Ceresy 1988 Press Universitaire de Grenoble, 1990, p.275-282 (tradução para o português de L.C. Martino, mecanografado, Brasília, 1999).

KATZ, Elihu. Canonic Texts in Media Research: Are There Any? Should There Be? How About These?. Cambridge: Wiley-blackwell, 2003.

KATZ, Elihu \& LAZARSFELD, Paul. Personal Influence. Nova Iorque: Free Press, 1955.

KATZ, Elihu. Social Research on Broadcasting: Proposals for Further Development. Londres: BBC, 1977.

KEMPLE, Thomas M. "Founders, Classics, Canons in the Formation of Social Theory" in

KOYRÉ, Alexandre. Do Mundo Fechado ao Universo Infinito. Rio de Janeiro: ForenseUniversitária, 1979.

KOYRÉ, Alexandre. Estudos de História do Pensamento Científico. Rio de Janeiro: Forense-Universitária, 1982. 
KRAGH, Helge. Introducción a la Historia de la Ciencia. Barcelona: Crítica, 2007.

LANG, Kurt. The European Roots. In: DENNIS, Everett E. e WARTELLA, Ellen. American Communication Research: The Remembered History. Mahwah: Lawrence Erlbaum Associates, 1996, pp. 1-20.

LASSWELL, Harold. Propaganda Techniques in World War. Nova Iorque: Peter Smith, 1938.

LASSWELL, Harold. Introduction. In: Propaganda Techniques in World War. Massachussets: MIT Press, 1971.

LASSWELL, Harold. "The Theory of Political Propaganda" in American Political Science Review, vol 21. Chicago: University of Chicago Press, 1927.

LASSWELL, Harold. "The Function of the Propagandist" in International Journal of Ethics, vol 38. Chicago: University of Chicago Press, 1928.

LASSWELL, Harold. "The structure and function of communications in society". In: The communications of ideas. Bryson (org.). Nova Iorque: Editora Harper, 1948.

LASSWELL, Harold. "The Status of Research on International Propaganda and Opinion" in Papers and Proceedings of the American Sociological Society, V 20. Chicago: University of Chicago Press, 1925.

LASSWELL, Harold. "The Strategy of Revolutionary and War Propaganda" in WRIGHT, Quincy. Public Opinion and World-Politics. Chicago: University of Chicago Press, 1933.

LASSWELL, Harold. "Propaganda" in: Encyclopaedia of the Social Sciences. 1st ed, 1934.

LASSWELL, Harold. "The Person: Subject and Object of Propaganda". CHILDS, Harwood L. (org.). Pressure Groups and Propaganda. Annals ofthe American Academy of Political and Social Science 179. Chicago: University of Chicago Press, 1935.

LASSWELL, Harold. "The Scope of Research on Propaganda and Dictatorship" in: CHILDS, Harwood L. (org.). Propaganda and Dictatorship: A Collection of Papers. Nova Jersey: Princeton University Press, 1936.

LASSWELL, Harold. "Propaganda and the Channels of Communication" in: ELLIS, Elmer (org.). Education against Propaganda: Developing Skill in the Use of the Sources of Information about Public Affairs. Cambridge: National Council for the Social Studies, 1937.

LASSWELL, Harold. "Propaganda in a Planned Society" in: MACKENZIE, Findlay (org.). Planned Society: Yesterday, Today, Tomorrow: A Symposium by Thirty-five Economists, Sociologists, and Statesmen. Nova Iorque: Prentice-Hall, 1937.

LASSWELL, Harold. "The Propaganda Technique of the Pamphlet on Continental Security" in: Psychiatry 1. 1938. 
LASSWELL, Harold. "The Propaganda Technique of Recent Proposals for the Foreign Policy of the U.S.A." [Materials for the Study of Propaganda, No.2.] Psychiatry 2, 1939.

LASSWELL, Harold. "The Propagandist Bids for Power" in: American Scholar 8, 1939.

LASSWELL, Harold. "Radio as an Instrument of Reducing Personal Insecurity." Studies in Philosophy and Social Science 9, 1941.

LASSWELL, Harold. "The Communications Front: Strategies of Political and Moral Warfare." Vital Speeches of the Day 8, 1942.

LASSWELL, Harold. "Communications Research and Politics" in: WAPLES, Douglas. Print, Radio, and Film in a Democracy. Chicago: University of Chicago Press, 1942.

LASSWELL, Harold. The Politically Significant Content of the Press: Coding Procedures" in: Journalism Quarterly 19, 1942.

LASSWELL, Harold. Public Opinion in War and Peace: How Americans Make Up Their Minds in: CUMMINGS, Howard H.. Problems in American Life. Washington: Departments of the National Education Association, 1942.

LASSWELL, Harold. "New Rivals of the Press: Film and Radio" in: BUTLER, Pierce. Books and Libraries in Wartime. Chicago: University of Chicago Press, 1945.

LASSWELL, Harold. "The Science of Communication and the Function of Libraries." College and Research Libraries 6, 1945.

LASSWELL, Harold. "Freedom of the Press: A Summary Statement of Principle' in: THE COMISSION ON FREEDOM OF THE PRESS: A Free and Responsible Press: A General Report on Mass Communication: Newspapers, Radio, Motion Pictures, Magazines, and Books. Chicago: University of Chicago Press, 1947.

LASSWELL, Harold. "The Structure and Function of Communication in Society" in: BRYSON, Lyman. The Communication of ideas. Nova Iorque: Institute for Religious and Social Studies, 1948.

LASSWELL, Harold. "The Rise of the Propagandist" ("The Propagandist Bids for Power"). The Analysis of Political Behaviour: An Empirical Approach. New York: Oxford University Press, 1948.

LASSWELL, Harold. "Detection: Propaganda Detection and the Courts" in: LASSWELL, Harold \& LEITE, Nathan. Language of Politics: Studies in Quantitative Semantics. Nova Iorque: George Stewart, 1949.

LASSWELL, Harold. "Why Be Quantitative?" in: LASSWELL, Harold \& LEITE, Nathan. Language of Politics,' Studies in Quantitative Semantics. Nova Iorque: George Stewart, 1949.

LASSWELL, Harold \& LEITE, Nathan. Language of Politics: Studies in Quantitative Semantics. Nova Iorque: George Stewart, 1949.

LASSWELL, Harold. "Propaganda and Mass Insecurity." Psychiatry 13, 1950. 
LASSWELL, Harold. "The Strategy of Soviet Propaganda." Proceedings of the Academy of Political Science 24, 1951.

LASSWELL, Harold. "Propaganda".Encyclopaedia Britannica, 1951.

LASSWELL, Harold. "Key Symbols, Signs and Icons" in: BRYSON, Lyman; FINKELSTEIN, Louis \& MCKEON, R. M. MacIver. Symbols and Values: An Initial Study: Thirteenth Symposium of the Conference on Science, Philosophy and Religion. Nova Iorque: Harper, 1954.

LASSWELL, Harold. Symbols of Democracy. Stanford: The Hoover Institute and Library on War, Revolution, and Peace at Stanford University and Stanford University Press, 1954.

LASSWELL, Harold. "Educational Broadcasters as Social Scientists" Quarterly of Film, Radio, and Television 7.2, 1954.

LASSWELL, Harold. The "Prestige Papers": A Survey of Their Editorials. Stanford: The Hoover Institute and Library on War, Revolution, and Peace at Stanford University and Stanford University Press, 1954.

LASSWELL, Harold. Research in International Communication: An Advisory Report of the Planning Committee. Stanford: The Hoover Institute and Library on War, Revolution, and Peace at Stanford University and Stanford University Press, 1954.

LASSWELL, Harold. "The Impact of Public Opinion Research On Our Society." Public Opinion Quarterly 21, 1957.

LASSWELL, Harold. "Communications as an Emerging Discipline." Audio-Visual Communication Review ,6, p.245-254., 1958.

LASSWELL, Harold. Introduction in: DOVRING, Karin Road of Propaganda: The Semantics of Biased Communication. Nova Iorque: Philosophical Library, 1959.

LASSWELL, Harold. Foreword in: FINN, David. Public Relations and Management. Nova Iorque: Reinhold Publishing, 1960.

LASSWELL, Harold. "Communication and the Mind" in: FARBER, Seymour M \& WILSON, Roger H. L. Control of the Mind. Nova Iorque: McGraw-Hill, 1961.

LASSWELL, Harold. "The Role of Communication Arts and Sciences in University Life." A V Communication Review 13, 1965

LASSWELL, Harold. "Freedom and Responsibility" in: DONNER, Stanley T. The Future of Commercial Television: 1965/1975. Stanford: Stanford University, Broadcasting and Film Division, 1966.

LASSWELL, Harold. "Toward World Community Now" in: NG., Larry. Alternatives to Violence: A Stimulus to Dialogue. Nova Iorque:Time-Life Books, 1968.

LASSWELL, Harold. Introduction: What Next? In: CASEY, Ralph D.; LASSWELL, Harold \& SMITH, Bruce Lannes. Propaganda and Promotiona lActivities: An Annotated Bibliography. Chicago: University of Chicago Press, 1969. 
LASSWELL, Harold. Political Communication: The Public Language of Political Elites in India and the United States. Nova Iorque: Holt, Rinehart and Winston, 1969.

LASSWELL, Harold. "Introduction" in: LASSWELL, Harold. Propaganda Technique in World War I. By Harold D. Lasswell. Cambridge: MIT Press, 1971.

LASSWELL, Harold. Politics: Who Gets What, When, How. Nova Iorque: The World Publishing Company, 1971.

LASSWELL, Harold. "Communications Research and Public Policy" in: Public Opinion Quarterly, 36, 1972.

LASSWELL, Harold. "Future Systems of Identity in the World Community" in: BLACK, Cyril \& FALK, Richard A. The Structure of the International Environment.Nova Jersey: Princeton University Press, 1972.

LASSWELL, Harold. The Future of World Communication: Quality and Style of Life. Honolulu: University of Hawaii, 1972.

LASSWELL, Harold. "Foreword" in: BUNTZ, George. Allied Propaganda and the Collapse af the German Empire in 1918. Nova Iorque: Arno Press, 1972.

LASSWELL, Harold. "Research in Policy Analysis: The Intelligence and Appraisal Functions" in: GREENSTEIN, Fred I. \& POLSBY, Nelson W. The Handbook of Reading: AddisonWesley, 1975.

LASSWELL, Harold. "The Future of World Politics and Society" in: SCHRAMM,. Wilbur \& LERNER, Daniel. Communication and Change: The Last Ten Years -and the Next. Honolulu: University Press of Hawaii, 1975.

LASSWELL, Harold. "Building As Political Communication: The Signature of Power on Environment" in: LERNER, Daniel \& NELSON, Lyle M. Communication Research -A Half-century Appraisal. Honolulu: University Press of Hawaii for the East-West Center, 1977.

LASSWELL, Harold. Communication in a divided world: opportunities and constraints. Lonres: International Institute of Communications, 1977.

LASSWELL, Harold. The Signature of Power: Buildings, Communication, and Policy. New Brunswick: Transaction Books, 1979.

LASSWELL, Harold. "The Symbolic Instrument in Early Times” in: LASSWEll, Harold; LERNER, Daniel \& SPEIER, Hans. Propaganda and Communication in World History. Vol 1. Honolulu: University Press of Hawaii for the East-West Center, 1979.

LASSWELL, Harold. "The Future of World Communication and Propaganda" in: : LASSWEll, Harold; LERNER, Daniel \& SPEIER, Hans. Propaganda and Communication in World History. Vol 1. Honolulu: University Press of Hawaii for the East-West Center, 1980.

LASSWELL, Harold. Emergence of Public Opinion in the West. In: : LASSWEll, Harold; LERNER, Daniel \& SPEIER, Hans. Propaganda and Communication in 
World History. Vol 1. Honolulu: University Press of Hawaii for the East-West Center, 1980.

LERDERBERG, Joshua. Introduction: Reflections on Scientific Biography. In:

KAUFMAN, William. The Excitement and Fascination of Science: Reflections. Vol. 3 Palo Alto: Annual Reviews Inc, 1990, p.31-37. Disponível em: <http://profiles.nlm.nih.gov/ps/retrieve/Narrative/BB/p-nid/29/p-docs/true $>$. Acesso em: 31 out. 2011.

LERNER, Daniel; NELSON, Lyle M. \& SCHRAMM, Wilbur Lang. Communication Research: a Half-century Appraisal. Havaí: University Press of Hawaii, 1977.

LIPPMANN, Walter. Public Opinion. New Bruswick: Transaction Publishers, 2007.

LITTLEJOHN, Stephen W. \& FOSS, Karen A.. Encyclopedia of Communication Theory. Thousand Oaks: Sage, 2009. 1 v.

LITTLEJOHN, Stephen W. \& FOSS, Karen A.. Theories of Human Communication. Stamford: Cengage Learning, 2007.

LAVILLE, Christian; DIONNE, Jean. A Construção do Saber: Manual de Metodologia da Pesquisa em Ciências Humanas. Belo Horizonte: Ed. UFMG, 1999.

MARSEN, Sky. Communication Studies. Nova Iorque: Palgrave Macmillan, 2006.

MARTINO, Luiz C. Abordagens e Representação do Campo Comunicacional. Comunicação, Mídia e Consumo (São Paulo), v. 3, p. 33-54, 2006.

MARTINO, L. C. "Cepticismo e Inteligibilidade do Saber Comunicacional". In: Galáxia, Revista do PPG PUC-SP Em Comunicação e Semiótica, São Paulo, v. 5, p. 53-67, 2003.

MARTINO, Luiz C. "Contribuições para o Estudo dos Meios de Comunicação". In: Revista Famecos. Porto Alegre: PUC-RS, 2000, n. 13, pp. 103-114.

MARTINO, L. C. Elementos para uma Epistemologia da Comunicação. In: FAUSTO NETO, A. ; PORTO, S; PRADO, A. Campo da Comunicação: caracterização, problematização e perspectivas. João Pessoa: Editora da UFPB, pp. 51-75, 2001.

MARTINO, L. C. "História e Identidade: Apontamentos Epistemológicos Sobre a Fundação e Fundamentação do Campo Comunicacional”. In: E-COMPÓS, www.compos.org.br, v. 1, p. 1-22, 2004.

MARTINO, Luiz C. Teorias da Comunicação: Muitas ou Poucas? Cotia: Ateliê Editorial, 2007.

MARTINO, Luís Mauro de. Teoria da Comunicação. Petropólis: Vozes, 2009.

MATTELART, Armand e MATTELART, Michèle. História das teorias da comunicação. São Paulo: Edições Loyola, 1994.

MATTELART, Armand; MATTELART, Michèle. Theories of Communication: a Short Introduction. Thousand Oaks: Sage, 1998. 
MCQUAIL, Denis \& WINDAHL, Swen. Communication Models for the Study of Mass Communications. Nova Iorque: Longman Publishers, 1993.

MCQUAIL, Denis. McQuail's Reader in Mass Communication Theory. Thousand Oaks: Sage, 2008.

MEAD, George H.. "A Behavioristic Account of The Significant Symbol” in: The Journal of Philosophy, v.19, 1922.

MEINGAST, Stefan. Die Lasswell-Formel: Ursprung und Bedeutung. Munique: Grin Verlag, 2007.

MELO, José Marques de. História do Pensamento Comunicacional. São Paulo: Paulus, 2003.

MELO, José Marques de. Teoria da Comunicação - Paradigmas Latino-Americanos. Petrópolis: Vozes, 1998.

MELO, José Marques de. Teoria e Pesquisa em Comunicação: Panorama Latinoamericano. São Paulo: Cortez, 1983.

MERRIAM, Charles. American Publicity in Italy. In: The American Political Science Review, Vol. 13, No. 4, (Nov., 1919), pp. 541-555

MERTON, Robert King. On the Shoulder of Giants. Chicago: University of Chicago Press, 1993.

MERTON, Robert. "The Uses and Abuses of Classical Theory". In: On social structure and science. MERTON, Robert King; SZTOMPKA, Piotr. Chicago: University of Chicago Press, 1997.

MEUNIER, Jean-Pierre \& PÉRAYA, Daniel. Introduction Aux Théories de la Communication: Analyse Semio-Pragmatique de la Communication Médiatique. Bruxelas: De Boeck, 2004.

MIEGE, Bernard. O Pensamento Comunicacional. Petrópolis: Editora Vozes, 2002.

MORTENSEN, C. David. Foundations of Communication Theory. Nova Iorque: Harper \& Row, 1970.

NARULA, Uma. Communication Models. Nova Deli: Atlantic, 2006.

ORTIZ, Renato. “Durkheim: Arquiteto e Herói Fundador”. Revista Brasileira de Ciências Sociais.

http://www.anpocs.org.br/portal/publicacoes/rbcs_00_11/rbcs11_01.htm. Acessado em 25/01/2009.

PARK, David W. \& POOLEY, Jefferson. The History of Media and Communication research: contested memories. Nova Iorque: Peter Lang, 2008.

MARTINO, Luiz C. \& PAVARINO, Rosana. Publicidade: Cenários da Emergência de um Fenômeno. In: XXXIII Congresso Brasileiro de Ciências da Comunicação, 2010, Caxias do Sul. Anais do XXXIII Congresso Brasileiro de Ciências da Comunicação. São Paulo: Intercom, 2010. 
PAVLOV, Ivan Petrovitch. Obras Escolhidas. São Paulo: Hemus, 1970.

PAVLOV, Ivan Petrovitch \& SKINNER, B. F. (1984). Textos Escolhidos. São Paulo: Abril Cultural.

PERRY, David K.. Theory and Research in Mass Communication: contexts and consequences. Mahwah: Routledge, 2002.

PETERS, John Durham; SIMONSON, Peter (2004). Mass Communication and American Social Thought: key texts, 1919-1968. Lanham: Rowman \& Littlefield.

PLOOY, G. M. du. Communication Research: Techniques, Methods and Applications. Claremont: Juta and Company. 2004.

POOLEY, Jefferson (2007). The Mnemonic Entrepreneur: Wilbur Schramm and the "Four Founders" Myth of Communication Research (Notas de apresentação). Dublin: The International Society for the History of the Behavioraland Social Sciences \& European Society for the History of the Human Sciences.

POPPER, Karl. "Towards a Rational Theory of Tradition". In: Conjectures and refutations. POPPER, Karl. Nova Iorque: Routledge, 2002.

PRIEST, Susanna Hornig. Doing Media Research: an Introduction. Thousand Oaks: Sage, 2009.

REDDI, C. V. Narasimha. Effective Public Relations and Media Strategy. Nova Deli: PHI Learning Private, 2009.

RENDÓN, José Carlos Lozano. Teoría e Investigación de la Comunicación de Masas. Naucalpan de Juaréz: Pearson Educación, 2007.

RICHARDS, Joan L. Introduction: Fragmented Lives in: Isis, n.4, 2006, p.302-305.

RIOUX, Jean Pierre. A Revolução Industrial: 1780-1880. São Paulo: Pioneira, 1975.

ROGERS, Everett. A History of Communication Study: A Biographical Approach. New York: The Free Press, 1994.

ROGERS, Everett. Intermedia Processes and Powerful Media Effects in BRYANT, Jennings \& ZILMANN, Dolf. Media Effects:Advances in Theory and Research. Nova Iorque: Routledge. 2002.648 p.

ROSTEN, Leo. "Harold Lasswell: a Memoir" in: ROGOW, Arnold. Politics, Personality and Social Science in the Twenthieth Century: Essays in Honor of Harold Lasswell. Chicago: The University of Chicago Press, 1968.

RÜDIGER, Francisco. As Teorias da Comunicação. Porto Alegre: Penso, 2011.

SAINT-BEAUVE, Augustin. What is a Classic. In: The Harvard Classics: 1909-14. Cambridge: Harvard University Press, 2001.

SCHILLER, Dan. Theorizing communication: a history. Nova Iorque: Oxford University Press, 1996.

SCHRAMM, Wilbur. The Beginnings of Communication Study in America: A Personal Memoir. Thousand Oaks: Sage Publications, 1995. 
SCHRAMM, Wilbur; CHAFFEE, Steven H. \&ROGERS, Everett M.. The Beginnings of Communication Study in America: a Personal Memoir. Thousand Oaks: Sage, 1997.

SCHÉRER, René. Structure et Fondement de la Communication Humaine: Essai Critique Sur les Théories Contemporaines de la Communication. Paris: Société d'édition d'enseignement supérieur, 1965.

SEMATI, Mehdi. New Frontiers in International Communication Theory. Lanham: Rowman \& Littlefield, 2004.

SEVERIN, Werner \& TANKARD, James. Communication Theories. Nova Iorque: Longman, 1997.

SHEPHERD, Gregory J.; JOHN, Jeffrey St.; STRIPHAS, Theodore G.. Communication as: perspectives on theory. Thousand Oaks: Sage, 2006. 276 p.

SHILS, Edward. "The Trend of Sociology". In: The Calling of Sociology and Other Essays on the Pursuit of Learning. SHILLS, Edward. Chicago: University of Chicago Press, 1980.

SHILS, Edward. Tradition. Chicago: University of Chicago Press, 2006.

SIMPSON, Christopher. Science of coercion: communication research and psychological warfare, 1945-1960. Nova Iorque: Oxford University Press, 1994. 204 p.

SMITH, Bruce Lannes. The Mystifying History of Harold D. Lasswell in: ROGOW, Arnold. Politics, Personality and Social Science in the Twenthieth Century: Essays in Honor of Harold Lasswell. Chicago: The University of Chicago Press, 1968.

SOLA POOL, Ithiel \& LASSWELL, Harold. The Prestige Press: A Comparative Study of Political Symbols. Michigan: MIT Press, 1970.

SOUSA, Jorge Pedro. Pesquisa e Reflexão sobre Jornalismo: até 1950... e Depois. In: Jornalismo: História, Teoria e Metodologia. Perspectivas Luso-Brasileiras. Porto: Edições Universidade Fernando Pessoa, 2008.

SPÀ, Miguel de Moragas. Teorías de la Comunicación: Investigaciones Sobre Medios en América y Europa. Barcelona: G. Gilli, 1981.

SPROULE, Michael J. “Commmunication': from Concept to Field to Discipline” in: PARK, David W. \& POOLEY, Jefferson. The History of Media and Communication Research: Contested Memories. Nova Iorque: Peter Lang, 2008.

STACKS, Don W. \& SALWEN, Michael Brian. An Integrated Approach to Communication Theory and Research. Mahwah: Taylor \& Francis, 2008.

STARBUCK, William. The Production of Knowledege: The Challenge of Social Science Research. Nova Iorque: Oxford University Press, 2006.

STEINBERG, Sheila. An Introduction to Communication Studies. Cidade do Cabo: Juta And Company, 2007.

TAN, Alexis S.. Mass Communication Theories and Research. Nova Iorque: Macmillan, 1985. 
TAYLOR, Philip M.. Munitions of the Mind. Oxford Road: Manchester University Press, 2003.

THOMPSON, D’Arcy. On Growth and Form. Cambridge: Cambridge University Press, 2004.

VARÃO, Rafiza. A Propaganda como Arma Política: a Influência de Charles Merriam na Obra de Harold Lasswell. Anais do XI IBERCOM, 2009.

VARÃO, Rafiza; SOUSA, Janara. Harold Lasswell: as Contribuições do "Paladino" do Saber Comunicacional. In: XXIX Congresso Brasileiro de Ciências da Comunicação - INTERCOM, 2006, Brasília. Anais do XXIX Congresso Brasileiro de Ciências da Comunicação - INTERCOM.

VEYNE, Paul. Como se Escreve a História e Foucault Revoluciona a História. Brasília: Editora da UnB, 1998.

WAHL-JORGENSEN, Karin. "How Not to Found a Field: New Evidence on the Origins of Mass Communication Research". In: Journal of Communication. Oklahoma: Universidade de Oklahoma, 2004, nº54, pp.547-564.

WAHL-JORGENSEN, Karin. Wilbur Schramm was not the Father of our Discipline. Disponível em: < http://www.allacademic.com/meta/p112074_index.html>. Acesso em: 25 de agosto de 2007.

WATSON, James. Media Communication: an Introduction to Theory and Process. Nova Iorque: Palgrave Macmillan, 1998.

WATSON, John B. Psychology as the Behaviorist Views it. Psychological Review, n. 20, p.158-177, 1913.

WEST, Richard; RICHARD, West \& TURNER, Lynn H.. Introducing Communication Theory: Analysis and Application. Nova Iorque: Routledge, 2009.

WIGGERSHAUS, Rolf. Escola de Frankfurt: História, Desenvolvimento Teórico, Significação Política. Rio de Janeiro: Difeel, 2002.

WIMMER, Roger D.; DOMINICK, Joseph R.. Mass Media Research: An Introduction. Stamford: Cengage Learning, 2010.

WINDAHL, Sven; SIGNITZER, Benno \& OLSON, Jean T.. Using Communication Theory: an Introduction to Planned Communication. Thousand Oaks: Sage, 1992.

WITKOWISKI, Nicolas. Uma História Sentimental da Ciência. Rio de Janeiro: Jorge Zahar Editor, 2004.

YAKOBSON, Sergious \& LASSWELL, Harold. "Trend: May Day Slogans in Soviet Russia, 1918-1943" in: LASSWELL, Harold \& LEITE, Nathan. Language of Politics, Studies in Quantitative Semantics. Nova Iorque: George Stewart, 1949.

WOLF, Mauro. Teorias da Comunicação. Lisboa: Editora Presença, 1985.

WOLF, Mauro. Teorias da Comunicação. Lisboa: Editora Presença, 2002. 